Scuola di Dottorato in Ingegneria "Leonardo da Vinci"

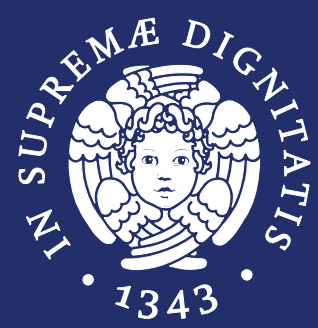

Corso di Dottorato di Ricerca in SICUREZZA NUCLEARE E INDUSTRIALE

Tesi di Dottorato di Ricerca

\title{
APPLICATION OF MCNP FOR PREDICTING POWER EXCURSION DURING LOCA IN ATUCHA-2 PHWR
}

Marco Pecchia 


\section{UNIVERSITÀ DI PISA}

Scuola di Dottorato in Ingegneria "Leonardo da Vinci"

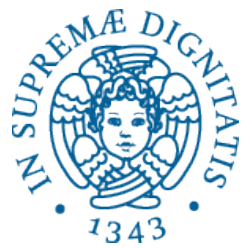

Corso di Dottorato di Ricerca in

SICUREZZA NUCLEARE E INDUSTRIALE

Tesi di Dottorato di Ricerca

\section{APPLICATION OF MCNP FOR PREDICTING POWER EXCURSION DURING LOCA IN ATUCHA-2 PHWR}

Autore:

Marco Pecchia

Firma

Relatori:

Prof. Francesco D’Auria

Dott. Carlo Parisi

Dott. Giorgio Galassi
Firma

Firma

Firma 
A Maria Elvira

iii 


\section{ACKNOWLEDGMENTS}

I express my gratitude to Prof. Francesco D'Auria (UNIPI-GRNSPG), for the invaluable possibility he gave me to learn.

I wish to express special gratitude to Carlo Parisi (ENEA). He mainly contributed to my scientific and professional advancement and I'm grateful to him for his expert supervision, for his precious and countless advices, and, most of all, for his friendship.

I wish also to express thanks to Prof. K. N. Ivanov (PSU), for suggestion about neutron transport calculations.

I express special thanks to CFD colleagues at the GRNSPG: Fabio Moretti, Daniele Melideo and Fulvio Terzuoli for their much valuable availability.

I'd like to acknowledge Oscar Mazzantini (NA-SA), for the invaluable possibility of learning from a real nuclear power plant under construction, and for the nice time I spent in Argentina.

I would like to give also special thanks to the other PhD thesis supervisor, Dr. G. Galassi for the support in carrying out this work.

Paolo Ferrara should be acknowledged as well, for the enjoyable time spent together at GRNSPG and for having sparked off my interest in nuclear science.

A special thank to my colleagues that make my time spent at GRNSPG a wonderful experience.

Finally, but above all, a very special thank is dedicated to my parents, to my brother Carlo, his wife Silvia and their daughter Alessia. 


\section{SOMMARIO}

Questa tesi consiste nello sviluppo e nell'applicazione di una metodologia basata nel codice MCNP per predire l'escursione di potenza e di reattivita' che dipende da differenti rappresentazioni delle variabili fisiche. L'applicazione di riferimento della metodologia è lo scenario DEGB-LBLOCA nella centrale nucleare ATUCHA-2 PHWR nel contesto dell'analisi di sicurezza (Capitolo 15 FSAR).

Gli incidenti di perdita di refrigerante (LOCA) riguardano la perdita di liquido di raffreddamento del reattore a un tasso superiore alla capacità del sistema di reintegro, dovuti ad una rottura nel confine in pressione del liquido stesso, fino ad includere una rottura equivalente per dimensioni alla rottura della più grande tubazione del sistema di refrigerazione del reattore con area equivalente pari a due volte quella della tubazione.

In ATUCHA-2 PHWR l'inserzione di reattività positiva causata dalla produzione di vuoti nei canali di raffreddamento è compensata principalmente dall'inserzione di reattività negativa da parte del sistema di spegnimento basato nell'iniezione rapida di una soluzione di acido borico nel recipiente del moderatore (JDJ). Codici di computazione fluido dinamica hanno analizzato il sistema JDJ mostrando una complessa distribuzione spaziale del Boro dentro il recipiente del moderatore.

L'effetto denominato "Boron self-shielding" indica la sovrastima della reattività negativa inserita dovuta alla diluizione di una soluzione molto concentrata di boro inserita dal sistema JDJ quando si usano regioni termo-idrauliche di grandi dimensioni (ordine di litri per ATUCHA-2) per modellare la sua distribuzione spaziale.

La disponibilità di metodi di calcolo con capacità di rappresentare il sistema con un livello di dettaglio oltre a quello della generazione attuale dei codici di sistema come il codice MCNP, basato sul metodo Monte Carlo, è richiesta in questo specifico scenario. La metodologia sviluppata è focalizzata nello sviluppare strumenti per un accoppiamento tridimensionale avanzato fra MCNP e un codice alla computazione fluidodinamica. Una caratteristica chiave della metodologia è la capacità di generare rappresentazioni basate su MCNP di complesse ed eterogenee distribuzioni spaziali. L'utilizzo di questa caratteristica combinata con la capacità della metodologia di utilizzare differenti livelli di rappresentazione permette di investigare escursioni di reattività a livello di reattore nello scenario analizzato.

Lo sviluppo di modelli MCNP5 per la simulazione di ATUCHA-2 in condizioni operazionali realistiche a livello di reattore è una parte della metodologia. Per questa ragione, l'attività di ricerca si è concentrata anche nell'utilizzo combinato di codici neutronici come NJOY e MONTEBURNS per implementare le condizioni al contorno termo-idrauliche fornite dalla cinetica di neutronica 3D accoppiata con il codice di sistema termo-idraulico RELAP5-3D@. 


\section{ABSTRACT}

This thesis consists in the developing and application of a methodology based on MCNP code to predict power and reactivity excursions depending on different representation of physical variables. The reference application of the methodology is the DEGB-LBLOCA scenario in ATUCHA-2 PHWR in the framework of the safety analysis of ATUCHA-2 nuclear power plant (NPP) (Chapter 15 FSAR).

Loss of coolant accidents (LOCA) mean those postulated accidents that result from the loss of reactor coolant at a rate in excess of the capability of the reactor coolant makeup system from breaks in the reactor coolant pressure boundary, up to and including a break equivalent in size to the double-ended rupture of the largest pipe of the reactor coolant system (DEGB LB-LOCA).

In the ATUCHA-2 PHWR the insertion of positive reactivity caused by the void production in coolant channels is compensated mainly by the negative reactivity inserted by shutdown system based on the fast injection of boric acid solution into the moderator tank (JDJ). Analysis of JDJ by a computational fluid dynamics code showed a complex spatial Boron distribution inside the moderator tank.

The so called "Boron self-shielding effect" is indicating the over-estimation of the inserted negative reactivity due by the dilution of the highly concentrated Boron solution inserted by the JDJ when modeling its spatial distribution using thermalhydraulics nodes of large dimensions (order of liters for the ATUCHA-2 case).

The availability of calculation methods with the capability of representing the system with a level of detail beyond the actual generation of system thermal hydraulics code such the Monte Carlo based MCNP code is required in this specific event scenario. The developed methodology is focused on the set up of tools for advanced three-dimensional coupling between MCNP and a computational fluid dynamics code. A key feature of the methodology is the capability to generate MCNP based representations of complex and heterogeneous spatial distribution of physical variables. The use of this feature combined with the methodology capability to use different level of representation detail permits the investigation of power and reactivity excursions at core level in the analyzed scenario and also the prediction of JDJ inserted reactivity at the beginning of the transient.

The development of MCNP5 models for simulation of ATUCHA-2 in realistic operational core conditions is a part of the methodology. Hence, research activity was focused also in the combined use of neutronic codes such as NJOY and MONTEBURNS to implement burnup effects and the thermal-hydraulic boundary conditions provided by 3D neutron kinetics coupled thermal-hydraulics (3D NK-TH) RELAP5-3D@ system codes. 


\section{INDEX}

ACKNOWLEDGMENTS v

SOMMARIO vii

ABSTRACT ix

INDEX. xi

ABBREVIATIONS xiv

LIST OF FIGURES $x v i$

LIST OF TABLES $\mathrm{xx}$

1 INTRODUCTION 1

1.1. Objectives of the research ................................................... 1

1.2. Description of the performed activity .................................... 2

1.3. Structure of the document ....................................................... 4

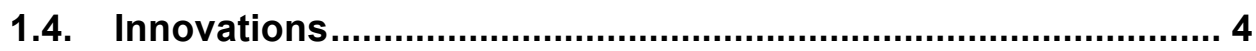

2 THE DESCRIPTION OF ATUCHA-2 NPP ............................... 5

2.1. General plant description .................................................. 5

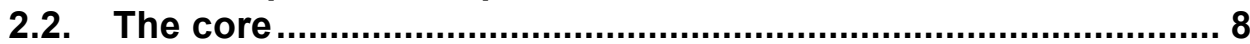

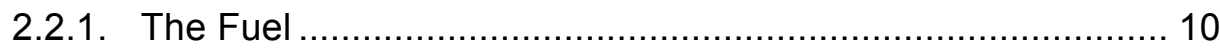

2.2.2. Control system ............................................................... 13

2.2.3. Fast Boron injection system (JDJ) ……………………..... 16

2.3. Fuel management and Burnup zone ....................................... 17

2.4. Boundary and initial core conditions .................................... 19

2.4.1. BOL with CZP core condition and fresh fuel ........................ 19

2.4.2. BEQ with HFP core condition................................................ 19

3 DESCRIPTION OF LB-LOCA IN ATUCHA-2 NPP ...................22

3.1. Description of the transient ................................................... 22

3.1.1. I Ph.W. - Fission power excursion (RIA) ……………….... 22

3.1.2. II Ph.W. - CHF occurrence \& clad temperature excursion ..... 23

3.1.3. III Ph.W. - Quenching \& fuel channels refill ............................. 23

3.1.4. IV Ph.W. - Long term cooling (LTC) ……………............... 23

3.2. Licensing framework ............................................................. 24

3.2.1. The regulatory framework ……........................................ 24

3.2.2. The international practice …………………………….... 24

3.2.3. The ARN requirements and the current status of the licensing

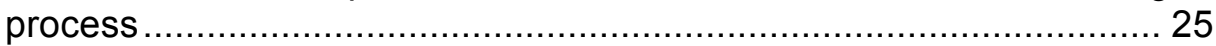

3.2.4. The BEPU Approach ..................................................... 26

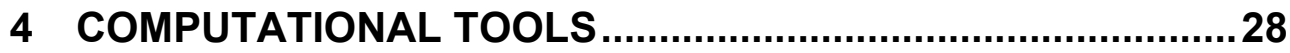

4.1. The use of coupled codes....................................................... 28 
4.2. The main tool for coupling CFX and MCNP5

4.2.1. The CFD2MCNP coupling routine ...................................... 31

4.2.2. Limit of applicability of CFD2MCNP program ....................... 35

4.2.3. Verification of the CFD2MCNP program …........................ 35

4.2.3.1. Verification of hexagonal mapping .......................................... 36

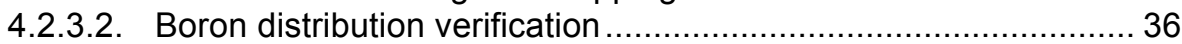

4.2.3.3. Tracking of Borated moderator mesh node ............................. 38

5 ANALYSIS RESULTS FOCUSING ON POWER PEAK...........40

5.1. Rationale for the analysis ................................................. 40

5.2. Temperature effects ............................................................ 40

5.3. Burnup considerations ......................................................... 41

5.4. The RELAP5-3D@ model for ATUCHA-2 ...............................44

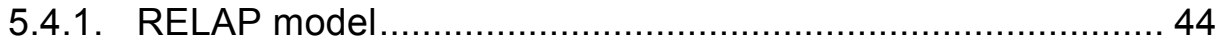

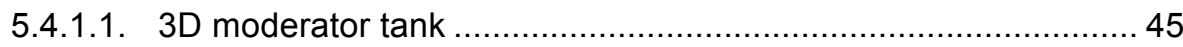

5.4.1.2. The Emergency Boron Injection System................................ 45

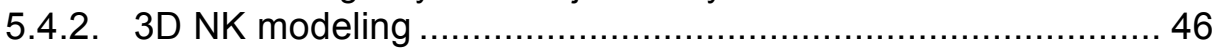

5.4.2.1. Cross Section Libraries development ..................................... 46

5.5. MCNP models and applications to ATUCHA-2 licensing ........ 47

5.5.1. MCNP model at BOL with CZP core condition..................... 47

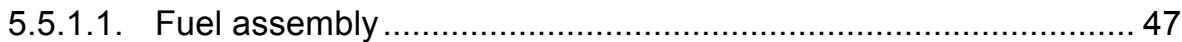

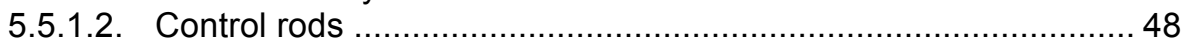

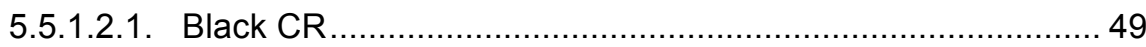

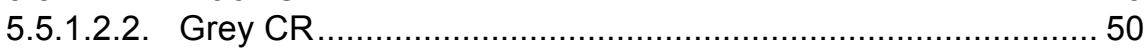

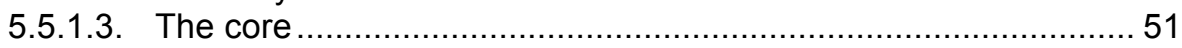

5.5.2. MCNP5 model at BEQ with HFP core condition .................. 52

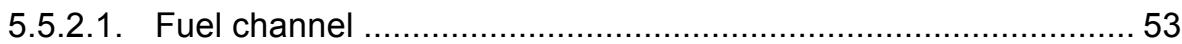

5.5.2.2. Representation of HFP core condition ........................................ 54

5.5.2.3. Burnup distribution based on pseudo $1 / 6^{\text {th }}$ core symmetry ..........55

5.5.3. MCNP5 models for Boron self-shielding analysis ................. 55

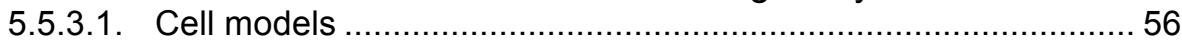

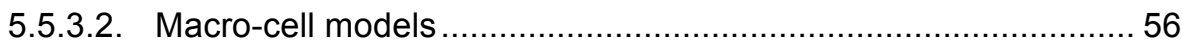

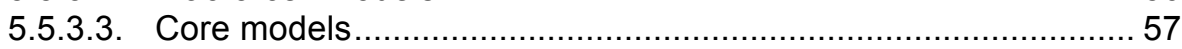

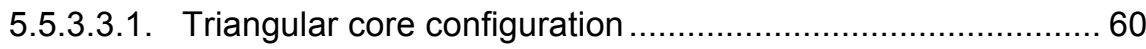

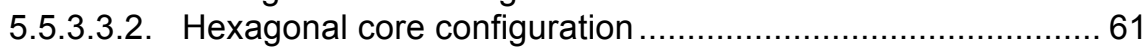

5.5.3.3.3. RELAP5-like core configuration ......................................... 62

5.5.4. Selection of results at BOL with CZP core condition............... 63

5.5.4.1. MCNP5 calculation of Beta delayed factor ................................ 63

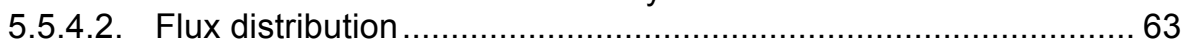

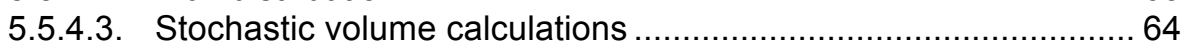

5.5.5. Benchmark between NESTLE and MCNP5 ........................ 66

5.5.5.1. Main differences between MCNP5 and NESTLE models ............66 66

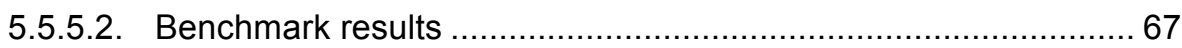

6 ANALYSIS OF BORON SELF-SHIELDING EFFECT ...............74

6.1. Boron self-shielding effect at cell and macro-cell level.......... 75

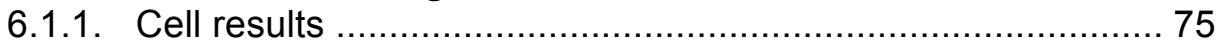




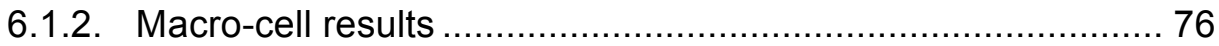

6.1.3. Comparison of cell and macro-cell results ........................... 77

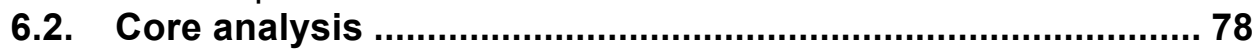

6.2.1. Analysis of Boron self-shielding effect ................................ 78

6.2.1.1. Selected Boron cloud configurations ........................................ 78

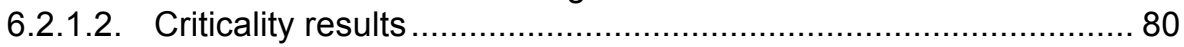

6.2.1.3. Evaluation of Boron self-shielding for averaged axial flux .......... 82

6.2.1.4. Evaluation of Boron self-shielding for NK nodes........................ 83

6.2.1.4.1. Results for a Boron configuration at time $\Delta t=+0.025 \mathrm{~s} \ldots \ldots \ldots .83$

6.2.1.4.2. Results for a Boron configuration at time $\Delta t=+0.325 \ldots \ldots \ldots . .85$

6.2.1.4.3. Results for a Boron configuration at time $\Delta t=+0.825 \ldots \ldots \ldots .87$

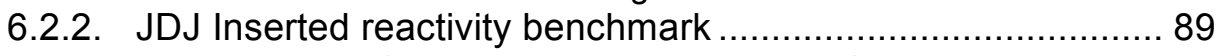

6.2.2.1. Evaluation of JDJ inserted reactivity by NESTLE ...................... 90

6.2.2.2. Benchmark of JDJ inserted reactivity using MCNP .................... 91

7 CONCLUSION......................................................................93

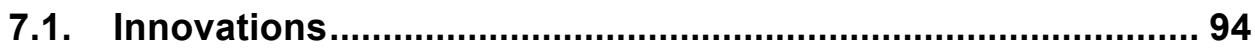

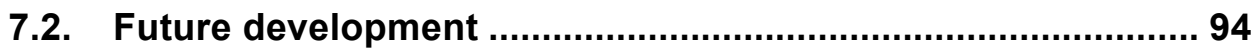

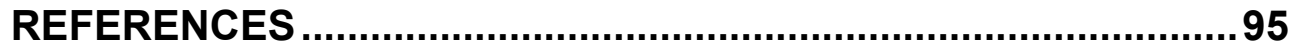

APPENDIX A. CODES USED WITHIN THE RESEARCH..............99

APPENDIX B. OTHER COMPUTATIONAL TOOLS ...................107

APPENDIX C. CROSS SECTION VALIDATION ........................118

APPENDIX D. SENSITIVITIES ON MCNP5 PARAMETERS.......131

APPENDIX E. BURNUP PROCEDURES .................................138

APPENDIX F. QUALITATIVE COMPARISON WITH EXISTING LITERATURE.........................................149

APPENDIX G. REACTIVITY CALCULATIONS FORMULAS ......150 


\section{ABBREVIATIONS}

\begin{tabular}{|c|c|}
\hline 3D & Three Dimensional \\
\hline ARI & All Rods In \\
\hline ARN & Autoridad Regulatoria Argentina \\
\hline ARO & All Rods Out \\
\hline ATWS & Anticipated Transient Without Scram \\
\hline $\mathrm{BE}$ & Best Estimate \\
\hline BEPU & Best Estimate Plus Uncertainty \\
\hline BEQ & Burnup at Equilibrium \\
\hline $\mathrm{BIC}$ & Boundary Initial Conditions \\
\hline BOL & Beginning Of Life \\
\hline BWR & Boiling Water Reactor \\
\hline CFD & Computational Fluid Dynamics \\
\hline $\mathrm{CHF}$ & Critical Heat Flux \\
\hline CIAU & Code with capability of Internal Assessment of Uncertainty \\
\hline CNA-2/Atucha-2 & Central Nuclear Atucha (CNA-2 is Atucha-2) \\
\hline CNA-II & Central Nucleare de Atucha (Atucha 2 NPP) \\
\hline CR & Control Rod \\
\hline CSAU & Code, Scaling Applicability and Uncertainty \\
\hline CSNI & Committee on the Safety of Nuclear Installations \\
\hline CZP & Cold Zero Power \\
\hline DBA & Design Basis Accident \\
\hline DEGB & Double Ended Guillotine Break \\
\hline DIMNP & $\begin{array}{l}\text { Department of Mechanical, Nuclear and Production } \\
\text { Engineering of University of Pisa, Italy }\end{array}$ \\
\hline DOE & Department of Energy (US) \\
\hline ECCS & Emergency Core Cooling System \\
\hline ENDF & Evaluated Nuclear Data File \\
\hline ENDL & Evaluated Nuclear Data Library \\
\hline FA & Fuel Assembly \\
\hline FC & Fuel Channel \\
\hline FP & Fission product \\
\hline FSAR & Final Safety Analysis Report \\
\hline GRNSPG & San Piero a Grado Nuclear Research Group \\
\hline GT & Guide Tube \\
\hline HEU & Highly Enriched U \\
\hline HFP & Hot Full Power \\
\hline HW & Heavy Water \\
\hline HZP & Hot Zero Power \\
\hline I\& C & Instrumentation and control \\
\hline IAEA & International Atomic Energy Agency \\
\hline ICSBEP & International Criticality Safety Benchmark Evaluation Project \\
\hline IEU & Intermediate Enriched U \\
\hline JDJ & Fast Boron injected safety system \\
\hline LANL & Los Alamos National Laboratory \\
\hline LB-LOCA & Large Break LOCA \\
\hline LOCA & Loss Of Coolant Accident \\
\hline
\end{tabular}




$\begin{array}{ll}\text { LTC } & \text { Long Term Cooling } \\ \text { MCP } & \text { Main Coolant Pumps } \\ \text { MM } & \text { 239Pu and Mixed Metal assemblies } \\ \text { MML } & \text { Material Master Library } \\ \text { MPI } & \text { Message Passing Interface } \\ \text { MT } & \text { ENDF section file } \\ \text { NA-SA } & \text { Nucleoelectrica Argentina - Societad Anonima } \\ \text { NEA } & \text { Nuclear Energy Agency } \\ \text { NK } & \text { Neutron Kinetics } \\ \text { NPP } & \text { Nuclear Power Plant } \\ \text { OECD } & \text { Organization for the Economic Cooperation and Development } \\ \text { ORNL } & \text { Oak Ridge National Laboratory } \\ \text { p-Xsec } & \text { Pseudo cross section for minor fission products } \\ \text { PCI } & \text { Pellet-Clad Interaction } \\ \text { Ph.W. } & \text { Phenomenological Window } \\ \text { PHWR } & \text { Pressurized Heavy Water Reactor } \\ \text { PSU } & \text { The Pennsylvania State University } \\ \text { PWR } & \text { Pressurized Water Reactor } \\ \text { RIA } & \text { Reactivity Initiated Accident } \\ \text { RPV } & \text { Reactor Pressure Vessel } \\ \text { SBDBA } & \text { Selected Beyond Design Basis Accident } \\ \text { SG } & \text { Steam Generator } \\ \text { SS } & \text { Steady-State } \\ \text { SYS } & \text { System } \\ \text { TH } & \text { Thermal-Hydraulics } \\ \text { UACSA } & \text { Uncertainty Analysis for Criticality Safety Assessment } \\ \text { UNIPI } & \text { University of Pisa } \\ \text { WPNCS } & \text { Working Party on Nuclear Criticality Safety } \\ \text { WPRS } & \text { Working Party on Reactor Systems } \\ \text { Xsec } & \text { Cross Sections } \\ & \end{array}$




\section{LIST OF FIGURES}

Figure 1 - Scheme of PhD activities ......................................................... 3

Figure 2 - Reactor coolant system logical layout ........................................... 7

Figure 3 - CNA-2 Main \& moderator cooling systems layouts .......................... 7

Figure 4 - CNA-2 RPV sketches................................................................. 8

Figure 5 - CNA-2 core radial arrangement .............................................. 9

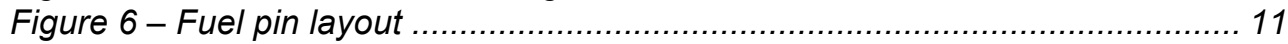

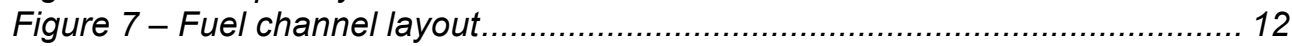

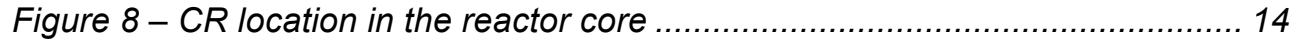

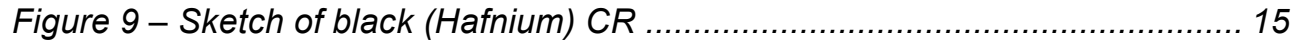

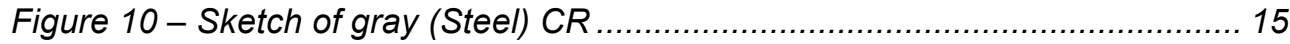

Figure 11 - Layout of one line of the fast boron injection system...................... 16

Figure 12 - Location of Boron injection lance within the core........................... 17

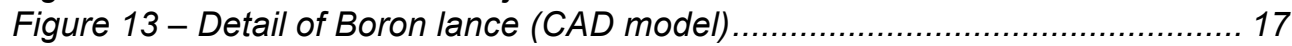

Figure 14 - Fuel Burnup Zones ............................................................. 18

Figure 15 - Sample of averaged fuel temperature axial profile ............................ 20

Figure 16 - Average burnup distribution [MWd/tonHM] .................................. 20

Figure 17 - Definition of the LB-LOCA phenomenological windows ................... 23

Figure 18 - Description of the interaction between the codes ............................ 26

Figure 19 - BEPU approach flowchart for ATUCHA-2 FSAR accident analysis ... 27

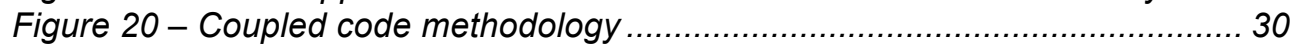

Figure 21 - CFX node mesh around a JDJ injection lance................................. 31

Figure 22 - Flow-chart to index CFX nodes to a regular prism lattice ................... 32

Figure 23 - CFX node indexing on a superimposed regular grid ........................ 33

Figure 24 - Base grid mapping to MCNP5 macro regions ............................. 33

Figure 25 - Flow-chart to calculate Boron concentration in MCNP regions..........34

Figure 26 - Mesh overlap issue .......................................................... 35

Figure 27 - Corrector procedure for node indexes assignation ........................ 36

Figure 28 - Comparison of calculated integral Boron mass to CFX ..................... 37

Figure 29 - Detailed Boron mass check for each MCNP5 region ...................... 37

Figure 30 - Sketch of calculated Boron mass distribution ................................ 38

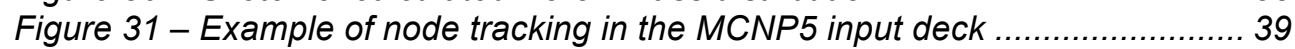

Figure 32 - Continuous and multi-group cross sections representations ............. 41

Figure 33 - Multiplication factor trend ......................................................... 43

Figure 34 - Relative fluxes versus Burnup .................................................... 43

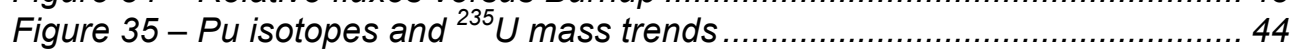

Figure 36 - Moderator tank 3D model (planar view).................................. 45

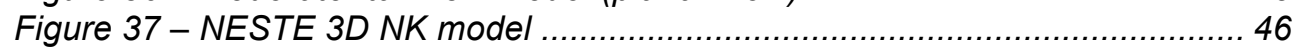

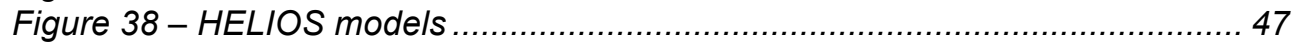

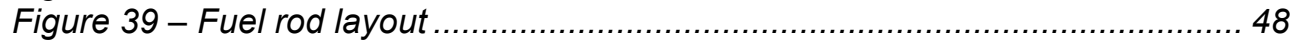

Figure 40 - Fuel channel models........................................................ 48

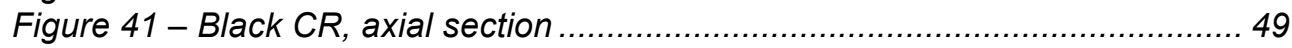

Figure 42 - Grey CR, axial section ..................................................... 50

Figure 43 - Detail of fuel rods and CR - MCNP5 model planar view $(x-y) \ldots \ldots \ldots . . . . . .51$

Figure 44 - MCNP5 Core model, longitudinal view ....................................... 51

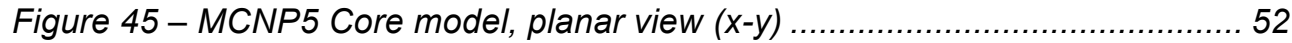

Figure 46 - Procedure to generate the MCNP5 input deck .............................. 53 
Figure 47 - MCNP5 model for ATUCHA-2 at BEQ conditions .......................... 54

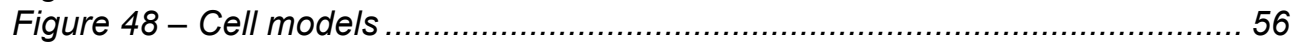

Figure 49 - Macro-cell models............................................................. 57

Figure 50 - Basic prism elements......................................................... 57

Figure 51 - Distribution of borated node, level 5 .......................................... 59

Figure 52 - Distribution of borated node, level 6 .......................................... 59

Figure 53 - Distribution of borated node, level 7 ............................................ 59

Figure 54 - Distribution of borated node, level 8 .......................................... 59

Figure 55 - Distribution of borated node, level 9 ........................................... 59

Figure 56 - Distribution of borated node, level 10 .......................................... 59

Figure 57 - Planar sketch of triangular core configuration.................................60

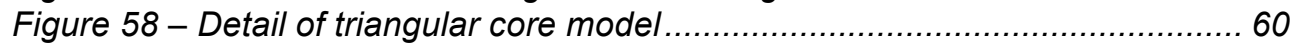

Figure 59 - Planar sketch of hexagonal core configuration ................................. 61

Figure 60 - Detail of hexagonal core model ................................................. 61

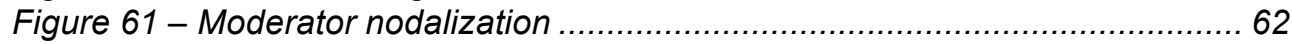

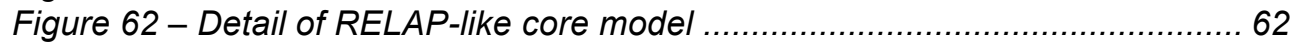

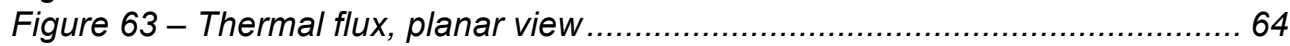

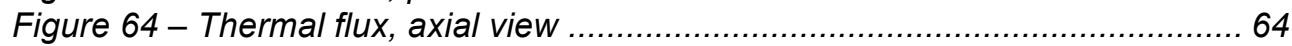

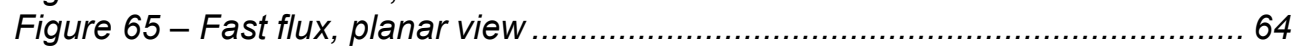

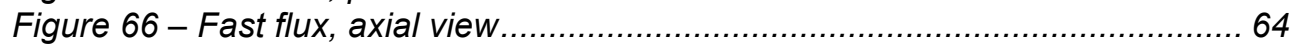

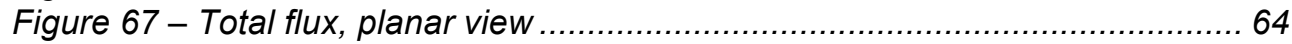

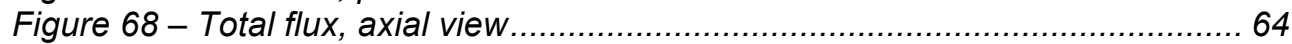

Figure 69 - Sketches of crossing the 3D NK hexagonal cells ........................... 65

Figure 70 - Stochastic Cell Volume procedure by MCNP5 tally .......................... 65

Figure 71 - Histogram of average channels relative flux percentage difference ... 67

Figure 72 - Average flux axial behavior by NESTLE and MCNP5 ..................... 68

Figure 73 - Histogram of nodes relative flux percentage difference......................6 68

Figure 74 - NESTLE channel flux distribution ................................................6 69

Figure 75 - MCNP5 channel flux distribution ................................................ 69

Figure 76 - Relative difference between MCNP5 and NESTLE channel distribution

Figure 77 - Absolute difference between MCNP5 and NESTLE channel distribution

Figure 78 - Relative difference for level 1 ..................................................... 70

Figure 79 - Absolute difference for level 1 ................................................. 70

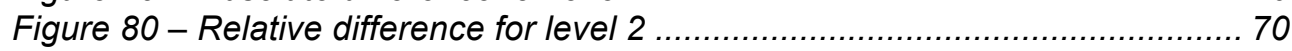

Figure 81 - Absolute difference for level 2 ............................................... 70

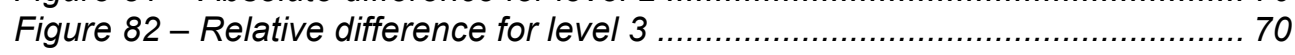

Figure 83 - Absolute difference for level 3 ............................................... 70

Figure 84 - Relative difference for level 4 ................................................. 71

Figure 85 - Absolute difference for level 4 ................................................. 71

Figure 86 - Relative difference for level 5 .................................................. 71

Figure 87 - Absolute difference for level 5 .............................................. 71

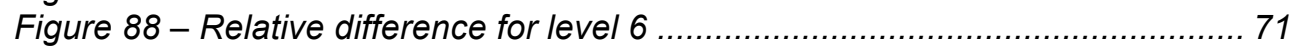

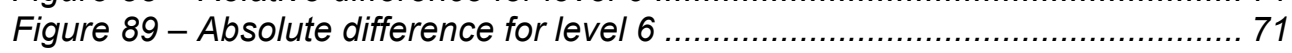

Figure 90 - Relative difference for level 7 ................................................ 72

Figure 91 - Absolute difference for level 7 ............................................... 72

Figure 92 - Relative difference for level 8 ..................................................... 72

Figure 93 - Absolute difference for level 8 ............................................... 72 


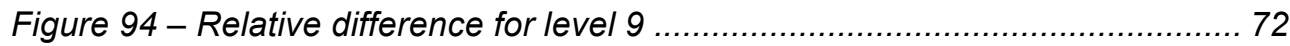

Figure 95 - Absolute difference for level 9 ................................................ 72

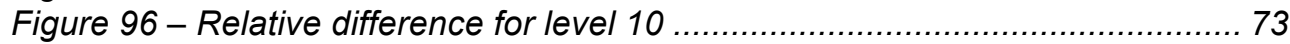

Figure 97 - Absolute difference for level 10 .............................................. 73

Figure 98 - Sketches of Boron cloud spatial distributions ................................. 74

Figure 99 - Cell model, reactivity versus Boron mass ..................................... 76

Figure 100 - Macro-cell model, reactivity versus boron mass........................... 77

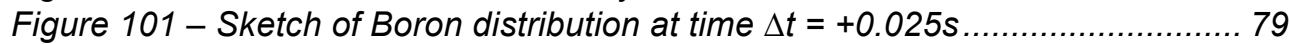

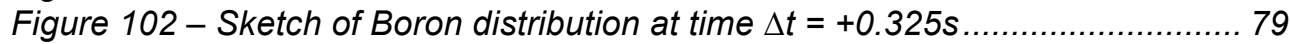

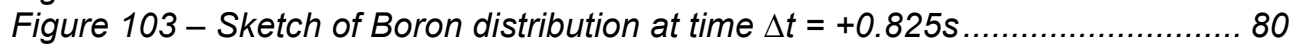

Figure 104 - Reactivity inserted at different time steps and mesh resolutions...... 81

Figure 105 - Reactivity comparison ............................................................... 81

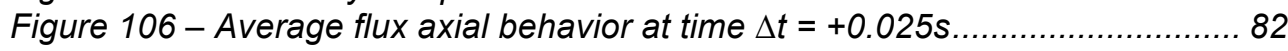

Figure 107 - Average flux axial behavior at time $\Delta t=+0.325$ s........................... 82

Figure 108 - Average flux axial behavior at time $\Delta t=+0.825$ s......................... 83

Figure 109 - Relative difference for level 10 ............................................... 84

Figure 110 - Relative difference for level 9 .............................................. 84

Figure 111 - Relative difference for level 8 ............................................... 84

Figure 112 - Relative difference for level 7 .................................................. 84

Figure 113 - Relative difference for level 6 .............................................. 84

Figure 114 - Relative difference for level 5 ............................................. 84

Figure 115 - Relative difference for level 4 ............................................. 85

Figure 116 - Relative difference for level 3 .............................................. 85

Figure 117 - Relative difference for level 2 .............................................. 85

Figure 118 - Relative difference for level 1 .............................................. 85

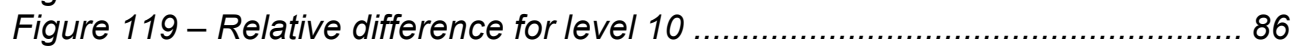

Figure 120 - Relative difference for level 9 ................................................ 86

Figure 121 - Relative difference for level 8 .............................................. 86

Figure 122 - Relative difference for level 7 .............................................. 86

Figure 123 - Relative difference for level 6 .............................................. 86

Figure 124 - Relative difference for level 5 ............................................. 86

Figure 125 - Relative difference for level 4 .............................................. 87

Figure 126 - Relative difference for level 3 .............................................. 87

Figure 127 - Relative difference for level 2 ............................................. 87

Figure 128 - Relative difference for level 1 ............................................ 87

Figure 129 - Relative difference for level 10 ............................................. 88

Figure 130 - Relative difference for level 9 ................................................ 88

Figure 131 - Relative difference for level 8 .................................................... 88

Figure 132 - Relative difference for level 7 .............................................. 88

Figure 133 - Relative difference for level 6 ............................................. 88

Figure 134 - Relative difference for level 5 ............................................. 88

Figure 135 - Relative difference for level 4 ................................................ 89

Figure 136 - Relative difference for level 3 .............................................. 89

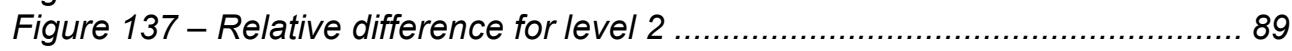

Figure 138 - Relative difference for level 1 ............................................... 89

Figure 139 - Prompt, delayed and total inserted reactivity by NESTLE ............... 90

Figure 140 - Absolute reactivity difference between NESTLE and MCNP5......... 92

Figure 141 - Simulation of a neutron history by a Monte Carlo code .................. 100

Figure 142 - Sketch of NJOY module chain ................................................... 104 
Figure 143 - MONTEBURNS working flow-chart ......................................... 105

Figure 144 - Example of scoring procedure by HEXMESH ............................ 108

Figure 145 - Affine transformation method ................................................ 108

Figure 146 - Selection of channel for HEXMESH verification ............................ 109

Figure 147 - Comparison of UNRESR and PURR results .............................. 111

Figure 148 - Check for negative Xsec .................................................... 111

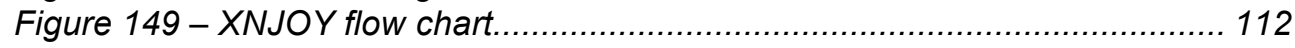

Figure 150 - NJOY thermal Xsec processing .............................................. 113

Figure 151 - ATUCHABURN working scheme ............................................ 114

Figure 152 - Selection of range of MLL burnup value ................................... 115

Figure 153 - ATUCHACORE input deck .................................................. 116

Figure 154 - XFPL main flow chart........................................................... 117

Figure 155 - Sample of p-Xsec for ATUCHA-2 ……................................. 117

Figure 156 - Benchmark and MCNP5 models ............................................ 118

Figure 157 - Sensitivity on ERR parameter................................................. 119

Figure 158 - Sensitivity on resonance ladder parameter ................................. 120

Figure 159 - Sensitivity on maximum energy for thermal treatment................... 121

Figure 160 - Sensitivity on equally probable angular bin ................................ 122

Figure 161 - Doppler coefficient: comparison of results................................... 122

Figure 162 - Computer time trend against MCNP5 mesh number.................... 131

Figure 163 - Comparison of kinf trend....................................................... 132

Figure 164 - Comparison of Shannon entropy trend ..................................... 132

Figure 165 - Comparison of kinf trend........................................................ 133

Figure 166 - Comparison of Shannon entropy trend ......................................... 133

Figure 167 - Example of reflective boundary conditions ................................. 134

Figure 168 - MCNP5 FA models used to model BEQ condition ....................... 135

Figure 169 - Relative flux difference between $A 1$ and $A 2$ models ..................... 136

Figure 170 - Absolute flux difference between $A 1$ and A2 models ................... 136

Figure 171 - Effects of TH-BIC to isotope mass production .............................. 141

Figure $172-{ }^{135} \mathrm{Xe}$ mass trend discontinuities .................................................. 141

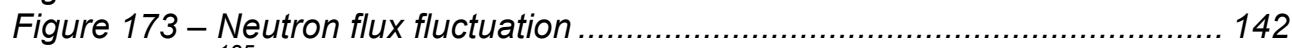

Figure $174-{ }^{135} \mathrm{Xe}$ trends........................................................................ 143

Figure 175 - Comparison of half-life between ORIGEN2.0 and ORIGEN-S libraries

Figure 176 - Sketch for benchmark model ..................................................... 145

Figure 177 - The verification model............................................................. 146

Figure 178 - Relative actinides mass differences in the test case .................... 146

Figure 179 - Comparison of actinides mass inventory ...................................... 147

Figure 180 - Comparison of fission products mass inventory .......................... 148

Figure 181 - Sketch of the NA-SA MCNP model and result............................ 149

Figure 182 - UNIPI results: Shielding effect at channel level ............................ 150 


\section{LIST OF TABLES}

Table 1 - Principal data of the CNA-2 primary system for full load operation ........ 6

Table 2 - Relevant CNA-2 reactor core geometrical data ................................ 9

Table 3 - FC geometrical dimensions ................................................. 10

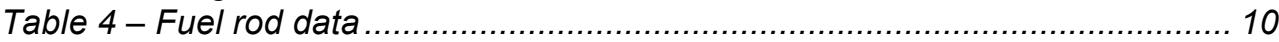

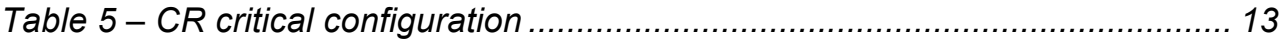

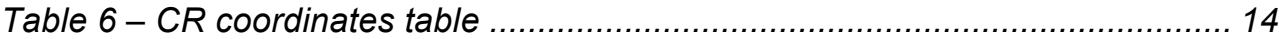

Table 7 - BOL with CZP core condition reference values .................................. 19

Table 8 - Fuel Assemblies movements for burnup management....................... 21

Table 9 - Codes used in the methodology ............................................. 28

Table 10 - Computational tools developed in this research .............................. 29

Table 11 - Regular grid mesh specification ................................................ 33

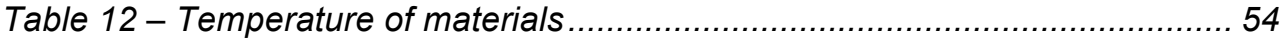

Table 13 - Density and pressure of heavy water..................................... 55

Table 14 - MCNP5 moderator mesh type ............................................... 57

Table 15 - Core models for detailed Boron cloud representation........................ 58

Table 16 - Calculated beta delayed factor by MCNP5 ................................ 63

Table 17 - Main differences between NESTLE and MCNP5 ...........................6 66

Table 18 - Summary of relative differences of average channel flux ...................67 67

Table 19 - Summary of relative differences of node flux ................................. 68

Table 20 - Mass of the Boron in the cases simulated ................................... 75

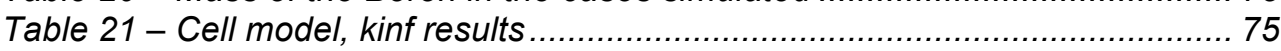

Table 22 - Cell model, reactivity inserted by different Boron distributions ............ 76

Table 23 - Macro-cell model, kinf results .................................................. 76

Table 24 - Macro-cell model, reactivity inserted by different Boron distributions .. 77

Table 25 - Boron configurations for time of interest in LB-LOCA ....................... 78

Table 26 - Normalized reactivity inserted by Boron cloud at different time steps . 80

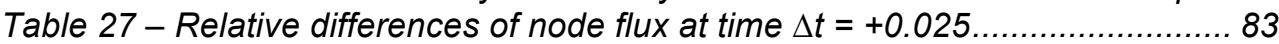

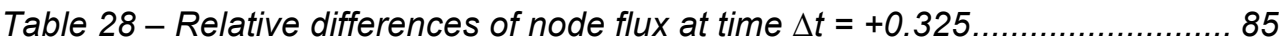

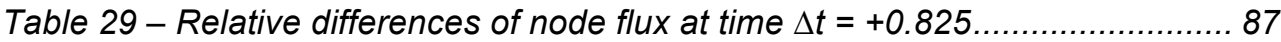

Table 30 - Reactivity results calculated at times of interest for LB-LOCA scenario

Table 31 - Brief description of NJOY modules ........................................... 104

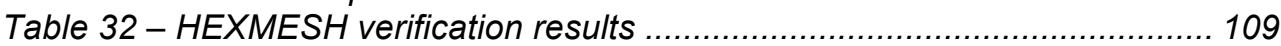

Table 33 - Criticality benchmark descriptions ....................................... 124

Table 34 - Criticality benchmark results .............................................. 128

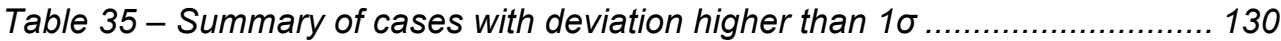

Table 36 - FA boundary condition options ................................................ 134

Table 37 - Initial conditions for the reference cases....................................... 134

Table 38 - Speed test for parallel environment ......................................... 137

Table 39 - MONTEBURNS2.0 main parameter description ............................ 138

Table 40 - Effects of relevant isotopes selection to kinf and mass production... 139

Table 41 - Selected nuclides for the ATUCHA-2 burnup simulations ................ 139

Table 42 - BIC from ATUCHA-2 cell representative of upper core ..................... 140

Table 43 - BIC from ATUCHA-2 cell representative of lower core ..................... 140 


\section{INTRODUCTION}

Loss of coolant accidents (LOCA) mean those postulated accidents that result from the loss of reactor coolant at a rate in excess of the capability of the reactor coolant makeup system from breaks in the reactor coolant pressure boundary, up to and including a break equivalent in size to the double-ended rupture of the largest pipe of the reactor coolant system (DEGB LB-LOCA).

A peculiarity of the ATUCHA-2 design is the positive void reactivity coefficient. This is a characteristic in common to other heavy water moderated reactors that utilize natural uranium as fuel. This implies that after a LB-LOCA event, the fission power peak at the very beginning of the transient is controlled by the void formation in the core channels, and then it is determined by the pressure wave propagation from the break. Indeed, the moderator is still liquid and flashes delayed with respect to the coolant, thus the LOCA event is also a RIA (reactivity insertion accident) event.

The insertion of positive reactivity caused by the void production in coolant channels is compensated mainly by the negative reactivity inserted by shutdown system based on the fast injection of boric acid solution into the moderator tank (JDJ).

The DEGB-LBLOCA scenario was simulated using the 3D neutron kinetics coupled thermal-hydraulics (3D NK-TH) RELAP5-3D@ system code. The calculation of the reactivity inserted by the JDJ was based in the implementation into RELAP5-3DC thermal-hydraulic $(\mathrm{TH})$ model of the time-dependent spatial distribution of Boron concentration in the moderator tank calculated by the computational fluid dynamics (CFD) CFX ${ }^{\mathrm{TM}}$ code.

The so called "Boron self-shielding effect" is indicating the over-estimation of the inserted negative reactivity due by the dilution of a highly concentrated Boron solution when modeling its spatial distribution using $\mathrm{TH}$ nodes of large dimensions (order of liters for the ATUCHA-2 case).

In the evaluation of effects by different spatial representation of physical variables may be useful of 3D neutron transport code with the capability of representing the system with a level of detail beyond the actual generation of system code such the Monte Carlo based MCNP code.

\subsection{Objectives of the research}

The nuclear reactor analysis relies strongly on the computer code to calculate the behavior of the reactor. With the increasing of computer performance, the use of computational costly tools like Monte Carlo based neutron transport code and CFD codes are nowadays the object of state-of-the-art research in nuclear safety field. Those codes allow the investigation phenomena requiring 3D representation with high level of spatial and energetic detail.

This thesis consists in the development of a methodology and tools to couple MCNP with computational fluid dynamics and thermal-hydraulic system codes to 
be used for the safety analysis core simulations. The goal of such methodology is to predict reactivity excursion during a LOCA transient in ATUCHA-2. The complex spatial Boron distribution inside the moderator tank simulated by the CFD CFX ${ }^{\mathrm{MM}}$ is used as datum by this methodology.

The investigation analysis was based on the capability of the methodology to represent the complex Boron cloud configuration with different level of spatial detail in the MCNP model of moderator tank. Then, the analysis was focused on the effect of such representation thermal neutron flux distribution and criticality multiplication factor $\left(k_{\text {eff }}\right)$. The results were used in the framework of the safety analysis of ATUCHA-2 NPP (Chapter 15 FSAR).

The representation of the complex peculiarity of a NPP within the capability of a computer code is always a challenging activity. This is particularly true for ATUCHA-2 PHWR due to its unique peculiarity. For this purpose the research activity was focus also in the development of a methodology to implement the operational ATUCHA-2 core condition in MCNP for 2A LB-LOCA scenario. This methodology includes the combined use of other neutronic code such as NJOY and MONTEBURNS.

\subsection{Description of the performed activity}

The activity performed for fulfilling the objectives of the research is outlined in Figure 1. The steps below were executed to fulfill the objectives:

- Acquisition of expertise in the neutronic field, taking advantage from the participation in international activities;

- Investigation of issue related to the use of Monte Carlo based neutronic codes and related methodologies;

- Development of a methodology and related tools for investigating the power peak excursion in safety analysis;

- Qualification activities to support the reliability of the analyses;

- Application of the methodology for predicting power excursion in case of LOCA transient scenario in ATUCHA-2 PHWR in the framework of the safety analysis (Chapter 15 FSAR).

Then, the Candidate was also taking part in international activities related to the PhD program:

- Participation to ATUCHA-2 project, commissioned by the Argentinean Na$\mathrm{Sa}$, for the benchmark of neutronic methodologies in the framework of the preparation of the FSAR (Chapter 15);

- In the framework of the ATUCHA-2 project, participation to Na-Sa neutronic group and with ARN representative of the Argentinean safety authority (ARN);

- Participation to the international meetings 'NJOY user group' and WPNCS Expert Group on Uncertainty Analysis for Criticality Safety Assessment (UACSA). 


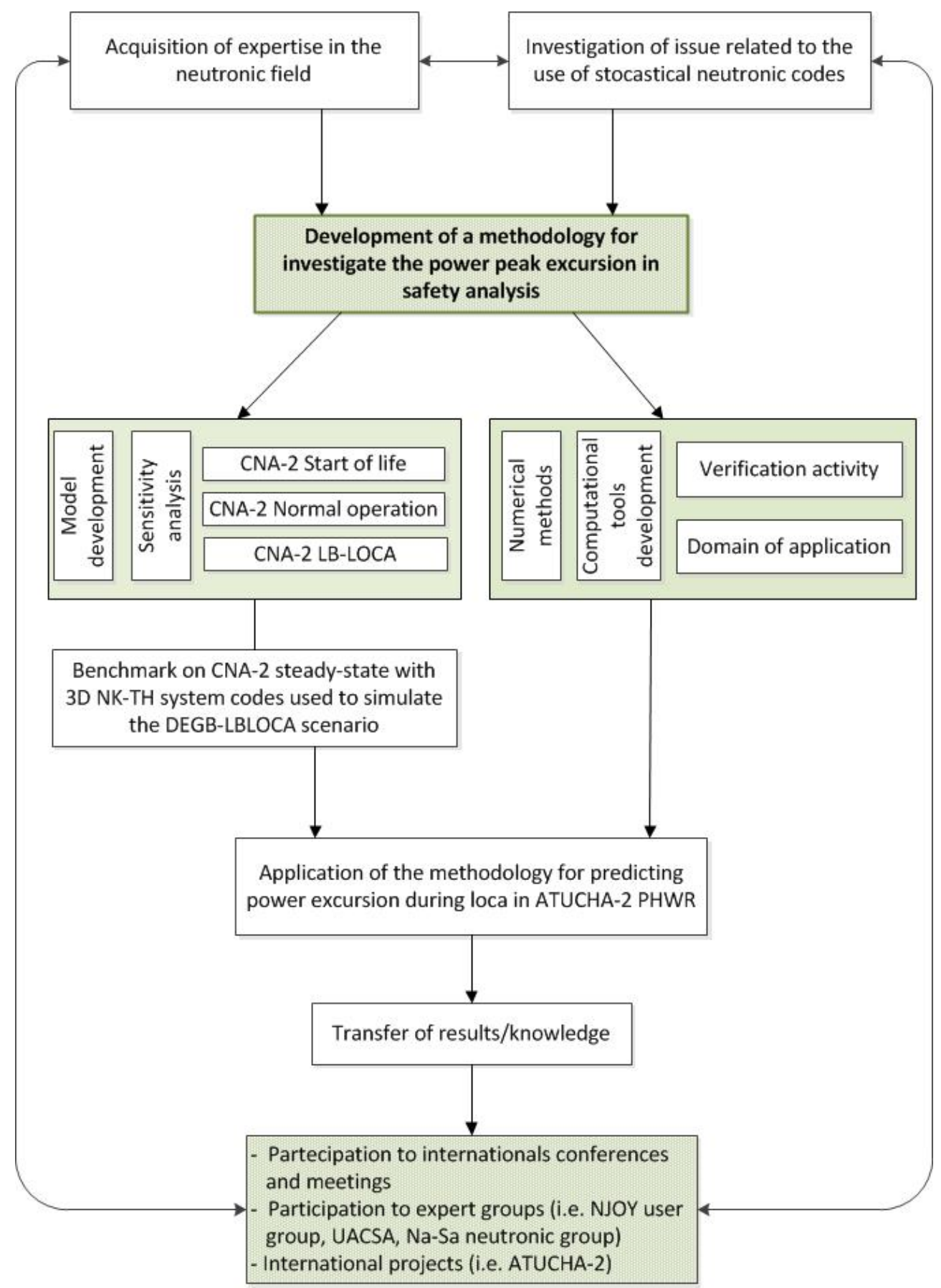

Figure 1 - Scheme of PhD activities 


\subsection{Structure of the document}

The thesis is divided in seven sections and seven appendixes.

The Introduction contains the background information and the objective of the activity.

Section 2 describes the Atucha-II NPP, highlighting the peculiarities of the plant.

Section 3 reports the peculiarities of the LB-LOCA. From this section it results clear that there is the need for the analysis of the availability of calculation methods that are not implemented in the standard system thermal hydraulic codes. In the same section, an outline of the specificity of the licensing is reported.

Section 4 contains the description of the methodology and the main computational tool developed in this research. Strong effort had been performed in verification of such tool.

Section 5 contains the description of the MCNP model to represent ATUCHA-2 operational core condition focused on the power peak. Then, the benchmark of CNA-2 steady state between MCNP and 3D NK-TH system codes used to simulate the DEGB-LBLOCA scenario is reported too.

Section 6 contains the results of the methodology for predicting reactivity excursion during LOCA in ATUCHA-2 PHWR.

Conclusions are drawn in Section 7, focusing on innovations together with hints for future developments.

\subsection{Innovations}

The application of the methodology helps to evaluate the reactivity excursion in case of the selected accident. A coupled code methodology between MCNP and a computational fluid dynamics code was a result of this research. This methodology was successfully implemented for core analysis and it permits to investigate the effects of spatial representation of physical variables beyond the current generation of system code. This innovative methodology allows the evaluation of local power excursion in the transient to support the safety analysis.

Analysis were performed based on representation of core condition during normal operation as it defines the status of fuel at the beginning of transient.

Within the overall objective of the research, the following relevant results may be highlighted:

1. Application of the methodology developed, to the FSAR Chapter 15 of Atucha NPP in construction in Argentina;

2. The development of a methodology for nuclear safety analysis beyond the actual capability of current generation of system code based on advanced 3D coupled codes. 


\section{THE DESCRIPTION OF ATUCHA-2 NPP}

ATUCHA-2 (CNA-2) NPP is a Pressurized Heavy Water Reactor (PHWR) under construction in the Republic of Argentina designed by SIEMENS. It belongs to a second-generation reactor type PHWR. Its construction started in the 80's and it is scheduled to start commercial service by late 2012. General design data are hereafter reported, giving an overview of the plant characteristics [1].

\subsection{General plant description}

ATUCHA-2 is a $745 \mathrm{MWe}(2160 \mathrm{MWt})$ nuclear power plant, heavy water moderated and cooled, of pressure-vessel design. The reactor core is approximately cylindrical in shape and consists of 451 natural uranium fuel assemblies (FA) located in the same number of coolant channels. The heat generated in the fuel assemblies is transferred to the reactor coolant, which flows through the coolant channels and transports the heat to the $2 \mathrm{U}$-Tube steam generators.

The coolant is separated from the outer moderator by the fuel channel (FC) tubes and flows through the fuel assembly from the base to the top. By throttling the flow rate in less loaded FC to match the radial nuclear power density distribution arising at the burnup equilibrium, an even temperature distribution at the outlets of the FC is accomplished.

The coolant channels are surrounded by the moderator, which is enclosed in the moderator tank. For reactivity reasons, the moderator is maintained at a lower temperature than the reactor coolant. This is accomplished by the moderator system, which extracts the moderator from the core, cools it down in the moderator coolers, and feeds it back into the core. Sketches of the reactor coolant system logical layout and the main \& moderator cooling systems are reported in Figure 2 and Figure 3, respectively. The heat removed from the moderator is used for preheating the feed-water. This is one of the reasons for the high net efficiency (approx. $32 \%$ ) of the power plant.

The reactor coolant system and the moderator system are connected by the pressure equalization openings of the moderator tank closure head. Therefore, the pressure differences in the core are comparatively small, which results in thin walls for the reactor pressure vessel internals. The lower part of the pressure vessel consists of the hemispherical bottom section, two shell courses and a shell flange which carries the coolant inlet and outlet nozzles and the support pads located between them. The reactor coolant inlet and outlet nozzles are arranged on one plane; there are no penetrations or pipe connections below this plane. The reactor core is housed below the plane of the inlet and outlet nozzles.

The closure head consists of a flange and a dome plate connected by a circumferential weld. The closure head dome carries the nozzles for coolant channels, moderator pipes, and control element drives and for in-core instrumentation. The nozzles are screwed into holes in the closure head dome and sealed by an overlay weld.

RPV layouts and sketches, with the FCs and internals disposition and primary system layout are showed in Figure 4. Principal ATUCHA-2 data about primary system are reported in Table 1. 
Table 1 - Principal data of the CNA-2 primary system for full load operation

\begin{tabular}{|c|c|c|}
\hline Parameter & Value & Unit \\
\hline Thermal Reactor output & 2160 & MW \\
\hline $\begin{array}{l}\text { Total thermal power transferred to the } \\
\text { FW/main steam circuit }\end{array}$ & Max. $2173.5\left(^{*}\right)$ & MW \\
\hline Total thermal power transferred to SG & $\begin{array}{c}\text { norm/max. } \\
1953.5 / 2026.5\end{array}$ & MW \\
\hline $\begin{array}{l}\text { Total thermal power transferred to the } \\
\text { moderator coolers }\end{array}$ & $220 / 147$ & MW \\
\hline Number of parallel coolant circuits & 2 & - \\
\hline Number of parallel moderator circuits & 4 & - \\
\hline Total coolant circulation flow & 10300 & $\mathrm{Kg} / \mathrm{s}$ \\
\hline Total moderator circulation flow & 889 & $\mathrm{Kg} / \mathrm{s}$ \\
\hline Normal operating pressure at RPV outlet & 11.5 & $\mathrm{MPa}$ \\
\hline Coolant temperature at RPV outlet & $312.3 / 313.5$ & ${ }^{\circ} \mathrm{C}$ \\
\hline Coolant temperature rise through the core & $34.4 / 35.5$ & ${ }^{\circ} \mathrm{C}$ \\
\hline Average moderator temperature & $\begin{array}{c}\text { Norm/max } \\
170 / 220\end{array}$ & ${ }^{\circ} \mathrm{C}$ \\
\hline Moderator inlet temperature & $140 / 195$ & ${ }^{\circ} \mathrm{C}$ \\
\hline Moderator outlet temperature & $194 / 239$ & ${ }^{\circ} \mathrm{C}$ \\
\hline Steam pressure at SG outlet & 54.9 & bar \\
\hline Steam temperature & 271.0 & ${ }^{\circ} \mathrm{C}$ \\
\hline Total steam flow & 956.6 & $\mathrm{Kg} / \mathrm{s}$ \\
\hline Pressure loss in the reactor coolant circuit & approx. 9.8 & bar \\
\hline Total coolant volume inclusive pressurizer & 239 & $\mathrm{~m}^{3}$ \\
\hline Total moderator volume & 231 & $\mathrm{~m}^{3}$ \\
\hline Total circulation time of the coolant & 15.3 & $\mathrm{~s}$ \\
\hline Total circulation time of the moderator & 235 & $S$ \\
\hline
\end{tabular}

$\left(^{*}\right)$ including power from the main coolant pumps 


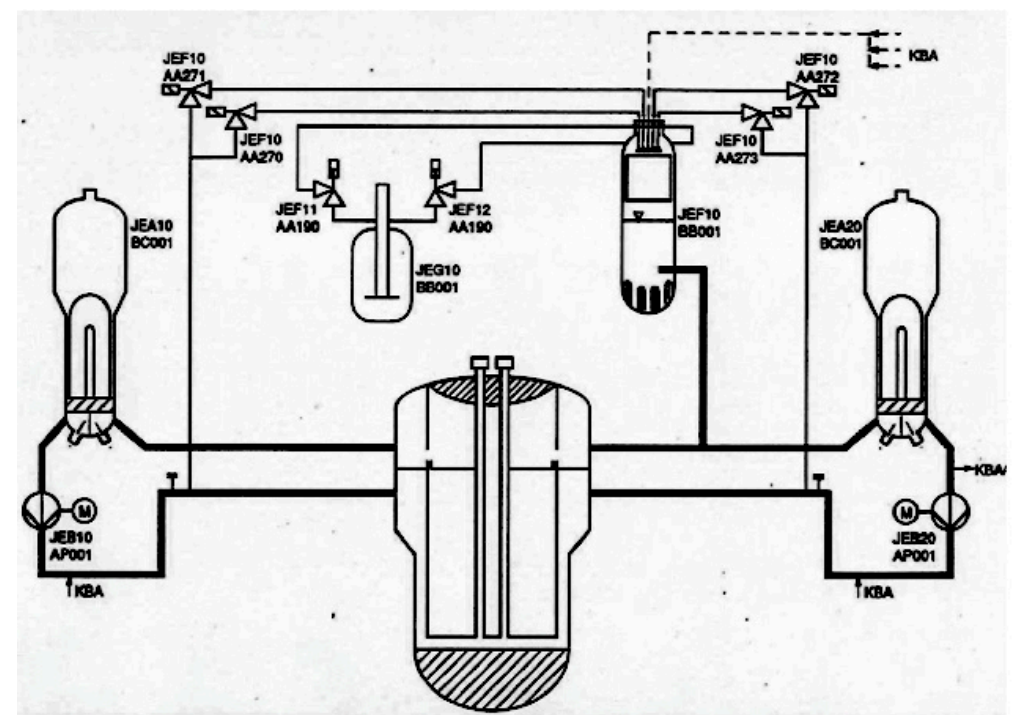

Figure 2 - Reactor coolant system logical layout
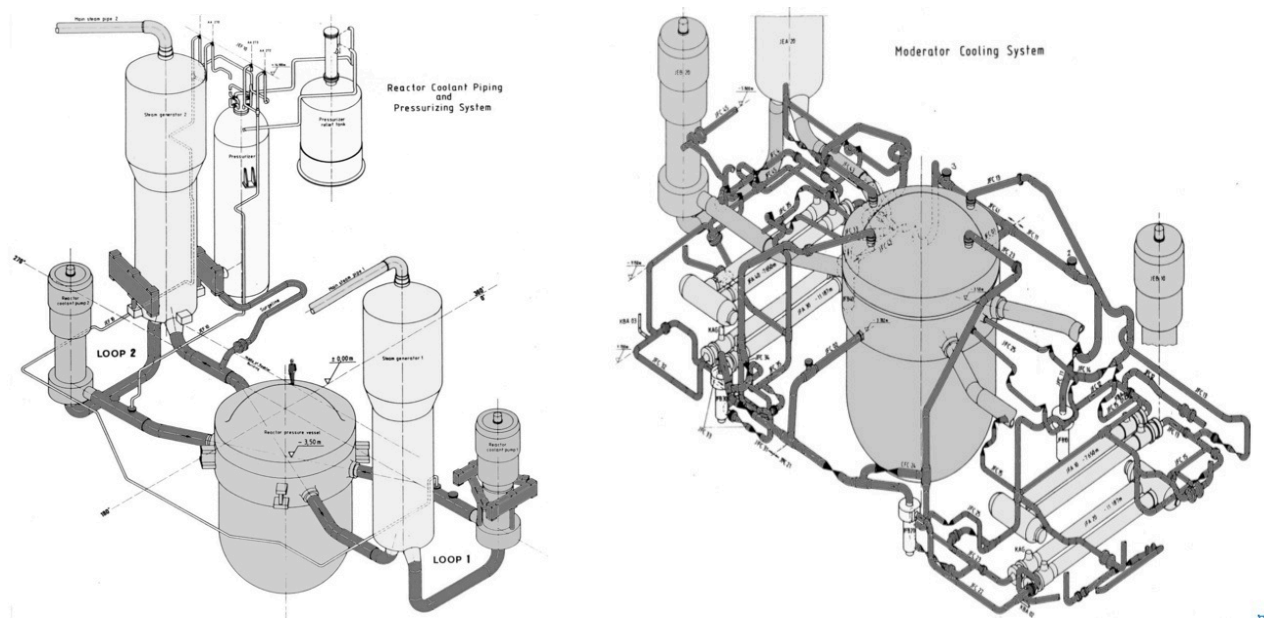

Figure 3 - CNA-2 Main \& moderator cooling systems layouts 

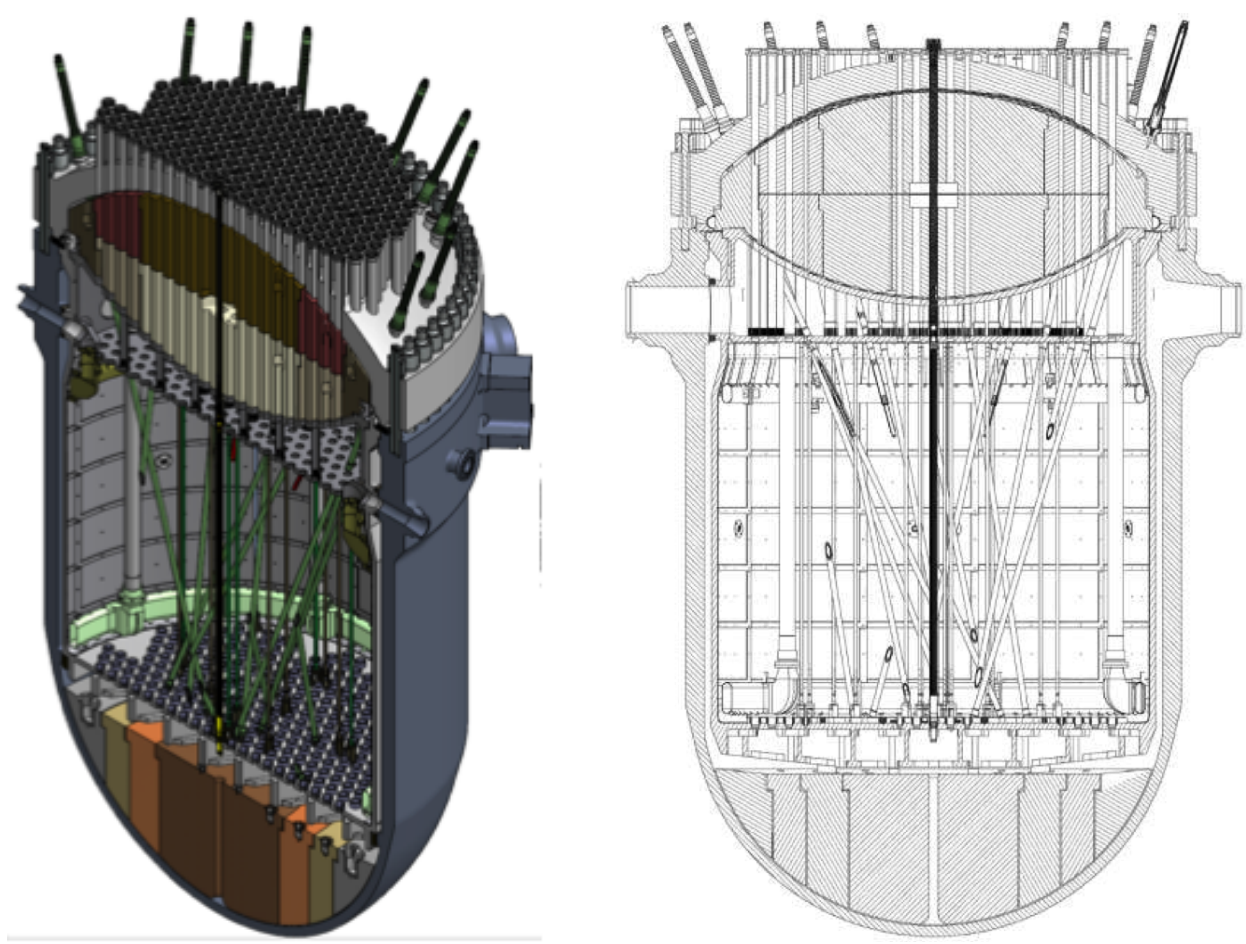

Figure 4-CNA-2 RPV sketches

\subsection{The core}

The reactor core is built up of 451 fuel assemblies located in discrete FC formed by shroud type tubes. The tubes are arranged in a vertical triangular lattice with a pitch of $272.4 \mathrm{~mm}$ within the moderator tank, that has an internal radius of $3.47 \mathrm{~m}$. The same tank contains 18 oblique CR guide tubes, 4 moderator downcomers, 4 safety Boron injection tubes and several tubes for in-core (see Figure 5). Active core has a length of $5.307 \mathrm{~m}$ and it is surrounded in the top by upper reflector ( $0.344 \mathrm{~m}$ thick) and in the bottom by lower reflector ( $0.482 \mathrm{~m}$ thick). All main reactor core geometrical data are summarized in Table 2. All the information given hereafter has to be considered for a reactor at hot conditions. 


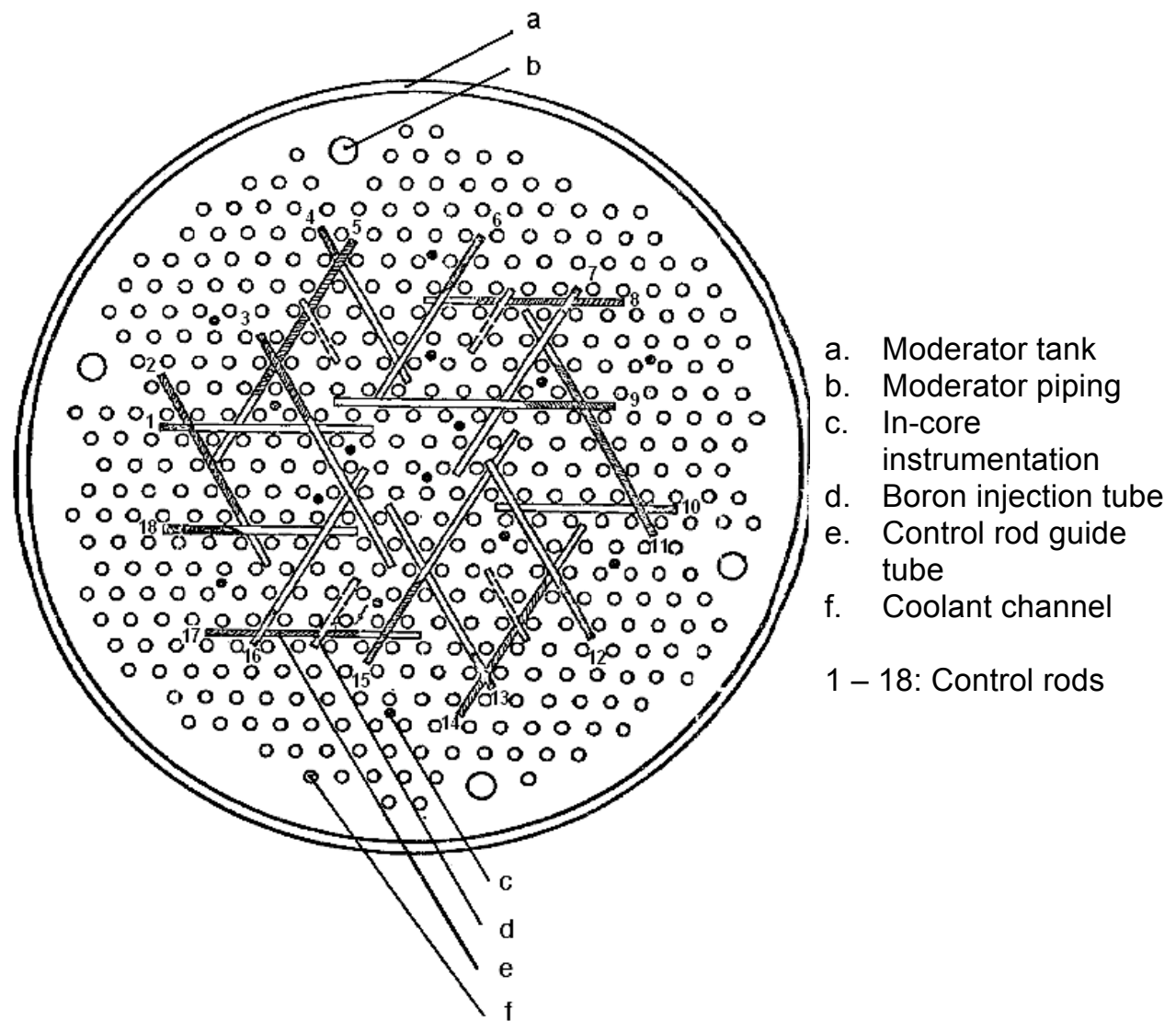

Figure 5-CNA-2 core radial arrangement

Table 2 - Relevant CNA-2 reactor core geometrical data

\begin{tabular}{|l|c|c||}
\hline \multicolumn{1}{|c|}{ Parameters } & Value & Unit \\
\hline \hline Number of active channels & 451 & - \\
\hline Lattice pitch (triangular) & 0.2724 & $\mathrm{~m}$ \\
\hline Active Length of the core & 5.307 & $\mathrm{~m}$ \\
\hline Moderator $/ \mathrm{UO}_{2}$ volume ratio & 13.82 & - \\
\hline Coolant/UO ${ }_{2}$ volume ratio & 1.11 & - \\
\hline Inner radius of the moderator tank & 3.47 & $\mathrm{~m}$ \\
\hline Upper axial reflector thickness & 0.344 & $\mathrm{~m}$ \\
\hline Lower axial reflector thickness & 0.482 & $\mathrm{~m}$ \\
\hline \hline
\end{tabular}




\subsubsection{The Fuel}

The FA are bundles of 37 closely packed fuel rods, which are arranged in 3 concentric circles with 6,12 and 18 fuel rods around a central fuel rod. Each fuel rod consists of a stack of natural uranium dioxide pellets enclosed by a thin walled Zry-4 canning tube, which is both gas and pressure tight. (see Figure 6). Each FC contains one FA. In order to limit heat exchange between coolant and moderator, a thin stagnant $\mathrm{D}_{2} \mathrm{O}$ film is kept around FC wall by a $0.2 \mathrm{~mm}$ Zry-4 sheet (see Figure 7). The fuel rods are held in position with respect to each other by means of several spacer grids set along the length of the FA. To support the FA within the FC, the spacer grids carry on their outer circumference sliding shoes. The FC geometrical dimension and fuel pin data are reported to Table 3 and Table 4, respectively.

Table 3-FC geometrical dimensions

\begin{tabular}{|c|c|c|c||}
\hline Parameters & Value & Unit & Notes \\
\hline \hline Internal Radius of FC & 54.185 & $\mathrm{~mm}$ & \\
\hline External Radius of FC & 55.915 & $\mathrm{~mm}$ & Zry-4 FC thickness: $1.73 \mathrm{~mm}$ \\
\hline Stagnant $\mathrm{D}_{2} \mathrm{O}$ External Radius & 57.60 & $\mathrm{~mm}$ & \\
\hline Zry-4 Sheet & 57.80 & $\mathrm{~mm}$ & Zry-4 Sheet thickness: $0.2 \mathrm{~mm}$ \\
\hline
\end{tabular}

Table 4 - Fuel rod data

\begin{tabular}{|c|c|c|}
\hline Fuel rod data & Value & Unit \\
\hline Fuel Rod Length & Approx. 5575 & $\mathrm{~mm}$ \\
\hline Active column Length & 5307 & $\mathrm{~mm}$ \\
\hline $\mathrm{UO}_{2}$ radius and clad inner radius & 5.88 & $\mathrm{~mm}$ \\
\hline Clad outer radius & 6.45 & $\mathrm{~mm}$ \\
\hline Material & Natural $\mathrm{UO}_{2}$ & - \\
\hline Mass of Uranium/FA & 189.111 & $\mathrm{Kg}$ \\
\hline Density of UO $\mathrm{O}_{2}$ pellets & 10.05866 & $\mathrm{~g} / \mathrm{cm}^{3}$ \\
\hline Form & $\begin{array}{c}\text { Pellets with dishing } \\
\text { on both end faces }\end{array}$ & \\
\hline Pellet length & 14 & $\mathrm{~mm}$ \\
\hline Volume of dishing/pellet & 21 & $\mathrm{~mm}^{3}$ \\
\hline Cladding Material & $Z r y-4$ & - \\
\hline Zry-4 density & $6.56 \mathrm{~g} / \mathrm{cm}^{3}$ & - \\
\hline
\end{tabular}




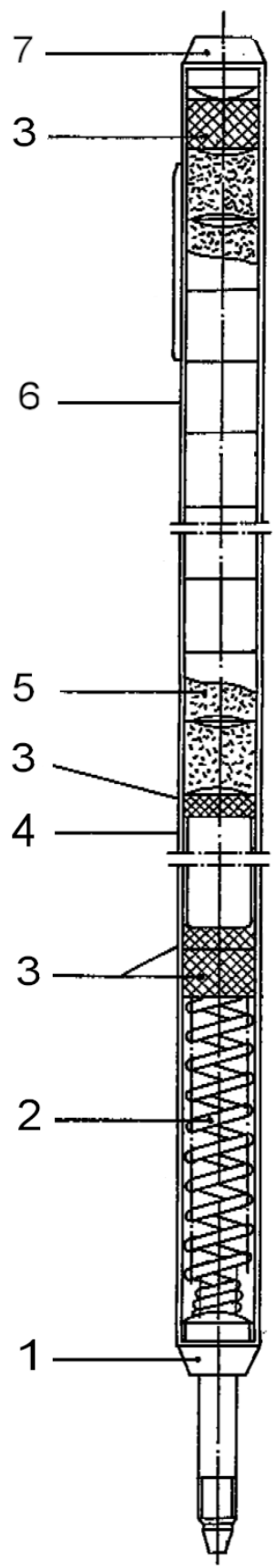

Figure 6 - Fuel pin layout 
1. Fuel assembly column

2. Fuel bundle

3. Spacer

4. The plate

5. The rod

6. Coupling

7. Filler body

8. Closure plug

9. Fuel rod

10. Lower end plug

11. Fuel pellets

12. Fission gas plenum

13. Upper end plug

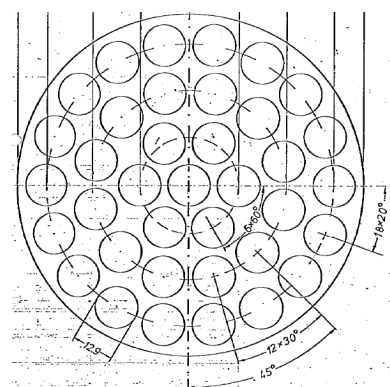

FA section

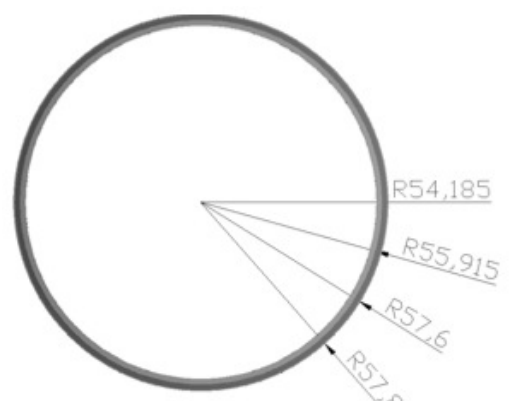

$\mathrm{FC}$ insulation tube

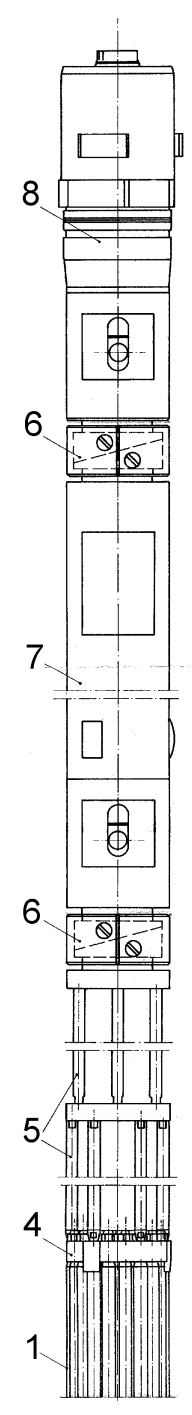

3
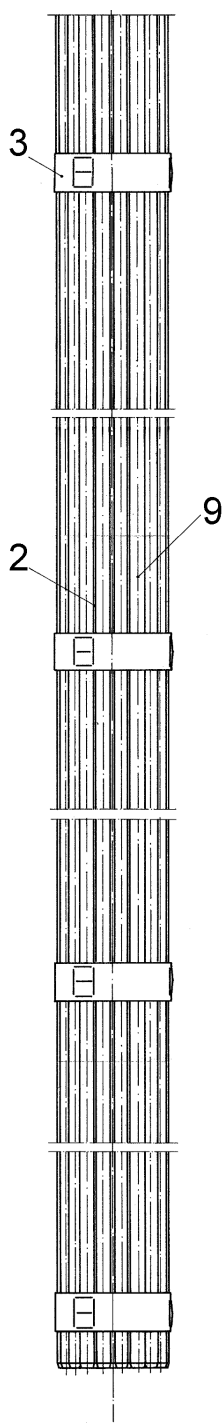

Figure 7 - Fuel channel layout 


\subsubsection{Control system}

Various methods are applied to control the reactivity, and thus the reactor power. The reactor contains nine "blacks" (absorbers made of hafnium) and nine "grey" (steel) control elements arranged in 3 groups. The control elements are used to control the reactivity and the power distribution, to compensate the build-up of xenon poisoning following a reactor power reduction, to provide damping of azimuthal xenon oscillations, and to shut down the reactor. The reactivity value of all control elements is sufficient to shut the reactor. The position of the CR inside the core is showed in Figure 8, then, a sketch of black and grey CR is reported in Figure 9 and Figure 10, respectively. Then, the CR coordinate and angle of insertion is reported in Table 6.

In addition to the control, elements, reactivity control is provided by the boric acid dosing system. The injection or extraction of boric acid serves to compensate slow reactivity changes due to the burnup during the first period of operation and to maintain the reactor in a safe subcritical condition at zero power. Anion exchangers extracts the boric acid.

Additionally, a Boron injection system, which injects boric acid into the moderator, is used as second independent shutdown system.

In addition to the reactivity control systems previously reported, the reactivity can also be controlled varying the moderator temperature within a certain range, which is advantageous for some operating modes.

The reactor pressure vessel constitutes the pressure boundary of the reactor core and encloses the core components and the reactor pressure vessel internals. The reactor pressure vessel consists of the lower part, the closure head, the studs and the nuts, which connect both sections. The connection is made leak-tight by means of a welded lip seal.

The core conditions simulated have All Rods Out (ARO) CR and critical CR configurations. The "critical CR configuration" is reported in Table 5. The insertion depth was measured from the top of the top reflector, and full insertion is at the bottom of the active core.

Table 5 - CR critical configuration

\begin{tabular}{|c|c||}
\hline CR bank & $\begin{array}{c}\text { Insertion } \\
{[\%]}\end{array}$ \\
\hline G10 & 94.00 \\
\hline G20 & 67.00 \\
\hline G30 & 24.50 \\
\hline S10 & 4.29 \\
\hline Shut-off & 0.00 \\
\hline
\end{tabular}


Table 6 - CR coordinates table

\begin{tabular}{|c|c|c|c|c|c|c|c||}
\hline $\begin{array}{c}\text { CR } \\
\#\end{array}$ & $\begin{array}{c}\text { CR } \\
\text { Type }\end{array}$ & $\begin{array}{c}\mathbf{X}- \\
\text { Lower }\end{array}$ & $\begin{array}{c}\text { Y- } \\
\text { Lower }\end{array}$ & $\begin{array}{c}\text { X- } \\
\text { Upper }\end{array}$ & Y-Upper & Material & Angle \\
\hline 1 & Shut-off & -40.62 & 35.38 & -223.34 & 35.38 & $H f$ & 19 \\
\hline 2 & G10 & -126.65 & -87.23 & -223.22 & 80.03 & Steel & 20 \\
\hline 3 & G30 & -15.44 & -91.17 & -139.16 & 123.12 & Steel & 25 \\
\hline 4 & Shut-off & -5.92 & 81.01 & -87.04 & 221.51 & $H f$ & 17 \\
\hline 5 & G20 & -173.09 & 6.79 & -54.97 & 211.39 & Steel & 24 \\
\hline 6 & S10 & -35.11 & 57.11 & 56.25 & 215.35 & $H f$ & 19 \\
\hline 7 & Shut-off & 34.31 & -11.33 & 136.15 & 165.07 & $H f$ & 21 \\
\hline 8 & G10 & -12.22 & 153.30 & 180.92 & 153.3 & Steel & 20 \\
\hline 9 & G30 & -71.23 & 58.96 & 176.21 & 58.96 & Steel & 25 \\
\hline 10 & Shut-off & 73.12 & -35.38 & 235.35 & -35.38 & $H f$ & 17 \\
\hline 11 & G20 & 92.43 & 146.51 & 210.55 & -58.09 & Steel & 24 \\
\hline 12 & S10 & 67.02 & 1.85 & 158.37 & -156.39 & $H f$ & 19 \\
\hline 13 & Shut-off & -18.59 & -38.55 & 77.97 & -205.81 & $H f$ & 20 \\
\hline 14 & G10 & 147.25 & -51.55 & 45.40 & -227.96 & Steel & 21 \\
\hline 15 & G30 & 86.68 & 32.21 & -37.04 & -182.08 & Steel & 25 \\
\hline 16 & Shut-off & -42.68 & -3.17 & -139.25 & -170.43 & $H$ & 20 \\
\hline 17 & G20 & 12.22 & -153.30 & -180.92 & -153.3 & Steel & 20 \\
\hline 18 & S10 & 67.02 & 1.85 & 158.37 & -156.39 & $H f$ & 19 \\
\hline \hline
\end{tabular}

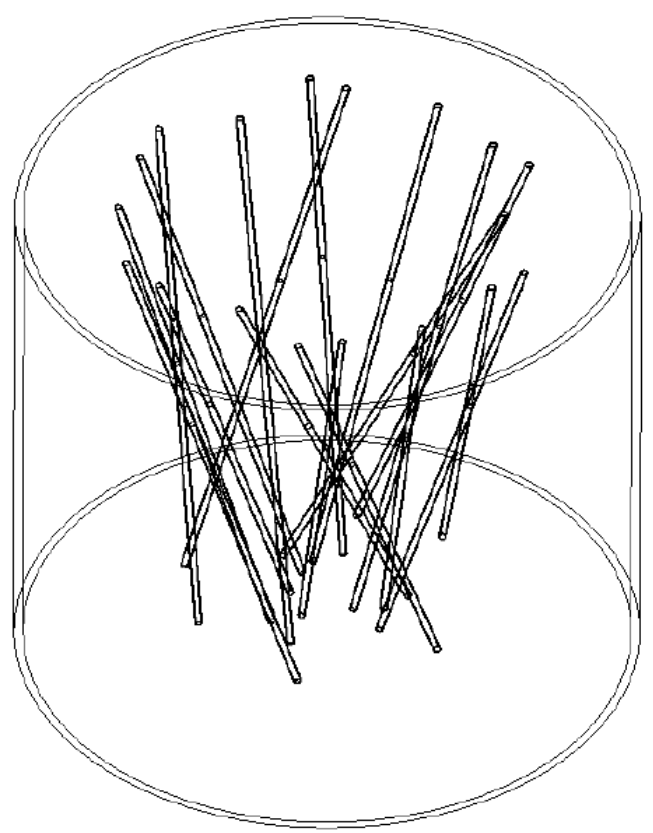

Figure $8-C R$ location in the reactor core 


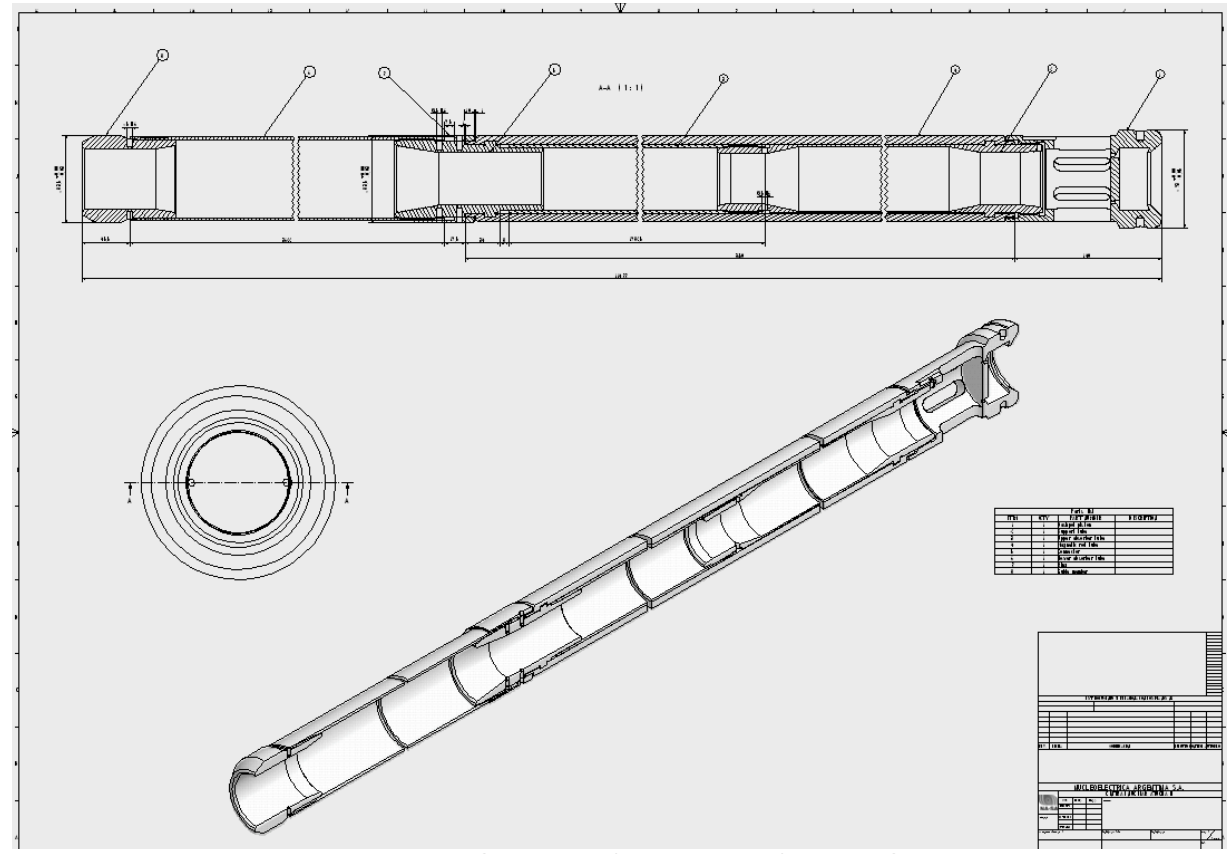

Figure 9 - Sketch of black (Hafnium) CR

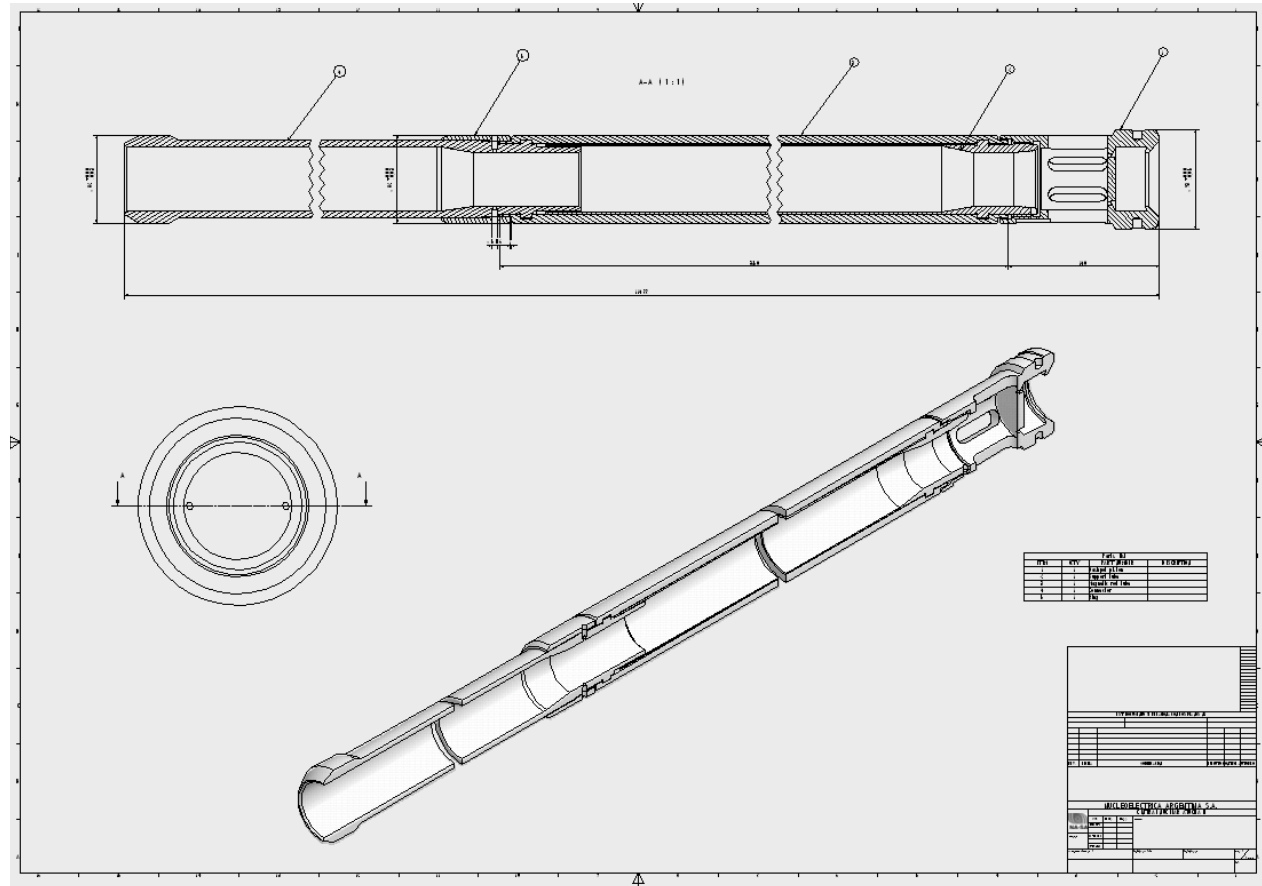

Figure 10 - Sketch of gray (Steel) CR 


\subsubsection{Fast Boron injection system (JDJ)}

The Fast Boron Injection system is the back shutdown system. It is based on four injection lances, which penetrate the RPV and reach the moderator tank interior, and through which a highly borated solution $\left(\mathrm{D}_{3} \mathrm{BO}_{3}\right)$ is injected, driven by pressurized air upstream of the tanks containing the boron solution (see Figure 11).

In detail the primary system places the following requirements on this system:

- Shutdown and maintenance of subcriticality of the reactor on loss of CR function. Should a given number of CR not reached their end position three seconds after reactor shutdown signal, boron injection is started by the reactor protection system;

- This function is actuated when limits such as primary pressure too high or reactor power too high are reached. The JDJ has been designed with the strict regard to safety aspect;

- Shutdown and maintenance of sub-criticality of the reactor in the event of a LOCA. (Boric acid is injected immediately into the moderator system);

- Maintenance of reactor sub-criticality by slow metered boric acid injection by the JDJ via throttling valves after Xenon reduction and unavailability of the control volume system (the KBA system in the German documentation).

Two out of four trains must be available to satisfy the requirements.

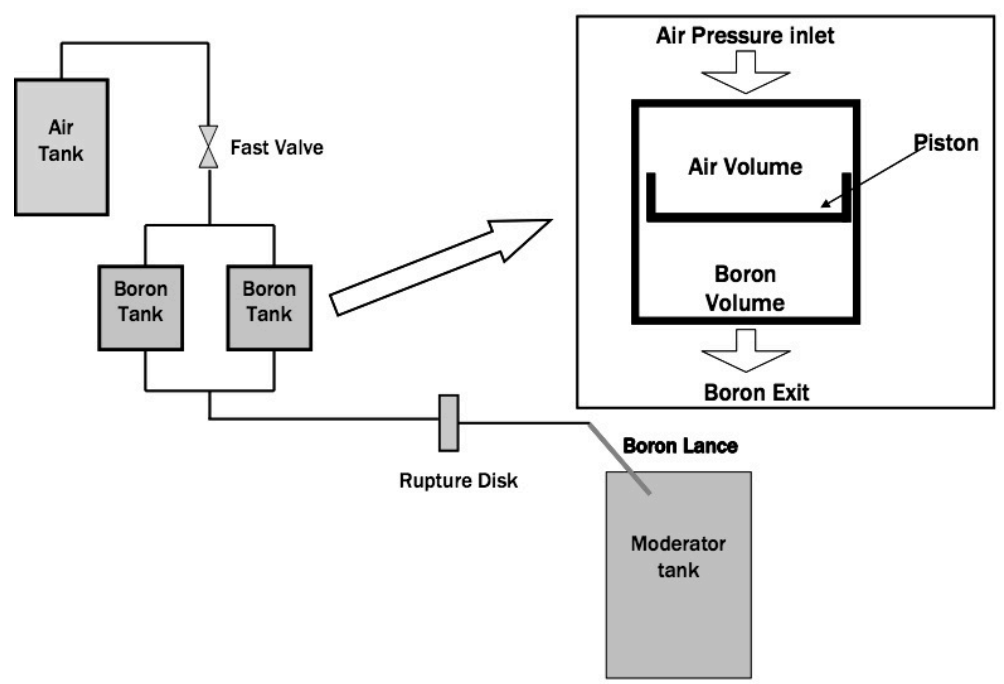

Figure 11 - Layout of one line of the fast boron injection system.

The location of the lances inside the core is also shown in Figure 12. Each lance is formed by two concentric tubes of different diameter, which superimpose for a portion of their length $(\sim 165 \mathrm{~cm})$ thus forming a "coaxial" zone. Two rows of 17 
small holes ( $1 \mathrm{~cm}$ diameter) with different orientations $\left(55^{\circ}\right.$ to $85^{\circ}$ with respect to the tube axis) are drilled on the outer tube within the coaxial zone, whereas two rows of 8 holes (same diameter; $30^{\circ}$ to $60^{\circ}$ ) are present on the inner tube, outside the coaxial zone; a central hole $(\sim 4 \mathrm{~cm}$ diameter $)$ is located at the end of the inner tube (see Figure 13).

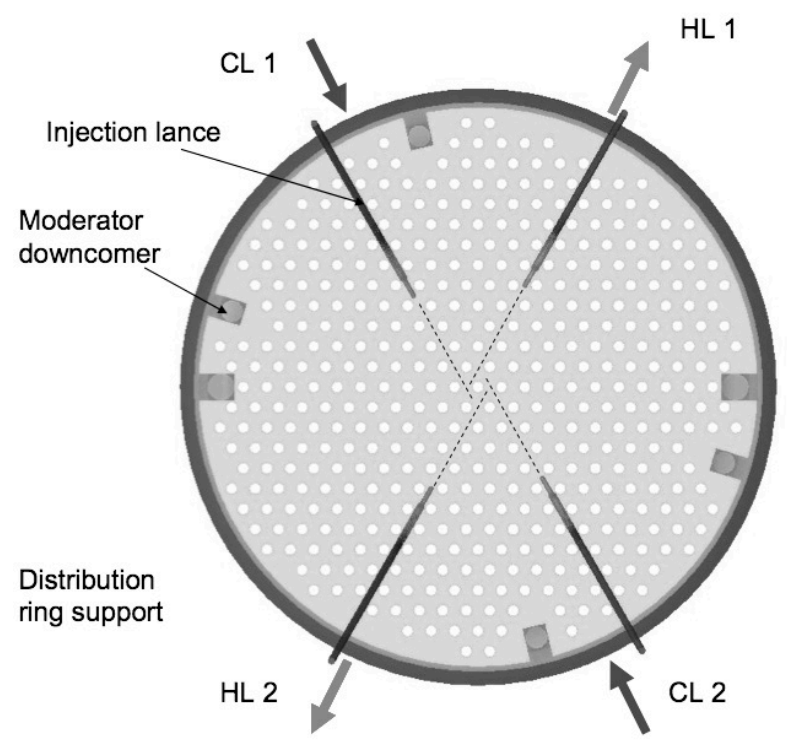

Figure 12 - Location of Boron injection lance within the core

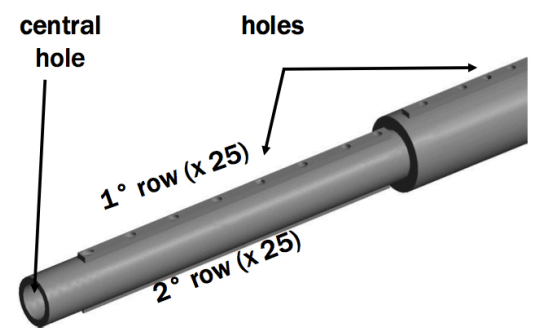

Figure 13 - Detail of Boron lance (CAD model)

\subsection{Fuel management and Burnup zone}

The ATUCHA-2 reactor has on-power re-fueling. The fuel bundle columns can be removed from the coolant channels during reactor operation by the refueling machine. The filler bodies serve to reduce the volume of the coolant in the reactor coolant system. After the equilibrium burnup core is reached (max. 7.8 $\mathrm{MWd} / \mathrm{kgHM}$ ), re-fueling is performed under the following rules:

The FA stays in the core in two positions. They are introduced fresh in one FC, stay in that FC until they reach a certain burnup, then they are moved to another FC, and stay there until they reach the exit burnup; 
- With respect to fuel management, the FC are divided in three "paths", and each "path" has two burnup zones; the FA enter the zone with lower average burnup, then is moved to the other zone (of the same "path") until it reaches the exit burnup of the path;

- $\quad$ The selection of the re-fueled FC is done by the plant physicist after he has calculated power and burnup distributions. He searches for the FA with highest average burnup, and that one is taken out from the core; then he searches for the FA of the other zone of the same path, and moves it to the other FC, putting a fresh FA in it. He should verify compliance with the FC and linear power limits and power ramp failures (Pellet Cladding Interaction, $\mathrm{PCl}$ ) prevention criteria. He should also try to keep an approximately symmetric power distribution in each of the six azimuthal sectors of the core. In case he has problems with the compliance of the criteria, he may introduce variations in the selection of the $\mathrm{FC}$, like not to choose the one with the highest burnup but the following one;

- In practice, all FCs, and the 10 axial sectors of each FC have a burnup between the value at which the FA enters the channel (which may be zero for some channels), and the value at which it leaves the channel, which may be the exit burnup for some FC.

The calculation of power and burnup distributions required for fuel management for CNA-2 is done with the NA-SA PUMA code. There are three refueling paths (see also Figure 14):

- Path 1: Fresh fuel enters zone 6, stays until a transition burnup (see Table 8 ), moves to 5 , stays until it reaches the exit burnup and leaves the core;

- Path 2: Same for zones 2 and 4;

- Path 3: Same for zones 3 and 1.

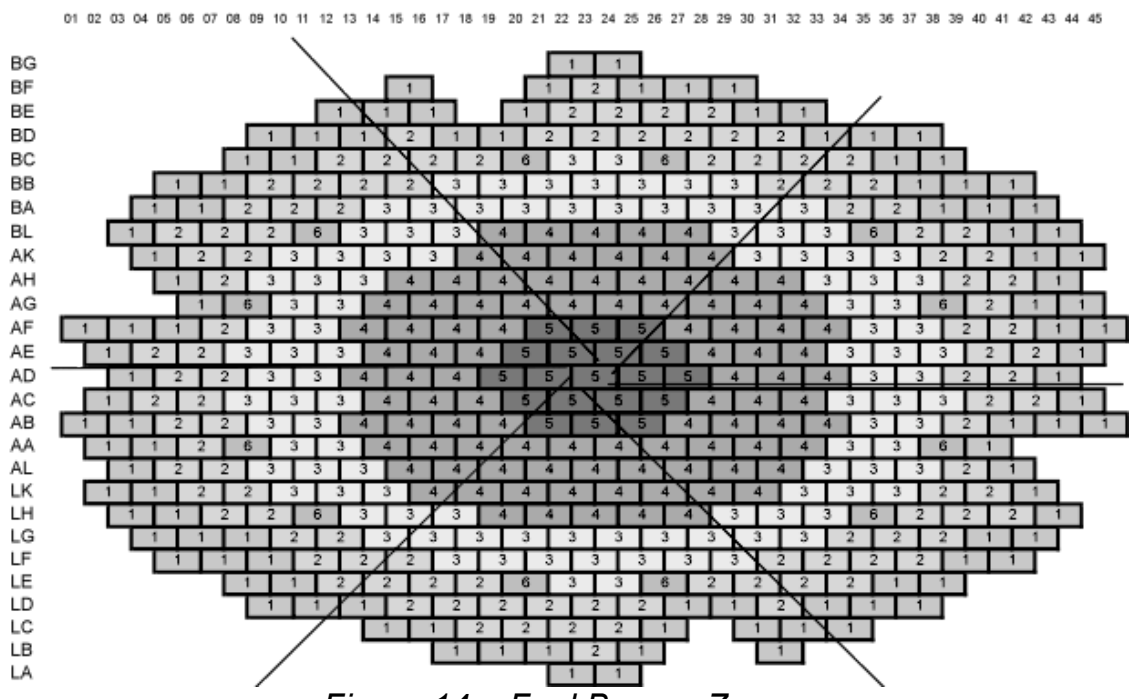

Figure 14 - Fuel Burnup Zones 
Example of a fuel management strategy for a core with equilibrium burnup fuel (BEQ) is given in Table 8. During the first plant start-up, nuclear fuel is composed by natural Uranium. Therefore, during the first months of operation, a breeding of $\mathrm{Pu}$ isotopes will happen, leading to an increase of reactivity whit an average burnup around $-1000 \mathrm{MWd}$ /ton HM This $\mathrm{Pu}$ accumulation leads to the sensible change of the reactivity coefficients (e.g., to an increase in magnitude of the void and Doppler coefficient) compared to the situation occurring with the core with burnup at equilibrium (BEQ). Therefore, in order to compensate the excess of reactivity and the change of reactivity coefficients, Boron is put into coolant and moderator and reactor power is limited below $70 \%$ of Nominal Power.

\subsection{Boundary and initial core conditions}

In this research 2 boundary and initial core conditions are used, beginning of life (BOL) at cold zero power (CZP) with fresh fuel and burnup at equilibrium (BEQ) at hot full power (HFP).

\subsubsection{BOL with CZP core condition and fresh fuel}

In the initial start up there are fresh fuel elements in the 451 channels in the core. The reactivity of the initial core is significantly higher than for the equilibrium core and consequently is necessary to add Boron in the moderator. To compensate this reactivity excess, it was evaluated that approximately $16 \mathrm{ppm}$ of Boron in the moderator circuit will be needed to have the reactor critical. This maximum excess is not expected to occur after the initial operation period because the normal operation condition will be an equilibrium burnup (BEQ) core. The core-averaged CZP conditions are reported in the following table,

Table $7-B O L$ with CZP core condition reference values

\begin{tabular}{|c|c|c|}
\hline Material & Temperature $[\mathrm{K}]$ & Density $\left[\mathbf{g} / \mathrm{cm}^{\mathbf{3}}\right]$ \\
\hline \hline Coolant & 293.6 & 1.11018 \\
\hline Moderator & 293.6 & 1.11018 \\
\hline Fuel & 293.6 & 10.05866 \\
\hline Fuel clad and FC wall & 293.6 & 6.56 \\
\hline
\end{tabular}

\subsubsection{BEQ with HFP core condition}

The burnup distribution in the core reached after a long period of the operation of the plant (of the order of two years) is called burnup at equilibrium (BEQ) distribution.

Characterization of ATUCHA-2 core at BEQ with hot full power (HFP) core condition requires the use of a large amount of data. This core condition requires the following specification:

- Physical parameters at HFP (temperature of materials, density of heavy water, coolant and moderator, etc). These values are not constant inside the core, in particular along the axial direction;

- The composition of fuel changes with the burnup, therefore, different burnup values has to be used to represent the fuel compositions. 
A sample of the temperature behavior along the axial direction is reported in Figure 15. This data was calculated by RELAP5-3D@ code using the 3D NK-TH 280 channels nodalization [27].

The ATUCHA-2 burnup distribution was provided by NA-SA [2] and for each fuel channel, a 10 layers axial burnup distribution was given, resulting in a total of 4510 values. A sample of the burnup distribution is shown in Figure 16.

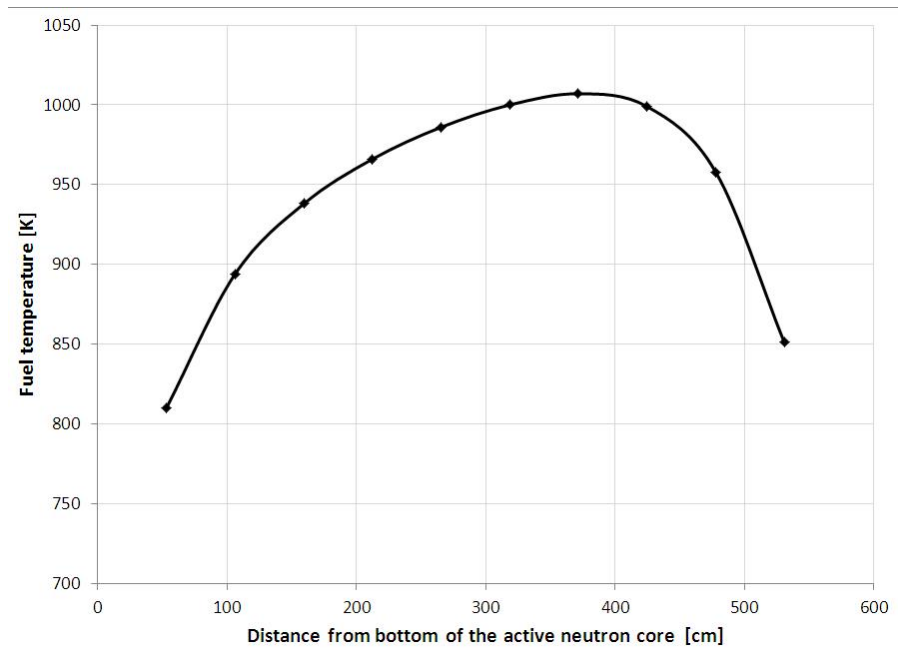

Figure 15 - Sample of averaged fuel temperature axial profile

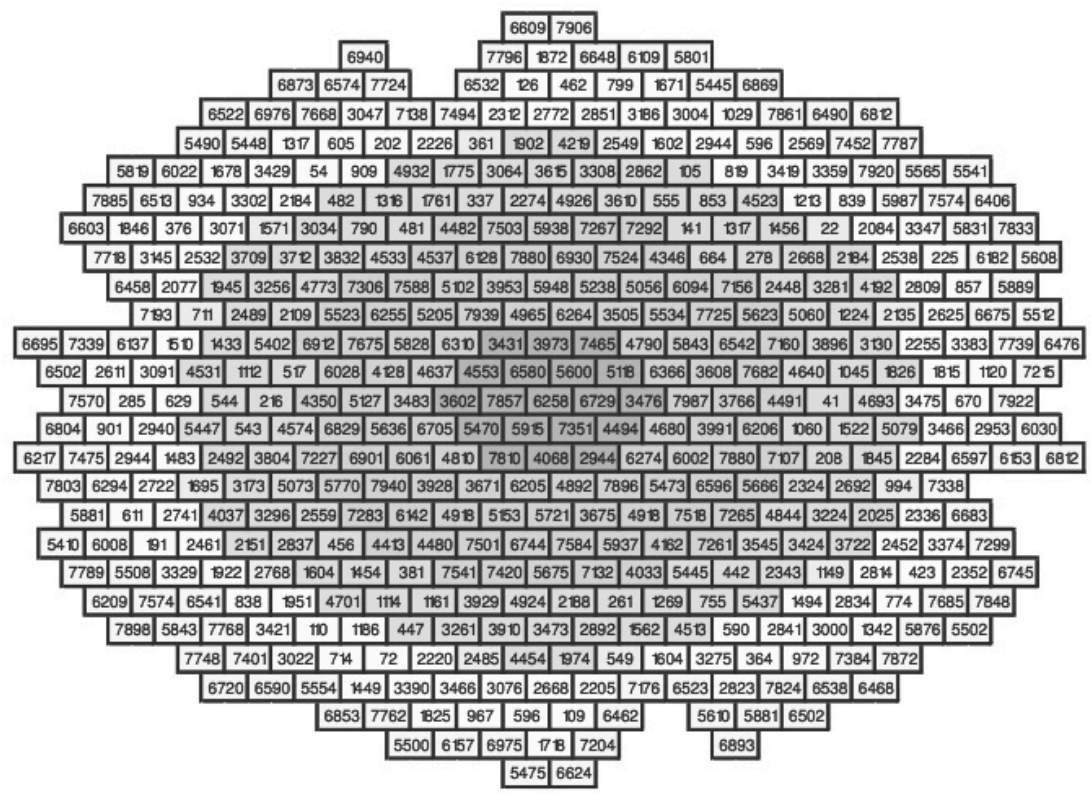

Figure 16 - Average burnup distribution [MWd/tonHM] 
Table 8 - Fuel Assemblies movements for burnup management

\begin{tabular}{|c|c|c|c|}
\hline Path & $\begin{array}{l}\text { Burning } \\
\text { Zone }\end{array}$ & Channels & $\begin{array}{l}\text { Burnup } \\
\text { [MWd/ } \\
\text { tonHM] } \\
\end{array}$ \\
\hline 1 & $\begin{array}{c}6 \\
\text { (Fuel Inlet) }\end{array}$ & $\begin{array}{l}\text { BC20 BC26 BL11 BL35 AG08 AG38 AA08 AA38 LH11 LH35 LE20 } \\
\text { LE26 }\end{array}$ & 2886 \\
\hline 1 & $\begin{array}{c}5 \\
\text { (Inlet) } \\
\downarrow \\
\text { Discharge } \\
\end{array}$ & $\begin{array}{l}\text { AF21 AF23 AF25 AE20 AE22 AE24 AE26 AD19 AD21 AD23 AD25 } \\
\text { AD27 AC20 AC22 AC24 AC26 AB21 AB23 AB25 }\end{array}$ & 8001 \\
\hline 2 & $\begin{array}{c}2 \\
\text { (Fuel Inlet) } \\
\downarrow\end{array}$ & $\begin{array}{l}\text { BF23 BE22 BE24 BE26 BE28 BD15 BD21 BD23 BD25 BD27 BD29 } \\
\text { BD31 BC12 BC14 BC16 BC18 BC28 BC30 BC32 BC34 BB09 } \\
\text { BB11 BB13 BB15 BB31 BB33 BB35 BA08 BA10 BA12 BA34 BA36 } \\
\text { BL05 BL07 BL09 BL37 BL39 AK06 AK08 AK38 AK40 AH07 AH39 } \\
\text { AH41 AG40 AF07 AF39 AF41 AE04 AE06 AE40 AE42 AD05 AD07 } \\
\text { AD39 AD41 AC04 AC06 AC40 AC42 AB05 AB07 AB39 AA06 AL05 } \\
\text { AL07 AL39 LK06 LK08 LK38 LK40 LH07 LH09 LH37 LH39 LH41 } \\
\text { LG10 LG12 LG34 LG36 LG38 LF11 LF13 LF15 LF31 LF33 LF35 } \\
\text { LF37 LE12 LE14 LE16 LE18 LE28 LE30 LE32 LE34 LD15 LD17 } \\
\text { LD19 LD21 LD23 LD25 LD31 LC18 LC20 LC22 LC24 LB23 }\end{array}$ & 3694 \\
\hline 2 & $\begin{array}{c}4 \\
\text { (Inlet) } \\
\downarrow \\
\text { Discharge }\end{array}$ & $\begin{array}{l}\text { BL19 BL21 BL23 BL25 BL27 AK18 AK20 AK22 AK24 AK26 AK28 } \\
\text { AH15 AH17 AH19 AH21 AH23 AH25 AH27 AH29 AH31 AG14 } \\
\text { AG16 AG18 AG20 AG22 AG24 AG26 AG28 AG30 AG32 AF13 } \\
\text { AF15 AF17 AF19 AF27 AF29 AF31 AF33 AE14 AE16 AE18 AE28 } \\
\text { AE30 AE32 AD13 AD15 AD17 AD29 AD31 AD33 AC14 AC16 AC18 } \\
\text { AC28 AC30 AC32 AB13 AB15 AB17 AB19 AB27 AB29 AB31 AB33 } \\
\text { AA14 AA16 AA18 AA20 AA22 AA24 AA26 AA28AA30 AA32 AL15 } \\
\text { AL17 AL19 AL21 AL23 AL25 AL27 AL29 AL31 LK16 LK18 LK20 } \\
\text { LK22 LK24 LK26 LK28 LK30 LH19 LH21 LH23 LH25 LH27 }\end{array}$ & 8001 \\
\hline 3 & $\begin{array}{c}3 \\
\text { (Fuel Inlet) } \\
\downarrow\end{array}$ & $\begin{array}{l}\text { BC22 BC24 BB17 BB19 BB21 BB23 BB25 BB27 BB29 BA14 BA16 } \\
\text { BA18 BA20 BA22 BA24 BA26 BA28 BA30 BA32 BL13 BL15 BL17 } \\
\text { BL29 BL31 BL33 AK10 AK12 AK14 AK16 AK30 AK32 AK34 AK36 } \\
\text { AH09 AH11 AH13 AH33 AH35 AH37 AG10 AG12 AG34 AG36 } \\
\text { AF09 AF11 AF35 AF37 AE08 AE10 AE12 AE34 AE36 AE38 AD09 } \\
\text { AD11 AD35 AD37 AC08 AC10 AC12 AC34 AC36 AC38 AB09 } \\
\text { AB11 AB35 AB37 AA10 AA12 AA34 AA36 AL09 AL11 AL13 AL33 } \\
\text { AL35 AL37 LK10 LK12 LK14 LK32 LK34 LK36 LH13 LH15 LH17 } \\
\text { LH29 LH31 LH33 LG14 LG16 LG18 LG20 LG22 LG24 LG26 LG28 } \\
\text { LG30 LG32 LF17 LF19 LF21 LF23 LF25 LF27 LF29 LE22 LE24 }\end{array}$ & 5546 \\
\hline 3 & $\begin{array}{c}1 \\
\text { (Fuel Inlet) } \\
\downarrow \\
\text { Discharge }\end{array}$ & $\begin{array}{l}\text { BG22 BG24 BF15 BF21 BF25 BF27 BF29 BE12 BE14 BE16 BE20 } \\
\text { BE30 BE32 BD09 BD11 BD13 BD17 BD19 BD33 BD35 BD37 BC08 } \\
\text { BC10 BC36 BC38 BB05 BB07 BB37 BB39 BB41 BA04 BA06 BA38 } \\
\text { BA40 BA42 BL03 BL41 BL43 AK04 AK42 AK44 AH05 AH43 AG06 } \\
\text { AG42 AG44 AF01 AF03 AF05 AF43 AF45 AE02 AE44 AD03 AD43 } \\
\text { AC02 AC44 AB01 AB03 AB41 AB43 AB45 AA02 AA04 AA40 AL03 } \\
\text { AL41 LK02 LK04 LK42 LH03 LH05 LH43 LG04 LG06 LG08 LG40 } \\
\text { LG42 LF05 LF07 LF09 LF39 LF41 LE08 LE10 LE36 LE38 LD09 } \\
\text { LD11 LD13 LD27 LD29 LD33 LD35 LD37 LC14LC16 LC26 LC30 } \\
\text { LC32 LC34 LB17 LB19 LB21 LB25 LB31 LA22 LA24 }\end{array}$ & 8001 \\
\hline
\end{tabular}




\section{DESCRIPTION OF LB-LOCA IN ATUCHA-2 NPP}

Loss of coolant accidents mean those postulated accidents that result from the loss of reactor coolant at a rate in excess of the capability of the reactor coolant makeup system from breaks in the reactor coolant pressure boundary, up to and including a break equivalent in size to the double-ended rupture of the largest pipe of the reactor coolant system.

A peculiarity of the ATUCHA-2 design is the positive void reactivity coefficient. This is a characteristic in common to other heavy water moderated reactors that utilize natural uranium as fuel (e.g CANDU $®$ reactor). This implies that after a LB-LOCA event, the fission power peak at the very beginning of the transient is controlled by the void formation in the core channels, and then it is determined by the pressure wave propagation from the break. Indeed, the moderator is still liquid and flashes delayed with respect to the coolant, thus the LOCA event is also a RIA event. We will refer in the following to "ATUCHA-2 LB-LOCA" to indicate the combined LOCA and RIA. The Double Ended Guillotine Break LOCA (DEGB LOCA or 2A LOCA) constitutes the "historical" event for the design of Emergency Core Cooling Systems (ECCS) in Water Cooled Reactors and is primarily adopted in vessel equipped Nuclear Power Plants. It is assumed that the largest pipe connected with the Reactor Pressure Vessel (RPV) can be broken: two end breaks are generated, typically at the RPV side and at the Main Coolant Pump (MCP) side. In the case of ATUCHA-2 the history of the construction and the agreement between the Regulatory Authority and the Utility brought to the exclusions of the 2A LOCA from the list of the Design Basis Accidents (DBA). Therefore, it is placed in an "ad hoc" category of events identified as Selected Beyond DBA (SBDBA).

\subsection{Description of the transient}

Four phenomenological windows (Ph.W) are identified, based on the key phenomena and the relevant thermal-hydraulic aspects occurring in ATUCHA-2 2A LOCA (see Figure 17). These Ph.W are:
I. Fission power excursion;
II. CHF occurrence and clad temperature excursion;
III. Quenching and fuel channels refill;
IV. Long term cooling.

These phases or Ph.W are adopted instead of the classical "Blow-down", "Refill" and "Reflood" phases adopted in systematic studies of the LB-LOCA in PWR [3].

\subsubsection{Ph.W. - Fission power excursion (RIA)}

From the start opening of the break till the time when total fuel energy achieves $90 \%$ of the value attained when power equals the decay value (this is to ensure that the RIA part of the transient is terminated and to include in this period possible damage mechanisms originated by energy deposition in the fuel, see Figure 17). The duration of the first Ph.W is of the order of one second. The propagation of the depressurization wave originated at the break and the consequent occurrence of the fission power peak are the characterizing phenomenon. Start of the CHF 
condition occurs in this period. The phenomena investigated in this research belong to this $\mathrm{Ph} . \mathrm{W}$.

\subsubsection{Ph.W. - CHF occurrence \& clad temperature excursion}

The second window lasts from the end of the previous window till (roughly) the time of actuation of accumulators. The duration of the second window is of the order of ten seconds. The widespread of the CHF condition and the rod surface temperature excursion including the occurrence of the peak cladding temperature and the related turnaround caused by liquid flashing and by flow reversal in the core, are the characterizing phenomena. Containment pressurization also occurs during this Ph.W.

\subsubsection{Ph.W. - Quenching \& fuel channels refill}

The third window ends when liquid level (mixture) fills all the core channels. At the beginning of the Ph.W. early quench occurs noticeably before the actuation of emergency systems and is caused by flow reversal in the core and flashing. The ECCS intervention keeps the clad temperature down and is necessary for refilling of the fuel channels. The duration of the third phenomenological window is of the order of a few minutes. In this period equalization of pressures between containment and primary circuit occurs.

\subsubsection{Ph.W. - Long term cooling (LTC)}

The fourth $\mathrm{Ph} . \mathrm{W}$ implies the continued containment sump recirculation operation and ensures the "post-LOCA long term" core cooling. The behavior of the sump (liquid level and temperature, other than debris effect), the performance of the SIP and the level distribution (and stabilization) in the primary loop constitute the characterizing thermal-hydraulic phenomena.

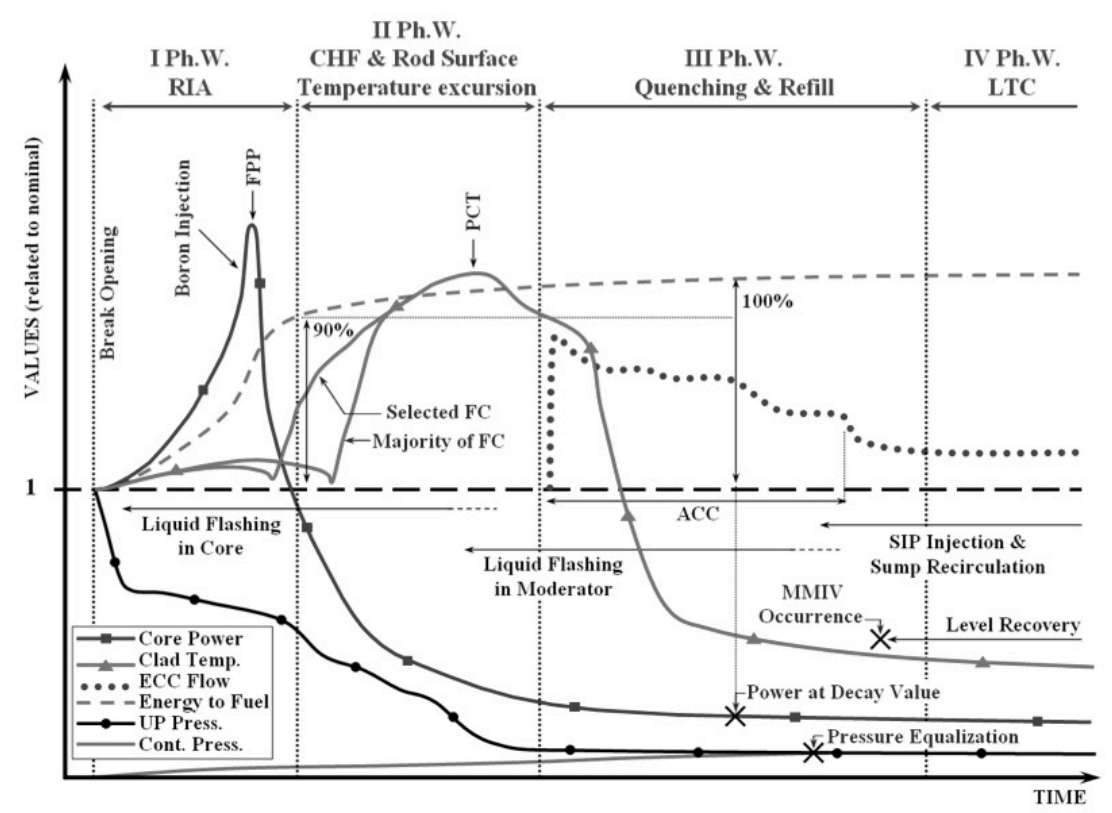

Figure 17 - Definition of the LB-LOCA phenomenological windows 


\subsection{Licensing framework}

\subsubsection{The regulatory framework}

An established regulatory framework exists in the nuclear technology in relation to the LB-LOCA analysis of vessel equipped water cooled nuclear reactors. Furthermore, an overview of the current trends on the same subject constituted a document issued within an agreement between UNIPI and NASA, i.e. [4].

\subsubsection{The international practice}

The DBA, including the DEGB LB-LOCA (or LOCA $2 \times 100 \%$ ) was intended in historical terms as a minimum set of enveloping scenarios whose positiveconservative evaluation, within the (overly)-conservative Appendix $\mathrm{K}$ approach could ensure that an adequate level of protection is provided by the designers.

TMl-2, Chernobyl-4 and also Fukushima unit 1 to 4 , were practical demonstrations that complex accidents out of the DBA list may occur. The needs from operator training, the accident management technology and, above all, the progress in the techniques for deterministic and probabilistic accident analysis, i.e. an outcome of the research programs carried out during the last three or four decades, suggested a change in the conservative approach.

A recent issued OECD/CSNI report, [5], identifies four classes of deterministic methods that can be seen as a historical progress for the licensing approach:

1) Very Conservative (Appendix K for LOCA);

2) Best Estimate Bounding;

3) Realistic Conservative;

4) Use of Best-Estimate Plus Uncertainty (BEPU).

A similar classification was proposed earlier by IAEA, e.g. [6], in a well known table ("table of options" for deterministic analyses) where "Type of Applied Code", "Type of BIC", "Assumption on System Availability" and "Type of Approach", are distinguished.

Without entering into detail of the four classes, neither of methods nor of the IAEA table, two remarks apply:

- Drawbacks from the Applicant and from the Licensing Authority side are identified when the approaches 1) to 3), or the "conservative" approaches of the IAEA table are pursued, see also [7];

- BEPU constitutes the current trend, as also testified by ongoing projects like OECD/CSNI BEMUSE, [8], or recently issued documents like US NRC RG 1.203, [9], and IAEA Safety Series Report on uncertainty methods, [10].

Thermal-hydraulic system codes, properly qualified and with techniques available for the proper application, are at the basis of the BEPU approach. The codes, noticeably, RELAP5, ATHLET, CATHARE, TRACE, CATHENA, APROS and MARS, must be supplemented or connected with uncertainty methods. Two categories of uncertainty methods are distinguished, e.g. [10], with approaches based on: 

a) Propagation of code input errors and statistical treatment of the resulting uncertainty;
b) Propagation of code output errors and "deterministic" treatment of the resulting uncertainty.

CSAU, GRS-method and CIAU are uncertainty methods suitable for technological applications. The development of BEPU methods had, as specific reference framework, the deterministic accident analysis and the acceptance criteria valid within the conservative approach, i.e. items 1) to 3) above. The BEPU approach in [11] is considered as "... the biggest effort for a proper use of best estimate models in order to minimize unnecessary conservatism while accounting for uncertainties associated to simulation results".

The current challenge is the "distributed" and "comprehensive" application of the BEPU methods within the FSAR, making reference to the physical barriers, the release of fission products and to the safety functions, other than considering the existing acceptability thresholds, i.e. the heredity from the conservative approach. The adoption of BEPU approach allows a homogeneous level of safety for all the issues that are part of the FSAR. Furthermore, the application of the BEPU methods is consistent with the best-latest available information in various technological sectors, see [4].

\subsubsection{The ARN requirements and the current status of the licensing process}

The consideration of the requirements of the Regulatory Authority constitutes the most important goal for a licensing analysis. The existing "framework-ofagreement", related to the construction and licensing of the CNA-2, between the Utility (NA-SA) and the Regulatory Authority (ARN) is summarized in the document at [12]. The following should be noted:

1) IAEA reports at [13] and [14], are mentioned in the document as at the top of the hierarchy for the ATUCHA-2 licensing;

2) ARN legal requirements do not make direct reference to the detailed Appendix $\mathrm{K}$ type of criteria. Rather, it is requested that a Farmer type of curve (probability versus consequences) must be respected by the Licensee [15];

3) On the one hand, the ARN legal requirements (issued in [16]) can be considered as a precursor to the risk-informed regulation. On the other hand, current international practice must be considered (this is consistent with ARN recommendation) although the concerned NPP design and construction start are two or three decades old, respectively;

4) ARN did not consider adequately substantiated the value of $10^{-7}$ event/year for the probability of the DEGB (2A or $2 \times 100 \%$ LB-LOCA) occurrence in ATUCHA-2 (this could level-down the relevance of this event). 


\subsubsection{The BEPU Approach}

Based on qualified tools and analytical procedures developed or available at UNIPI, a modern and technically consistent approach has been built upon best estimate methods including an evaluation of the uncertainty in the calculated results (Best Estimate Plus Uncertainties or BEPU approach). The complete description of the approach, available in [3], is outside the aim of the present document. In the present section only specific notes will be provided.

Adopting a "best estimate approach" for safety analyses means that, for each expected phenomenon, the best available tools and codes should be used. At present, no single code is capable of covering all phenomena involved in the nuclear safety field. Therefore, the best estimate analyst will meet the situation of working with two or more codes, and will have to develop an interface between those two [3].

In the overall approach, MCNP code will be used in connection with other codes, as outlined in Figure 18 with the aim of investigating the 3D performance of core with main reference to multiplication factor and neutron flux in steady state conditions. Figure 19 reports the simplified flowchart of the overall approach.

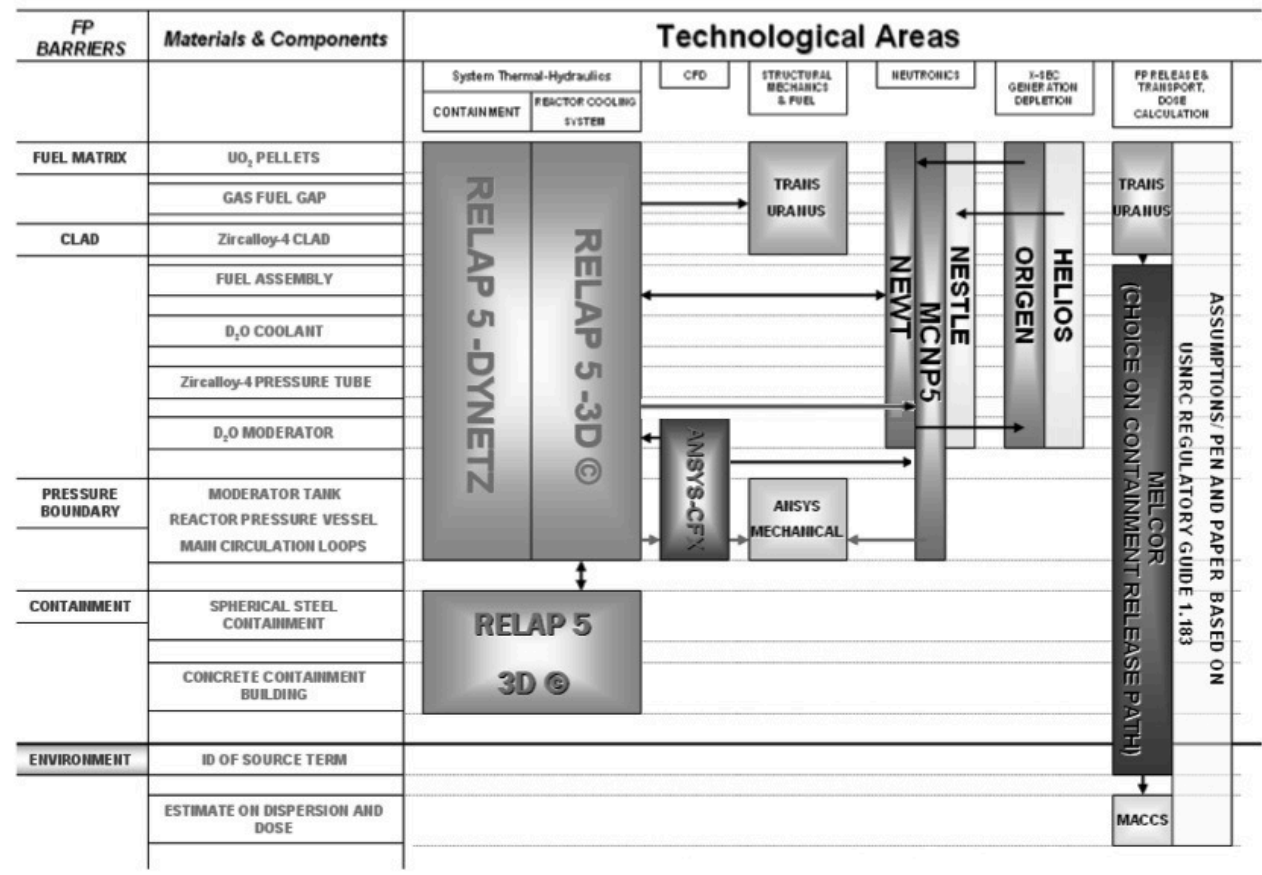

Figure 18 - Description of the interaction between the codes 


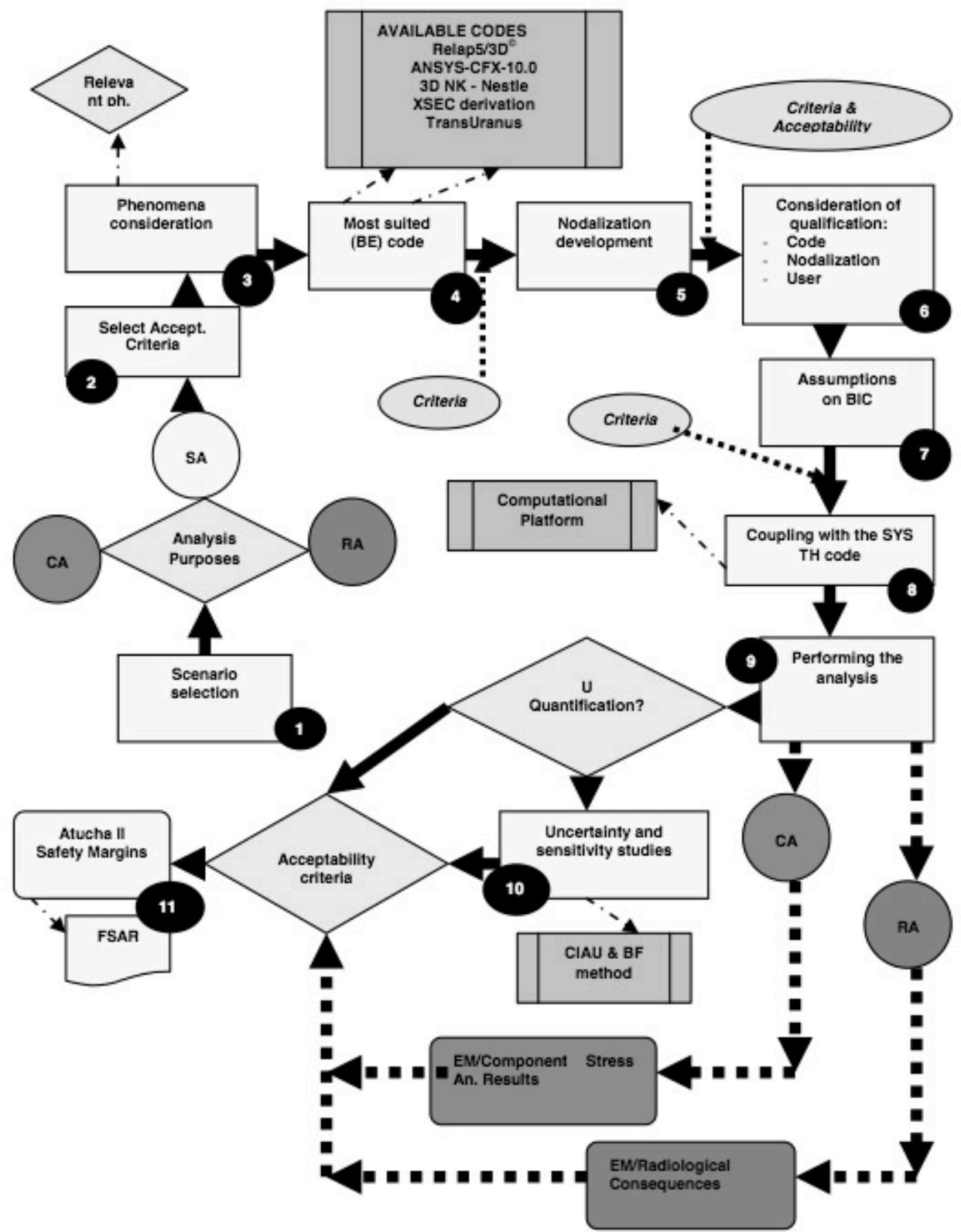

Figure $19-B E P U$ approach flowchart for ATUCHA-2 FSAR accident analysis 


\section{COMPUTATIONAL TOOLS}

\subsection{The use of coupled codes}

The evaluation of inserted reactivity in a transient scenario using MCNP5 required the development of a dedicated methodology. The flow-scheme reported in Figure 20 summarizes the main points of such methodology.

The scope of this methodology is not bound to a particular nuclear power plant and could be applied also to other scenarios in which the detailed geometrical (and energy) representation of physical variable is required. However, the assessment of LB-LOCA in ATUCHA-2 NPP is the final product of this research; hence, attention will be focused on ATUCHA-2 hereafter.

The computational tools used within the methodology consist on well-known codes for neutronic analyses and ad-hoc computer program developed for several kinds of task. The neutronic codes are briefly described in Table 9, more information and references about such codes are reported in APPENDIX A. The CFX [21] and RELAP-3D@/NESTLE [22] and were added since they provided relevant boundary conditions used within the methodology.

Table 9 - Codes used in the methodology

\begin{tabular}{|c|l|}
\hline Codes & \multicolumn{1}{|c|}{ Description } \\
\hline \hline MCNP5 & Monte Carlo based neutron transport code \\
\hline MONTEBURNS2.0 & Monte Carlo based burnup code \\
\hline ORIGEN2.2 & Radioactive decay and burnup code \\
\hline NJOY (99/up256) & $\begin{array}{l}\text { Calculates point-wise and multi-group } \\
\text { Xsec from evaluated nuclear data in the } \\
\text { ENDF/B format }\end{array}$ \\
\hline \hline RELAP-3D/NESTLE & $\begin{array}{l}\text { TH system code coupled to 3D NK } \\
\text { neutron kinetic }\end{array}$ \\
\hline CFX & Computational fluid dynamic code \\
\hline
\end{tabular}

The computational tools developed to fulfill the objective of the research are listed in Table 10. The main tool is the CFD2MCNP program that links the MCNP code to the CFD CFX ${ }^{\mathrm{TM}}$ and it is presented in Par. 4.2. A detailed description of the other tools is reported in APPENDIX B. The auxiliary tools are used implicitly in the methodology to improve the accuracy and reliability of the results. 
Table 10 - Computational tools developed in this research

\begin{tabular}{|c|l||}
\hline Tools & \multicolumn{1}{|c|}{ Description } \\
\hline \hline CFD2MCNP & $\begin{array}{l}\text { Automate and control the overall process of } \\
\text { converting data from CFX to MCNP5 }\end{array}$ \\
\hline HEXMESH & $\begin{array}{l}\text { Subroutine embedded in the MCNP code to calculate } \\
\text { the neutron flux on a system super-imposed } \\
\text { hexagonal prism lattice }\end{array}$ \\
\hline ATUCHABURN & $\begin{array}{l}\text { Calculate the burnup dependent material composition } \\
\text { using a Material Master Library (MML) via polynomial } \\
\text { interpolation }\end{array}$ \\
\hline ATUCHACORE & Generates MCNP5 input decks for core simulation \\
\hline \hline Auxiliary tools & \multicolumn{1}{c|}{ Description } \\
\hline \hline XNJOY & $\begin{array}{l}\text { Manage the overall process of Xsec generation using } \\
\text { NJOY code }\end{array}$ \\
\hline XFPL & $\begin{array}{l}\text { Calculate continuous energy lumped Xsec for minor } \\
\text { fission products }\end{array}$ \\
\hline
\end{tabular}

The methodology can be summarized in 3 main blocks. The first block is dedicated to convert the CFD data in the MCNP5 representation of the system. The CFD2MCNP manages such conversion of data.

The task of the second block is the generation of realistic MCNP5 model for ATUCHA-2 core simulations. This task starts with the creation of a database of Xsec for ATUCHA-2 hot full power (HFP) core condition using the NJOY code (through the XNJOY auxiliary program). Then, the MONTEBURNS2.0 code calculates a burnup dependent material master library (MML). The ATUCHABURN program generates the MCNP5 material compositions using the MML and the burnup map provided by NA-SA specialists. Finally the ATUCHACORE program generates the MCNP5 input deck for realistic core simulation including the CFD data converted by CFD2MCNP program.

The third block is the execution of the MCNP5 input deck. A parallel environment was used to reduce the simulation time. The tally of the neutron flux over the ATUCHA-2 active neutron core is done by a modified version of MCNP5 in which the neutron tracks are processed by the HEXMESH subroutine (see APPENDIX B).

The use of this methodology in the licensing of ATUCHA-2 required an acceptable level of verification and validation on each step. The developed computational tools were thoroughly verified. Then, international benchmarks were used to validate the continuous energy Xsec and to benchmark the burnup procedure (see APPENDIX $\mathrm{C}$ and APPENDIX E, respectively). 


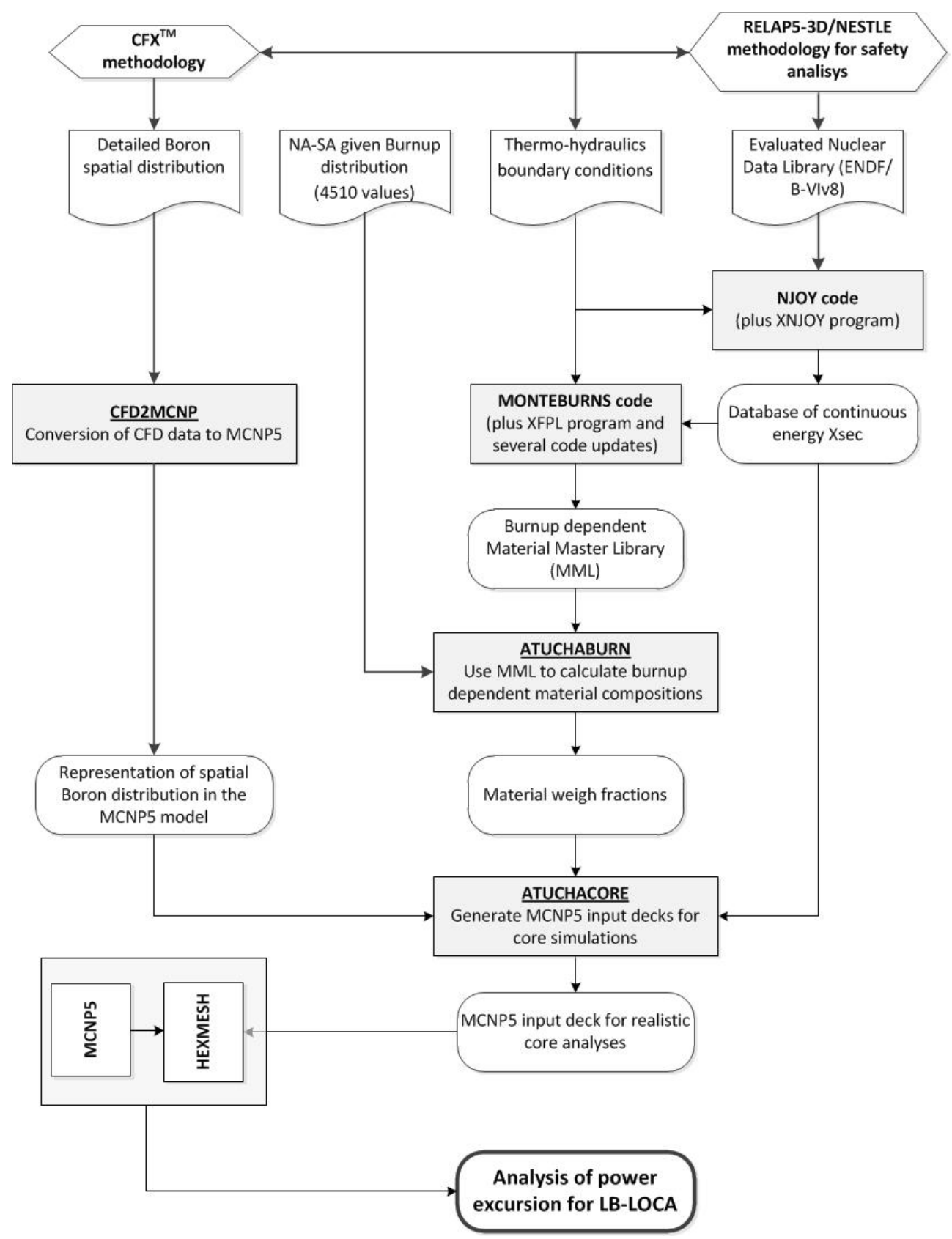

Figure 20 - Coupled code methodology 


\subsection{The main tool for coupling CFX and MCNP5}

\subsubsection{The CFD2MCNP coupling routine}

The numerical method used by CFX code divides the simulated volume in a number of finite element meshes in which the fluid-dynamics equations are solved. The choice of a suitable mesh grid is a delicate problem depending on the phenomena to be analyzed. At the end of simulation, each node contains time dependent data about the relevant physical quantities (e.g. density and temperature of heavy water, Boron concentration, etc.).

The CFD codes are nowadays a frontier of nuclear safety and current generation of computer [36] allows very complex model with an enormous number of mesh zone. As example, the CFD simulations investigating the JDJ system employed about 1.6 million of meshes [24]. A sketch of CFX mesh model around a JDJ injection lance is reported in Figure 21.

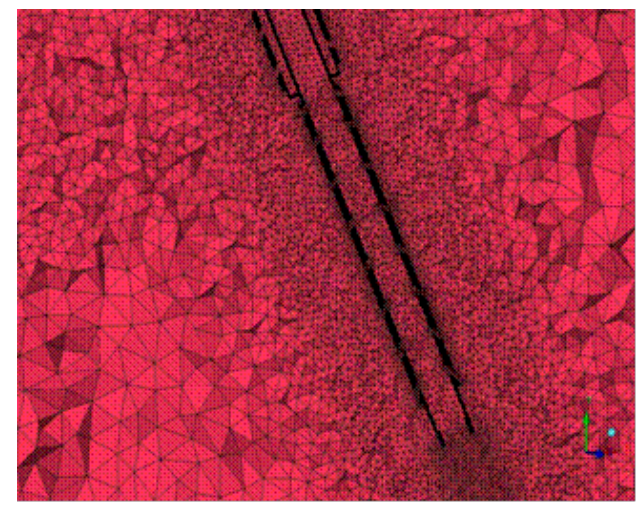

Figure $21-C F X$ node mesh around a JDJ injection lance

The computer routine CFD2MCNP written in mixed languages C/PERL, was developed to automate and control the overall process of converting data from CFX to MCNP5. The conversion algorithm is based on CFX node indexes mapping to user-defined MCNP5 macro region. Every physical quantity of interest can be converted from a CFX calculation to MCNP5; however, the user has to provide in the source code the correct homogenization function for the selected quantity of interest. Hereafter, the Boron concentration in a CFX node will be selected as reference physical quantity of interest due to its relevance in this research.

The CFD2MCNP routine consists on 2 main flow processes. The first flow process is used to convert the CFX mesh structure to MCNP5 regions. A scheme of such mapping procedure is reported in Figure 22. The algorithm starts assigning a set of indexes to each CFX node. Those indexes identify the CFX nodes to a regular 3D prism map. The program allows 2 pre-defined kinds of regular prism maps, Cartesian and triangular. The dimensions of these maps are user-defined and have to be selected to match the MCNP5 model. Hereafter, description will be focused only to the triangular mapping. This choice was due to the hexagonal FC lattice used in ATUCHA-2 NPP. 


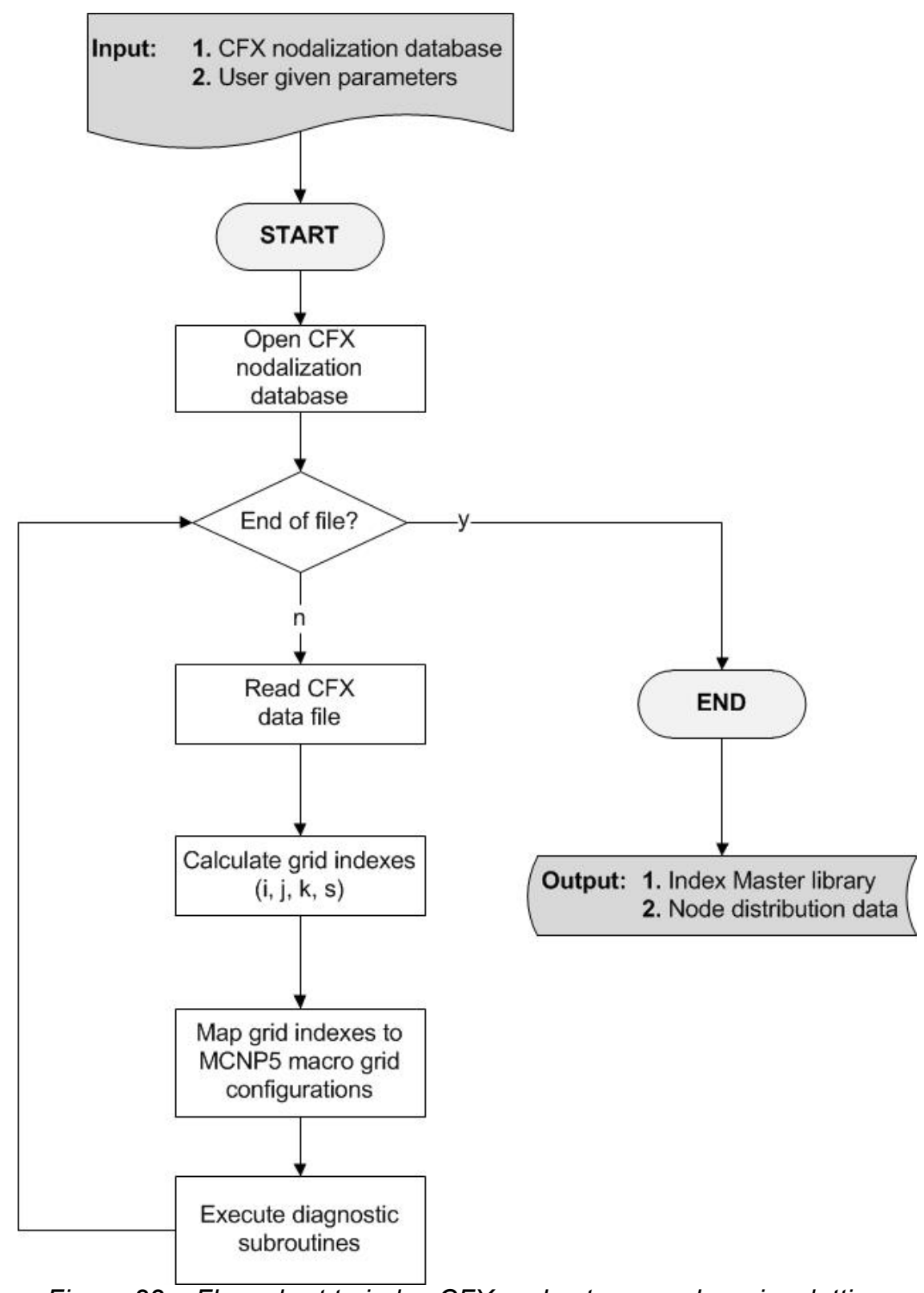

Figure 22 - Flow-chart to index CFX nodes to a regular prism lattice 
The program calculates 4 indexes for each CFX node. The spatial Cartesian coordinates are given by 3 indexes $(i, j, k)$, then, the latter identifies at fixed (i, j, $k$ ) the destination triangular prism. A sketch about this mapping is reported in Figure 23 , then information about the triangular regular grid used in this research are reported in Table 11.
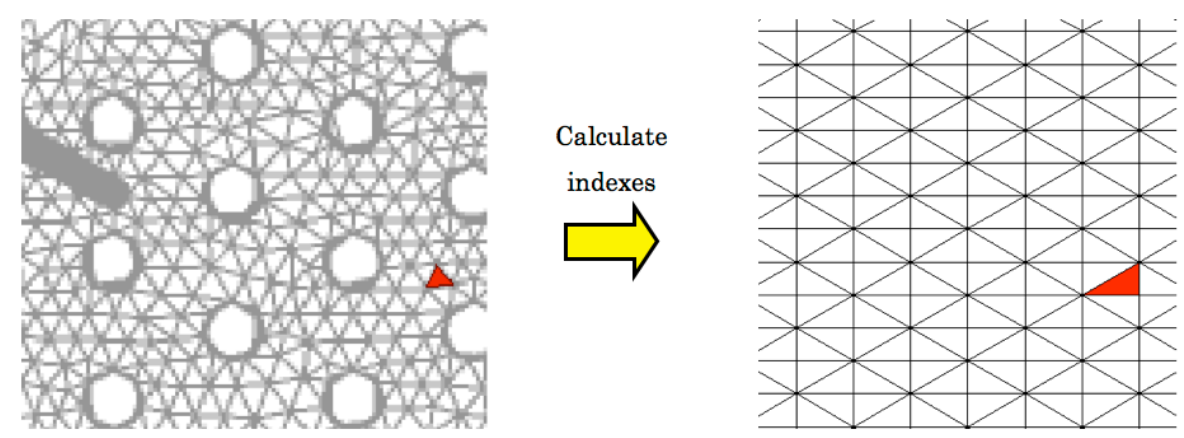

Figure 23 - CFX node indexing on a superimposed regular grid

Table 11 - Regular grid mesh specification

\begin{tabular}{|c|c|c|c|}
\hline Index & $\begin{array}{c}\text { Number of } \\
\text { meshes }\end{array}$ & $\begin{array}{c}\text { Grid total } \\
\text { dimension [cm] }\end{array}$ & $\begin{array}{c}\text { Mesh dimension } \\
\text { [cm] }\end{array}$ \\
\hline \hline $\mathrm{i}$ & 52 & 694 & 13.3 \\
\hline $\mathrm{j}$ & 88 & 694 & 7.9 \\
\hline $\mathrm{k}$ & 10 & 530.7 & 53.07 \\
\hline $\mathrm{s}$ & 2 & -- & -- \\
\hline \multicolumn{2}{|c|}{ \#Total meshes } & \multicolumn{2}{|c|}{91520} \\
\hline
\end{tabular}

The following step is to map the indexes to a new geometrical map configuration that correspond to the MCNP5 macro-regions used in simulations. These new geometrical configurations are constructed from the base triangular prism (see Figure 24). The indexing and mapping processes are executed only once and it generates an Index Master Library that is stored for later use.
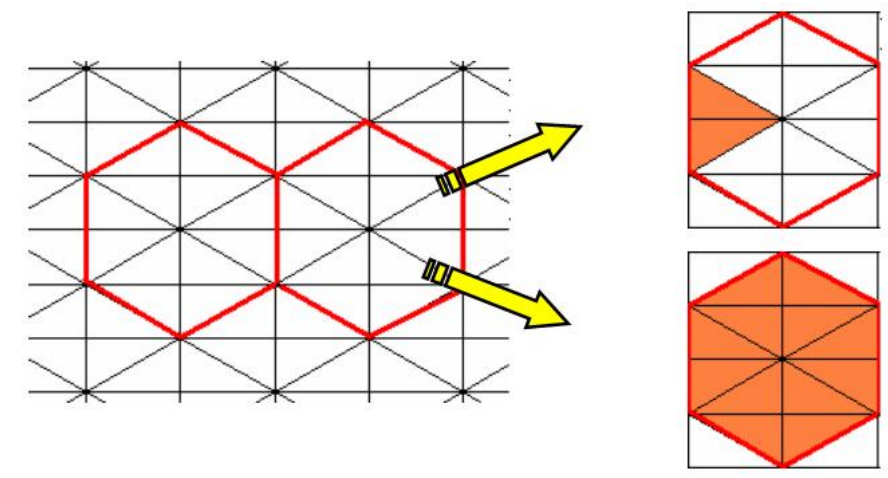

Figure 24 - Base grid mapping to MCNP5 macro regions 
The second flow process calculates the MCNP5 material weigh fractions from the Boron mass concentrations contained in the CFX nodes. A scheme is reported in Figure 25.

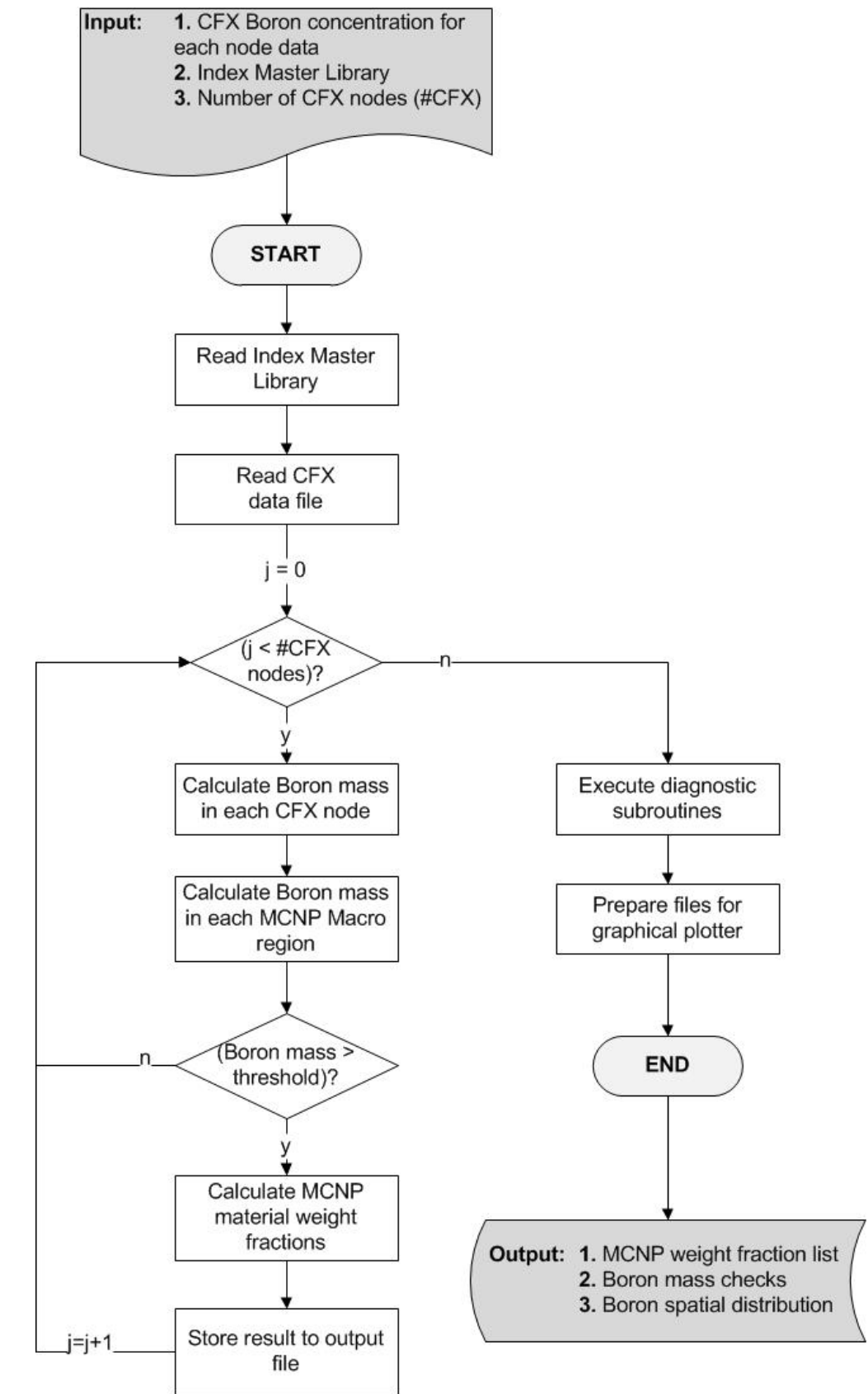

Figure 25 - Flow-chart to calculate Boron concentration in MCNP regions 
Such process use the Index Master Library to link each CFX node to the MCNP5 meshing map, then it collects all the Boron mass in each MCNP5 node from CFX data. Finally the resulting weight fractions used by MCNP5 are calculated. The procedure generates from CFX data a list of moderator material compositions ready for MCNP5 core simulations.

\subsubsection{Limit of applicability of CFD2MCNP program}

The CFD2MCNP program converts the detailed representation of complex CFD configurations to regular user-defined hexagonal or Cartesian prism lattice used in the MCNP5 model. The level of detail simulated with MCNP5 code in this research is beyond the actual level of detail available to current generation of system codes. However, the algorithm implemented in the CFD2MCNP program limits the dimension of the MCNP5 zones that can be used to represent a system. This limit is due to a problem of mesh overlap. A CFX mesh is located within the MCNP5 region using the coordinates of its center. This means that the CFX nodes around the MCNP macro region boundary will be partially excluded or included. A sketch of such mesh overlap issue in the case of hexagonal macro region is reported in Figure 26,

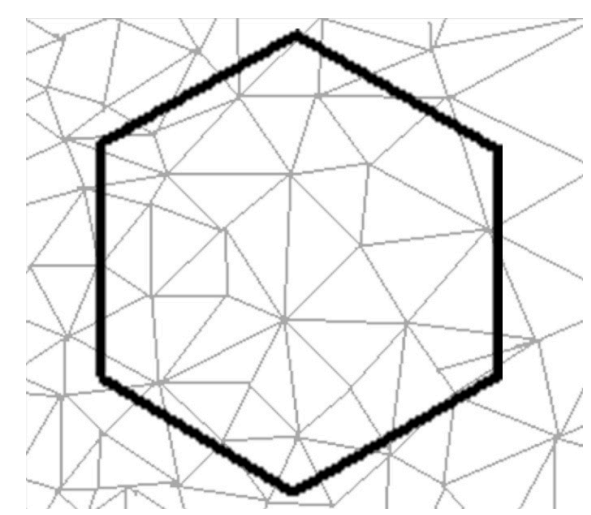

Figure 26 - Mesh overlap issue

The homogenization algorithm is valid until the volume of a CFX node is small compared to the volume of MCNP region. The Boron concentration was checked against this problem for all the MCNP5 model developed (see Par. 5.5.3.3 for more information about such models) and a difference up to $0.5 \%$ was found in the central part of the core and within $2 \%$ in some peripheral region. Further level of geometrical detail increases such difference beyond the level of acceptability for the analysis performed.

\subsubsection{Verification of the CFD2MCNP program}

The conversion process from CFX data to MCNP5 involves the processing of several Megabytes (Mb) of numerical data. Some dedicated subroutines were designed to control the most critical algorithms of the CFD2MCNP procedure. Such subroutines are devoted to check the hexagonal index assignation, then the Boron mass integral value and distribution inside the core. Those subroutines are part of the verification process of the CFD2MCNP computer routine. Those check demonstrate that the physical quantities of interest are consistently implemented 


\subsubsection{Verification of hexagonal mapping}

A subroutine was designed to check the indexing of CFX nodes. A different algorithm of index assignation was implemented for this purpose. The hexagonal coordinates are calculated by this subroutine using affine transformations to map the original hexagonal map to a new coordinates system in which the assignment of hexagonal coordinates can be easily calculated.

The subroutine is fault tolerant about location assignment because it checks if the track starting point is inside the selected hexagonal prism and if not (e.g. due to numerical round-off) a corrector subroutine moves the actual node to the correct location. A sketch of the corrector procedure is reported in Figure 27.

The node indexes calculated by this subroutine were compared to the node indexes calculated by the CFD2MCNP algorithm. The comparison showed an exact match; hence the indexing procedure was correctly implemented.
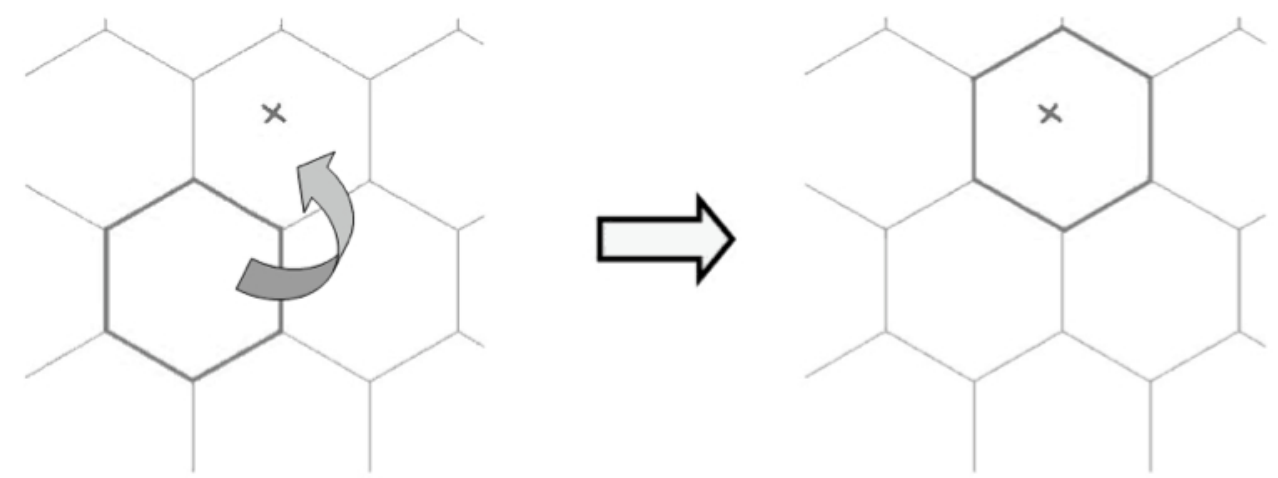

Figure 27 - Corrector procedure for node indexes assignation

\subsubsection{Boron distribution verification}

The Boron mass and its spatial distribution inside the ATUCHA-2 active core are checked by dedicated subroutines. At the end of each CFD2MCNP run the data collected by those subroutine are stored to several data files. In those files are reported the integral Boron mass used in the MCNP5 model inside the moderator tank, then a detailed report of the Boron mass in each MCNP5 node and its location inside the core and the Boron distribution plot data for each axial layer in which ATUCHA-2 core is modeled by MCNP5. Several considerations follow the analysis of such data. The Boron mass inside the radial reflector is negligible for all the time instant simulated. Hence in the MCNP5 model the radial reflector was modeled assuming homogeneous axial dependent physical boundary conditions. The integral Boron mass used in the final MCNP5 input is checked twice, the first by the CFD2MCNP routine and then by a support routine that calculate the Boron mass from the moderator mass weight fraction used in the MCNP5 input. The comparison of integral Boron mass calculated by CFX and CFD2MCNP is reported in Figure 28. It shows that the correct integral mass of Boron is used in the MCNP5 model. An example of the detailed reports of the Boron mass inside each MCNP5 moderator mesh node is reported in Figure 29. The Boron mass used in the MCNP5 input deck is compared with the original Boron amount calculated by the CFD2MCNP routine, therefore only negligible deviation due to numerical round-off error were found. An example of the Boron spatial distribution is reported in Figure 30 . 


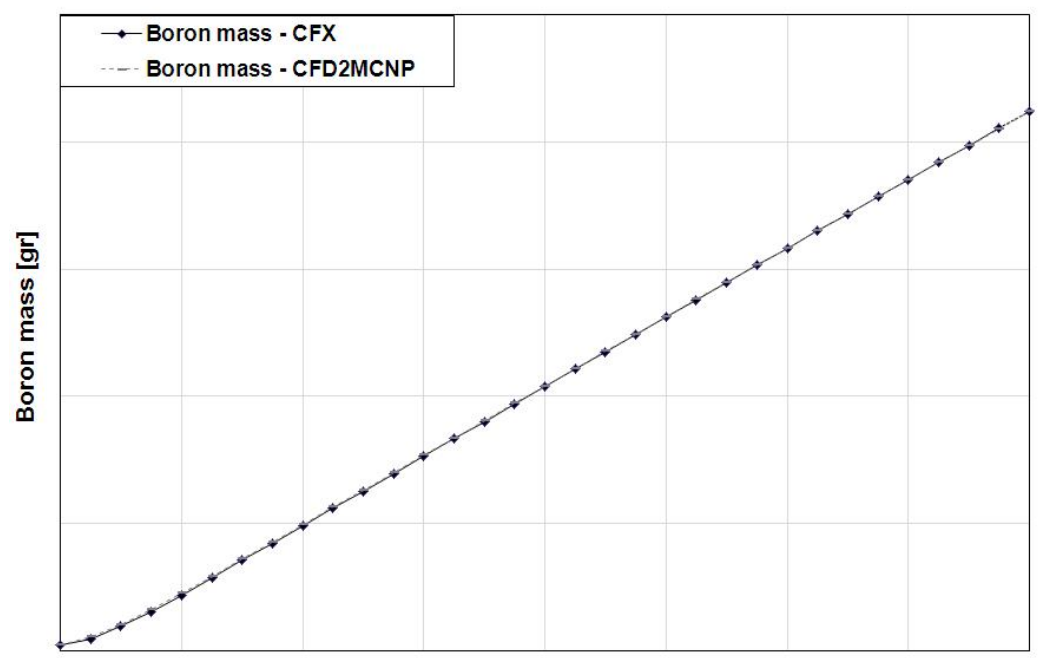

Time since first drop of borated water enter moderator tank [s]

Figure 28 - Comparison of calculated integral Boron mass to CFX

\begin{tabular}{|c|c|c|c|c|c|c|c|c|c|c|c|c|c|}
\hline FC & i-coord & jecord & level & $\begin{array}{l}\text { zone 1 } \\
\text { [wf] }\end{array}$ & $\begin{array}{c}\text { zone } 2 \\
\text { [wf] }\end{array}$ & $\begin{array}{c}\text { zone } 3 \\
\text { [wf] }\end{array}$ & $\begin{array}{l}\text { zone 4 } \\
\text { [wf] }\end{array}$ & $\begin{array}{c}\text { zone } 5 \\
\text { [wf] }\end{array}$ & $\begin{array}{c}\text { zone } 6 \\
\text { [wf] }\end{array}$ & $\begin{array}{c}\text { Total mass (from wf) } \\
\text { [gr] }\end{array}$ & $\begin{array}{c}\text { Total mail } \\
\text { [Er] }\end{array}$ & $\begin{array}{c}\text { Rel diff } \\
\text { [\%] }\end{array}$ & $\begin{array}{c}\text { Ab! diff } \\
\text { [Er] }\end{array}$ \\
\hline 1 & 22 & 3 & 10 & $9.11259 \mathrm{E}-21$ & $1.81822 \mathrm{E}-23$ & |3.49851E-21 & 1.30492E- 24 & 2.85427E-19 & 7.72959E- 23 & $2.98135 \mathrm{E}-19$ & $2.98135 \mathrm{E}-19$ & $0.00 \mathrm{E}+00$ & $0.00 \mathrm{E}+00$ \\
\hline 2 & 23 & 3 & 10 & $8.27033 \mathrm{E}-26$ & $1.86506 \mathrm{E}-23$ & $1.40489 \mathrm{E}-26$ & $3.75163 \mathrm{E}-23$ & $4.21013 \mathrm{E}-24$ & $9.19590 \mathrm{E}-23$ & $1.52433 \mathrm{E}-22$ & $1.52433 \mathrm{E}-22$ & $0.00 \mathrm{E}+00$ & $0.00 \mathrm{E}+00$ \\
\hline 3 & 19 & 4 & 10 & $1.14699 \mathrm{E}-14$ & $2.47606 \mathrm{E}-15$ & $3.63307 \mathrm{E}-14$ & $5.65057 \mathrm{E}-14$ & 6.29423E-11 & $1.08504 \mathrm{E}-11$ & $7.38994 \mathrm{E}-11$ & $7.38994 \mathrm{E}-11$ & $0.00 \mathrm{E}+00$ & $0.00 \mathrm{E}+00$ \\
\hline 4 & 20 & 4 & 10 & $1.33078 \mathrm{E}-15$ & $9.62412 \mathrm{E}-17$ & $4.07637 \mathrm{E}-15$ & $2.14405 \mathrm{E}-15$ & $5.57699 \mathrm{E}-12$ & $8.81882 \mathrm{E}-13$ & $6.46652 \mathrm{E}-12$ & $6.46652 \mathrm{E}-12$ & $0.00 \mathrm{E}+00$ & $0.00 \mathrm{E}+00$ \\
\hline 5 & 21 & 4 & 10 & $4.09068 \mathrm{E}-17$ & $1.03360 \mathrm{E}-19$ & $4.21966 \mathrm{E}-17$ & $8.13381 \mathrm{E}-20$ & 4.33752E-15 & $2.39520 \mathrm{E}-17$ & $4.44476 \mathrm{E}-15$ & $4.44476 \mathrm{E}-15$ & $0.00 \mathrm{E}+00$ & $0.00 \mathrm{E}+00$ \\
\hline 6 & 22 & 4 & 10 & $9.26556 \mathrm{E}-57$ & $9.26556 \mathrm{E}-57$ & $1.85993 \mathrm{E}-21$ & $2.88914 \mathrm{E}-23$ & $2.87667 \mathrm{E}-19$ & $8.95129 \mathrm{E}-21$ & $2.98507 \mathrm{E}-19$ & $2.98507 \mathrm{E}-19$ & $0.00 \mathrm{E}+00$ & $0.00 \mathrm{E}+00$ \\
\hline 7 & 23 & 4 & 10 & $9.26556 \mathrm{E}-57$ & $1.03246 \mathrm{E}-20$ & $9.62949 \mathrm{E}-24$ & $2.93757 \mathrm{E}-20$ & $8.14242 \mathrm{E}-22$ & 1.26143E-18 & $1.30195 \mathrm{E}-18$ & $1.30195 \mathrm{E}-18$ & $0.00 \mathrm{E}+00$ & $0.00 \mathrm{E}+00$ \\
\hline 8 & 26 & 4 & 10 & $7.90147 \mathrm{E}-18$ & $4.81289 \mathrm{E}-18$ & $4.60824 \mathrm{E}-17$ & $4.16745 \mathrm{E}-17$ & $2.83840 \mathrm{E}-14$ & $1.10975 \mathrm{E}-13$ & $1.39459 \mathrm{E}-13$ & $1.39459 \mathrm{E}-13$ & $0.00 \mathrm{E}+00$ & $0.00 \mathrm{E}+00$ \\
\hline 9 & 17 & 5 & 10 & 1.64995E-13 & $1.78328 \mathrm{E}-11$ & $1.65201 \mathrm{E}-12$ & $1.79870 \mathrm{E}-10$ & $3.13786 \mathrm{E}-10$ & $9.71011 \mathrm{E}-09$ & $1.02234 \mathrm{E}-08$ & $1.02234 \mathrm{E}-08$ & $0.00 \mathrm{E}+00$ & $0.00 \mathrm{E}+00$ \\
\hline 10 & 18 & 5 & 10 & 6.19917E-12 & $3.42500 \mathrm{E}-12$ & $1.00630 \mathrm{E}-10$ & $8.20145 \mathrm{E}-10$ & $1.04821 \mathrm{E}-07$ & 1.87369E-07 & $2.93120 \mathrm{E}-07$ & $2.93120 \mathrm{E}-07$ & $0.00 \mathrm{E}+00$ & $0.00 \mathrm{E}+00$ \\
\hline 11 & 19 & 5 & 10 & $9.26556 \mathrm{E}-57$ & $9.26556 \mathrm{E}-57$ & $5.82029 \mathrm{E}-10$ & 1.60582E-10 & $2.12876 \mathrm{E}-07$ & 1.53735E-08 & $2.28992 \mathrm{E}-07$ & $2.28992 \mathrm{E}-07$ & $0.00 \mathrm{E}+00$ & $0.00 \mathrm{E}+00$ \\
\hline 12 & 20 & 5 & 10 & $9.26556 \mathrm{E}-57$ & $9.26556 \mathrm{E}-57$ & $3.55442 \mathrm{E}-12$ & $9.95260 \mathrm{E}-15$ & $3.13558 \mathrm{E}-10$ & $9.03624 \mathrm{E}-12$ & $3.26158 \mathrm{E}-10$ & $3.26158 \mathrm{E}-10$ & $0.00 \mathrm{E}+00$ & $0.00 \mathrm{E}+00$ \\
\hline 13 & 21 & 5 & 10 & $9.26556 \mathrm{E}-57$ & $9.26556 \mathrm{E}-57$ & $1.36214 \mathrm{E}-15$ & $1.32952 \mathrm{E}-19$ & $3.97379 \mathrm{E}-14$ & $1.47582 \mathrm{E}-16$ & $4.12478 \mathrm{E}-14$ & $4.12478 \mathrm{E}-14$ & $0.00 \mathrm{E}+00$ & $0.00 \mathrm{E}+00$ \\
\hline 14 & 22 & 5 & 10 & $9.26556 \mathrm{E}-57$ & $9.26556 \mathrm{E}-57$ & 1.89244E-19 & $2.27055 \mathrm{E}-20$ & 6.83315E-18 & $2.17732 \mathrm{E}-18$ & $9.22242 \mathrm{E}-18$ & $9.22242 \mathrm{E}-18$ & $0.00 \mathrm{E}+00$ & $0.00 \mathrm{E}+00$ \\
\hline 15 & 23 & 5 & 10 & $9.26556 \mathrm{E}-57$ & $4.25919 \mathrm{E}-17$ & $1.17036 \mathrm{E}-18$ & $1.80992 \mathrm{E}-16$ & $1.18398 \mathrm{E}-15$ & $5.33437 \mathrm{E}-14$ & $5.47525 \mathrm{E}-14$ & $5.47525 \mathrm{E}-14$ & $0.00 \mathrm{E}+00$ & $0.00 \mathrm{E}+00$ \\
\hline 16 & 25 & 5 & 10 & $5.19268 \mathrm{E}-14$ & $2.69252 \mathrm{E}-18$ & $2.33970 \mathrm{E}-13$ & $3.76709 \mathrm{E}-13$ & $1.45233 \mathrm{E}-10$ & $1.03840 \mathrm{E}-09$ & $1.18430 \mathrm{E}-09$ & $1.18430 \mathrm{E}-09$ & $0.00 \mathrm{E}+00$ & $0.00 \mathrm{E}+00$ \\
\hline 17 & 26 & 5 & 10 & $9.26556 \mathrm{E}-57$ & $1.89454 \mathrm{E}-14$ & 2.46199E-12 & $1.67878 \mathrm{E}-13$ & 4.85482E-10 & $9.04611 \mathrm{E}-11$ & $5.78592 \mathrm{E}-10$ & $5.78592 \mathrm{E}-10$ & $0.00 \mathrm{E}+00$ & $0.00 \mathrm{E}+00$ \\
\hline 18 & 27 & 5 & 10 & $1.37369 \mathrm{E}-14$ & $2.22164 \mathrm{E}-16$ & $4.23682 \mathrm{E}-13$ & 1.68189E-15 & $1.45641 \mathrm{E}-11$ & $4.69978 \mathrm{E}-14$ & $1.50504 \mathrm{E}-11$ & $1.50504 \mathrm{E}-11$ & $0.00 \mathrm{E}+00$ & $0.00 \mathrm{E}+00$ \\
\hline 19 & 14 & 6 & 10 & $7.12689 \mathrm{E}-16$ & $8.14460 \mathrm{E}-15$ & $9.95502 \mathrm{E}-16$ & $3.40918 \mathrm{E}-13$ & $2.13671 \mathrm{E}-14$ & 1.18404E-11 & $1.22126 \mathrm{E}-11$ & $1.22126 \mathrm{E}-11$ & $0.00 \mathrm{E}+00$ & $0.00 \mathrm{E}+00$ \\
\hline 20 & 15 & 6 & 10 & $1.19518 \mathrm{E}-13$ & $1.56264 \mathrm{E}-11$ & 1.30414E-12 & 2.26500E-10 & $1.62719 \mathrm{E}-09$ & $1.19053 \mathrm{E}-08$ & $1.37760 \mathrm{E}-08$ & $1.37760 \mathrm{E}-08$ & $0.00 \mathrm{E}+00$ & $0.00 \mathrm{E}+00$ \\
\hline 21 & 16 & 6 & 10 & $1.45496 \mathrm{E}-10$ & $8.53444 \mathrm{E}-09$ & $8.15723 \mathrm{E}-10$ & $1.04574 \mathrm{E}-06$ & $1.68015 \mathrm{E}-06$ & 6.49182E-05 & $6.76536 \mathrm{E}-05$ & $6.76536 \mathrm{E}-05$ & $0.00 \mathrm{E}+00$ & $0.00 \mathrm{E}+00$ \\
\hline 22 & 17 & 6 & 10 & $2.91637 \mathrm{E}-07$ & $7.64033 \mathrm{E}-07$ & $3.50352 \mathrm{E}-06$ & $1.22579 \mathrm{E}-05$ & $7.36506 \mathrm{E}-04$ & 7.56914E-04 & $1.51024 \mathrm{E}-03$ & $1.51024 \mathrm{E}-03$ & $0.00 \mathrm{E}+00$ & $0.00 \mathrm{E}+00$ \\
\hline 23 & 18 & 6 & 10 & $9.26556 \mathrm{E}-57$ & $1.16365 \mathrm{E}-09$ & $1.35461 \mathrm{E}-06$ & $1.51766 \mathrm{E}-06$ & $5.12631 \mathrm{E}-04$ & $1.98305 \mathrm{E}-04$ & $7.13809 \mathrm{E}-04$ & $7.13809 \mathrm{E}-04$ & $0.00 \mathrm{E}+00$ & $0.00 \mathrm{E}+00$ \\
\hline 24 & 19 & 6 & 10 & $9.26556 \mathrm{E}-57$ & $1.11728 \mathrm{E}-11$ & $8.93755 \mathrm{E}-08$ & $1.53630 \mathrm{E}-09$ & $3.89737 \mathrm{E}-05$ & $1.18456 \mathrm{E}-06$ & $4.02492 \mathrm{E}-05$ & $4.02492 \mathrm{E}-05$ & $0.00 \mathrm{E}+00$ & $0.00 \mathrm{E}+00$ \\
\hline 25 & 20 & 6 & 10 & $9.26556 \mathrm{E}-57$ & $9.26556 \mathrm{E}-57$ & $3.63675 \mathrm{E}-11$ & 1.99144E-13 & $2.94428 \mathrm{E}-08$ & $3.55244 \mathrm{E}-10$ & $2.98346 \mathrm{E}-08$ & $2.98346 \mathrm{E}-08$ & $0.00 \mathrm{E}+00$ & $0.00 \mathrm{E}+00$ \\
\hline 26 & 21 & 6 & 10 & $9.26556 \mathrm{E}-57$ & $9.26556 \mathrm{E}-57$ & $4.37704 \mathrm{E}-14$ & 1.34885E-17 & 1.54061E-12 & $7.99647 \mathrm{E}-14$ & 1.66435E-12 & 1.66435E-12 & $0.00 \mathrm{E}+00$ & $0.00 \mathrm{E}+00$ \\
\hline 27 & 22 & 6 & 10 & $9.26556 \mathrm{E}-57$ & $9.26556 \mathrm{E}-57$ & $2.27769 \mathrm{E}-18$ & $3.79531 \mathrm{E}-15$ & $3.07427 \mathrm{E}-16$ & $3.18660 \mathrm{E}-13$ & $3.22765 \mathrm{E}-13$ & $3.22765 \mathrm{E}-13$ & $0.00 \mathrm{E}+00$ & $0.00 \mathrm{E}+00$ \\
\hline 28 & 23 & 6 & 10 & $1.59756 \mathrm{E}-17$ & 1.88550E- 11 & $2.11021 \mathrm{E}-13$ & 1.22437E-11 & 7.82872E-11 & $2.97710 \mathrm{E}-09$ & $3.08669 \mathrm{E}-09$ & $3.08669 \mathrm{E}-09$ & $0.00 \mathrm{E}+00$ & $0.00 \mathrm{E}+00$ \\
\hline 29 & 24 & 6 & 10 & $8.56625 \mathrm{E}-12$ & \begin{tabular}{|c|}
$3.39984 \mathrm{E}-11$ \\
\end{tabular} & $4.01237 \mathrm{E}-10$ & $8.92895 \mathrm{E}-10$ & $7.51855 \mathrm{E}-08$ & $1.65511 \mathrm{E}-07$ & $2.42033 \mathrm{E}-07$ & $2.42033 \mathrm{E}-07$ & $0.00 \mathrm{E}+00$ & $0.00 \mathrm{E}+00$ \\
\hline 30 & 25 & 6 & 10 & $8.80084 \mathrm{E}-11$ & \begin{tabular}{|l|}
$3.31901 \mathrm{E}-14$ \\
\end{tabular} & 1.66579E-08 & $8.71092 \mathrm{E}-09$ & $2.18153 \mathrm{E}-06$ & $4.70912 \mathrm{E}-06$ & $6.91610 \mathrm{E}-06$ & $6.91610 \mathrm{E}-06$ & $0.00 \mathrm{E}+00$ & $0.00 \mathrm{E}+00$ \\
\hline 31 & 26 & 6 & 10 & $2.55638 \mathrm{E}-09$ & $3.22834 \mathrm{E}-10$ & $3.81361 \mathrm{E}-08$ & 1.11492E-09 & $1.94108 \mathrm{E}-06$ & $6.47127 \mathrm{E}-07$ & $2.63033 \mathrm{E}-06$ & $2.63033 \mathrm{E}-06$ & $0.00 \mathrm{E}+00$ & $0.00 \mathrm{E}+00$ \\
\hline 32 & 27 & 6 & 10 & $2.23335 \mathrm{E}-12$ & $6.13580 \mathrm{E}-14$ & 9.90782E-11 & $2.43125 \mathrm{E}-13$ & 1.50899E- 08 & $5.83996 \mathrm{E}-10$ & $1.57755 \mathrm{E}-08$ & $1.57755 \mathrm{E}-08$ & $0.00 \mathrm{E}+00$ & $0.00 \mathrm{E}+00$ \\
\hline 33 & 28 & 6 & 10 & $3.40577 \mathrm{E}-14$ & $1.35878 \mathrm{E}-15$ & $1.11943 \mathrm{E}-12$ & 4.83192E-15 & $3.87895 \mathrm{E}-11$ & 2.82569E- 12 & $4.27748 \mathrm{E}-11$ & $4.27748 \mathrm{E}-11$ & $0.00 \mathrm{E}+00$ & $0.00 \mathrm{E}+00$ \\
\hline 34 & 13 & 7 & 10 & 7.47198E-17 & $9.26556 \mathrm{E}-57$ & $3.31475 \mathrm{E}-16$ & $6.33025 \mathrm{E}-14$ & $4.23351 \mathrm{E}-15$ & $1.44743 \mathrm{E}-12$ & $1.51537 \mathrm{E}-12$ & $1.51537 \mathrm{E}-12$ & $0.00 \mathrm{E}+00$ & $0.00 \mathrm{E}+00$ \\
\hline 35 & 14 & 7 & 10 & $9.26556 \mathrm{E}-57$ & $2.95807 \mathrm{E}-12$ & $1.16664 \mathrm{E}-11$ & $5.79229 \mathrm{E}-09$ & $5.88652 \mathrm{E}-10$ & $1.36589 \mathrm{E}-07$ & $1.42985 \mathrm{E}-07$ & $1.42985 \mathrm{E}-07$ & $0.00 \mathrm{E}+00$ & $0.00 \mathrm{E}+00$ \\
\hline 36 & 15 & 7 & 10 & $1.26820 \mathrm{E}-07$ & $1.17290 \mathrm{E}-06$ & $1.06671 \mathrm{E}-07$ & $9.16757 \mathrm{E}-06$ & 6.42061E-06 & $3.26359 \mathrm{E}-04$ & $3.43353 \mathrm{E}-04$ & 3.43353E- 04 & $0.00 \mathrm{E}+00$ & $0.00 \mathrm{E}+00$ \\
\hline 37 & 16 & 7 & 10 & $3.63681 \mathrm{E}-04$ & 1.15447E-02 & 7.64839E-04 & $5.67268 \mathrm{E}-02$ & $1.24404 \mathrm{E}-02$ & $1.17736 \mathrm{E}-01$ & $1.99577 \mathrm{E}-01$ & $1.99580 \mathrm{E}-01$ & \begin{tabular}{|c|}
$-1.90 \mathrm{E}-03$ \\
\end{tabular} & $-3.50 \mathrm{E}-06$ \\
\hline 38 & 17 & 7 & 10 & 7.32372E-03 & $2.28289 \mathrm{E}-03$ & $6.03818 \mathrm{E}-02$ & $1.20564 \mathrm{E}-02$ & $1.76860 \mathrm{E}-01$ & $1.01107 \mathrm{E}-01$ & $3.60011 \mathrm{E}-01$ & $3.60021 \mathrm{E}-01$ & \begin{tabular}{|l}
$-2.69 \mathrm{E}-03$ \\
\end{tabular} & $-9.70 \mathrm{E}-06$ \\
\hline 39 & 18 & 7 & 10 & $1.26483 \mathrm{E}-03$ & $5.81038 \mathrm{E}-05$ & $1.56494 \mathrm{E}-03$ & $3.87600 \mathrm{E}-05$ & $2.01450 \mathrm{E}-02$ & $1.20500 \mathrm{E}-03$ & $2.42766 \mathrm{E}-02$ & $2.42767 \mathrm{E}-02$ & $-3.71 E-04$ & $-9.00 \mathrm{E}-08$ \\
\hline
\end{tabular}

Figure 29 - Detailed Boron mass check for each MCNP5 region 

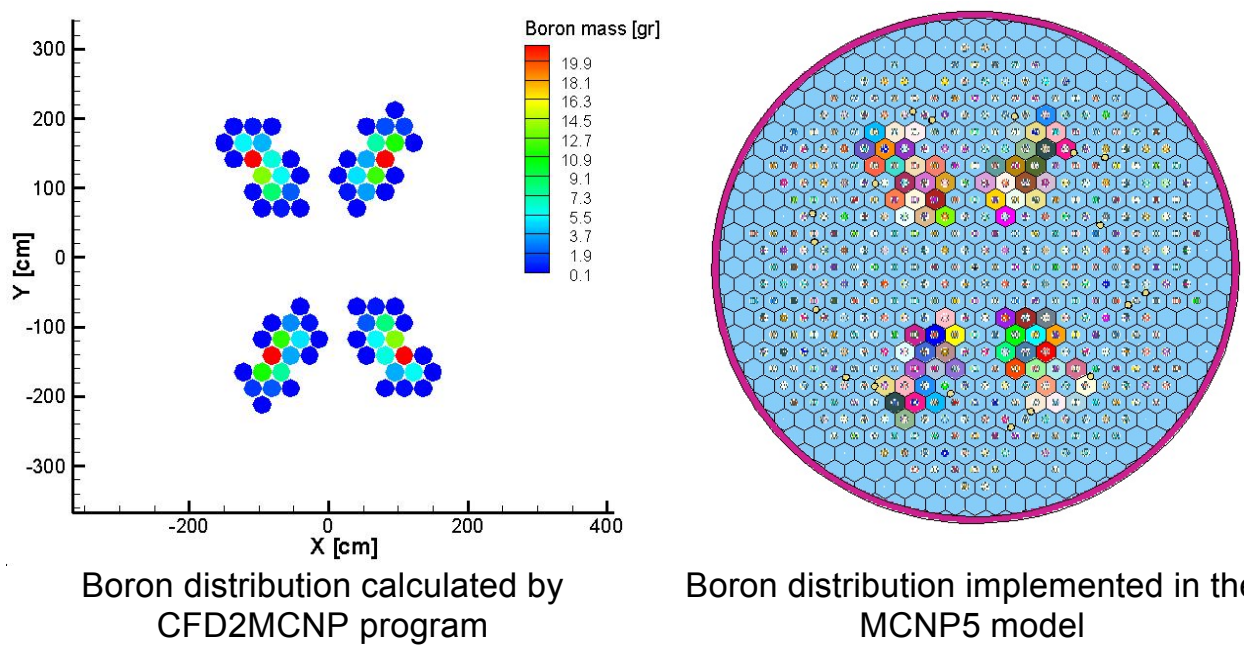

Boron distribution implemented in the MCNP5 model

Figure 30 - Sketch of calculated Boron mass distribution

\subsubsection{Tracking of Borated moderator mesh node}

At the end of the CFD2MCNP procedure all the information about the data contained in the MCNP5 moderator region is summarized in the MCNP5 input deck. A further benefit of such information report is to locate quickly the node inside the ATUCHA-2 core for checking purpose. The data reported are the following:

- Node identification number (MCNP5 universe concept [17]);

- Boron mass content [gr];

- NESTLE correspondent identification number;

- CNA-2 correspondent identification number;

- Hexagonal $x$-coordinate (origin is set in the central channel);

- Hexagonal y-coordinate (origin is set in the central channel);

- Axial z-coordinate (levels id increase from the lowest to the highest part of the core).

It is relevant to highlight that MCNP5 cell nomenclature [17] was chosen to allow an easier track of the node inside the core. An example of node header is reported in Figure 31. The 3 less relevant digits of node identification number (id) correspond to the CNA-2 id (circle in Figure 31), then the 2 less relevant digits of fuel material label correspond to the NESTLE id (square in Figure 31). Those info allow the tracking of the node in the MCNP5 core map distribution, hence it is easier to check the node location inside the core. 


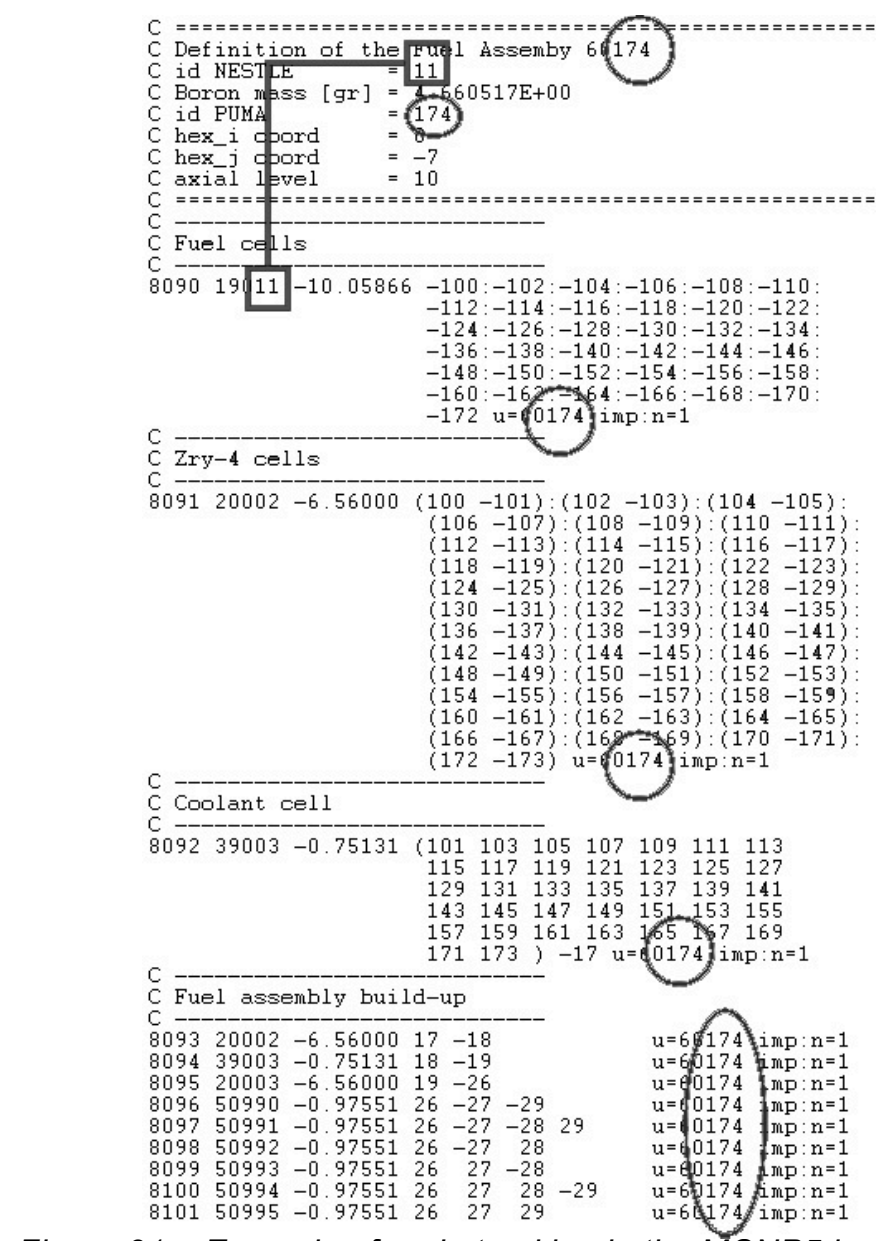

Figure 31 - Example of node tracking in the MCNP5 input deck 


\section{ANALYSIS RESULTS FOCUSING ON POWER PEAK}

\subsection{Rationale for the analysis}

The representation of the complex peculiarity of a NPP within the capability of a computer code is always a challenging activity. This is particularly true for ATUCHA-2 PHWR due to its unique peculiarity. For ATUCHA-2 the application of conservative tools could not realistically demonstrate the safety level, therefore the application of the best estimate tools like RELAP5-3D@ is needed.

In the framework of the Addendum to the "Agreement UNIPI-NA-SA No.2", several benchmarking activities, requested by the ARN (Argentinean Nuclear Safety Authority), were performed on the RELAP5-3DC model developed by the San Piero a Grado Nuclear Research Group (GRNSPG) of the University of Pisa (UNIPI). The scope of these activities was to assess the reliability of the developed ATUCHA-2 3D NK-TH models in simulating steady-states and transient conditions.

The MCNP5 code had a central role in these benchmark activities due to its capability of model complex 3D system and the use of continuous energy Xsec. For this purpose, the research activity was focus also in the development of a methodology to implement realistic operational ATUCHA-2 core condition in MCNP for steady state and 2A LB-LOCA scenarios in order to support the qualification of the 3D NK-TH models.

The continuous energy issue is discussed in Par. 5.2. Then, considerations about burnup effects are reported in Par. 5.3. A brief description of the RELAP53DC/NESTLE model is found in Par. 5.4 and finally, The MCNP5 models and a selection of those benchmark activities are reported in Par 5.5.

\subsection{Temperature effects}

The temperature effects have important consequences in neutronic analyses that can't be neglected. A key feature of Monte Carlo codes is the capability to use the 'continuous energy' Xsec. In this contest the meaning of 'continuous energy' Xsec means the representation of the Xsec for thousand energy values. This number of energy point is considerable larger compared to the libraries used by deterministic code (most sophisticated codes uses up to 289 energy group structure representation). A comparison of the different level of representation with 'continuous energy' and 239-group averaged Xsec is reported in Figure 32. 


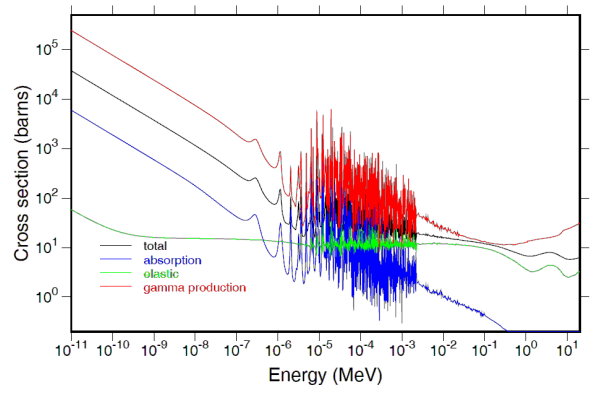

Continuous energy

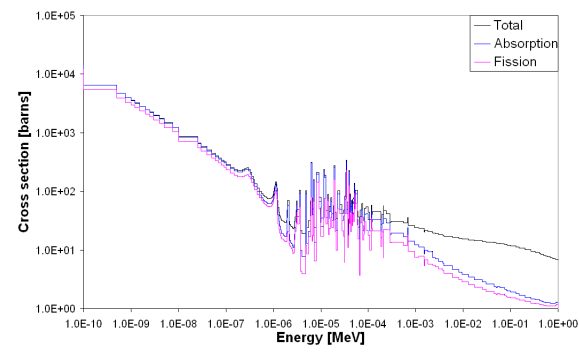

239 energy group

Figure 32 - Continuous and multi-group cross sections representations

The 'continuous energy' Xsec avoids the use of several approximations commonly used in the multi-group Xsec used by deterministic code.

In order to represent the neutron interactions at the temperature of interest, the temperature is to be specified in the Xsec generation process. The MCNP5 standard library has several Xsec libraries processed at pre-defined temperatures. Those libraries could not be used in this research since they not represent the ATUCHA-2 BEQ with HFP core condition with an adequate level of realism. Hence, the process of generation Doppler-broaden Xsec library with an acceptable level of validation was thoroughly investigated.

The NJOY code, developed by the Los Alamos National Laboratory, was used to process the evaluated nuclear data library (ENDL) to the continuous energy format used by MCNP5 (details about this code are reported in APPENDIX A). The NJOY input deck used in this research was based on the specification used to generate ENDF/B-VI standard Xsec included in the MCNP5 database. Then, several improvements were done base on literature review and sensitivities using an international benchmark (see APPENDIX C). A dedicated computer program (the XNJOY program, described in APPENDIX B) automates the overall Xsec generation process.

Particular care was dedicated to the validation of the generated Xsec. A validation suite was used to check the processed library. The results showed that the goal of generation Xsec with acceptable level of validation was reached (validation results are reported in APPENDIX C). The Doppler-broaded Xsec used within this research are derived from the ENDF/B-VI version 8 data library.

\subsection{Burnup considerations}

Irradiation of nuclear fuel causes changes in its material composition and in the neutron energy spectra. New material compositions can be calculated using a depletion code that solves the decay and transmutation equations using a set of given energy group-averaged Xsec. These Xsec are strongly reactor-dependent and are not constant during the burnup, hence, they should be in turn periodically updating by a neutron transport code.

In this research the burnup dependent nuclear proprieties of ATUCHA-2 FA were investigated using the MONTEBURNS2.0 code (details about this code are reported in APPENDIX A). The aim of such activity was to calculate a database of 
burnup-depending material compositions. This Material Master Library (MML) was used to calculate the burnup-depending material compositions required to characterize the ATUCHA-2 at BEQ with HFP core condition, according to NA-SA specification.

In order to have more accurate results, several improvements in the MONTEBURNS2.0 procedure were implemented. Such improvements consist in updating the MONTEBURNS2.0 data library, then, an innovative methodology was developed to include the effect of minor fission product using special lumped continuous energy Xsec. Finally, a special care was dedicated to check all the isotopes contained in the MML. The methodology to fix the ${ }^{135} \mathrm{Xe}$ concentration was he follow-up of such investigation. Qualification of the improved MONTEBURNS2.0 burnup methodology was done comparing results to the deterministic 2D neutron transport code NEWT/SCALE6 [26] in the framework of an OECD/NEA international benchmark. The APPENDIX E contains such qualification activity together with the MONTEBURNS2.0 methodology and improvements.

Several results can be obtained from a MONTEBURNS2.0 simulation. An example is the dependence of kinf and relative neutron flux (in the fuel materials) against the burnup, reported in Figure 33 and Figure 34, respectively. In Figure 33 the initial fall of reactivity is due by Xenon and Samarium poisoning whereas the reactivity peak around $1000 \mathrm{MWD} /$ tonHM is caused by ${ }^{239} \mathrm{Pu}$ breeding. Another sample result is the production of the ${ }^{235} \mathrm{U}$ and some Pu isotopes masses against the burnup, reported in Figure 35.

The average ATUCHA-2 fuel burnup is around $4100 \mathrm{MWd}$ /tonHM. Such low average, together with the use of natural uranium burnup, is the cause of a low dependence of fission macroscopic Xsec from burnup (deviations from average value are within $2 \%$ ). Hence, the power distribution was found proportional to the neutron thermal flux to a large extent. One of the goal of this work is to evaluate the deviation of relative power due to different representations of the same core condition. Sensitivity analyses showed that deviations in relative power and in relative thermal neutron flux have the same order of magnitude with an error negligible for the purpose of this research. Hence differences in power are evaluated calculating difference in thermal neutron flux. 


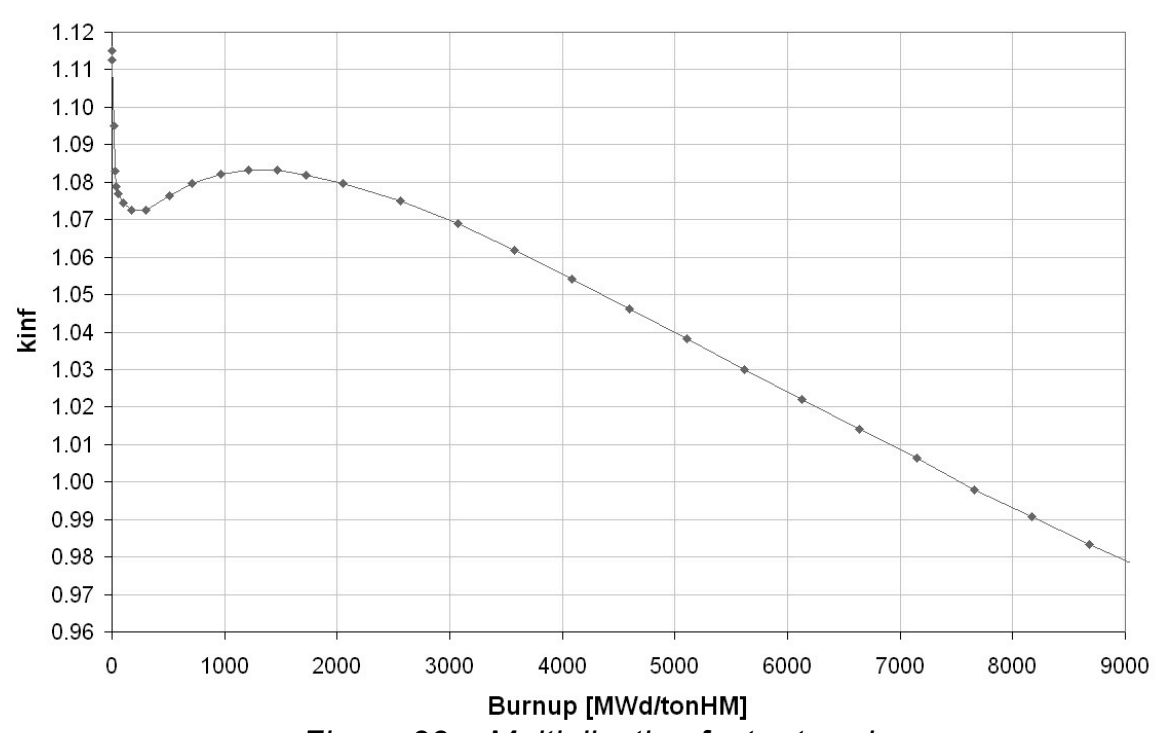

Figure 33 - Multiplication factor trend

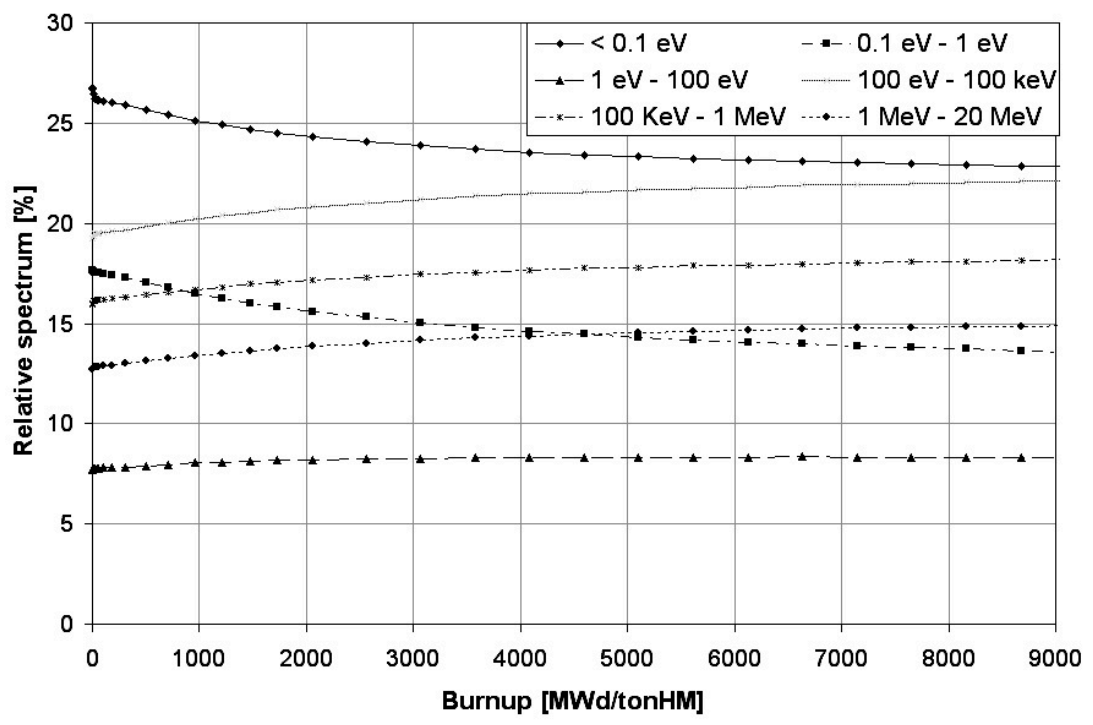

Figure 34 - Relative fluxes versus Burnup 


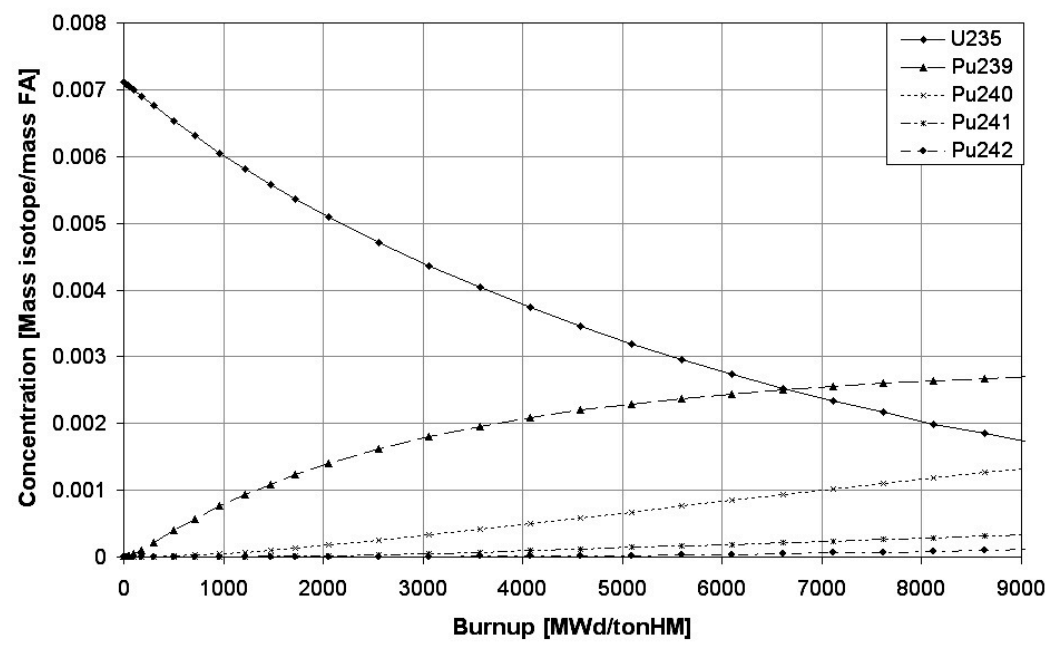

Figure $35-\mathrm{Pu}$ isotopes and ${ }^{233} \mathrm{U}$ mass trends

\subsection{The RELAP5-3D@ model for ATUCHA-2}

In the framework of the Agreement "NA-SA - University of Pisa" [4], a detailed of the under construction ATUCHA-2 PHWR was developed [27]. The aim of this activity was to have a state-of-the-art tool for performing realistic safety analyses for the licensing of ATUCHA-2. The results of RELAP5-3D@/NESTLE are compared to MCNP results in benchmark activities. Hence a brief description of the main features of RELAP5-3D@/NESTLE model is reported hereafter.

\subsubsection{RELAP model}

3D NK and TH calculations were performed using the well-known and validated US-DOE RELAP5-3DC System (SYS) code [22]. This Best Estimate (BE) code allows representing sophisticated TH system and phenomena by the setting up of detailed nodalizations. One of its important features is the possibility to use 3D TH components. A 3D NK subroutine, serially integrated in the SYS code and based on the 3D NK nodal code NESTLE [23], allows to perform coupled 3D NK TH SS and transient calculations too.

The ATUCHA-2 core is composed by $451 \mathrm{FC}$, placed on a massive core bottom plate. This bottom plate is then divided into several rhomboidal sub-plena, each one also connected through some holes with the neighbor sub-plena. This peculiarity, the different azimuthal positions of the cold and hot legs, along with a further characterization of the FC according to their inlet nozzle characteristics, required a detailed RPV and core TH modeling. Thus, the RPV was divided in sectors of 10 degrees, and modeled using a fictitious 3D TH nodalization. The 451 FC were instead modeled by 280 equivalent TH channels, scaled according to the following criteria:

- Hydraulic characteristics (throttled type/un-throttled);

- Belonging to rhomboidal sub-plena;

- Power distribution;

- Transient type;

- Code resources. 


\subsubsection{1. $3 D$ moderator tank}

The need to reconstruct the Boron clouds injected by the Boron Emergency Systems (JDJ) during some transients, had, as a consequence, the development of a 3D TH model for the moderator tank. This was achieved using the RELAP53D(C) multi-dimensional TH components, which allow the user to model a general volume with Cartesian or Cylindrical geometry. The moderator tank was modeled using three cylindrical multi-dimensional components, one for the bottom reflector zone, one for core active zone and one for the top reflector zone. The core active zone was then further divided in 10 axial layers of $0.53 \mathrm{~m}$ each. All the multidimensional components are divided in 6 radial zones and 16 azimuthal zones. A sketch of the radial and azimuthal zones is reported in Figure 36 . The heat exchange between the $280 \mathrm{FC}$ and the moderator water is modeled by ad-hoc heat structures, simulating the FC tubes. Special heat structures were also used for modeling the heat generation by the neutron moderation and gamma heating into the moderator.

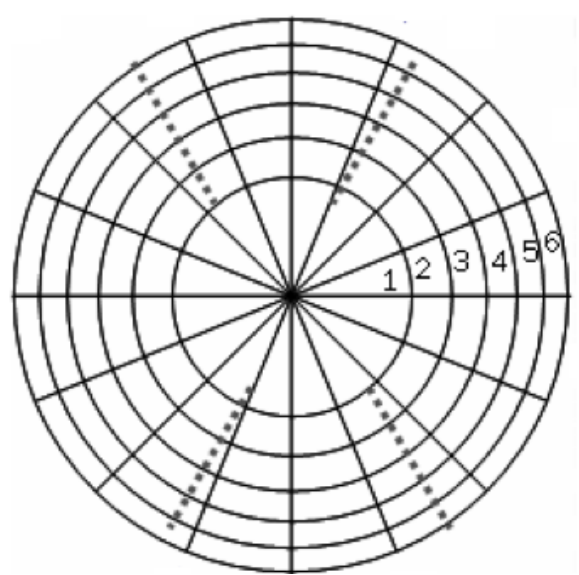

Figure 36 - Moderator tank 3D model (planar view)

\subsubsection{The Emergency Boron Injection System}

Four Boron clouds can be created in the moderator tank by the borated water injected by the Boron Emergency System during some type of accidents (e.g., LBLOCA, ATWS). In the framework of the "UNIPI-NA-SA Agreement No.1" [4], calculations of the area affected by those Boron cloud were executed by computational fluid dynamics (CFD) code CFX. In this way, the concentration of the Boron in the tank versus time was obtained. Then, the values of the Boron concentration versus time in the CFD volumes were used for reconstruct the Boron concentration versus time in the RELAP5-3D@ moderator tank volumes. This was achieved by the implementation of appropriate injection law for several time dependent junction components. A final verification of the integral of the mass of boron injected by the RELAP5-3DC over the whole tank with the same value calculated by the CFX CFD code was done. The same verification was done using the results of the calculation by RELAP5-3DC of the Boron Injection Emergency System. 


\subsubsection{D NK modeling}

A hexagonal representation of the core lattice was used for the NESTLE 3D NK modeling. The modeled nodes (fuel channels and reflector nodes) together with the correspondence between the 3D NK nodes and the moderator radial and azimuthal zones are shown in Figure 37.

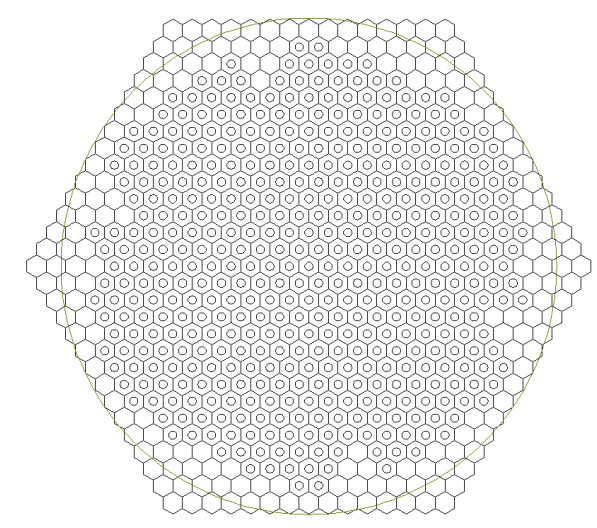

NESTLE NK nodes

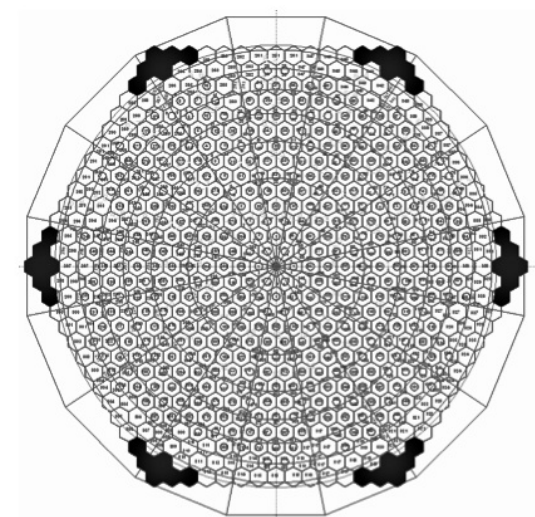

Correspondence to moderator nodes

Figure 37 - NESTE 3D NK model

The characteristics of the 3D NK model are the following:

- Hexagonal lattice with $27.24 \mathrm{~cm}$ pitch;

- 6420 NK nodes, organized in 10 axial layers for the active core, each one with an height of $0.53 \mathrm{~m}$;

- 1 layer for the bottom reflector, $0.482 \mathrm{~m}$ height;

- 1 layer for the Top Reflector, 0.344 m height.

Feedbacks from RELAP5-3D@ TH model are considered by a mapping that is linking the fuel channels and the moderator zones to the 3D NK nodes. The feedbacks that are included in the 3D NK calculations are the following:

- Fuel temperature;

- Coolant temperature;

- Coolant density;

- Moderator temperature;

- Boron concentration in the moderator.

Using the values of these parameters at each time step, the NESTLE 3D NK code is able to calculate the neutron flux in each node and its power. This power is then associated to the relative heat structure for the new TH iteration.

\subsubsection{Cross Section Libraries development}

Cross sections (Xsec) libraries calculations were performed for a Burnup Equilibrium (BEQ) core. The reference core status, with the design CRs insertion and a reference Burnup distribution was defined according to NA-SA procedures [2]. Lattice physics calculations were performed using the well-known code HELIOS-1.9, developed by Studsvik Scandpower [28]. Transport solutions were then used to homogenize the nuclear data in a set of two groups (fast and thermal) 
energy data. Three HELIOS geometric models were developed, one for the FA, one for the radial and axial reflectors and one for the control rods (see Figure 38).
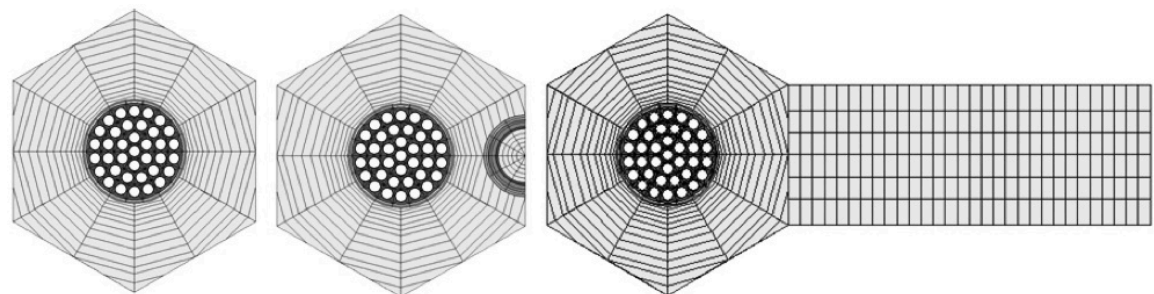

Figure 38 - HELIOS models

Reflector Xsec were derived imposing non re- entrant current as a boundary condition on the outer reflector boundary and they were parameterized as function of the neighbour FC physical conditions. A color-set model, based on a lattice of 4 FC, was developed for calculating the effect of a CR on a FC. The CR section was modelled considering it as vertically inserted. Correction coefficients were then calculated and used for taking into account their obliquity (see [29]). Five Xsec libraries were calculated.

\subsection{MCNP models and applications to ATUCHA-2 licensing}

This paragraph contains a detailed description of the MCNP models for ATUCHA-2 used within this research. The 3D modeling capability of MCNP was relevant in the licensing activity due to the geometrical peculiarity of ATUCHA-2. In Par. 5.5.4 several results at BOL with fresh fuel are presented. The scope of those applications were to benchmark and qualify the NESTLE model in the framework of the Second and Third Agreement "NA-SA - University of Pisa" for the licensing of ATUCHA-2 NPP. In this context a benchmark activity between NESTLE and MCNP was set up to qualify the CR effect to the neutron thermal flux. This benchmark activity is presented in Par. 5.5.5 for all rods out (ARO) CR configuration and it showed that the developed MCNP5 model is suitable to investigate the reactivity excursion in LB-LOCA in ATUCHA-2.

\subsubsection{MCNP model at BOL with CZP core condition}

In this paragraph a detailed description of the MCNP5 model of ATUCHA-2 NPP at BOL with CZP core condition is presented. The active neutron part of the ATUCHA-2 core is represented in the MCNP5 model up to fuel pin level detail without relevant geometrical approximation. All the figures hereafter reported concerning the MCNP5 models were taken using the MCNP5 visual editor VISED.EXE [30].

\subsubsection{Fuel assembly}

The fuel pin was modeled using 2 concentric cylinders, an inner cylinder for the fuel material and an outer one for the Zirconium clad (see Figure 39). No axial and radial subdivisions were assumed. 


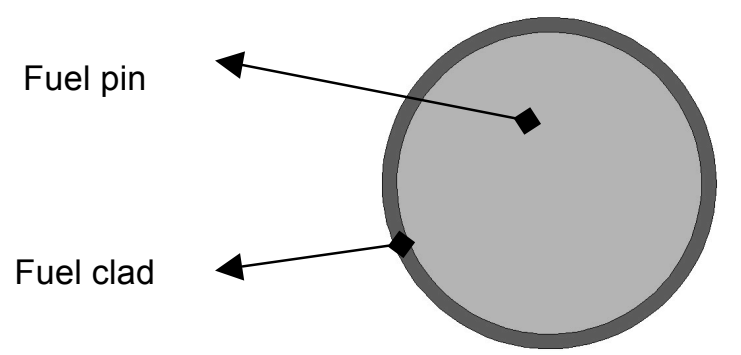

Figure 39 - Fuel rod layout

The FC structure was built-up by assembling 37 fuel pins, the shroud tube of the FC and the insulation tube (made by a Zircaloy film layer). Then, the FC structure was loaded in a hexagonal mesh using the MCNP5 "UNIVERSE" card command [17]. The FC structure and its neighbor hexagonal moderator sector will be hereafter referred as Fuel Assembly (FA). The thin insulation film layer tube was include in the model since a sensitivity showed a relevant effect $(+270 \mathrm{pcm})$ to the criticality eigenvalue and $0.3 \%$ of difference in the thermal neutron flux.

The optimal MCNP5 geometrical mesh for the FC structure was investigated. From these sensitivities two different mesh grouping of fuel pins were used in the simulations. The FA model was represented using 6 MCNP5 mesh zone, then, one MCNP5 mesh zone for the representation of FA in the core simulation. Those FA models are reported in Figure 40.

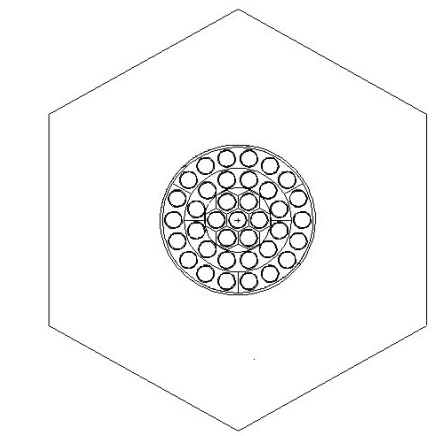

FA model for cell calculations

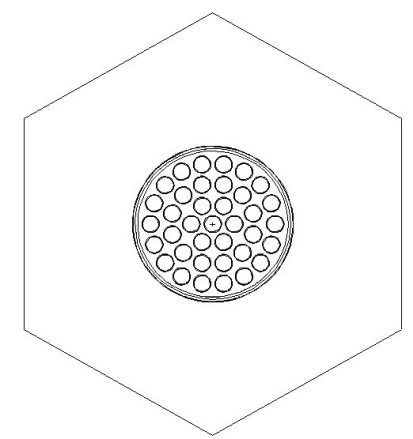

FA model for core calculations

Figure 40 - Fuel channel models

Different physical boundary conditions for the moderator and coolant heavy water can be set up in the MCNP5 input deck (e.g., material densities, isotopic composition and neutron Xsec).

\subsubsection{Control rods}

All the 18 CR used in the ATUCHA-2 NPP were modeled in the MCNP5 core model. The $\mathrm{CR}$ were modeled by distinguishing different rod types, angles of 
insertion and lower and upper CR sections. CR guide tubes were also modeled. In the following two paragraphs Black and Grey CR model are presented.

\subsection{Black $C R$}

Black CR neutron absorber is made by Hafnium. Such CR are used for shut-down purpose. The upper and lower sections have different sizes and a thicker steel layer cover the hafnium layer in the upper section. All these characteristics were modeled. Sketches of black CR sections are reported in Figure 41.
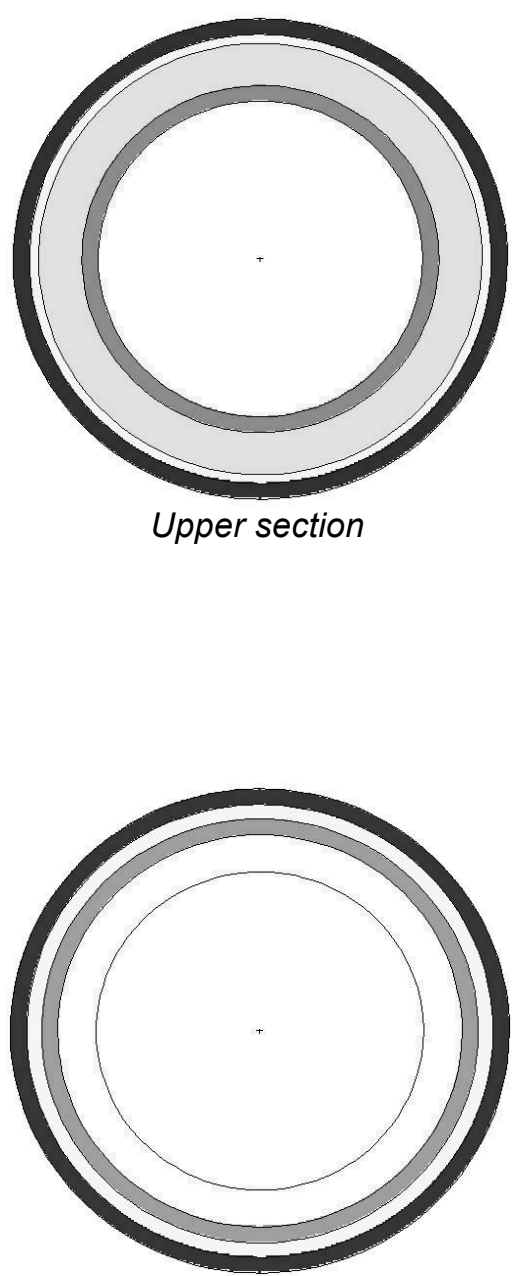

Lower section

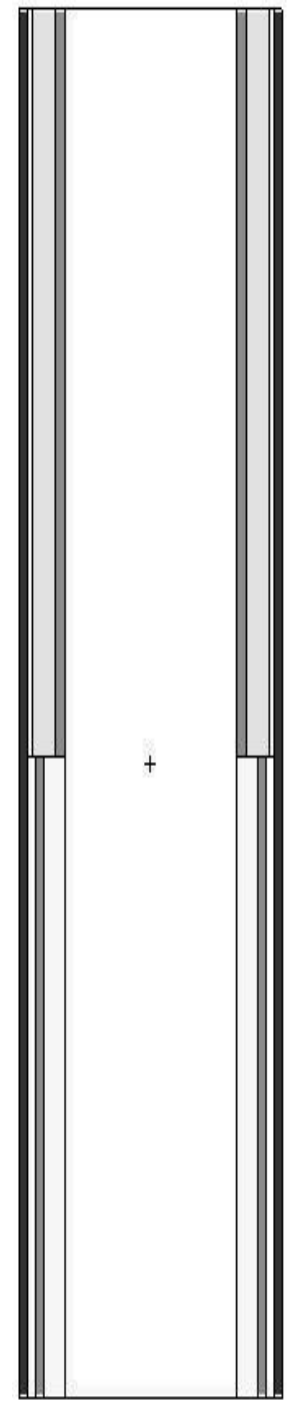

Axial section

Figure 41 - Black CR, axial section 


\subsection{Grey $C R$}

The grey CR absorber is made by steel. Such rods are used mainly for normal operation. The grey CR are modeled by a stainless steel cylinder, having different size in the upper and lower sections. Sketches of grey CR sections are reported in Figure 42.
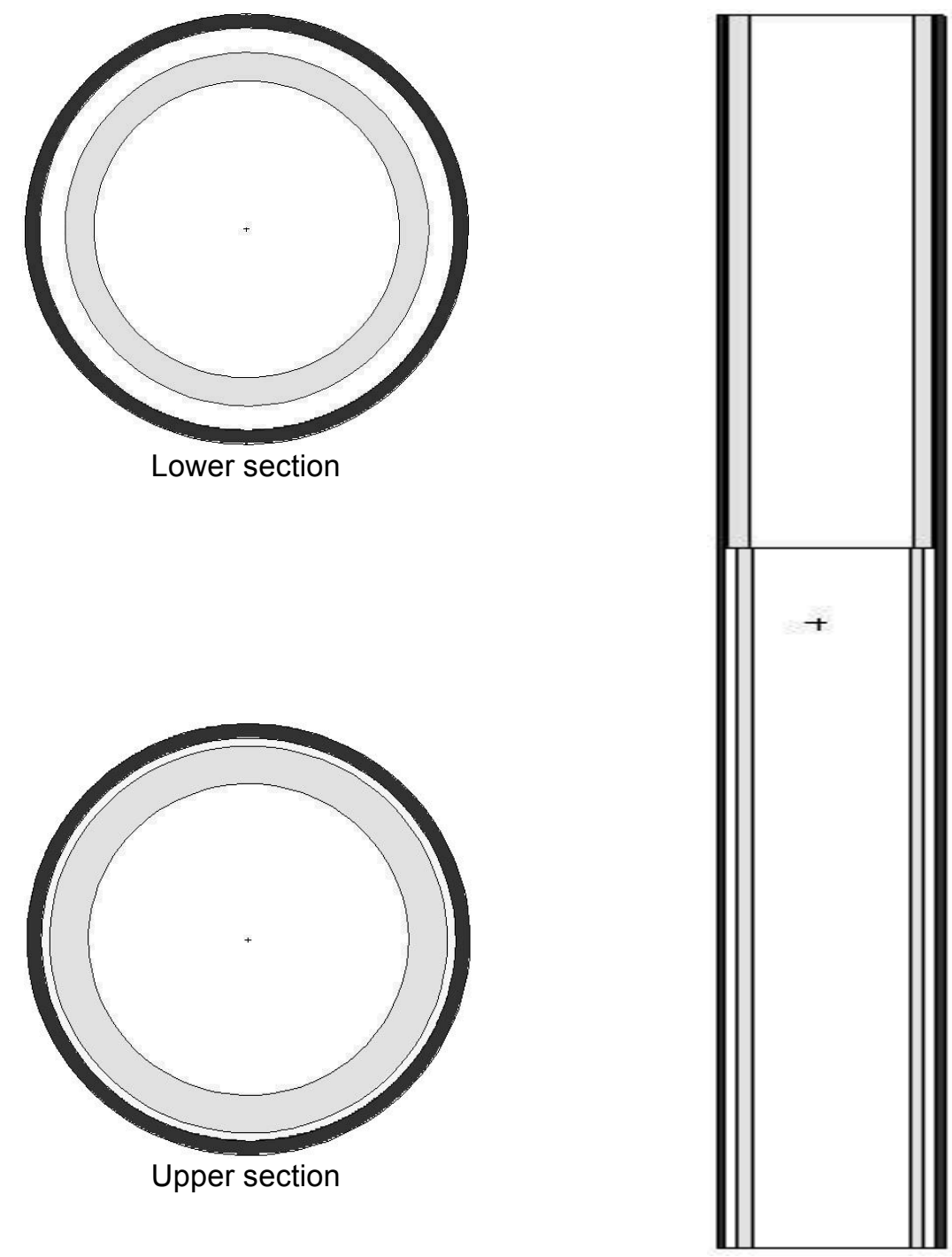

Axial section

Figure 42 - Grey $C R$, axial section 


\subsubsection{The core}

All the $451 \mathrm{FC}$ of ATUCHA-2 are represented in the MCNP5 core model. The FC are placed in a triangular lattice within the moderator tank using the MCNP5 FILL command card [17]. A hexagonal lattice representation was selected (see Figure 43). The upper and lower reflectors are simulated using two cylindrical sections with the appropriate height. Finally, all these structures are enclosed in a steel cylinder, simulating the barrel. Some sketches of the complete model are reported from Figure 44 to Figure 45 (the small ellipses are CR projection on the view plane).

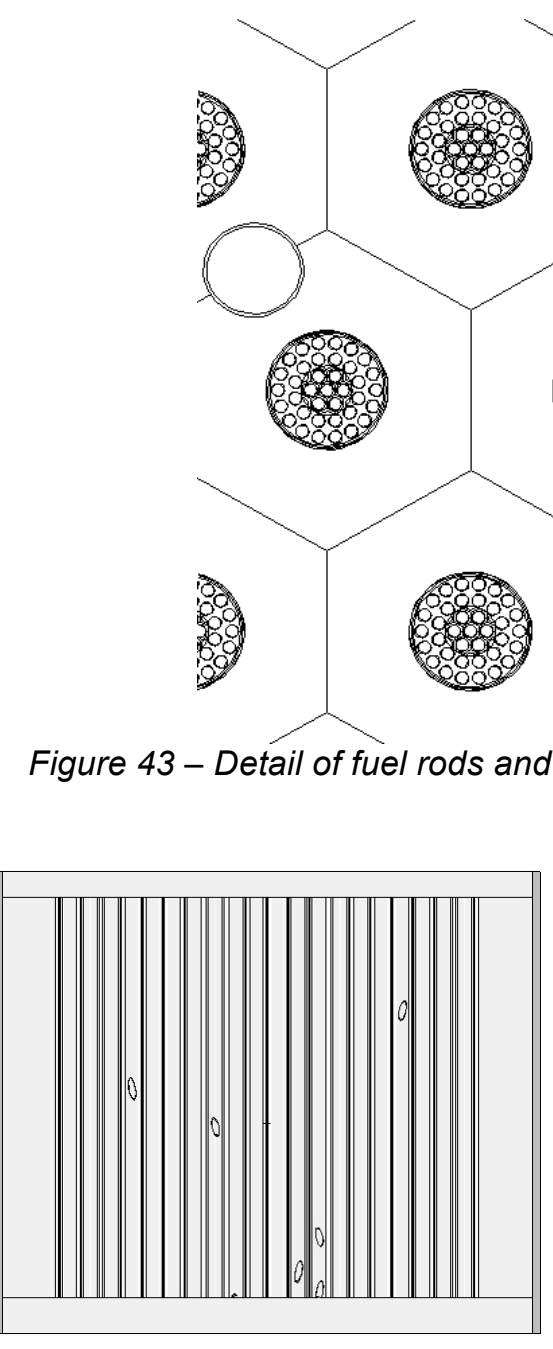

FA detail

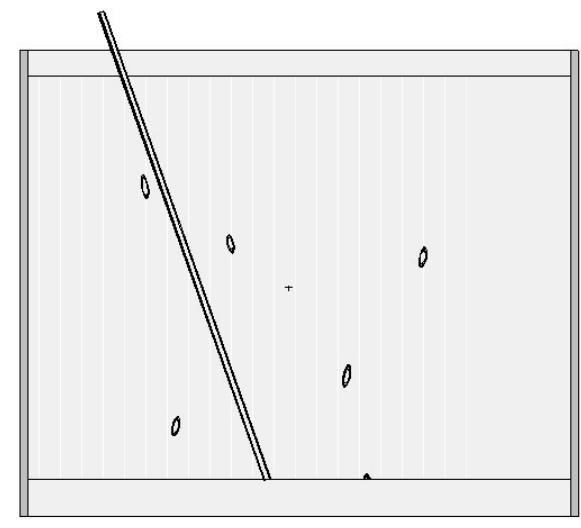

CR detail

Figure $44-$ MCNP5 Core model, longitudinal view 


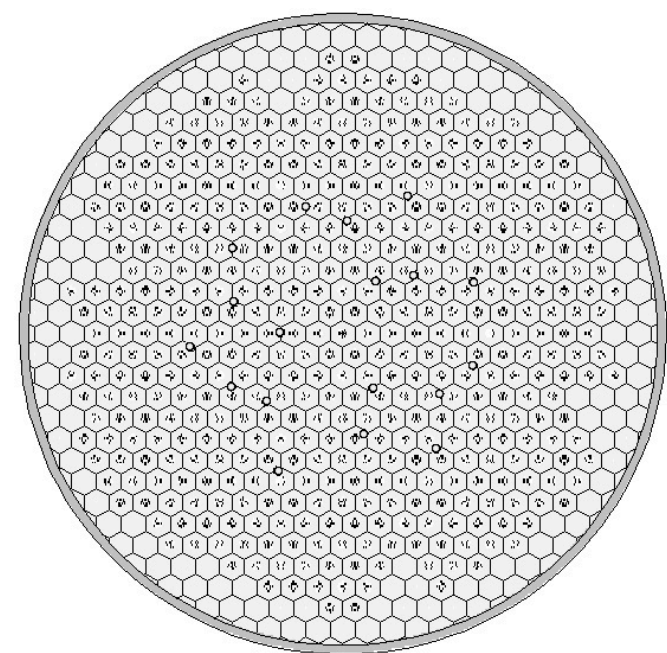

Figure 45 - MCNP5 Core model, planar view $(x-y)$

\subsubsection{MCNP5 model at BEQ with HFP core condition}

The MCNP5 model presented in the previous paragraph was used as base model to implement the proprieties at BEQ with HFP core condition. The characterization of such core status requires a huge amount of data than the model at BOL with fresh fuel. Thus, the model here presented is considerably more complex and exploit the capability of MCNP5 modeling.

Implementation of $\mathrm{BEQ}$ core condition requires the implementation of the correspondent fuel burnup distribution inside the core. Such burnup data were provided by NA-SA [2]. The overall procedure to generate the MCNP input deck was presented in Chapter 4 within the general methodology to predict power excursion in LB-LOCA for ATUCHA-2. Hence, here is summarized only the procedure to generate a suitable input deck for simulation at BEQ with HFP core condition. A scheme of the chain of codes and auxiliary program used is reported in Figure 46. The auxiliary tools ATUCHACORE and ATUCHABURN are reported in APPENDIX B. The thermal-hydraulic data, such as temperature and densities of material compositions), were provided by RELAP5-3DCNESTLE simulations.

To speed up the results MCNP5 was run in a parallel environment using a cluster computer machine. Sensitivities about system performance are reported in APPENDIX D. 


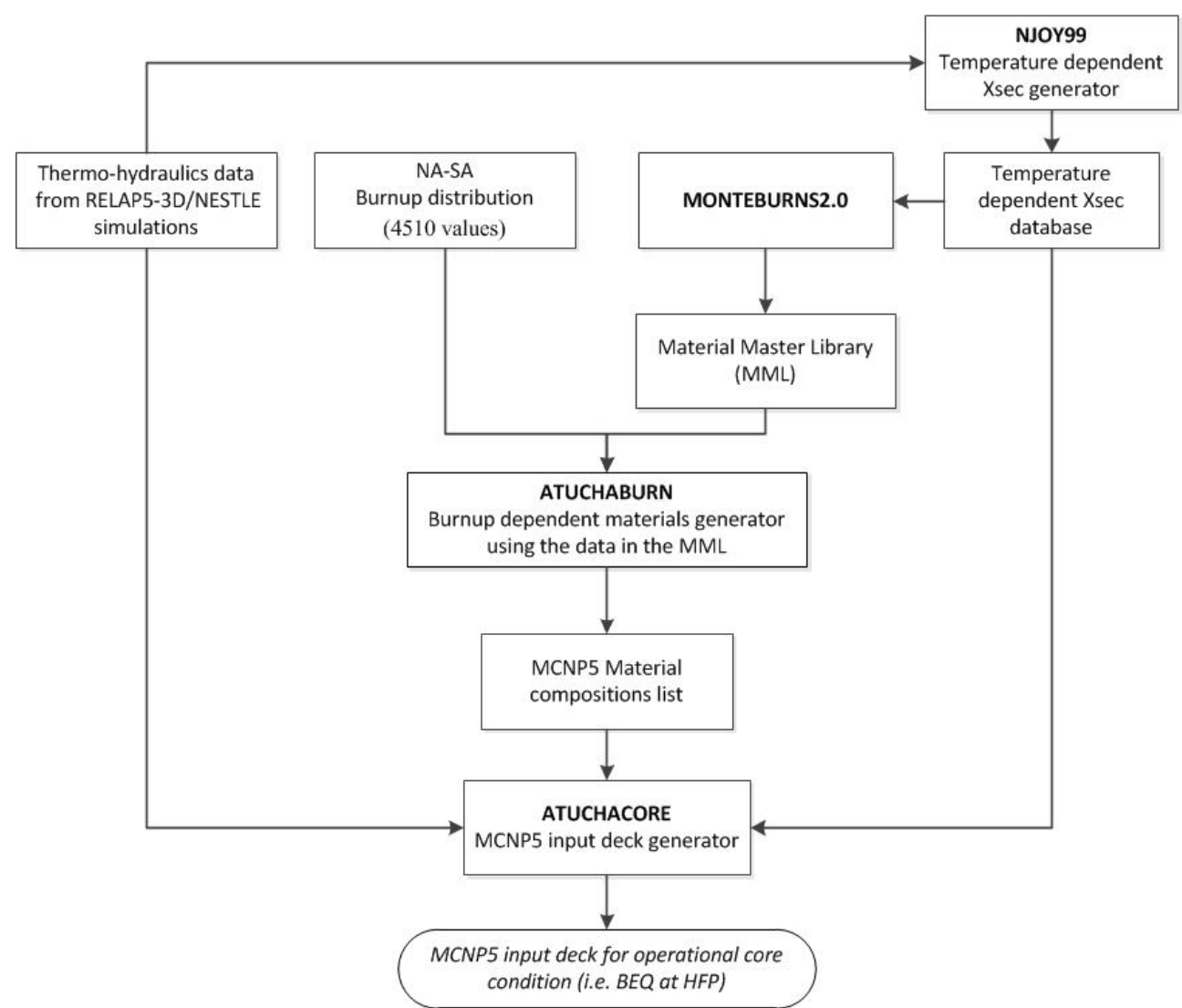

Figure 46 - Procedure to generate the MCNP5 input deck

\subsubsection{Fuel channel}

A single fuel material composition was used to characterize the FC node (each FC is represented using 10 axial regions). This material composition is an average from the 4 materials representation used for burnup calculations (see APPENDIX E for detail about the burnup procedure). Sensitivity showed that such simplified representation assures an acceptable compromise between level of detail and computational time cost (see APPENDIX D, section D.5.). Then, a core-averaged constant temperature value was used for the Zry-4 cladding and insulation tube in order to save MCNP5 material composition cards and computer memory resource. Those values were set to the average values of $550.17 \mathrm{~K}$ and $506.97 \mathrm{~K}$, respectively. 


\subsubsection{Representation of HFP core condition}

The HFP core condition is represented splitting the active core in 10 axial layers. Each layer is $53.07 \mathrm{~cm}$ thick. This is consistent to the RELAP5-3D@/NESTLE model. In each of this layer one averaged temperature is used for each material (i.e. fuel and heavy waters). This strong approximation was adopted to simplify the MCNP5 model. A sketch of the core model is reported in Figure 47, in which are visible the 10 layers used for characterizing the HFP status and a detail of the planar view. Each different color in the FA indicates a different MCNP5 material.

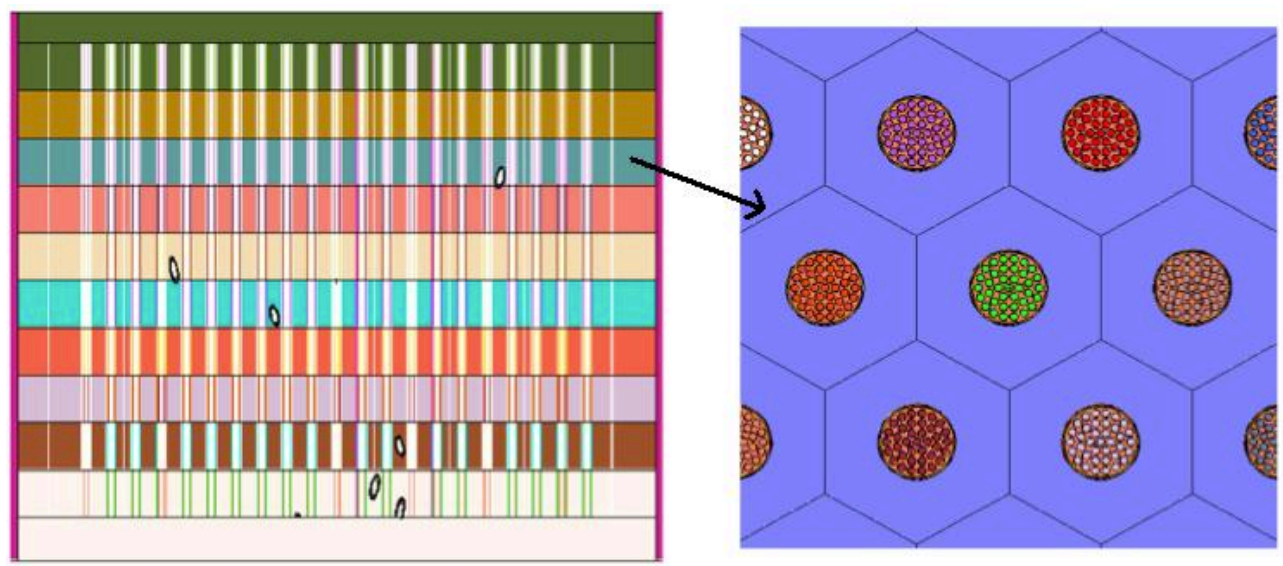

Figure 47 - MCNP5 model for ATUCHA-2 at BEQ conditions

The HFP boundary conditions were provided by RELAP5-3DCNESTLE simulations [3]. The thermal-hydraulic data used in MCNP5 simulations are reported in Table 12 and Table 13.

Table 12 - Temperature of materials

\begin{tabular}{|c||c|c|c|c||}
\hline $\begin{array}{c}\text { Axial level } \\
\text { (Bottom to top) }\end{array}$ & $\begin{array}{c}\text { Fuel } \\
{[\mathrm{K}]}\end{array}$ & $\begin{array}{c}\text { Moderator } \\
{[\mathrm{K}]}\end{array}$ & $\begin{array}{c}\text { Coolant } \\
{[\mathrm{K}]}\end{array}$ & $\begin{array}{c}\text { Clad } \\
{[\mathrm{K}]}\end{array}$ \\
\hline \hline 1 & 810.05 & 424.01 & 554.25 & 533.12 \\
\hline 2 & 894.21 & 425.90 & 557.71 & 535.21 \\
\hline 3 & 938.95 & 428.78 & 561.56 & 539.95 \\
\hline 4 & 966.00 & 433.65 & 565.58 & 544.38 \\
\hline 5 & 986.73 & 438.52 & 569.78 & 548.76 \\
\hline 6 & 1000.79 & 443.06 & 573.89 & 553.05 \\
\hline 7 & 1007.64 & 448.69 & 578.01 & 557.16 \\
\hline 8 & 999.10 & 454.93 & 581.87 & 560.88 \\
\hline 9 & 958.65 & 460.60 & 585.15 & 563.94 \\
\hline 10 & 851.37 & 466.16 & 587.43 & 565.31 \\
\hline
\end{tabular}


Table 13 - Density and pressure of heavy water

\begin{tabular}{||c||c|c|c|c||}
\hline $\begin{array}{c}\text { Axial level } \\
\text { (Bottom to } \\
\text { top) }\end{array}$ & $\begin{array}{c}\text { Moderator } \\
\text { Pressure } \\
\text { [KPa] }\end{array}$ & $\begin{array}{c}\text { Moderator } \\
\text { Density } \\
\text { [gr/cm }{ }^{3} \text { ] }\end{array}$ & $\begin{array}{c}\text { Coolant } \\
\text { Pressure } \\
\text { [KPa] }\end{array}$ & $\begin{array}{c}\text { Coolant } \\
\text { Density } \\
\text { [gr/cm }{ }^{\text {] }}\end{array}$ \\
\hline \hline 1 & 11663.2 & 1.02396 & 12183.9 & 0.83794 \\
\hline 2 & 11657.9 & 1.02207 & 12105.7 & 0.83257 \\
\hline 3 & 11652.6 & 1.01905 & 12053.7 & 0.82385 \\
\hline 4 & 11647.3 & 1.01389 & 12001.3 & 0.81486 \\
\hline 5 & 11642.0 & 1.00857 & 11948.5 & 0.80301 \\
\hline 6 & 11636.8 & 1.00361 & 11867.7 & 0.79295 \\
\hline 7 & 11631.6 & 0.99601 & 11813.8 & 0.78247 \\
\hline 8 & 11626.5 & 0.98872 & 11759.4 & 0.77142 \\
\hline 9 & 11621.3 & 0.97627 & 11704.5 & 0.76260 \\
\hline 10 & 11616.2 & 0.97627 & 11649.1 & 0.75131 \\
\hline
\end{tabular}

\subsubsection{Burnup distribution based on pseudo $1 / 6^{\text {th }}$ core symmetry}

In the NESTLE model the 4510 values of equilibrium burnup distribution were reduced to 780 values assuming, where possible, a $1 / 6^{\text {th }}$ symmetry of the core [27]. The reason of this approach is to minimize the size of the transient libraries, making more efficient the interpolation during the transient calculations, thus resulting in less time on updating Xsec. This reduced burnup distribution was implemented in the MCNP5 burnup distribution in order to enhance the similarity to the NESTLE model and to further reduce the simulation computer time.

\subsubsection{MCNP5 models for Boron self-shielding analysis}

Hereafter, the MCNP5 models used to investigate the Boron self-shielding phenomena and to predict the reactivity inserted by JDJ system are reported. The analysis is based on 3 kinds of models:

- Cell models;

- Macro-cell models;

- Core models.

The cell and macro-cell models were used to investigate the basic proprieties of Boron self-shielding phenomena. For this purpose BOL with fresh fuel core condition were selected in the sake of simplicity without losing the main feature of such phenomena. Then, the quantitative analyses were based on realistic core models, in which the Boron cloud was represented with high level of detail. 


\subsubsection{Cell models}

A single idealized ATUCHA-2 FA was used to analyze the Boron self-shielding at cell level. Three Boron spatial distributions were represented at cell level. Those models share the same amount of Boron mass in the moderator heavy water. BOL boundary conditions were selected and fresh fuel material was used.

The first Boron spatial distribution is a uniform distribution ( $C 1$ model), i.e. the boron mass is uniformly distributed in moderator water. The other two distributions are heterogeneous distributions ( $\mathrm{C} 2$ and $\mathrm{C} 3$ models), in which the Boron mass is concentrated in a smaller zone of the moderator region. In the latter cases, the volume of the zone in which the boron is spread is equal to a $1 / 6$ and $1 / 12$ of the moderator volume contained in a hexagonal prism volume. A sketch of the cell models is reported in Figure 48 (the borated heavy water is located in the darker zone).

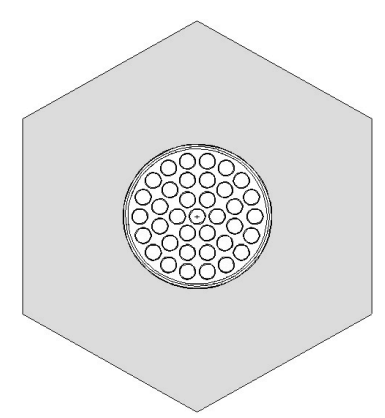

C1 model

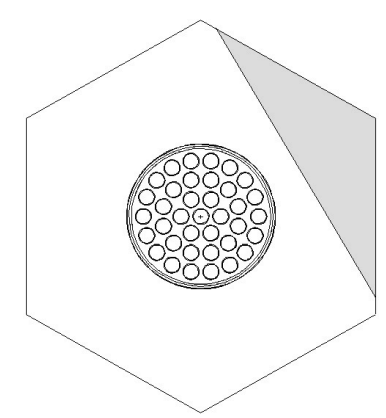

C2 model

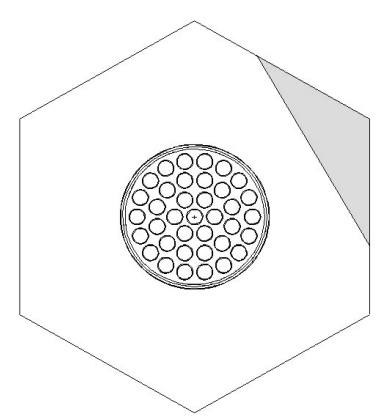

C3 model

Figure $48-$ Cell models

\subsubsection{Macro-cell models}

A lattice of FA was used to analyze the Boron self-shielding at macro-cell level. Only the central FA contains borated heavy water. The boron spatial distributions used in the central channel are similar to the one used for cell models, i.e. a homogeneous case (M1 model) and one heterogeneous case (M2 model). In the latter case, the Boron is placed in a zone having a volume equal to $1 / 6$ of the hexagonal prism volume. Also in this case BOL boundary conditions were selected and fresh fuel material was used. This model was developed because it is more similar to the configuration of the ATUCHA-2 moderator tank when boron is injected (Boron is concentrated in a small zone with the other FA un-affected). The Boron mass is the same for those two different configurations (analogous to the cell models). A sketch of the cell models is reported in Figure 49 (the borated heavy water is located in the grey zone). 

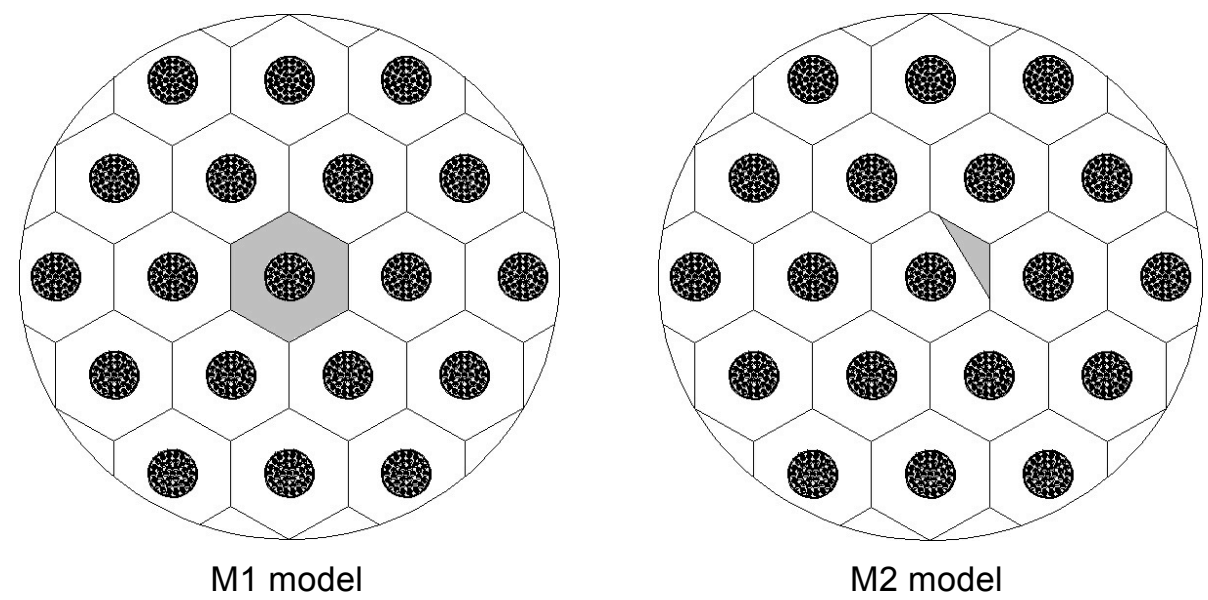

Figure 49 - Macro-cell models

\subsubsection{Core models}

Several core configurations were developed to investigate at core level the Boron self-shielding effect. Different levels of moderator heavy water representations characterize those models (i.e. different representation of the Boron cloud). The geometrical details of each representation increase to assess the Boron selfshielding effect. Two geometrical objects are the basic elements to represent the moderator region, a triangular prism and a hexagonal prism. The thickness of those elements is $53.07 \mathrm{~cm}$ and correspond to the thickness of NK nodes represented by NESTLE. The triangular prism volume is $1 / 6$ of the hexagonal prism. Geometrical information is reported in Table 14, then, a graphical sketch is shown in Figure 50.

Table 14 - MCNP5 moderator mesh type

\begin{tabular}{|c|c|c|}
\hline Type of prism & Axial thickness [cm] & Volume ratio \\
\hline Hexagonal & 53.07 & 1 \\
\hline Triangular & 53.07 & $1 / 6$ \\
\hline
\end{tabular}

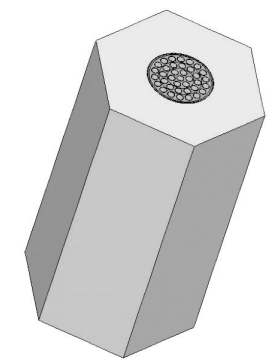

Hexagonal prism

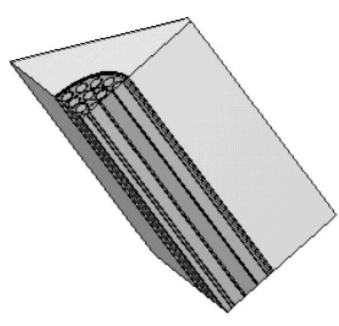

Triangular prism

Figure 50 - Basic prism elements 
From the analysis of the CFX data results that the Boron cloud has a limited spread inside the core for all the time instant of relevance in the LB-LOCA transient. This means that only a small portion of the MCNP5 macro regions contain a relevant amount of borated water, i.e. the Boron mass in most of MCNP5 zones is negligible. This information was implemented in MCNP5 moderator model, i.e. only MCNP5 regions with a Boron concentration above a fixed threshold are characterized. Sensitivity analyses showed that Boron densities below $10^{-6}$ $\mathrm{gr} / \mathrm{cm}^{3}$ have no effect (i.e. variations are inside the statistical uncertainty). The CFD2MCNP program selects the relevant nodes and calculates the Boron weight fraction using the CFX pre-calculated data, then, the ATUCHACORE program put those node in the correct location inside the core. The benefits are the significant reduction of simulation time, due to a large save of MCNP5 cell cards, and the possibility to check easily the Boron distribution in the MCNP5 model.

Several sketches of the MCNP5 core model for Boron cloud simulations are reported from Figure 51 to Figure 56, in which a sample Boron cloud distribution is shown from axial level 5 up to axial level 10 of ATUCHA-2 core representation (no Boron is present in lower levels). The background colors represent the implementation of HFP BIC (i.e. different colors means different kind of material, hence different physical conditions), then the cluster of colored node represent the spatial distribution of the Boron cloud. In the following paragraphs are presented the models used in the simulations. The models developed are reported in Table 15.

Table 15 - Core models for detailed Boron cloud representation

\begin{tabular}{||c|c|c|c||}
\hline Case & $\begin{array}{c}\text { Model } \\
\text { name }\end{array}$ & $\begin{array}{c}\text { Basic prism used to } \\
\text { represent the Boron } \\
\text { cloud }\end{array}$ & $\begin{array}{c}\text { Volume region ratio } \\
\text { (Referred to the } \\
\text { Triangular model) }\end{array}$ \\
\hline \hline 1 & Triangular & Triangular & 1 \\
\hline 2 & Hexagonal & Hexagonal & 6 \\
\hline 3 & RELAP-like & Hexagonal & $\begin{array}{c}30 / 48 \\
\text { (Minimum/maximum) }\end{array}$ \\
\hline
\end{tabular}




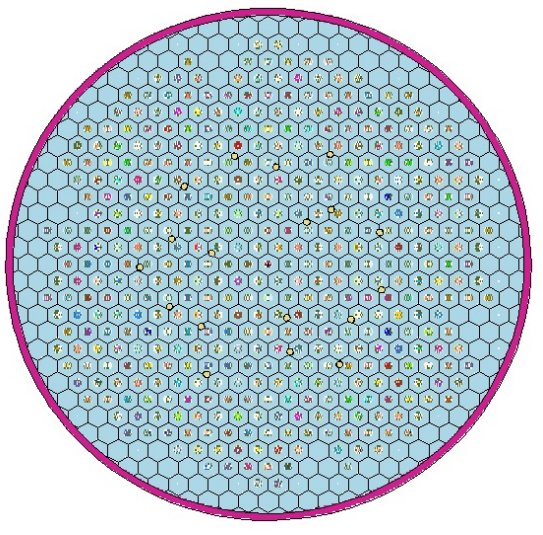

Figure 51 - Distribution of borated node, level 5

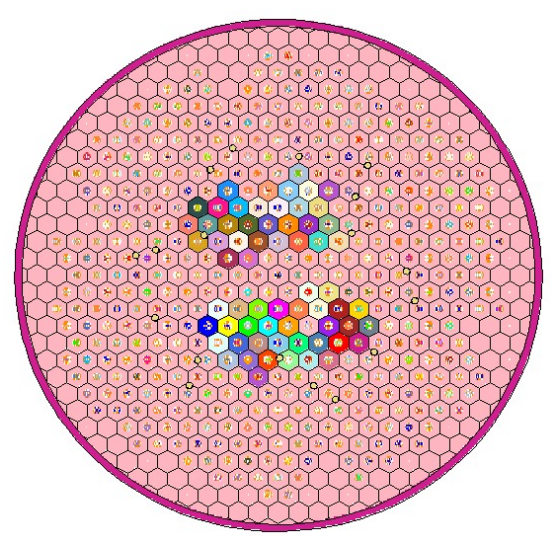

Figure 53 - Distribution of borated node, level 7

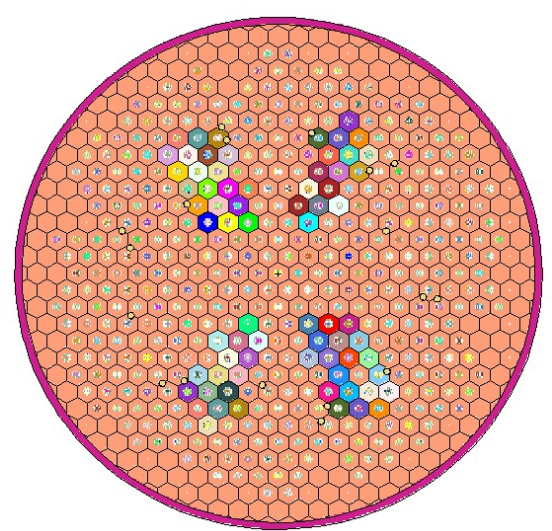

Figure 55 - Distribution of borated node, level 9

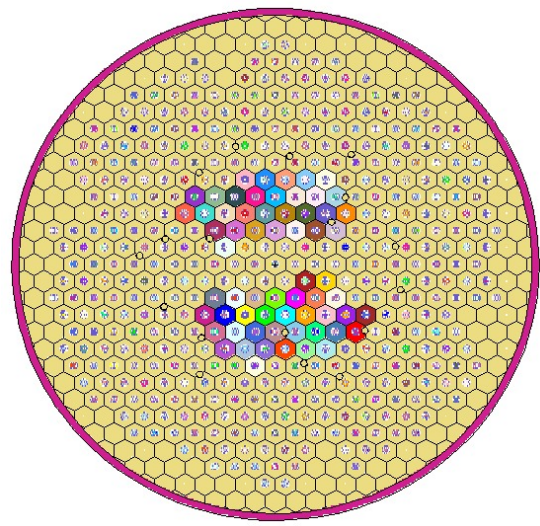

Figure 52 - Distribution of borated node, level 6

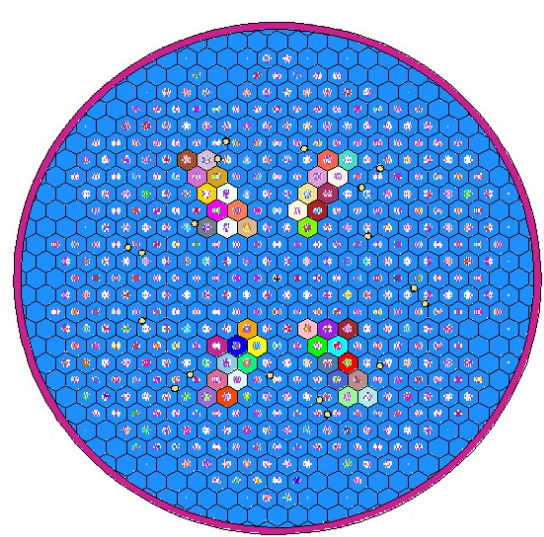

Figure 54 - Distribution of borated node, level 8

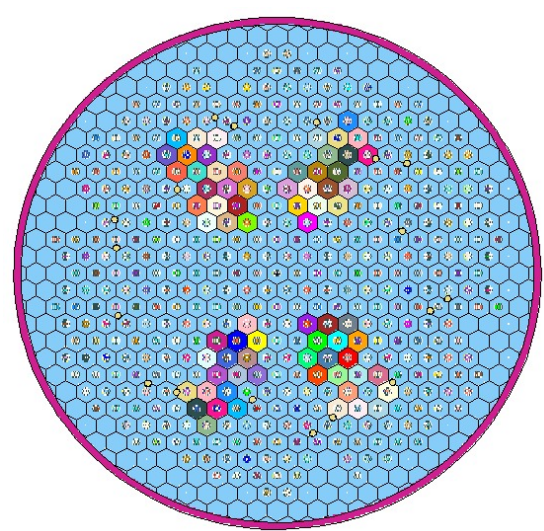

Figure 56 - Distribution of borated node, level 10 


\subsection{Triangular core configuration}

The moderator representation was modeled using the triangular prism type. A sketch of such configuration is reported in Figure 57 and Figure 58. The number of MCNP5 cells and materials depend by the time instant used for Boron cloud reconstruction (if more Boron is spread, then more cells and materials are used in the MCNP5 input deck). About 14000 MCNP5 cell cards and $~ 3700$ moderator materials are used to represent this configuration.

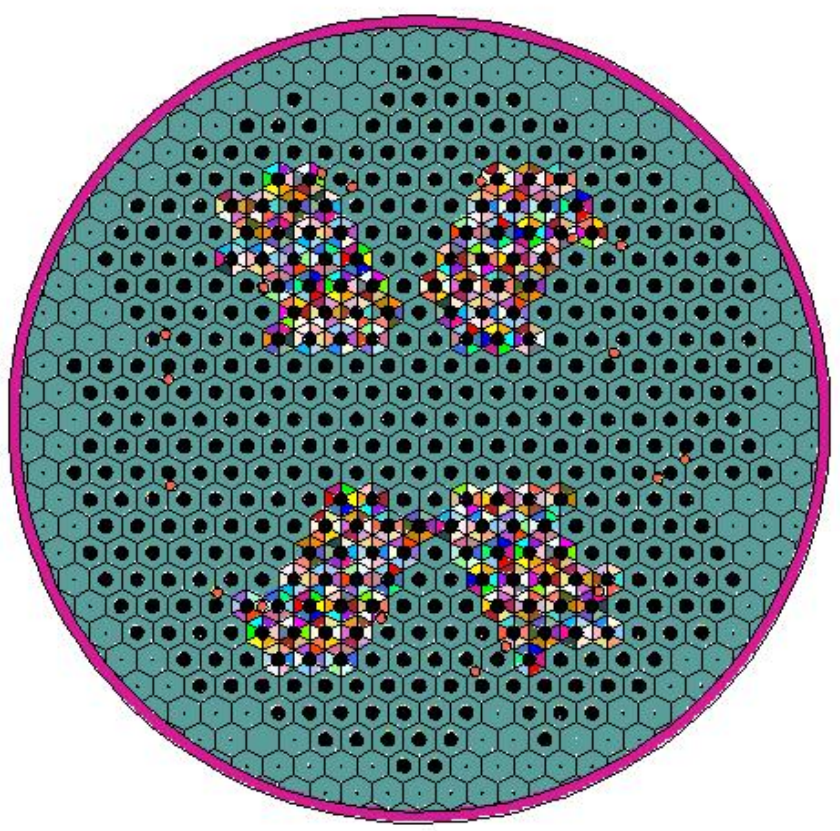

Figure 57 - Planar sketch of triangular core configuration

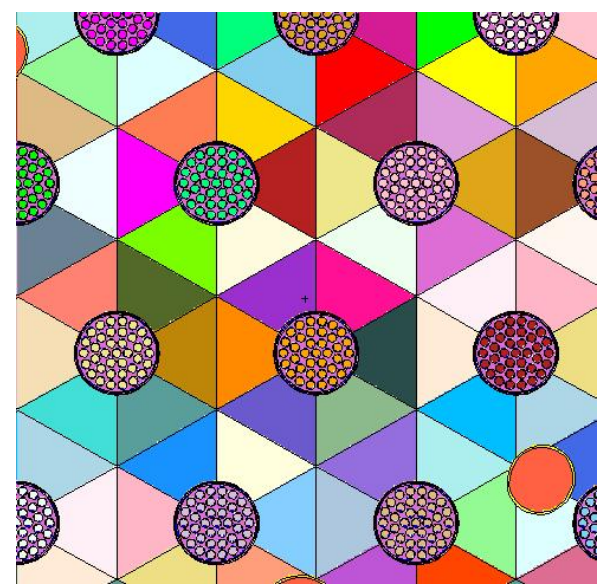

Figure 58 - Detail of triangular core model 


\subsection{Hexagonal core configuration}

In this model it was used the hexagonal moderator mesh type. A sketch of such configuration is reported in Figure 59 and Figure 60. The number of MCNP5 cells and materials depend by the time instant used for Boron cloud reconstruction (if more Boron is spread, then more cells and materials are used in the MCNP5 input deck). About 6900 MCNP5 cell cards and $\sim 300$ moderator materials are used to represent this configuration.

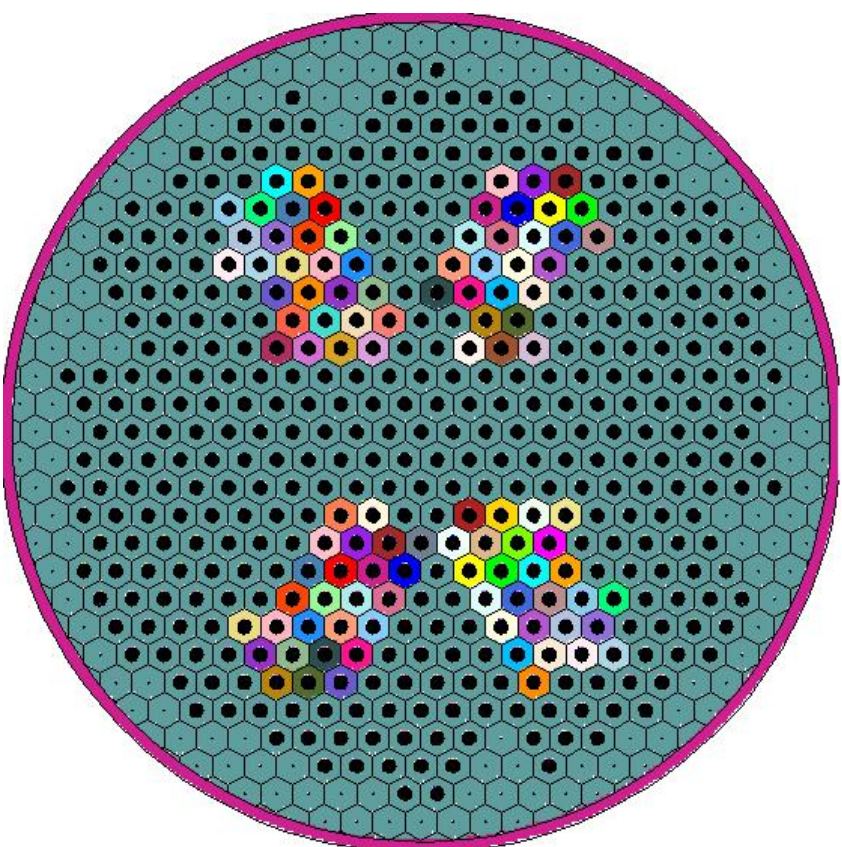

Figure 59 - Planar sketch of hexagonal core configuration

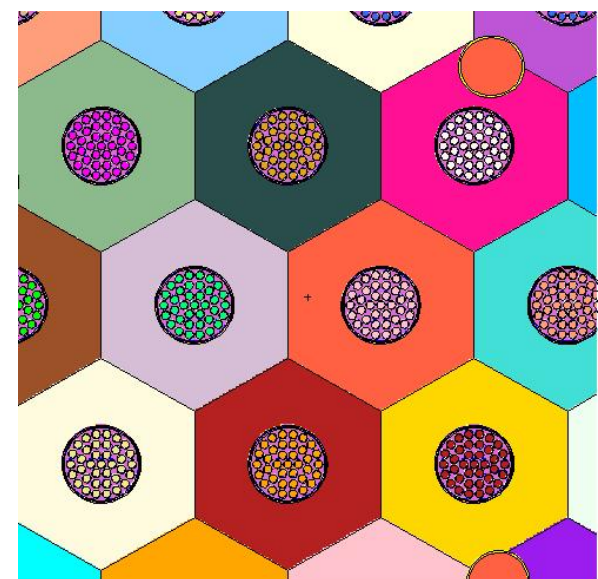

Figure 60 - Detail of hexagonal core model 


\subsection{RELAP5-like core configuration}

To investigate the effect of "Boron self-shielding" in the case of a moderator meshing similar to the one used in RELAP5-3DC calculations, a special MCNP5 model was developed. RELAP5-3D@ nodalization divide moderator tank in 960 node mesh (see Par. 5.4.1.1). A MCNP5 model was prepared in which the Boron is homogenized in a nodes having the volumes equivalent to the ones of the RELAP5-3D@/NESTLE nodalization. A sketch of this core configuration and the analogous RELAP5-3DC/NESTLE moderator model is reported in Figure 61. The RELAP-like macro zone was constructed joining different hexagonal meshes. About 31000 MCNP5 cell cards and $\sim 810$ moderator materials are used to represent this configuration (in this case the optimization of MCNP5 cell based on Boron concentration was not used).

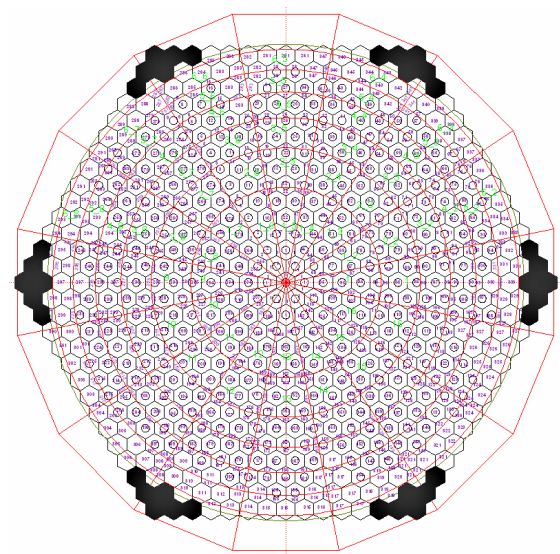

RELAP5-3D@/ NESTLE moderator representation

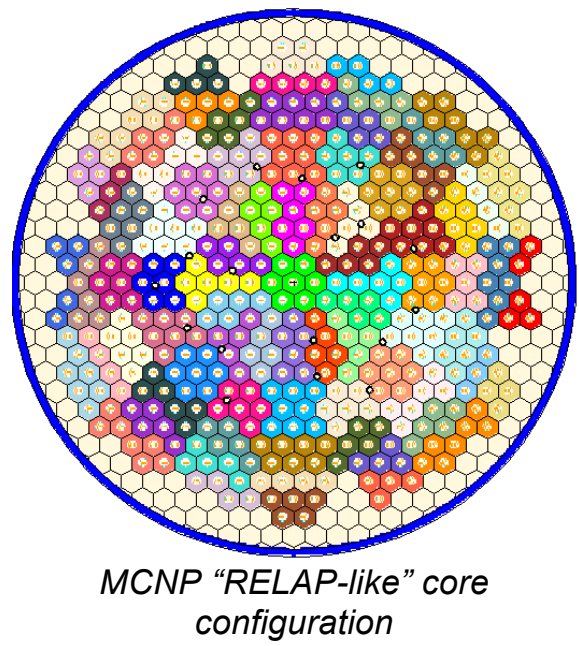

configuration

Figure 61 - Moderator nodalization

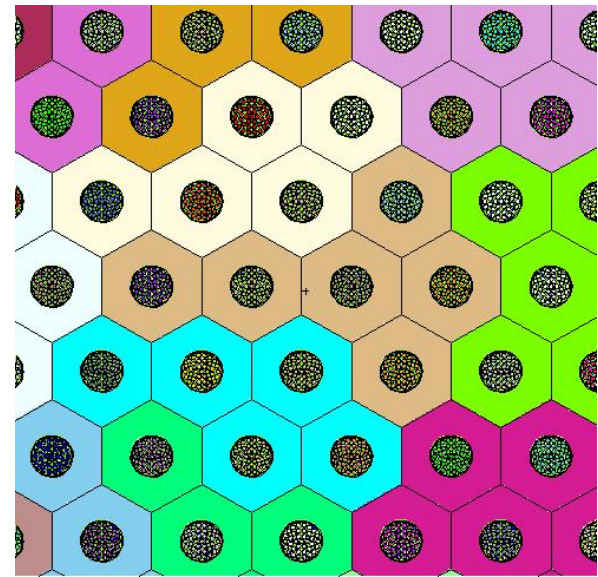

Figure 62 - Detail of RELAP-like core model 


\subsubsection{Selection of results at BOL with CZP core condition}

Criticality results were calculated for the ATUCHA-2 core in several configurations. Then, an application of MCNP5 volume calculation used in the NESTLE model was presented. In the following paragraphs the cases simulated and their relative results are presented. In those simulations the MCNP5 KCODE [17] option was used with 50000 particles per cycle and 3000 active histories simulated, for a total of $7.5 \times 10^{7}$ histories. A preliminary calculation was used to generate a suitable guess source distribution. All the estimated standard deviations resulting from MCNP5 calculations reported hereafter should be intended at the $68 \%$ of the confidence level. The criticality eigenvalue and Shannon entropy convergence was reached in each calculation. Several sensitivities about MCNP criticality parameters are reported in APPENDIX D.

\subsubsection{MCNP5 calculation of Beta delayed factor}

The calculation of the beta delayed neutron fraction, namely $\beta_{\text {eff }}[31]$, is possible using a feature of MCNP5 code. In a criticality calculation using KCODE command card, the contribution of both delayed and prompt neutron is computed (default MCNP5 option). The calculation of requires an additional criticality calculation using only the contribution of the prompt neutrons (using the MCNP5 command card "TOTNU NO" [17]). Then, $\beta_{\text {eff }}$ is computed according to the following formula:

$$
\beta_{\text {eff }}=1-\frac{k_{P}}{k_{T}}
$$

where, $k_{P}$ is the multiplication factor given by the prompt neutrons and $k_{T}$ is the multiplication factor using both prompt and delayed neutrons. The calculated $\beta_{\text {eff }}$ together with the reference value supplied by NA-SA is reported in Table 16. The difference of $2 \%$ is due to different Xsec libraries and a slight difference in fuel material compositions.

Table 16 - Calculated beta delayed factor by MCNP5

\begin{tabular}{||c|c|c|c|c||}
\hline $\mathbf{k}_{\mathrm{P}}(\boldsymbol{\sigma}[\mathrm{pcm}])$ & $\mathbf{k}_{\mathrm{T}}(\boldsymbol{\sigma}[\mathrm{pcm}])$ & $\boldsymbol{\beta}_{\text {eff }}[\mathrm{mk}]$ & $\mid \mathrm{Err}$ & Reference NA-SA [mk] \\
\hline \hline $1.10825(5)$ & $1.11589(5)$ & 6.84 & 0.09 & 6.98 \\
\hline
\end{tabular}

\subsubsection{Flux distribution}

A detailed neutron flux distribution was calculated using the MCNP5 FMESH command card. A cylindrical mesh grid was superimposed to the whole core model for a total of $3.74 \times 105$ elements (170 x 100 planar elements and 22 axial ones). Three ranges of energy were considered:

- Thermal energy range (from 0 to $0.625 \mathrm{eV}$ )

- $\quad$ Fast energy range (from $0.625 \mathrm{eV}$ to $20 \mathrm{MeV}$ )

- Total energy range (from $0.0 \mathrm{eV}$ to $20 \mathrm{MeV}$ )

The ARI configuration was chosen in order to analyze the CR effects on the neutron flux distribution. The neutron flux distribution is reported from Figure 63 to Figure 68. The planar view sections are cut at $215 \mathrm{~cm}$ from the bottom reflector. 


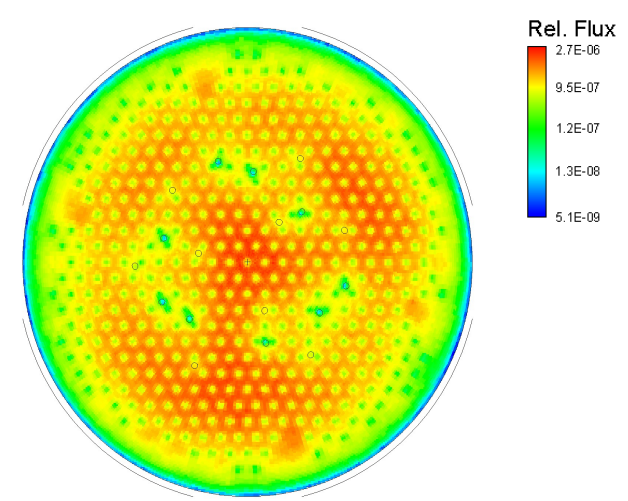

Figure 63 - Thermal flux, planar view

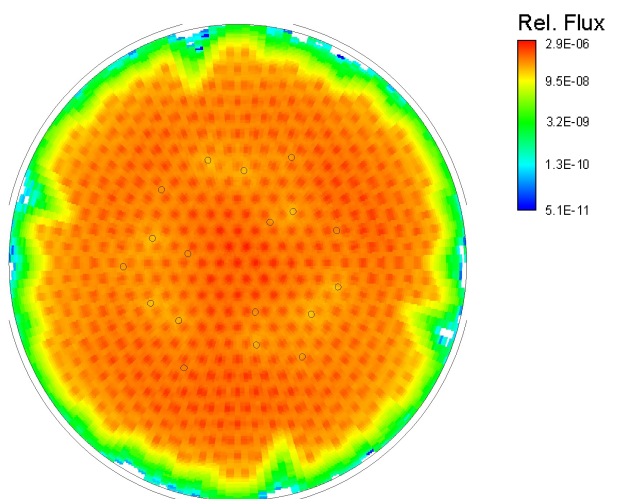

Figure 65 - Fast flux, planar view

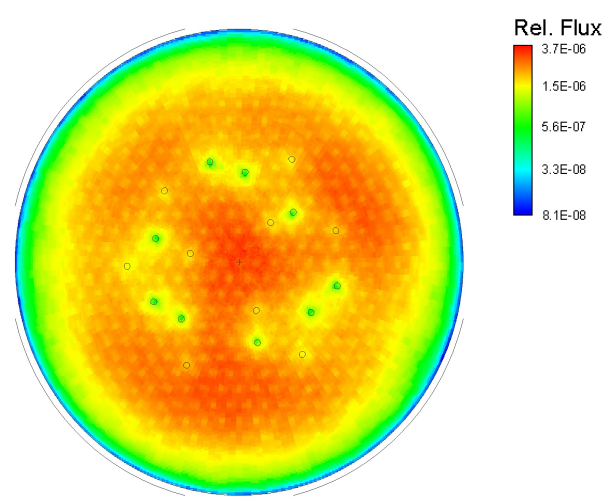

Figure 67 - Total flux, planar view

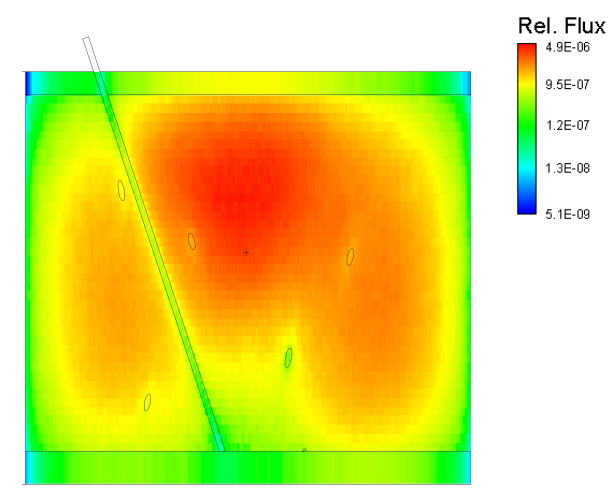

Figure 64 - Thermal flux, axial view

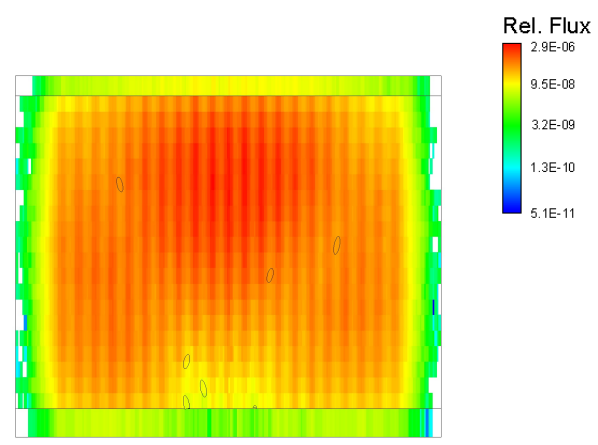

Figure 66 - Fast flux, axial view

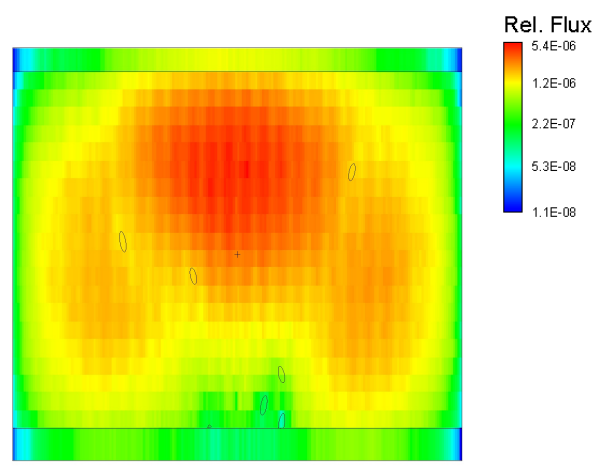

Figure 68 - Total flux, axial view

\subsubsection{Stochastic volume calculations}

Each oblique $C R$ is intersecting in several different ways the various 4510 hexagonal prisms composing the MCNP5 representation of ATUCHA-2 FC. The same FC hexagonal representation is used by the 3D NK NESTLE code (see Par. 5.4). The Macroscopic Xsec used by NESTLE are calculated by the deterministic 
2D transport code HELIOS (see Par. 5.4.2.1). This code can't take into account all these possible CR intersection to the hexagonal FC axial nodes in the Xsec libraries generation. Therefore, in order to introduce correction factors, several cases of intersection had to be identified and the relative cell $C R$ volumes calculated by tools with 3D modeling capability. The methodology applied for such calculations was the stochastic volume calculations of the CR by MCNP5.
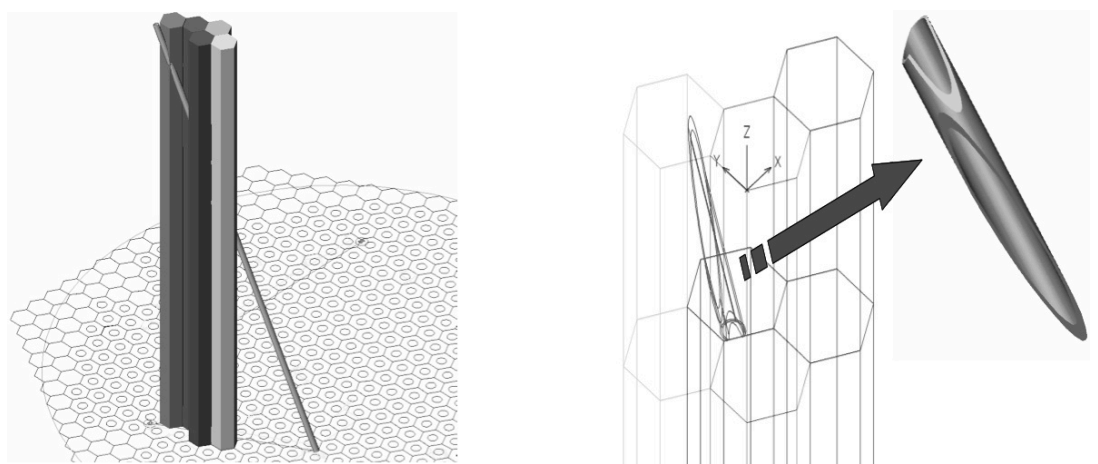

Figure 69 - Sketches of crossing the 3D NK hexagonal cells

The developed procedure was the following. The CR volume to be measured was enclosed in a sphere and an inward spherical distribution of neutron particles was employed for flooding the objects, i.e. the $C R$ and the intersected hexagonal prisms. A flux tally got the resulting volume calculation. A scheme of the procedure is reported in Figure 70.
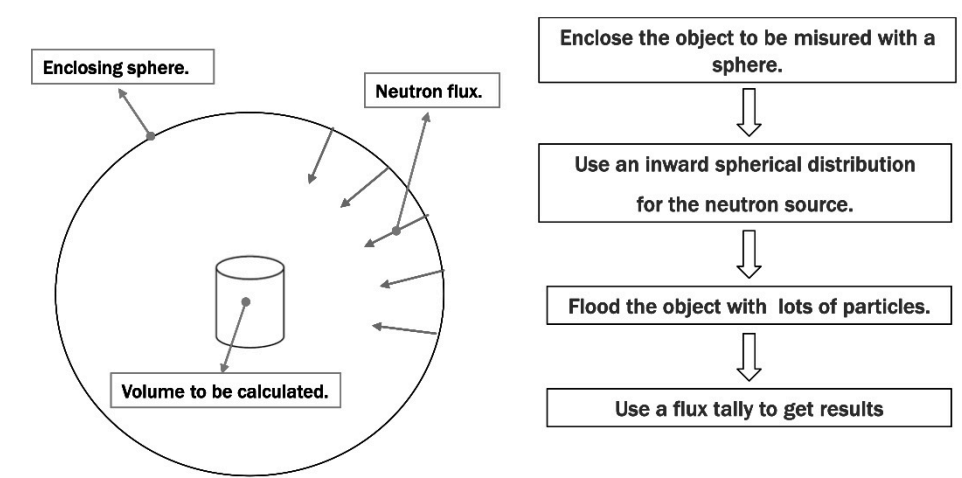

Figure 70 - Stochastic Cell Volume procedure by MCNP5 tally

An automatic auxiliary program was developed for calculating the optimal dimension of the enclosing sphere and simplify the geometrical model (only the interested axial piece is considered). Then, the program allowed to automatically create the MCNP5 input files for the calculations of the all possible CR volumes resulting from the intersection of the $18 \mathrm{CR}$ with 3D NK hexagonal meshes. Symmetry considerations allowed the reduction of the number of CR intersections to be investigated to $10 \mathrm{CR}$, thus resulting in $10 * 40=400$ volumes calculations. Then, $10^{6}$ neutron histories were employed to minimize statistical fluctuations. This volume calculation procedure underwent to a verification check using the Autodesk 
AUTOCAD ${ }^{\mathrm{TM}}$ model, developed for a single CR. The deviation between the 2 calculation ranges from a maximum of $+9.7 \%$ to a minimum of $+0.34 \%$. The average error was about $+2 \%$.

\subsubsection{Benchmark between NESTLE and MCNP5}

In the framework of the Second and Third Agreement "NA-SA - University of Pisa" for the licensing of ATUCHA-2 NPP a benchmark of NESTLE model using the MCNP code was set up [32]. In the following paragraphs are summarized the main difference between the 2 models and the results for ARO CR configuration. In this benchmark the MCNP active cycle were raised to 7000 , for a total of $3.5 \times 10^{8}$ neutron histories simulated. Then, the same calculation was repeated changing the random number seed [17]. The convergence of fluxes in nodes was assessed using a feature of HEXMESH routine (see APPENDIX B). It was found that most nodes have a deviation within $0.1 \%$. A higher deviation around $1 \%$ was found in several nodes belonging to the radial reflector.

\subsubsection{Main differences between MCNP5 and NESTLE models}

The neutron transport solution methods used by NESTLE and MCNP5 are very different. NESTLE code solves nodal diffusion equations while MCNP5 uses a Monte Carlo stochastic approach. This fundamental difference in the neutron transport solution method implies a difference in developing of the models and methodologies. The most relevant differences between NESTLE and MCNP5 concerning the models for ATUCHA-2 are summarized in Table 17.

Table 17 - Main differences between NESTLE and MCNP5

\begin{tabular}{|c|c|c|}
\hline Issue & $\begin{array}{l}\text { NESTLE } \\
\end{array}$ & MCNP5 \\
\hline $\begin{array}{l}\text { Transport } \\
\text { method }\end{array}$ & Diffusion theory & Monte Carlo method \\
\hline $\begin{array}{l}\text { Fuel cell } \\
\text { modeling }\end{array}$ & Homogenized node & $\begin{array}{l}\text { Explicit representation of fuel } \\
\text { clusters up to fuel pin level }\end{array}$ \\
\hline $\begin{array}{l}\text { Fuel cell } \\
\text { constants }\end{array}$ & $\begin{array}{l}\text { 2-groups collapsed from Xsec } \\
\text { calculated by HELIOS code }\end{array}$ & $\begin{array}{l}\text { Explicit representation of fuel } \\
\text { cluster materials }\end{array}$ \\
\hline $\begin{array}{c}\mathrm{CR} \\
\text { modeling }\end{array}$ & $\begin{array}{c}280 \text { straight virtual CR } \\
\text { simulating the } 18 \text { oblique CR } \\
\text { using volume and Xsec } \\
\text { weights }\end{array}$ & $\begin{array}{c}\text { Explicit representation of } \\
\text { oblique CR at exact angles of } \\
\text { insertion }\end{array}$ \\
\hline $\begin{array}{c}\text { CR } \\
\text { constants }\end{array}$ & $\begin{array}{l}\text { 2-groups collapsed from Xsec } \\
\text { calculated by HELIOS (super- } \\
\text { cell model) }\end{array}$ & $\begin{array}{c}\text { Explicit representation of CR } \\
\text { (geometrical and material } \\
\text { compositions) }\end{array}$ \\
\hline Burnup & $\begin{array}{l}780 \text { values using } 1 / 6^{\text {th }} \text { core } \\
\text { pseudo symmetry }\end{array}$ & Same as NESTLE \\
\hline $\begin{array}{c}{ }^{135} \mathrm{Xe} \\
\text { concentration }\end{array}$ & $\begin{array}{l}\text { Equilibrium }{ }^{135} \text { Xe embedded } \\
\text { in HELIOS Xsec }\end{array}$ & $\begin{array}{c}\text { Equilibrium }{ }^{135} \mathrm{Xe} \\
\text { concentration added after } \\
\text { burnup calculation }\end{array}$ \\
\hline Energy groups & 2-groups & Continuous energy \\
\hline $\begin{array}{l}\text { Temperatures } \\
\text { and HW } \\
\text { densities }\end{array}$ & Defined for each NK node & Averaged for each axial layer \\
\hline
\end{tabular}




\subsubsection{Benchmark results}

The criticality value, i.e. the core multiplication factor (keff), calculated by MCNP5 was $656 \mathrm{pcm}$ larger than the reference value calculated by NESTLE. This deviation was caused by an underestimation of ${ }^{135} \mathrm{Xe}$ concentration in the MCNP5 model by a factor 1.46. However, the Xenon was already at instant equilibrium and the flux distribution was not affected by such correction. The keff difference using the corrected ${ }^{135} \mathrm{Xe}$ concentration was about $98 \mathrm{pcm}$.

The comparison of average channel fluxes shows that about $82 \%$ of the values calculated by MCNP5 differs by less than $5 \%$ from NESTLE results and only 1 channel has a deviation larger than $10 \%$ (the peripheral channel 434). The channels relative percentage differences are reported in Table 18 and the corresponding histogram in Figure 71.

Table 18 - Summary of relative differences of average channel flux

\begin{tabular}{|c|c|c||}
\hline \hline |Diff.| [\%] & Channel number & Channel fraction [\%] \\
\hline \hline$<0.1$ & 15 & 3.4 \\
\hline $0.1-1$ & 80 & 17.7 \\
\hline $1-5$ & 273 & 60.5 \\
\hline $5-10$ & 82 & 18.2 \\
\hline $10-15$ & 1 & 0.2 \\
\hline$>15$ & 0 & 0.0 \\
\hline
\end{tabular}

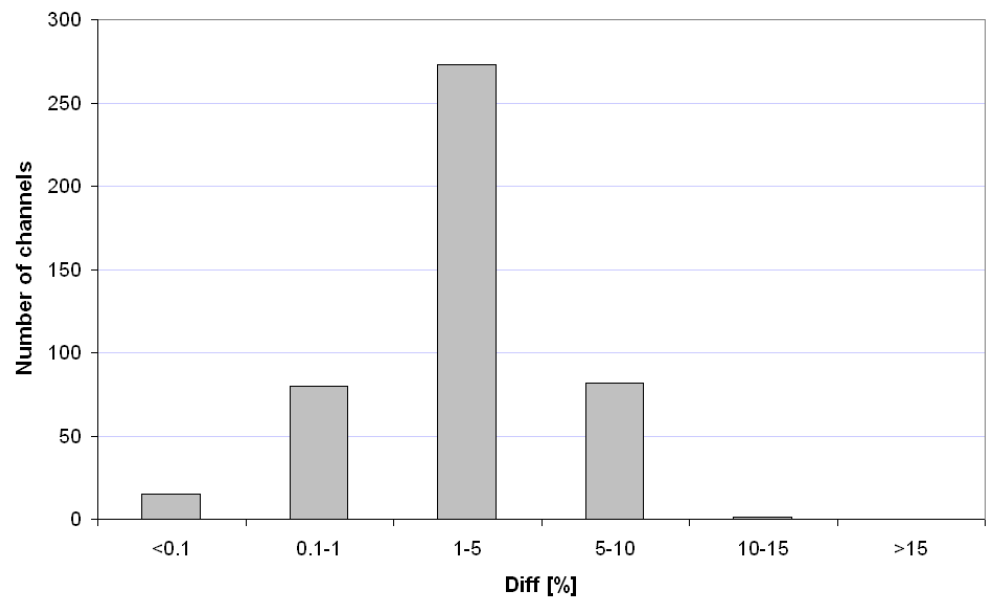

Figure 71 - Histogram of average channels relative flux percentage difference

Both codes predict the same maximum average flux channel. The average axial flux behavior calculated by NESTLE and MCNP5 is shown in Figure 72. MCNP5 predicts slightly lower flux in the upper part of the core and slightly higher flux in the lower part of the core, nevertheless the trend is very similar. 


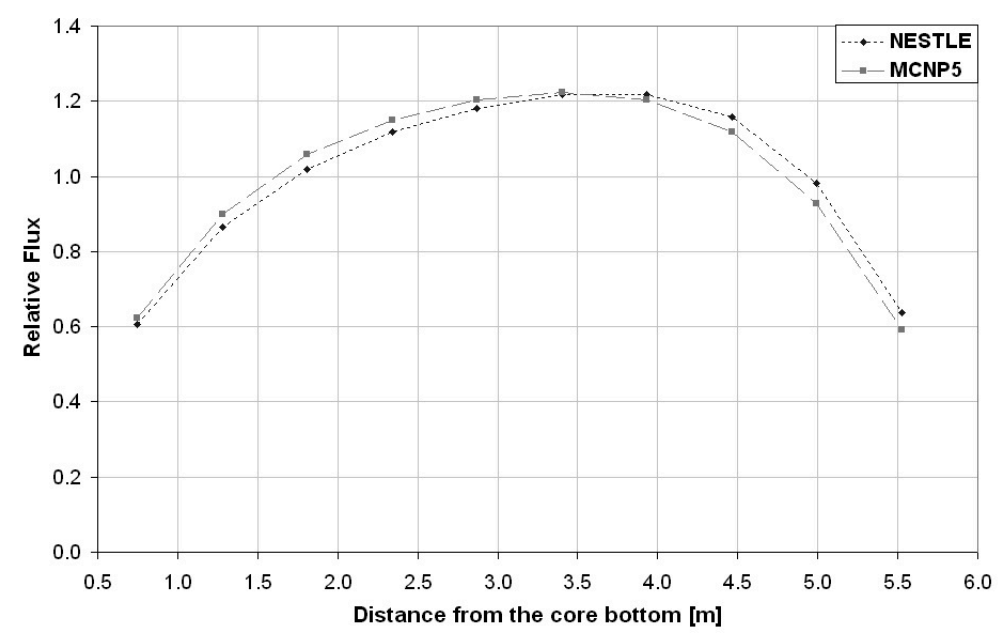

Figure 72 - Average flux axial behavior by NESTLE and MCNP5

The comparison of relative flux by nodes shows an acceptable agreement, about $85 \%$ of the node sectors differs by less than $5 \%$ from NESTLE results and less than $1 \%$ has a deviation between $10-15 \%$. The nodes relative percentage differences are reported in Table 19 and the corresponding histogram in Figure 73.

Table 19 - Summary of relative differences of node flux

\begin{tabular}{|c|c|c|}
\hline |Diff.| [\%] & Number of nodes & Node fraction [\%] \\
\hline \hline$<0.1$ & 44 & 1.3 \\
\hline $0.1-1$ & 621 & 16.9 \\
\hline $1-5$ & 3000 & 66.6 \\
\hline $5-10$ & 803 & 14.7 \\
\hline $10-15$ & 42 & 0.5 \\
\hline$>15$ & 0 & 0.0 \\
\hline
\end{tabular}

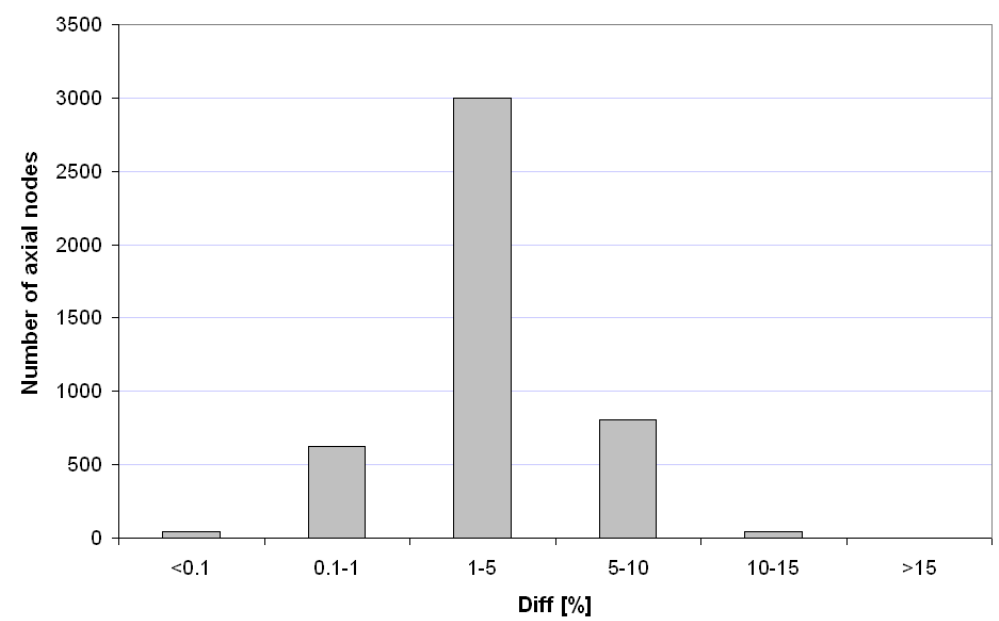

Figure 73 - Histogram of nodes relative flux percentage difference 
The average channel flux distributions calculated by NESTLE and MCNP5 are reported in Figure 74 and Figure 75, respectively. The distributions of relative and absolute differences (NESTLE - MCNP5) are shown in Figure 76 and Figure 77, respectively. The strongest deviations are located in the central part of the core and in some of the peripheral channels.

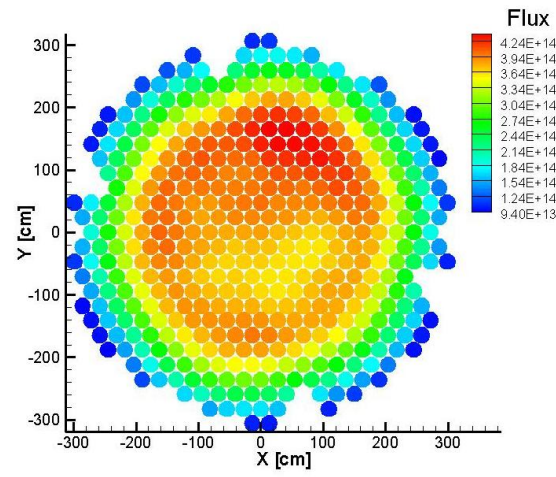

Figure 74 - NESTLE channel flux distribution

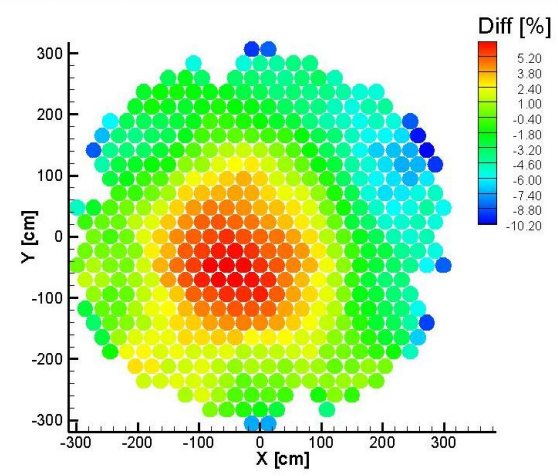

Figure 76 - Relative difference between MCNP5 and NESTLE channel distribution

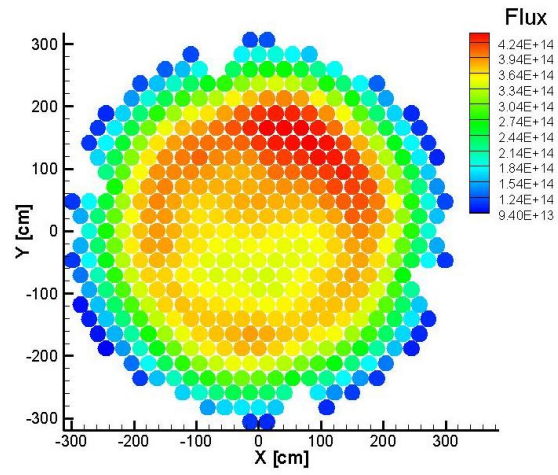

Figure $75-M C N P 5$ channel flux distribution

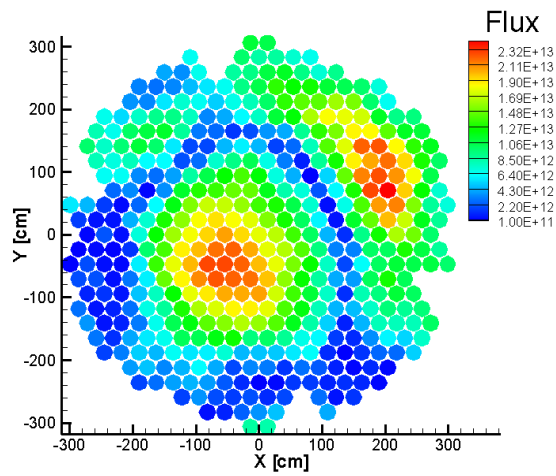

Figure 77 - Absolute difference between MCNP5 and NESTLE channel distribution

The distribution of relative and absolute differences (NESTLE - MCNP5) for each axial layer are reported in Figure 78 to Figure 97.

The agreement between the 2 codes was considered acceptable for the purpose of this research; however, deviations up to $10 \%$ were found for several nodes. In the context of ATUCHA-2 licensing this benchmark was further investigated. A better agreement was found using a MCNP5 model with both radial and axial node TH characterization [33]. 


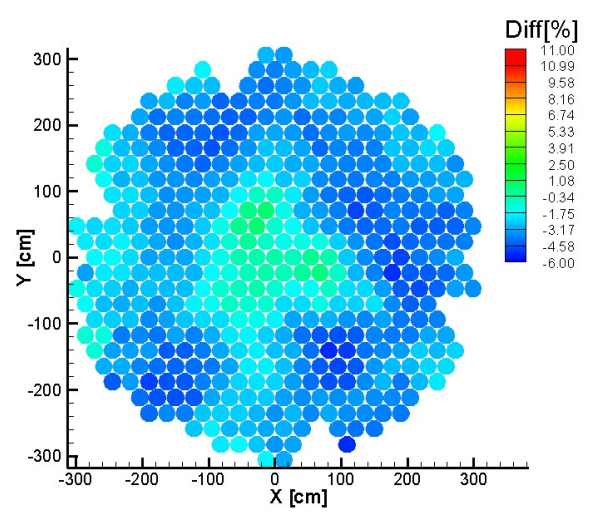

Figure 78 - Relative difference for level 1

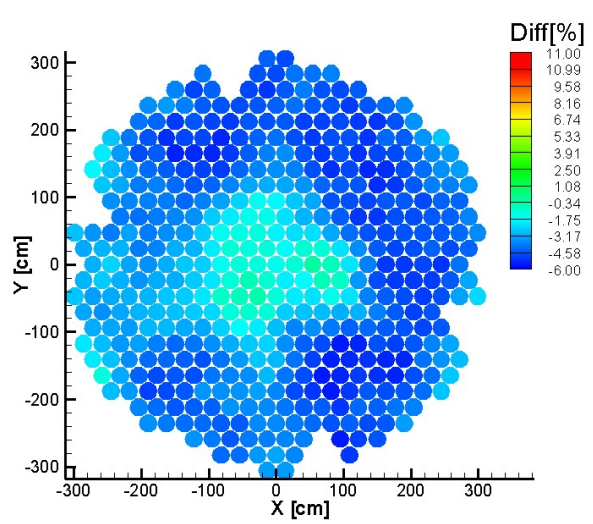

Figure 80 - Relative difference for level 2

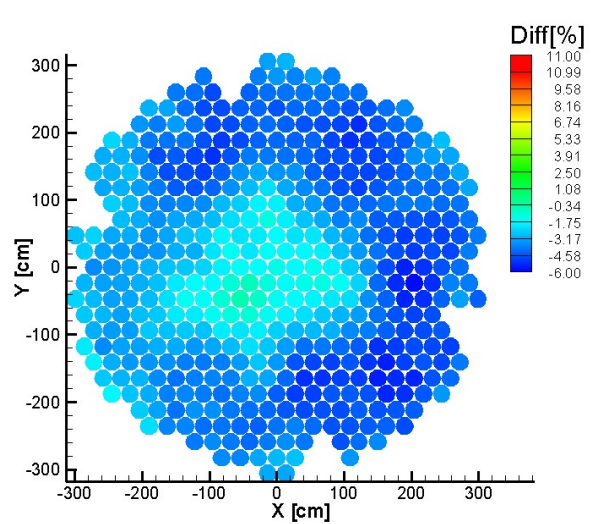

Figure 82 - Relative difference for level 3

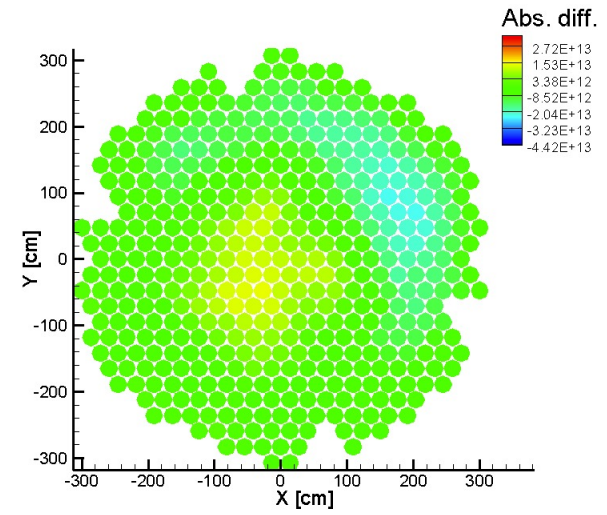

Figure 79 - Absolute difference for level 1

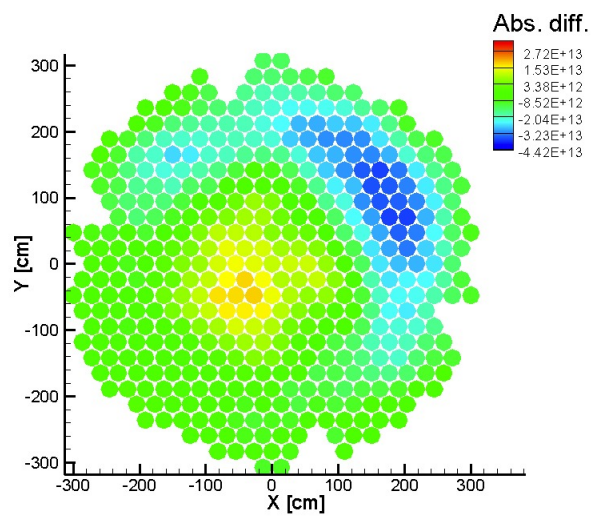

Figure 81 - Absolute difference for level 2

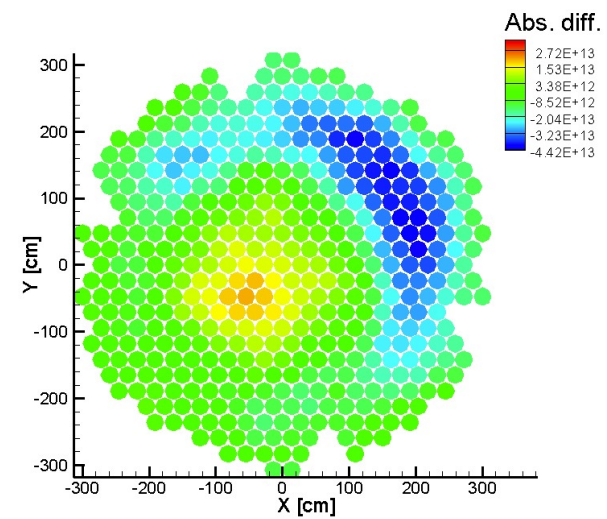

Figure 83-Absolute difference for level 3 


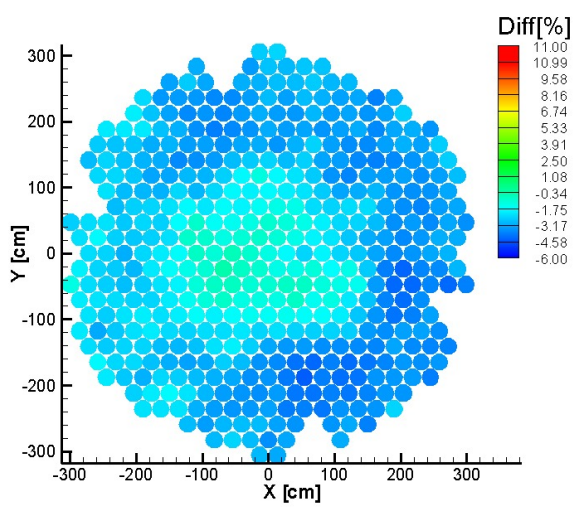

Figure 84 - Relative difference for level 4

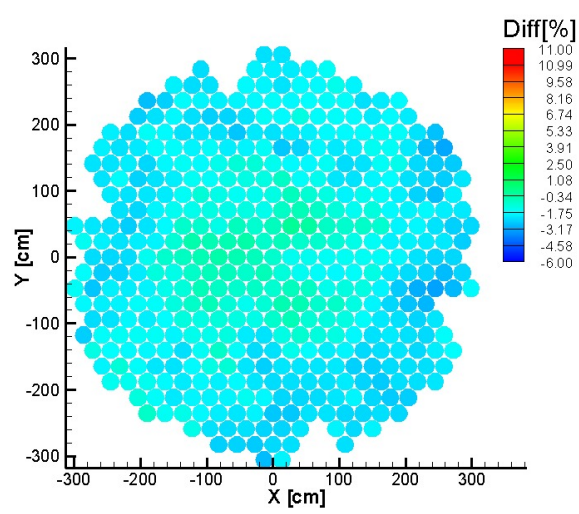

Figure 86 - Relative difference for level 5

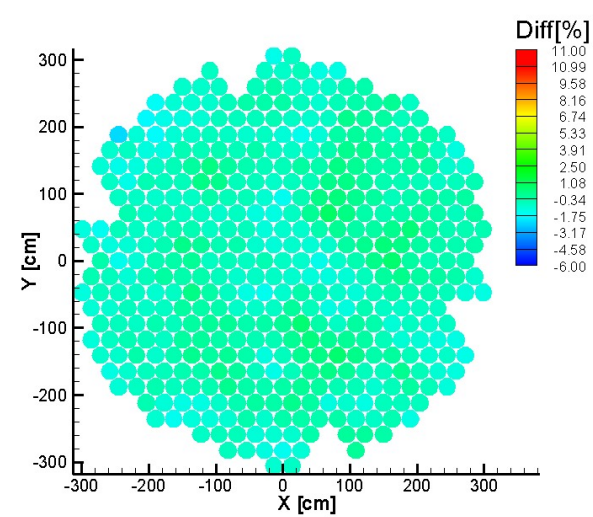

Figure 88 - Relative difference for level 6

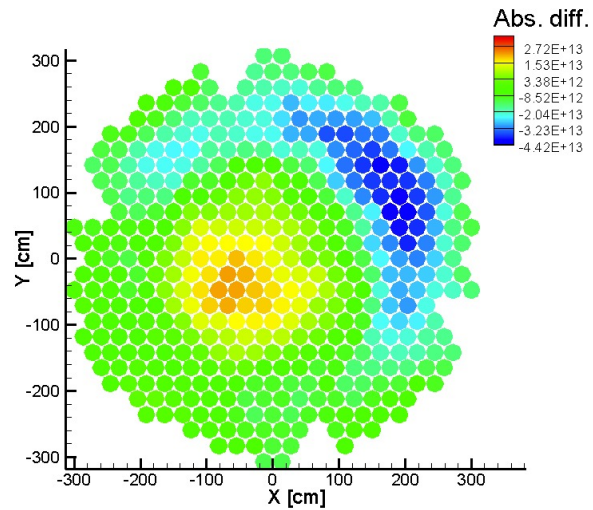

Figure 85 - Absolute difference for level 4

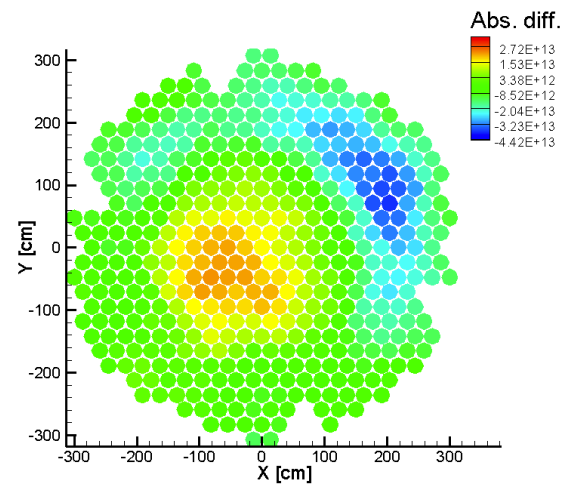

Figure 87 - Absolute difference for level 5

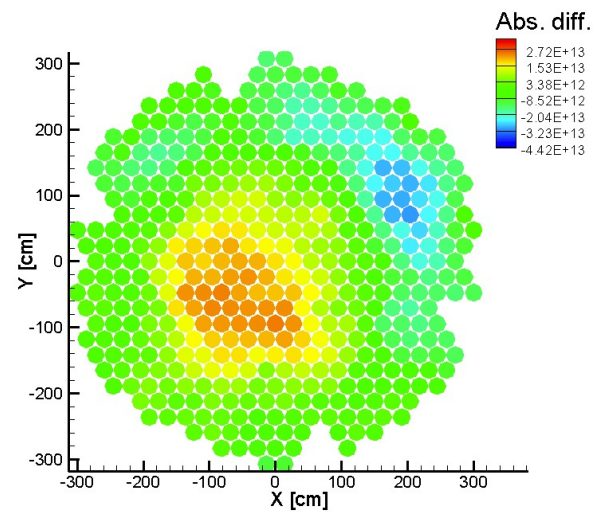

Figure 89 - Absolute difference for level 6 


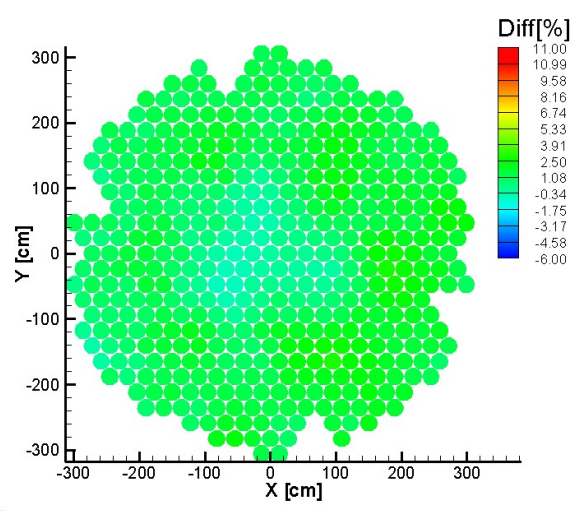

Figure 90 - Relative difference for level 7

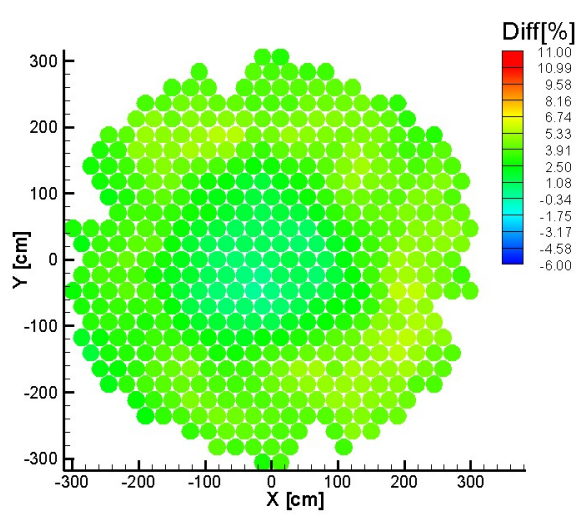

Figure 92 - Relative difference for level 8

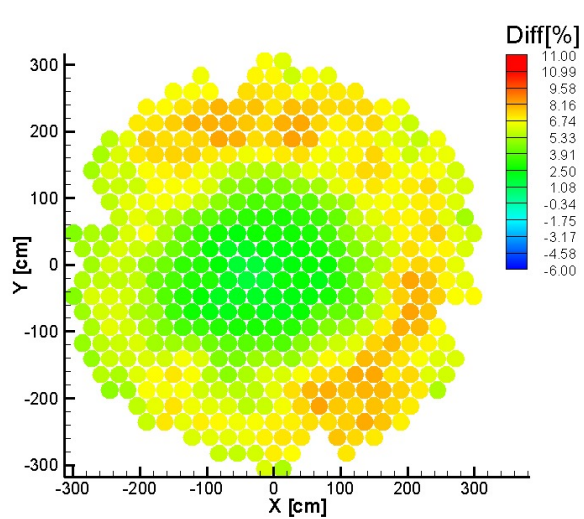

Figure 94 - Relative difference for level 9

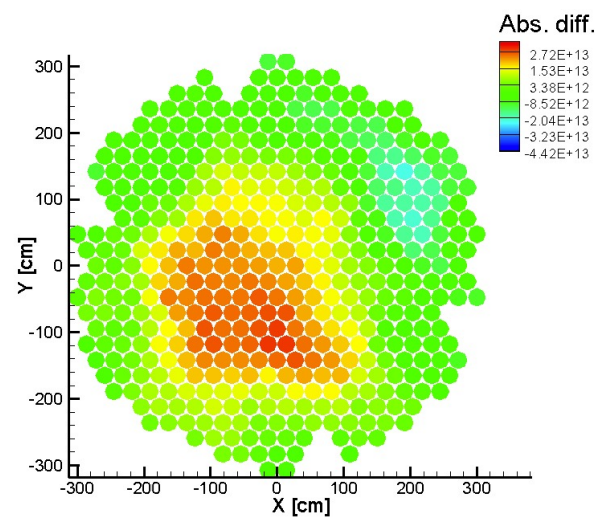

Figure 91 - Absolute difference for level 7

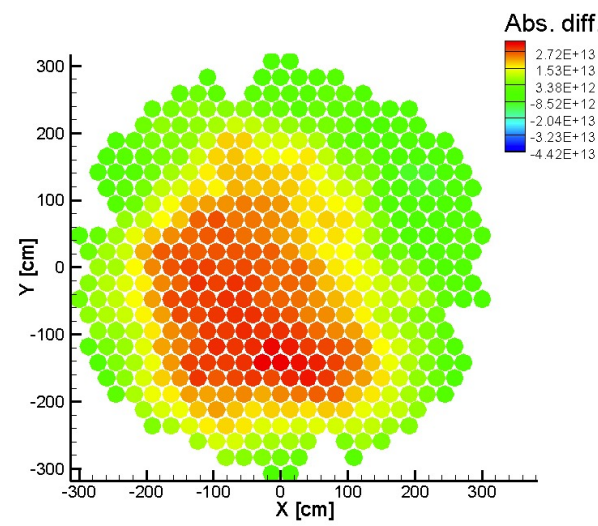

Figure 93 - Absolute difference for level 8

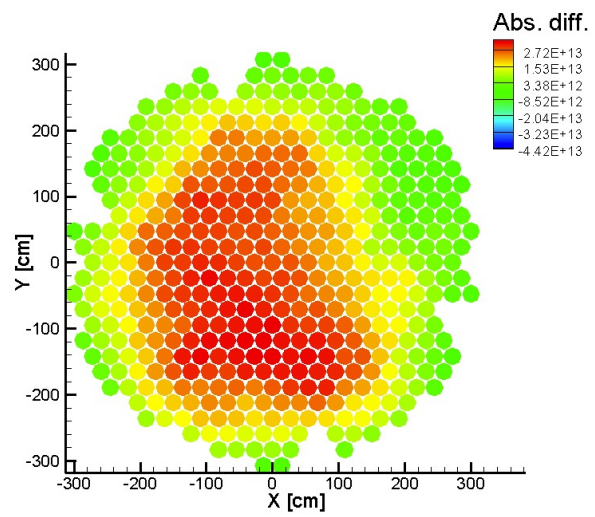

Figure 95 - Absolute difference for level 9 


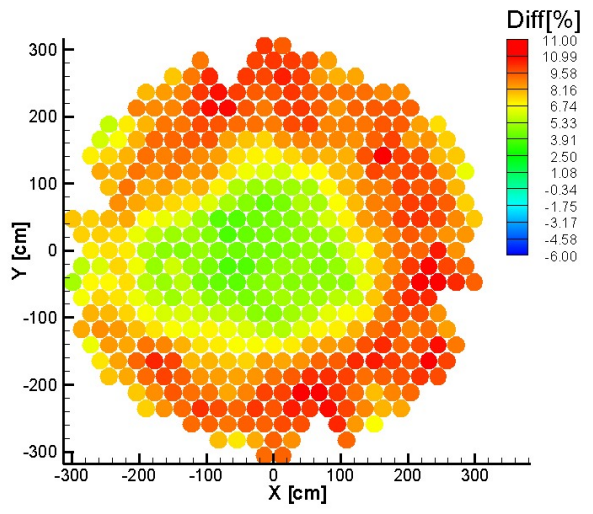

Figure 96 - Relative difference for level 10

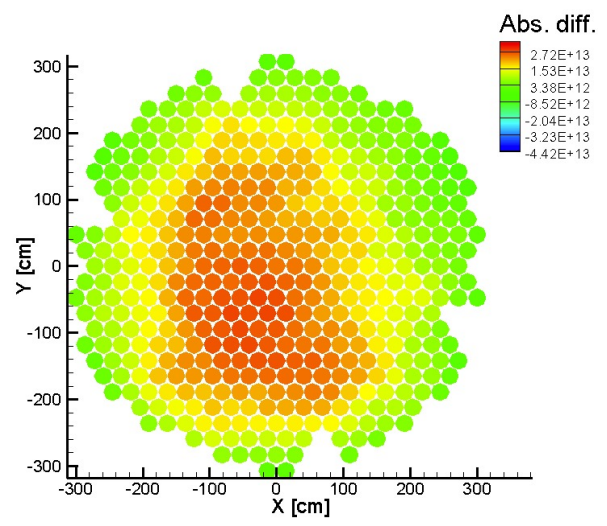

Figure 97 - Absolute difference for level 10 


\section{ANALYSIS OF BORON SELF-SHIELDING EFFECT}

The correct prediction of the reactivity inserted by Boron emergency injection system (JDJ) in the moderator of ATUCHA-2 is of great relevance for the correct safety evaluation of a Double Ended Guillotine Break Large Break LOCA (DEGBLB-LOCA). In such event, the insertion of positive reactivity caused by the void production in coolant channels is compensated by the negative reactivity inserted by the JDJ. The way in which the Boron propagates through the moderator was simulated by the CFD CFX ${ }^{\mathrm{TM}}$ code [24]. Results showed a complex spatial and temporal distribution. An example of the complex Boron configuration within the reactor core is showed in Figure 98.
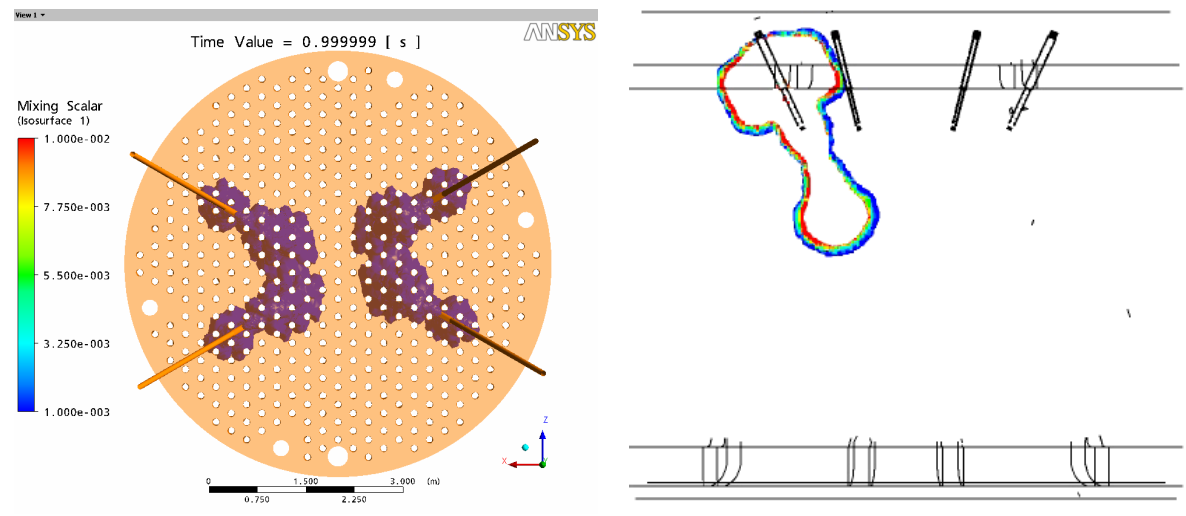

Figure 98 - Sketches of Boron cloud spatial distributions

The DEGB-LBLOCA scenario was simulated using the 3D neutron kinetics coupled thermal-hydraulics (3D NK-TH) RELAP5-3D@/NESTLE code. For calculating the reactivity inserted by the JDJ, the CFX calculated time-dependent spatial distribution of Boron concentration in the moderator tank were implemented into RELAP5-3DC thermal-hydraulic model [27]. The so called "Boron self-shielding effect" is indicating the over-estimation of the inserted negative reactivity due by the dilution of a highly concentrated Boron solution when modeling its spatial distribution using TH nodes of large dimensions (order of liters for the ATUCHA-2 case). The MCNP5 code was used to investigate the Boron shielding effect at cell, macro-cell and core level for ATUCHA-2 using different moderator mesh models. In the latter case the computer program CFD2MCNP (see Chapter 4) implements the data about Boron cloud (i.e. spatial and Boron mass distribution) to the MCNP5 input deck. The cell and macro-cells models helps to understand the basic proprieties of the Boron self-shielding effects. Then, the core models are used for quantitative analyses to investigate the Boron self-shielding effect and predict the JDJ inserted reactivity trend in order to benchmark the RELAP5-3D@/NESTLE results. Those results were used in the Chapter 15 of the final safety analysis report of ATUCHA-2 NPP. Finally, a comparison of results to existing literature is reported in APPENDIX F. 


\subsection{Boron self-shielding effect at cell and macro-cell level}

In this paragraph the Boron self-shielding effect is analyzed using the cell and macro-cell models introduced in Par. 5.5.3.1 and Par. 5.5.3.2. Those models represent a fixed amount of Boron mass using different moderator representations. Then, the multiplication factor (kinf) versus the Boron concentration is calculated. The amount of Boron used in each set of simulation is reported in Table 20. The Boron concentration used in the homogeneous cases (C1 and M1 models) is reported together with the equivalent Boron mass. This boron mass is then used for deriving the concentrations of the Boron distribution in the heterogeneous cases. The mass values were calculated for a NK node volume.

For these calculations MCNP5 KCODE option [17] was used setting 50000 neutron particles per cycle and 1000 active cycles of simulation, for a total of $5 \times 10^{7}$ neutron histories simulated. A preliminary calculation was used to generate a suitable guess source distribution. All the estimated standard deviations resulting from MCNP5 calculations reported hereafter should be intended at the $68 \%$ of the confidence level. For cell calculation periodic reflective boundary condition was used [17]. The inserted reactivity and the relative errors were calculated according to the formula reported in APPENDIX G.

Table 20 - Mass of the Boron in the cases simulated

\begin{tabular}{|c||c|c||}
\hline $\begin{array}{c}\text { Case } \\
\text { Id }\end{array}$ & $\begin{array}{c}\text { Boron concentration in the } \\
\text { homogeneous case [ppm] }\end{array}$ & $\begin{array}{c}\text { Boron Mass } \\
\text { [gr] }\end{array}$ \\
\hline \hline 1 & 0 & 0.00 \\
\hline 2 & 10 & 0.34 \\
\hline 3 & 100 & 3.39 \\
\hline 4 & 500 & 16.93 \\
\hline 5 & 1000 & 33.84 \\
\hline
\end{tabular}

\subsubsection{Cell results}

The kinf trends in the cell model in the cases simulated are reported in Table 21. Then, the inserted negative reactivity introduced by the boron is given in Table 22. The behavior of reactivity versus boron mass for the different cases of spatial distributions is reported in Figure 99.

Table 21 - Cell model, kinf results

\begin{tabular}{|c|c|c|c|c|c|c|}
\hline Case Id & $\begin{array}{c}\text { C1 model } \\
\text { (homogeneous) }\end{array}$ & $\begin{array}{c}\boldsymbol{\sigma} \\
\text { [pcm] }\end{array}$ & $\begin{array}{c}\text { C2 } \\
\text { model }\end{array}$ & $\begin{array}{c}\boldsymbol{\sigma} \\
\text { [pcm] }\end{array}$ & $\begin{array}{c}\text { C3 } \\
\text { model }\end{array}$ & $\begin{array}{c}\boldsymbol{\sigma} \\
\text { [pcm] }\end{array}$ \\
\hline \hline 1 & 1.14059 & 7 & 1.14059 & 6 & 1.14059 & 6 \\
\hline 2 & 1.06463 & 7 & 1.04927 & 7 & 1.04950 & 7 \\
\hline 3 & 1.02408 & 7 & 1.00366 & 7 & 1.00541 & 7 \\
\hline 4 & 0.68657 & 8 & 0.68524 & 8 & 0.71584 & 8 \\
\hline 5 & 0.32330 & 6 & 0.41569 & 7 & 0.48373 & 7 \\
\hline
\end{tabular}


Table 22 - Cell model, reactivity inserted by different Boron distributions

\begin{tabular}{|c||c|c|c|c|c|c||}
\hline Case Id & $\begin{array}{c}\text { C1 model } \\
{[\$]}\end{array}$ & $\begin{array}{c}\text { Err } \\
{[\%]}\end{array}$ & $\begin{array}{c}\text { C2 model } \\
{[\mathbf{\$}]}\end{array}$ & $\begin{array}{c}\text { Err } \\
{[\%]}\end{array}$ & $\begin{array}{c}\text { C3 model } \\
{[\mathbf{\$}]}\end{array}$ & $\begin{array}{c}\text { Err } \\
{[\%]}\end{array}$ \\
\hline \hline 1 & -9.13 & 0.01 & -11.13 & 0.01 & -11.10 & 0.08 \\
\hline 2 & -14.56 & 0.01 & -17.46 & 0.01 & -17.20 & 0.09 \\
\hline 3 & -84.63 & 0.02 & -85.05 & 0.03 & -75.94 & 0.16 \\
\hline 4 & -323.5 & 0.10 & -223.19 & 0.06 & -173.79 & 0.30 \\
\hline 5 & -513.95 & 0.18 & -295.40 & 0.07 & -219.27 & 0.40 \\
\hline
\end{tabular}

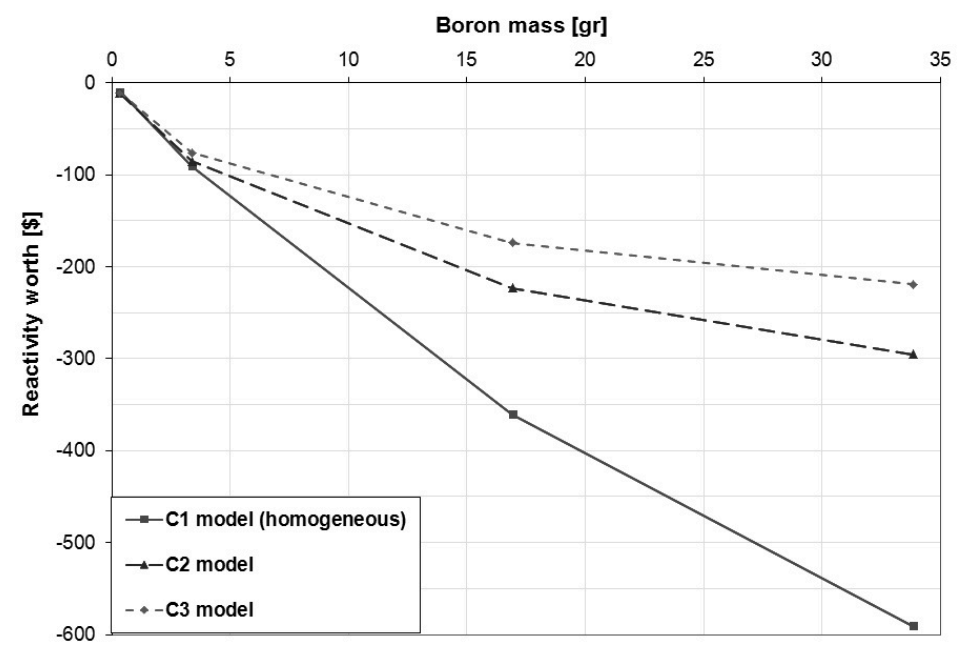

Figure 99 - Cell model, reactivity versus Boron mass

\subsubsection{Macro-cell results}

The kinf trends in the cell model in the cases simulated are reported in Table 23. Then, the relative negative reactivity introduced by the boron is given in Table 24 . The behavior of reactivity versus boron mass for the different cases of spatial distributions is reported in Figure 100.

Table 23 - Macro-cell model, kinf results

\begin{tabular}{|c||c|c|c|c||}
\hline CASE ID & $\begin{array}{c}\mathbf{k}_{\text {inf }} \\
\text { Homogeneous case }\end{array}$ & $\begin{array}{c}\boldsymbol{\sigma} \\
\text { [pcm] }\end{array}$ & $\begin{array}{c}\mathbf{k}_{\text {inf }} \\
\mathbf{1 / 6} \text { case }\end{array}$ & $\begin{array}{c}\boldsymbol{\sigma} \\
\text { [pcm] }\end{array}$ \\
\hline \hline 1 & 1.13851 & 6 & 1.13851 & 6 \\
\hline 2 & 1.13437 & 6 & 1.13359 & 6 \\
\hline 3 & 1.10591 & 6 & 1.10917 & 6 \\
\hline 4 & 1.05814 & 7 & 1.08537 & 7 \\
\hline 5 & 1.04010 & 7 & 1.07807 & 7 \\
\hline
\end{tabular}


Table 24 - Macro-cell model, reactivity inserted by different Boron distributions

\begin{tabular}{||c|c|c|c|c||}
\hline $\begin{array}{c}\text { CASE } \\
\text { ID }\end{array}$ & $\begin{array}{c}\text { M1 model } \\
\text { (Homogeneous) [\$] }\end{array}$ & Err & $\begin{array}{c}\text { M2 model } \\
\text { [\$] }\end{array}$ & Err \\
\hline 1 & -0.46 & 0.06 & -0.55 & 0.06 \\
\hline 2 & -0.74 & 0.06 & -0.87 & 0.06 \\
\hline 3 & -3.77 & 0.07 & -3.39 & 0.07 \\
\hline 4 & -9.73 & 0.08 & -6.27 & 0.07 \\
\hline 5 & -12.13 & 0.08 & -7.18 & 0.07 \\
\hline
\end{tabular}

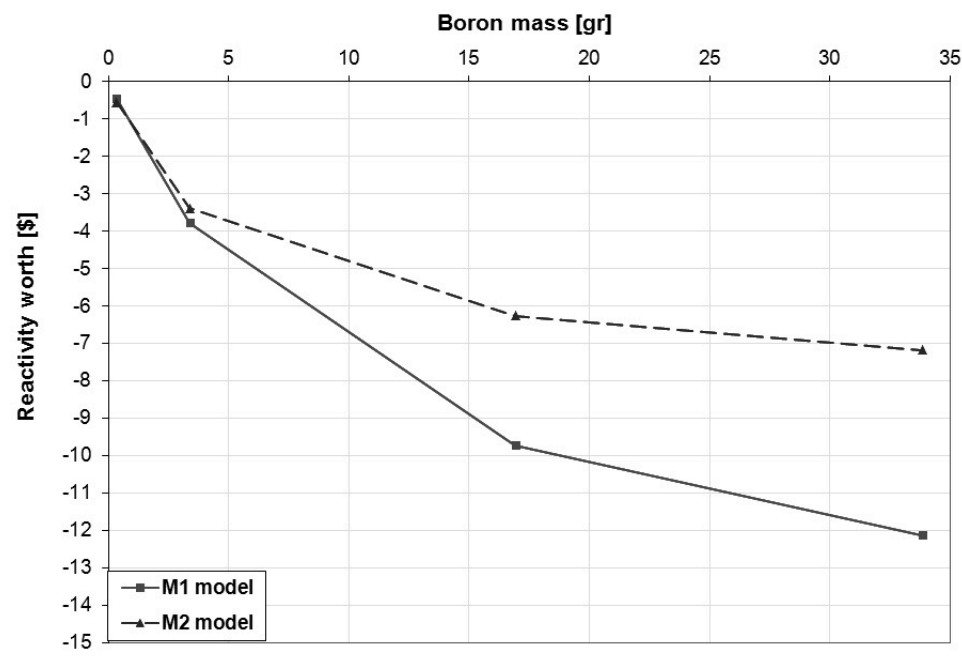

Figure 100 - Macro-cell model, reactivity versus boron mass

\subsubsection{Comparison of cell and macro-cell results}

Results reported in the previous paragraphs demonstrate that the inserted negative reactivity for both models (cell and macro-cell models) is over-estimated when a significant mass of boron (>3 grams) is spread over larger nodes.

This effect is particularly evident when considering these Boron masses diluted over larger volumes. In the investigated cases, an over-estimation of the inserted reactivity around $30-40 \%$ was found in the $C 1$ and $M 1$ models if Boron masses are greater than 3 grams. In those models the Boron is diluted over a hexagonal prism with a volume 6-12 times bigger than the heterogeneous cases ( $C 2, \mathrm{C} 3$ and M2).

The explanation of such effect follows from the neutron physics, i.e. the probability for a neutron to cross the borated region in the heterogeneous cases is smaller compared to the probability for the homogeneous case. Although the Boron concentration is higher in the heterogeneous cases, the net effect is an increase of the probability of the neutron to be captured by the Boron nuclei in the homogeneous case (hence, an increase of negative reactivity). Results showed that the so-called "boron self-shielding" effect (over-estimation of boron reactivity) is relevant when considering sub-volumes of fuel cells with boron masses greater than 3 grams. Then, the study shows also that the sub-cell volumes having a boron concentration of around $600 \mathrm{ppm}$ can be diluted over the whole fuel cell moderator volume without causing any sensible effect over the estimated reactivity. 


\subsection{Core analysis}

In this paragraph the core models introduced in Par. 5.5.3.3 are used for quantitative analyses to investigate the reactivity inserted by JDJ and the Boron self-shielding effect at core level. In those models the Boron cloud configuration has a different level detail of spatial representation. The MCNP5 simulation parameters are the same used in the benchmark reported in Par 5.5.5.

\subsubsection{Analysis of Boron self-shielding effect}

Several Boron cloud configuration corresponding to selected time of interest in the LB-LOCA transient are analyzed. For each Boron cloud configuration is investigated the criticality eigenvalue, then the effects on power at axial node level. The routine HEXMESH (see APPENDIX B, section B.1.) was used combined to the MCNP5 code to collect all the results.

\subsubsection{Selected Boron cloud configurations}

The Boron self-shielding effect was investigated at core level for 3 different Boron cloud configurations i.e. at 3 different instants of injection by the JDJ system. The volume of the borated water increases from the first instant in which the Boron is located around the injection lance to a configuration in which the Boron cloud is more diffused within the core. The Boron cloud configurations correspond to selected time of interest for the DEGB-LBLOCA scenario. Those times are referred from the first drop of borated water exit from JDJ system and are reported in Table 25. The sketches of such Boron cloud configuration are reported from Figure 101 to Figure 103 (only the top part of the core is shown).

Table 25 - Boron configurations for time of interest in LB-LOCA

\begin{tabular}{|c|c|}
\hline $\begin{array}{c}\text { Boron } \\
\text { configurations }\end{array}$ & $\begin{array}{c}\text { Time } \Delta \mathbf{t} \text { from first drop of } \\
\text { borated water exit from JDJ [s] }\end{array}$ \\
\hline \hline 1 & $+0.025 \mathrm{~s}$ \\
\hline 2 & $+0.325 \mathrm{~s}$ \\
\hline 3 & $+0.825 \mathrm{~s}$ \\
\hline
\end{tabular}




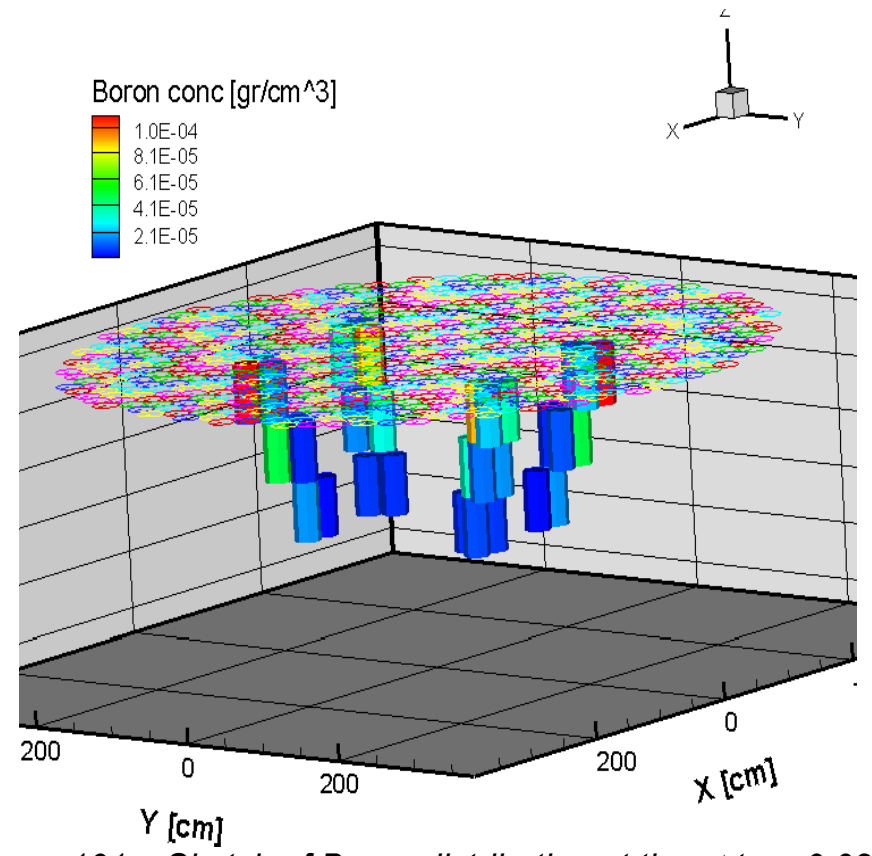

Figure 101 - Sketch of Boron distribution at time $\Delta t=+0.025 \mathrm{~s}$

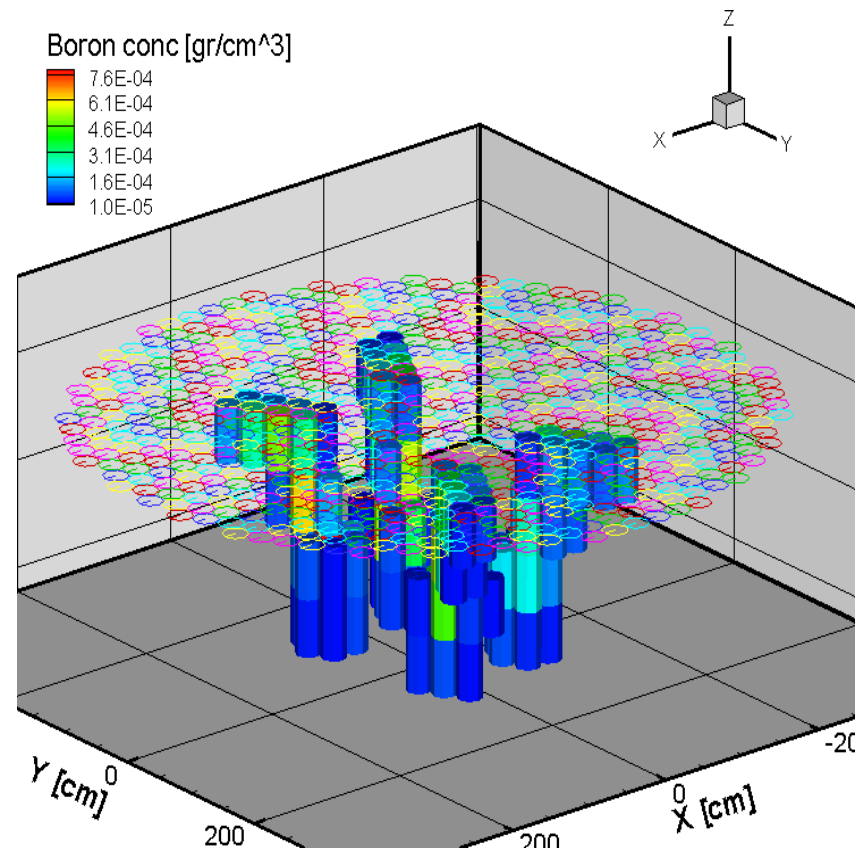

Figure $102-$ Sketch of Boron distribution at time $\Delta t=+0.325 \mathrm{~s}$ 


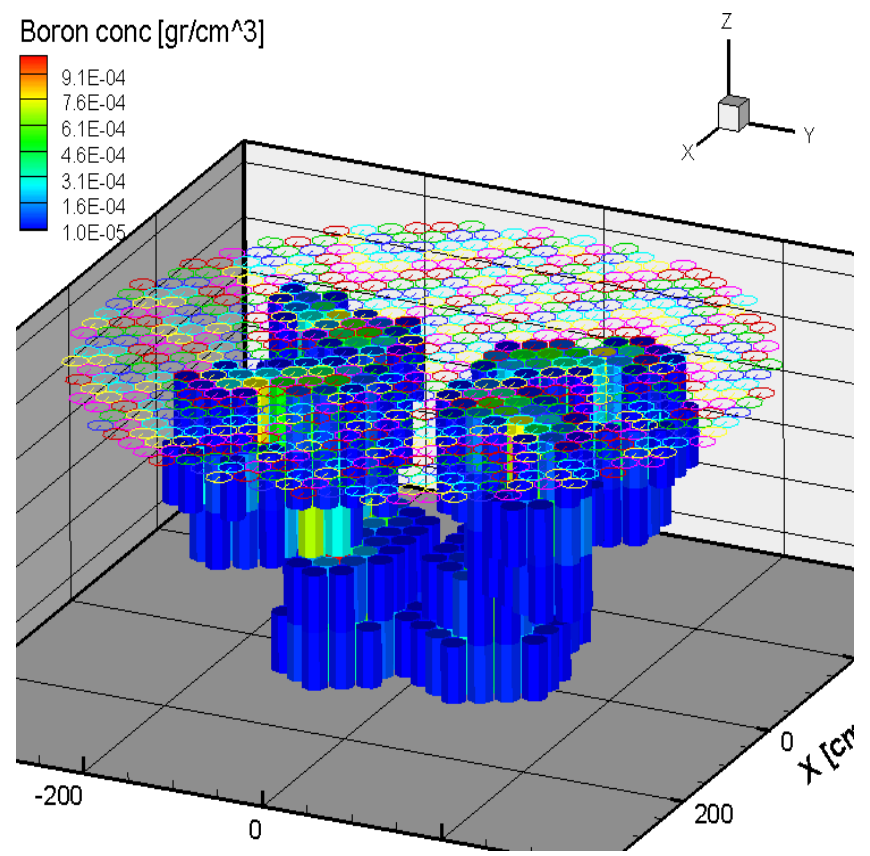

Figure 103 - Sketch of Boron distribution at time $\Delta t=+0.825 \mathrm{~s}$

\subsubsection{Criticality results}

The normalized static reactivity inserted by the Boron cloud for the time steps simulated is reported to Table 26 . The reactivity was calculated using the formulas reported to APPENDIX G. A histogram with the normalized reactivity inserted in each case is reported in Figure 104. Then, the reactivity inserted in the hexagonal and RELAP-like cases was compared to the reactivity inserted in the triangular mesh case (the most detailed representation available). The absolute difference in reactivity is reported to Figure 105.

In all cases simulated the inserted reactivity was always negative. A general observation is that for each time step a coarser moderator mesh corresponds to a stronger inserted reactivity. The comparison of triangular and hexagonal core models shows that the shielding effect has a small effects for all the time step simulated with absolute difference between $0.02 \$$ and $0.04 \$$. A different trend was found comparing the triangular model to the RELAP-like model. In this case the shielding effects increase as the borated water spread inside the moderator. At time $t=+0.025 \mathrm{~s}$ the effect is small with a difference of $\sim 0.04 \$$. Then a difference increase at time $t=+0.325 \mathrm{~s}$ with a value of $\sim 0.1 \$$. Finally, at time $t=+0.825 \mathrm{~s}$ a $0.26 \$$ of difference was found.

Table 26 - Normalized reactivity inserted by Boron cloud at different time steps

\begin{tabular}{|c||c|c|c|}
\hline $\begin{array}{c}\Delta \mathbf{T} \\
\mathbf{s}]\end{array}$ & Triangular model & Hexagonal model & RELAP-like model \\
\hline \hline+0.025 & -0.04 & -0.05 & -0.06 \\
\hline+0.325 & -0.52 & -0.54 & -0.57 \\
\hline+0.825 & -0.88 & -0.90 & -1.00 \\
\hline
\end{tabular}




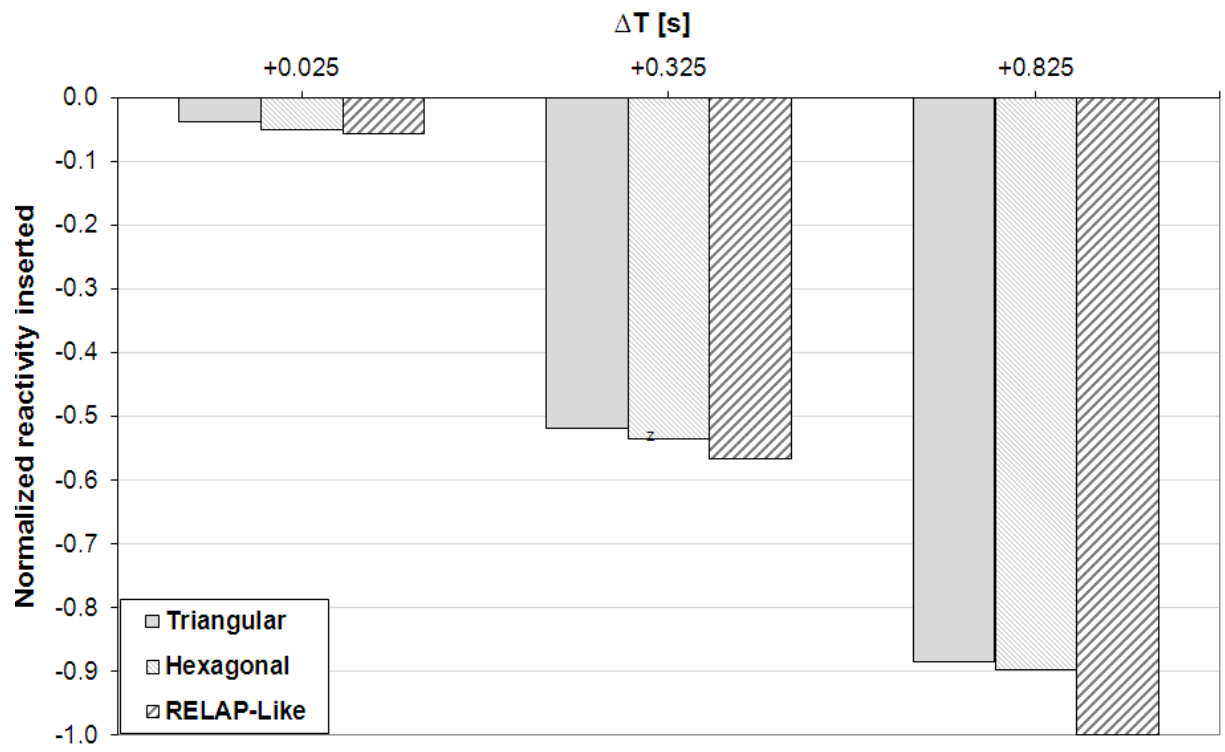

Figure 104 - Reactivity inserted at different time steps and mesh resolutions

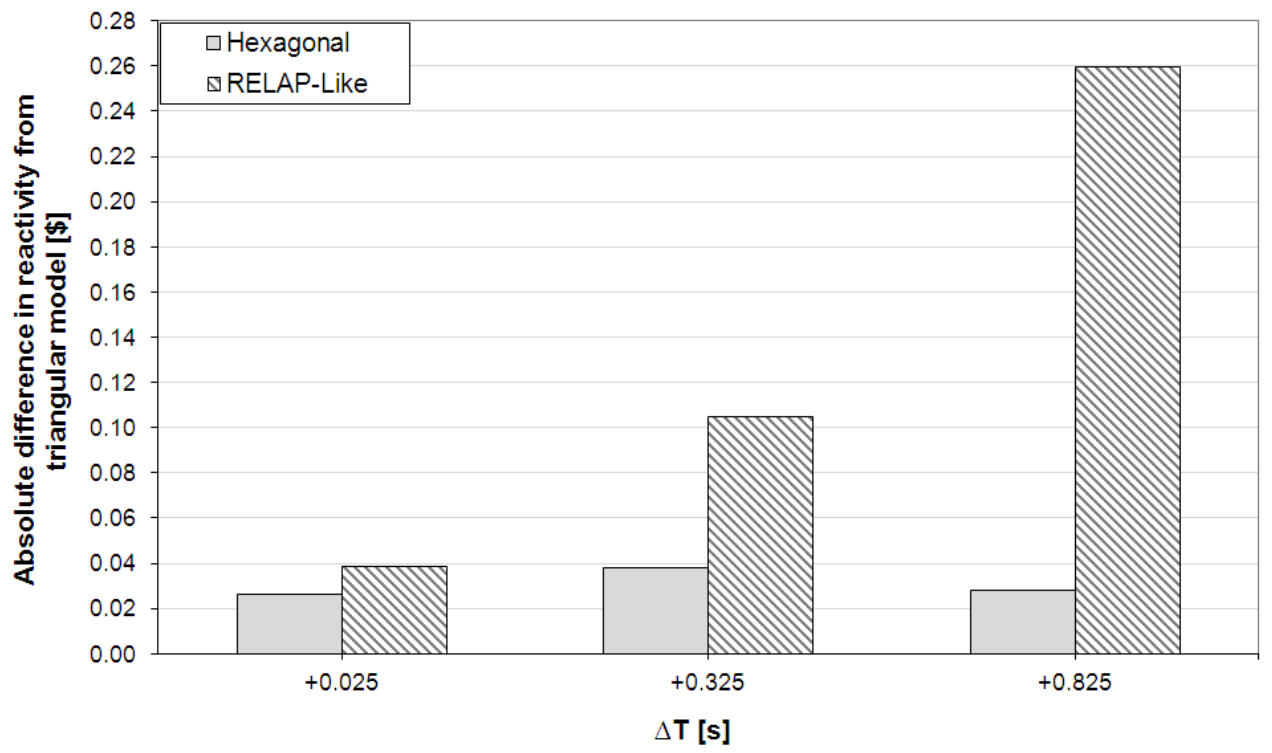

Figure 105 - Reactivity comparison 


\subsubsection{Evaluation of Boron self-shielding for averaged axial flux}

The average axial flux behavior was calculated using the Triangular and RELAPlike models. Their behavior together with the Boron cloud depth inside the core is reported for the 3 Boron configurations in the following figures. In each case the effect of the Boron cloud is stronger in the RELAP-like model and such effect increases as the Boron spread into the moderator tank. The relative difference between the 2 models is stronger in the upper layer (the $10^{\text {th }}$ ) and increase from $8.7 \%$ at time $\Delta \mathrm{t}=+0.025 \mathrm{~s}$ to $39 \%$ at time $\Delta \mathrm{t}=+0.825 \mathrm{~s}$.

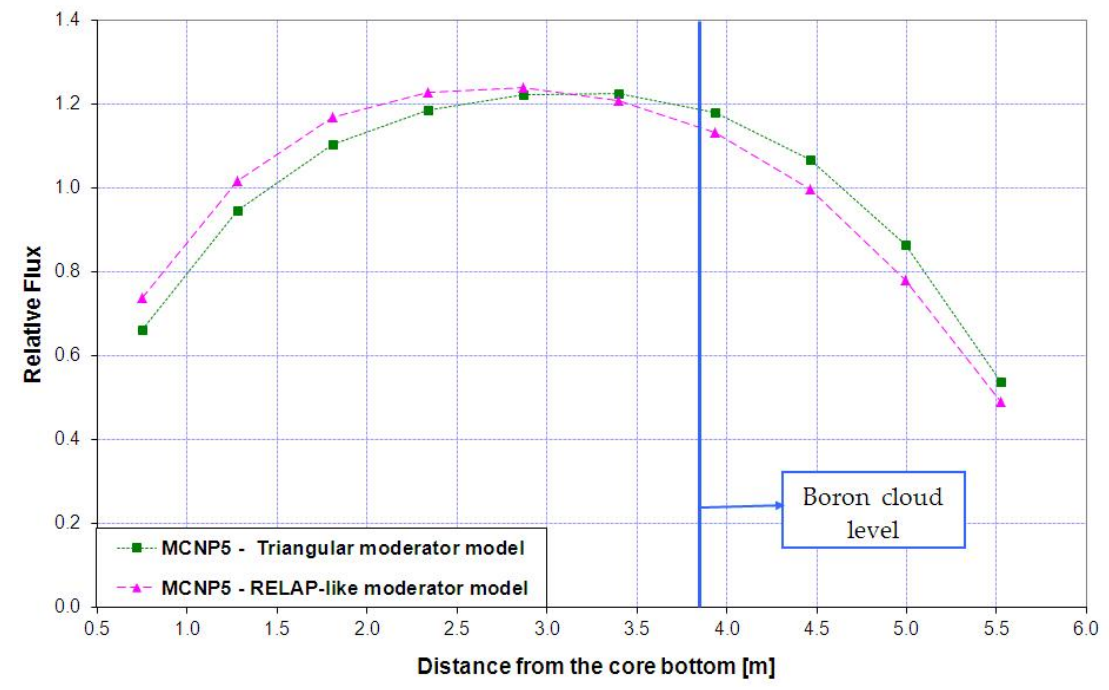

Figure 106 - Average flux axial behavior at time $\Delta t=+0.025 \mathrm{~s}$

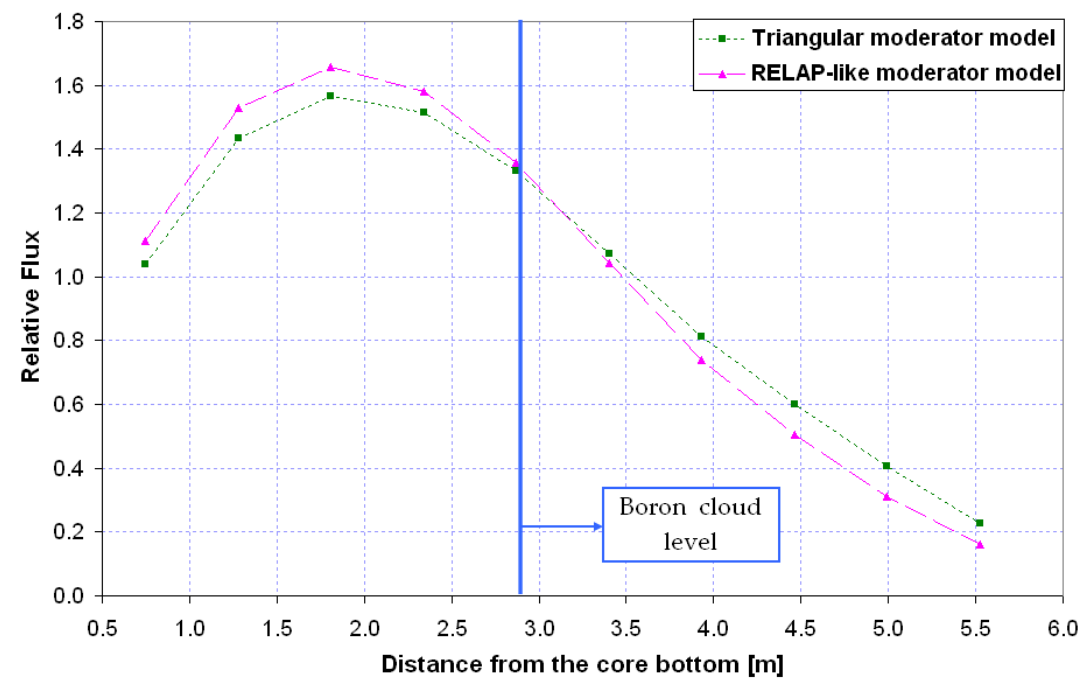

Figure 107 - Average flux axial behavior at time $\Delta t=+0.325 \mathrm{~s}$ 


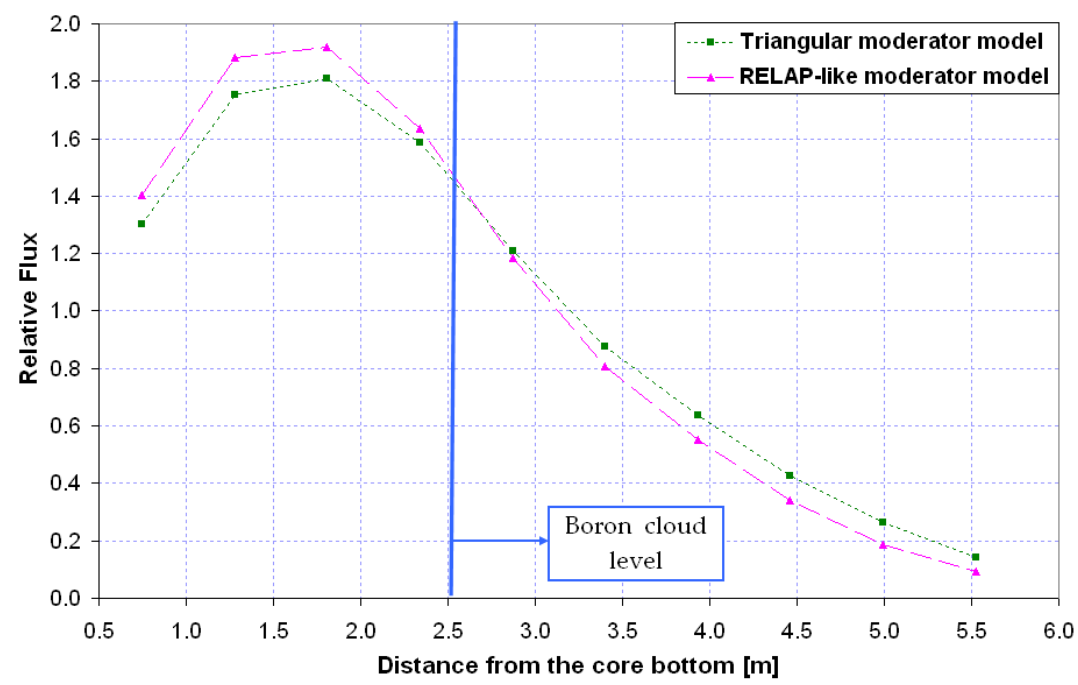

Figure 108 - Average flux axial behavior at time $\Delta t=+0.825 \mathrm{~s}$

\subsubsection{Evaluation of Boron self-shielding for NK nodes}

The effect of Boron self-shielding for each of the 4510 NK node in which ATUCHA2 is represented is reported in this paragraph. The HEXMESH subroutine (see APPENDIX B) was used to calculate the neutron flux in these nodes. Then, the relative power differences were computed using the triangular and RELAP-like moderator models, i.e. the most detailed and the coarsest, respectively. As expected, the deviation increase as the Boron cloud spreads within the moderator tank. Results showed that Boron self-shielding effect is strong on NK nodes around the Boron injection lance with deviation within $30 \%$ at time $\Delta t=+0.025 \mathrm{~s}$ and up to $60 \%$ and beyond in some nodes for $\Delta \mathrm{t}>+0.325 \mathrm{~s}$.

6.2.1.4.1. Results for a Boron configuration at time $\Delta t=+0.025 \mathrm{~s}$

The nodes percentage differences are reported in Table 27. Then, the distribution of relative differences (NESTLE - MCNP5) for each axial layer is reported from Figure 109 to Figure 118.

Table 27 - Relative differences of node flux at time $\Delta t=+0.025$

\begin{tabular}{|c||c|c|}
\hline |Diff.|[\%] & Number of nodes & Node fraction [\%] \\
\hline$<1$ & 353 & 7.8 \\
\hline $1-5$ & 1546 & 34.3 \\
\hline $5-10$ & 1648 & 36.5 \\
\hline $10-15$ & 780 & 17.3 \\
\hline $15-30$ & 183 & 4.1 \\
\hline$>30$ & 0 & 0.0 \\
\hline
\end{tabular}




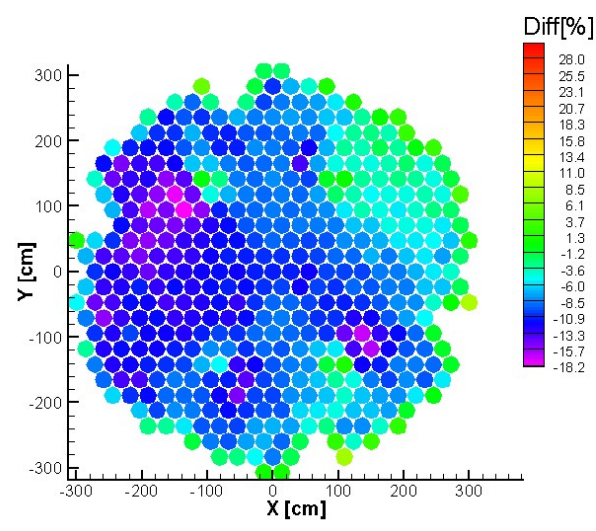

Figure 109 - Relative difference for level 10

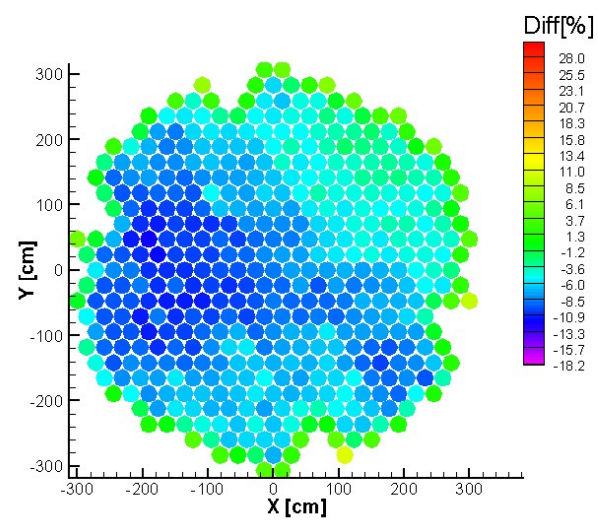

Figure 111 - Relative difference for level 8

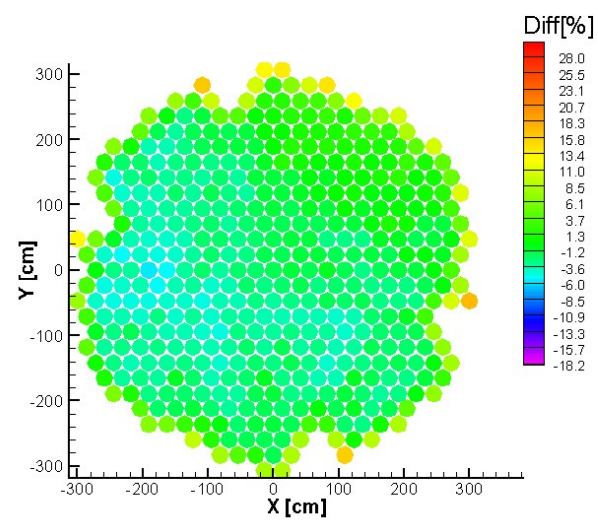

Figure 113 - Relative difference for level 6

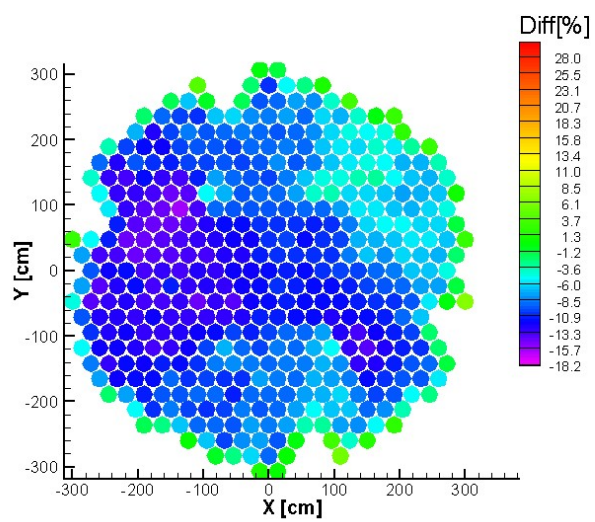

Figure 110 - Relative difference for level 9

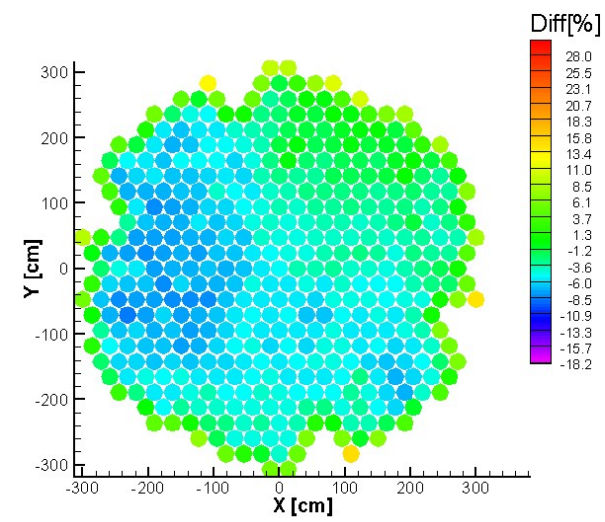

Figure 112 - Relative difference for level 7

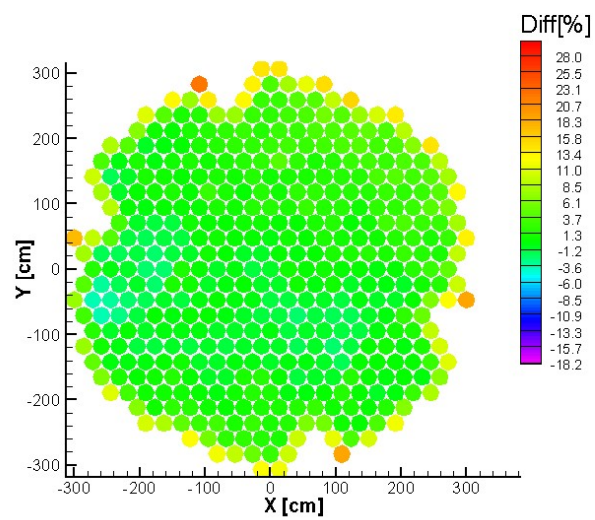

Figure 114 - Relative difference for level 5 


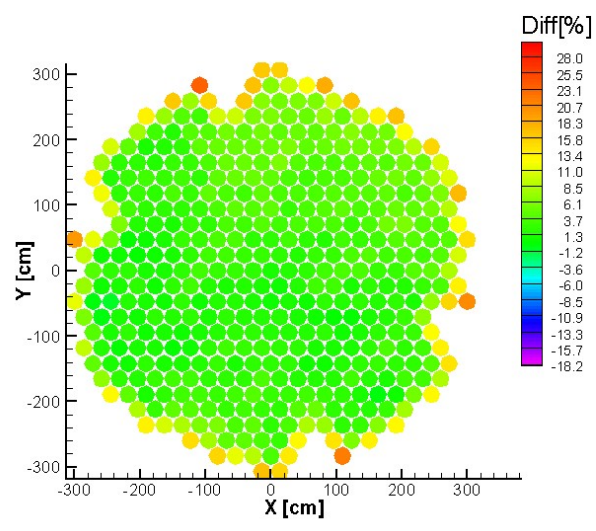

Figure 115 - Relative difference for level 4

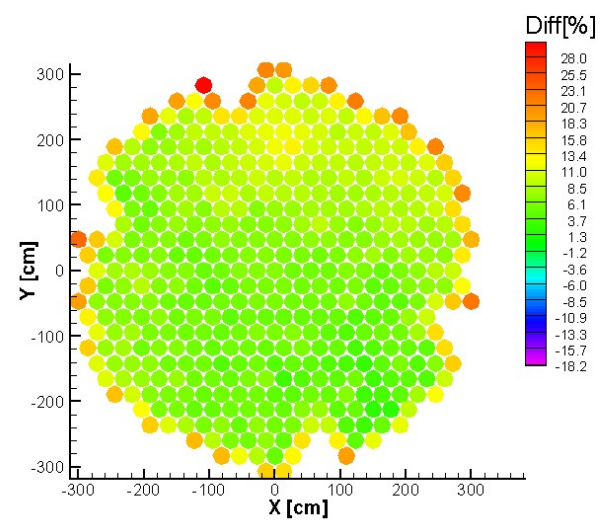

Figure 117 - Relative difference for level 2

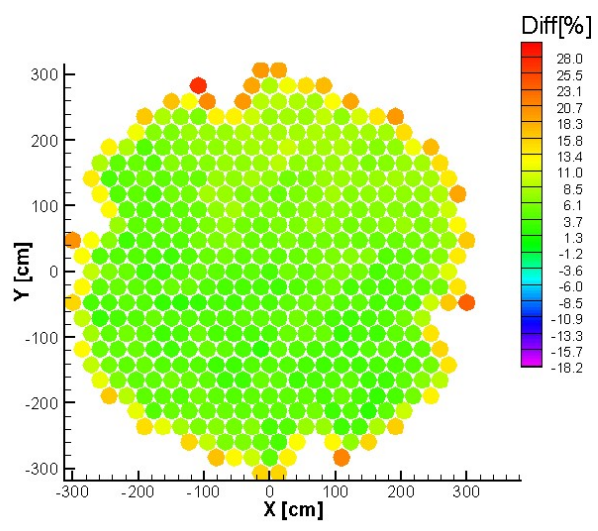

Figure 116 - Relative difference for level 3

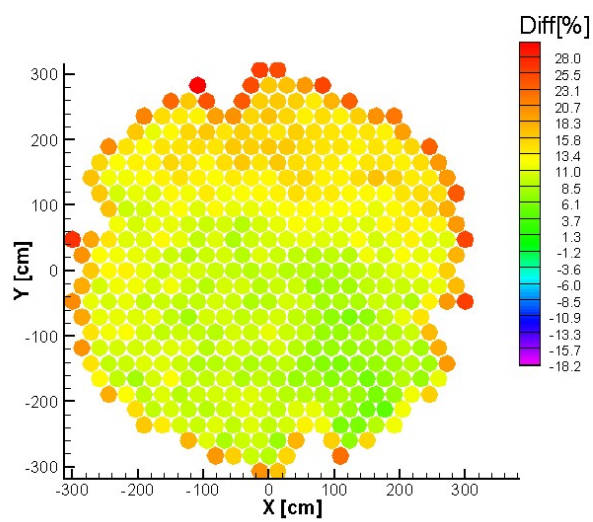

Figure 118 - Relative difference for level 1

\subsection{Results for a Boron configuration at time $\Delta t=+0.325$}

The nodes percentage differences are reported in Table 28. The distribution of relative differences (NESTLE - MCNP5) for each axial layer is reported from Figure 119 to Figure 124.

Table $28-$ Relative differences of node flux at time $\Delta t=+0.325$

\begin{tabular}{|c||c|c||}
\hline \hline |Diff.| [\%] & Number of nodes & Node fraction [\%] \\
\hline \hline$<1$ & 245 & 5.4 \\
\hline $1-5$ & 1140 & 25.3 \\
\hline $5-10$ & 1841 & 40.8 \\
\hline $10-20$ & 580 & 12.9 \\
\hline $20-30$ & 305 & 6.8 \\
\hline $30-50$ & 278 & 6.2 \\
\hline $50-60$ & 102 & 2.3 \\
\hline$>60$ & 19 & 0.3 \\
\hline
\end{tabular}




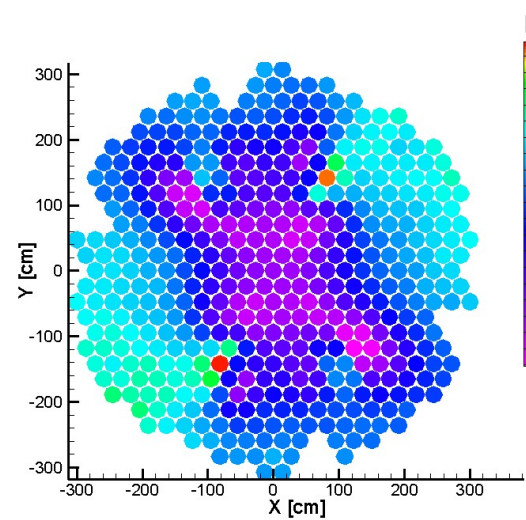

Figure 119 - Relative difference for level 10

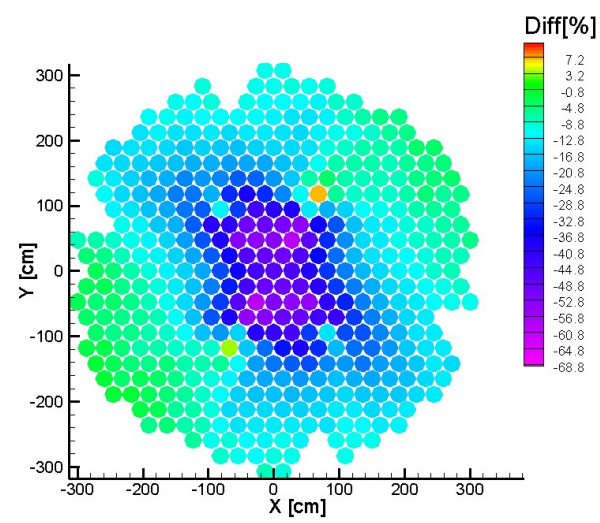

Figure 121 - Relative difference for level 8

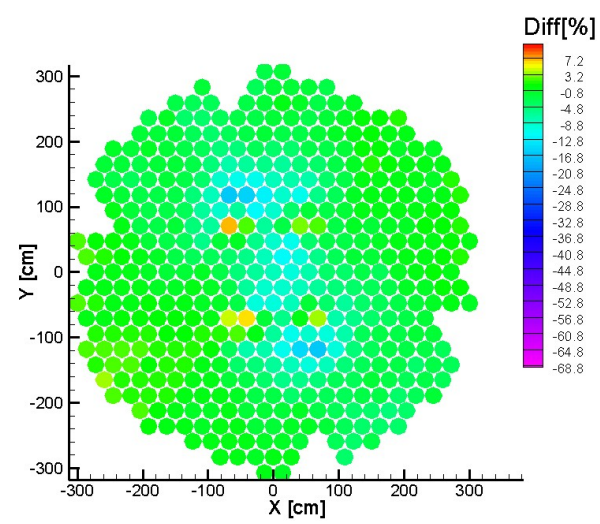

Figure 123 - Relative difference for level 6
Diff[\%]

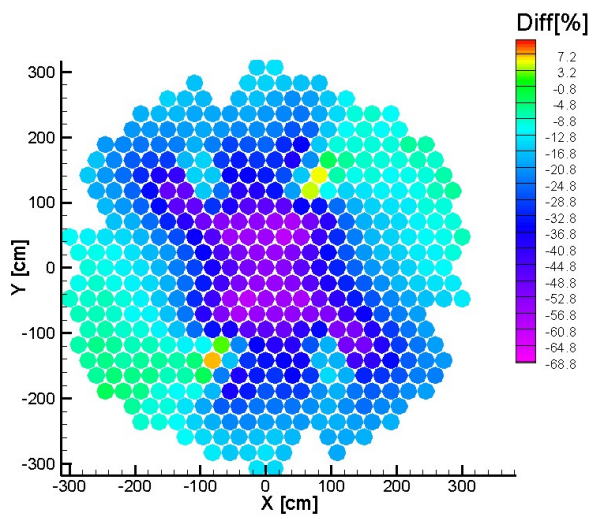

Figure 120 - Relative difference for level 9

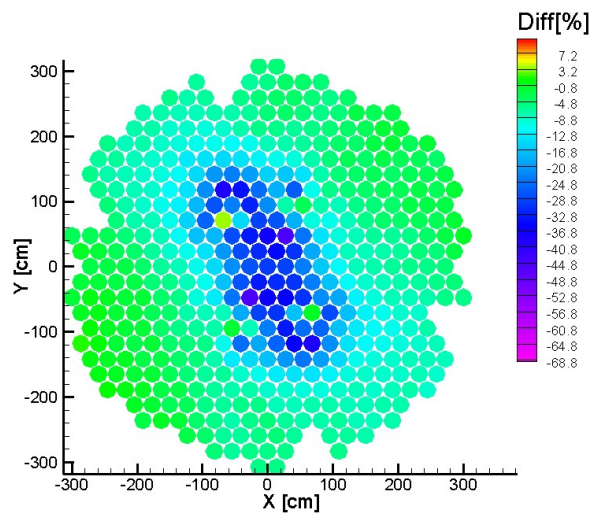

Figure 122 - Relative difference for level 7

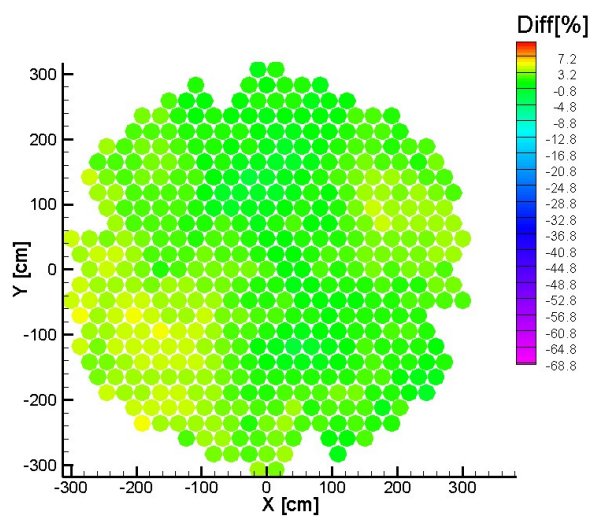

Figure 124 - Relative difference for level 5 


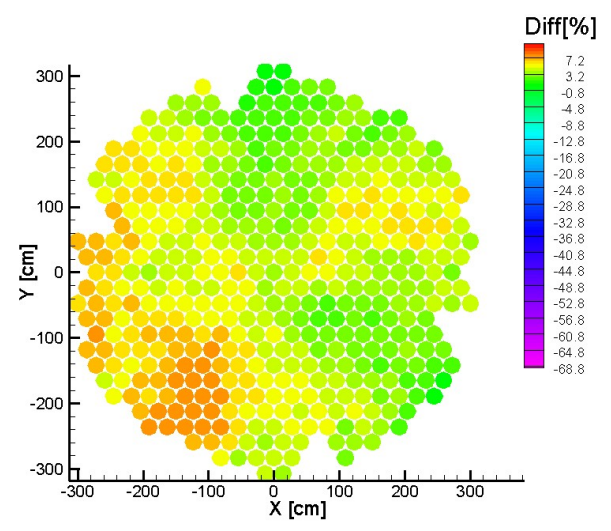

Figure 125 - Relative difference for level 4

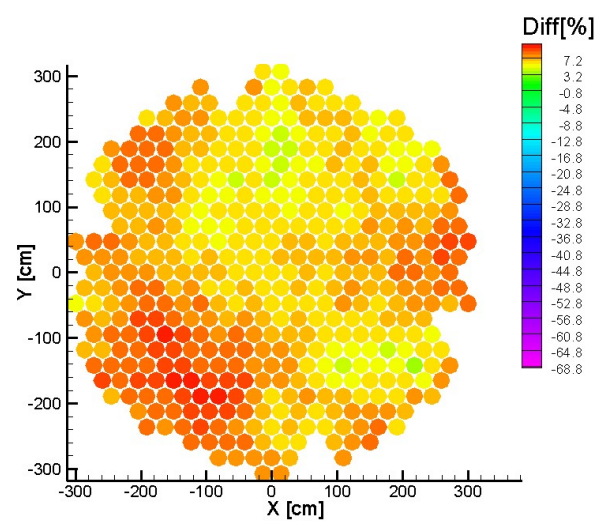

Figure 127 - Relative difference for level 2

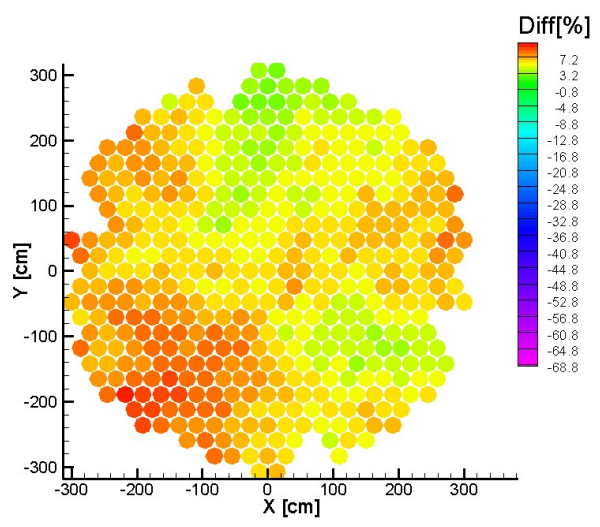

Figure 126 - Relative difference for level 3

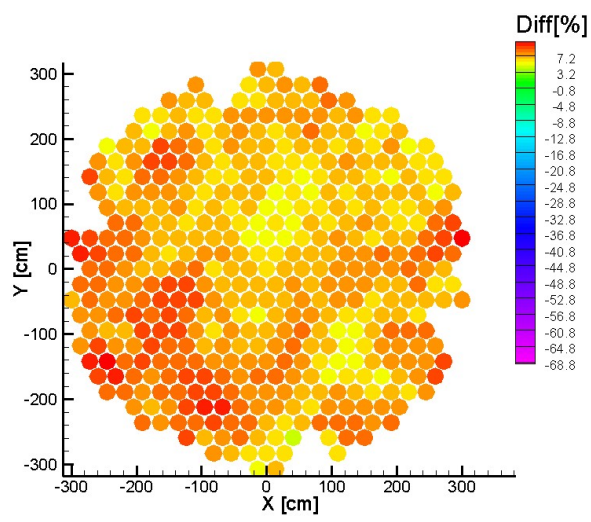

Figure 128 - Relative difference for level 1

\subsection{Results for a Boron configuration at time $\Delta t=+0.825$}

The nodes percentage differences are reported in Table 29. Then, the distribution of relative differences (NESTLE - MCNP5) for each axial layer is reported from Figure 129 to Figure 138.

Table 29-Relative differences of node flux at time $\Delta t=+0.825$

\begin{tabular}{|c|c|c|}
\hline |Diff.| [\%] & Number of nodes & Node fraction [\%] \\
\hline$<1$ & 221 & 4.9 \\
\hline $1-5$ & 905 & 20.1 \\
\hline $5-10$ & 1582 & 35.1 \\
\hline $10-20$ & 709 & 15.7 \\
\hline $20-30$ & 382 & 8.5 \\
\hline $30-50$ & 446 & 9.9 \\
\hline $50-60$ & 161 & 3.6 \\
\hline$>60$ & 104 & 2.2 \\
\hline
\end{tabular}




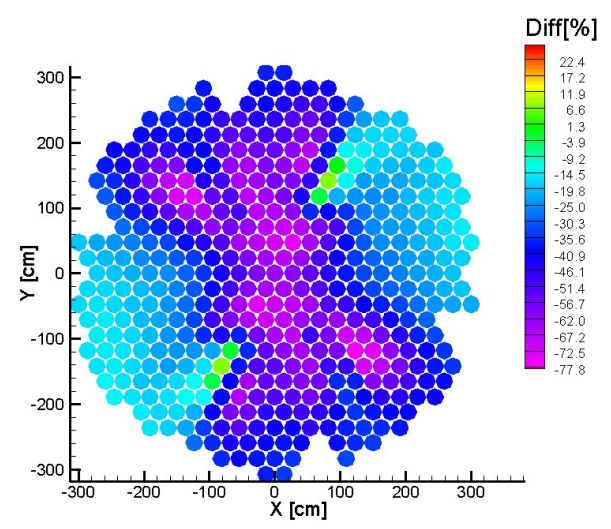

Figure 129 - Relative difference for level 10

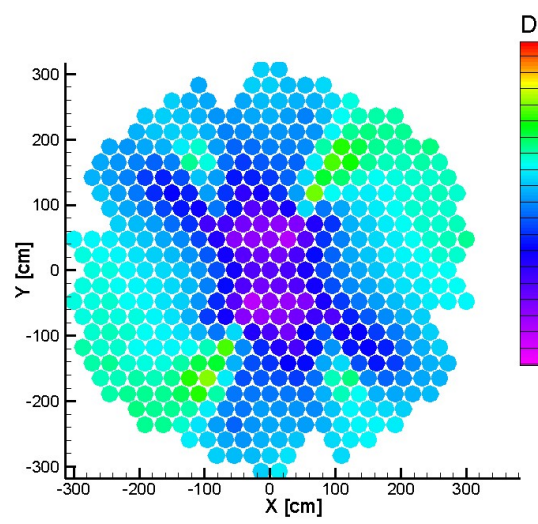

Figure 131 - Relative difference for level 8

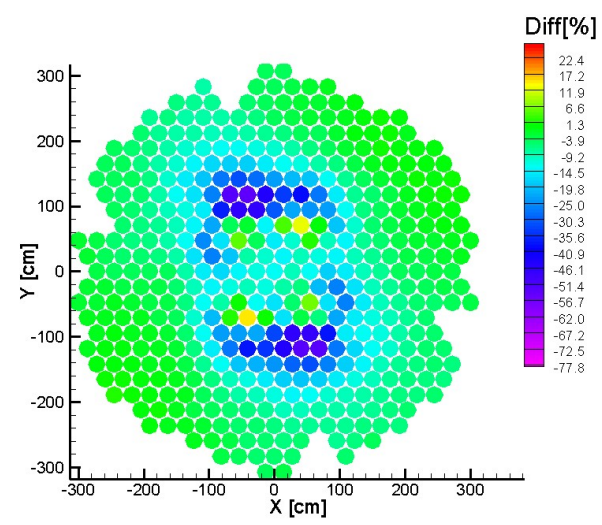

Figure 133 - Relative difference for level 6

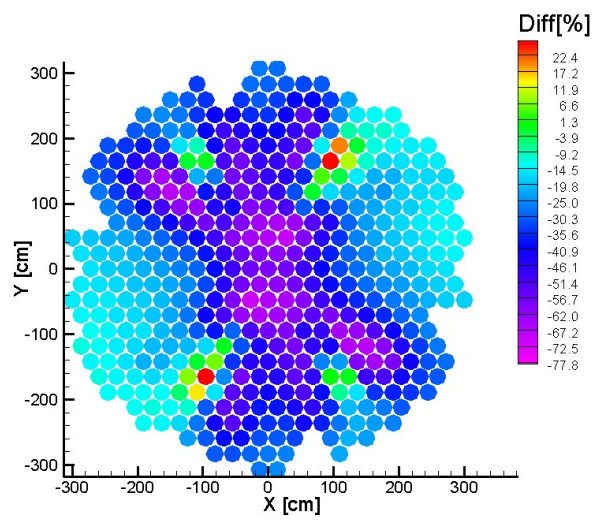

Figure 130 - Relative difference for level 9

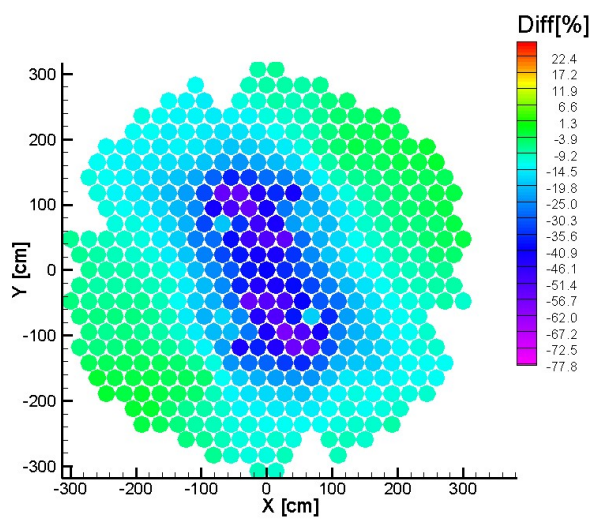

Figure 132 - Relative difference for level 7

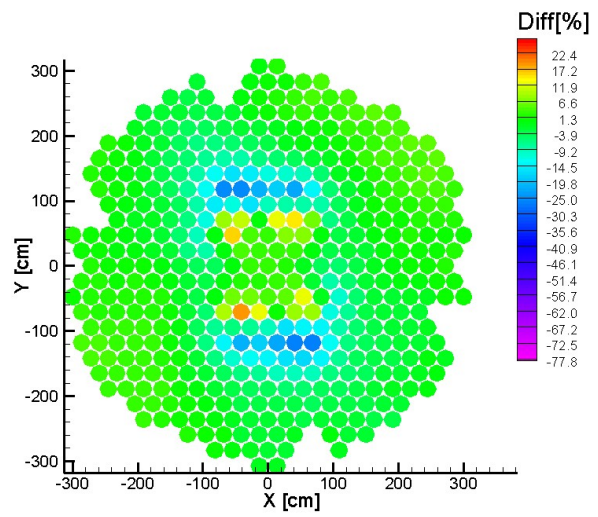

Figure 134 - Relative difference for level 5 


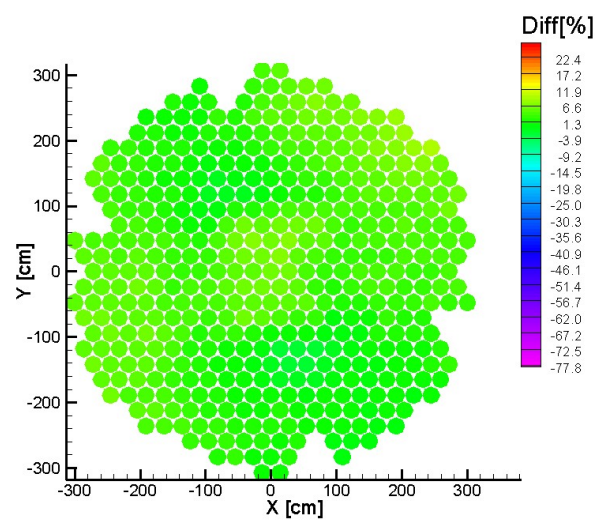

Figure 135 - Relative difference for level 4

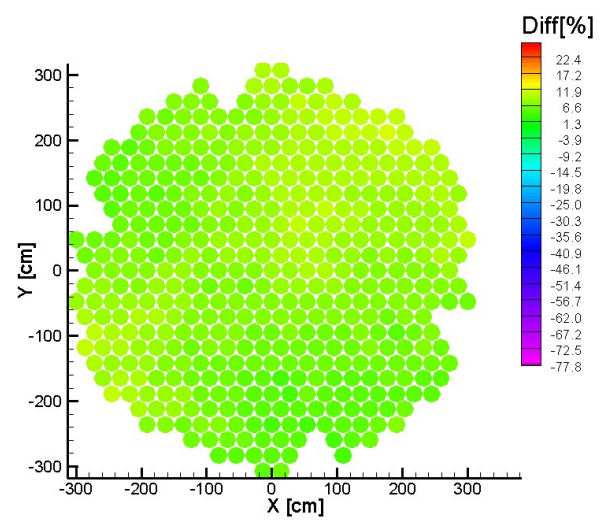

Figure 137 - Relative difference for level 2

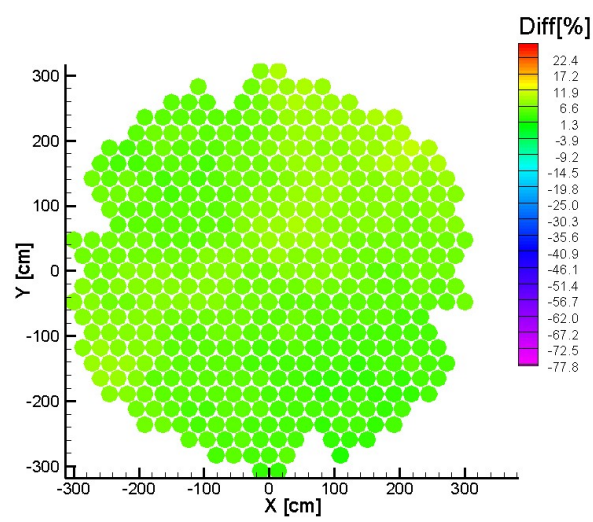

Figure 136 - Relative difference for level 3

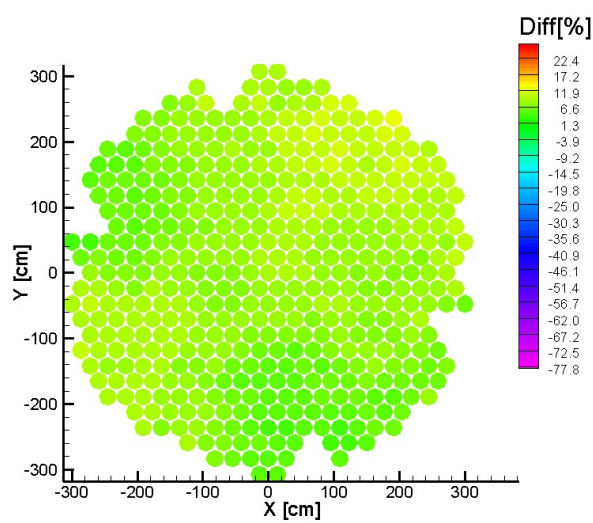

Figure 138 - Relative difference for level 1

\subsubsection{JDJ Inserted reactivity benchmark}

The aim of this benchmark is the qualification of RELAP5-3D@/NESTLE prediction of inserted reactivity by JDJ using MCNP5. The importance of such qualification is due to the relevance of the reactivity inserted by Boron emergency injection system (JDJ) in DEGB-LBLOCA transient scenario for ATUCHA-2.

The negative reactivity inserted by the JDJ was evaluated using the MCNP5 code for several time-steps of interest for DEGB-LBLOCA transient scenario. Then, the reactivity trend was compared to the analogous results calculated from RELAP53D@/NESTLE.

The initial time selected for the analysis corresponds to the time in which the first drop of borated water exit from the injection lances into the moderator tank. The simulated time range is $\Delta t=0.3 \mathrm{~s}$, such time cover the time range from the arrival of borated water to the quenching of the power peak according to calculation for LBLOCA [3]. 


\subsubsection{Evaluation of JDJ inserted reactivity by NESTLE}

The RELAP5-3D@/NESTLE does not have the feature to calculate directly the reactivity trend. Hence, the reactivity was calculated from the power using the following inverse kinetic equations [22]:

$$
\left\{\begin{array}{l}
\rho_{\text {prompt }}(t)=\frac{\Lambda}{\beta P(t)} * \frac{\Delta P(t)}{\Delta t} \\
\rho_{\beta_{i}}\left(t_{i}\right)=e^{-\lambda_{i} \Delta t} * \rho_{\beta_{i}}\left(t_{i-1}\right)+\frac{\beta_{i}}{\beta * \lambda_{i}} *\left(\left(1-e^{-\lambda_{i} \Delta t}\right) * \frac{\Delta P(t)}{\Delta t} \quad i=1, . .6\right.
\end{array}\right.
$$

Where $P$ is the power, $\rho_{\text {prompt }}$ and $\rho_{\beta}$ is the reactivity due to prompt and delayed neutrons, respectively. Then, $\Lambda$ is the reactor period, $\lambda_{\mathrm{i}}$ the decay constant for each of the 6 delayed groups, $\beta$ the beta delayed factor and finally the $\beta_{i}$ are the delayed factors for each of the 6 delayed groups. The numerical values of those constant are given in [48].

The power trend was calculated by RELAP5-3D@/NESTLE using the model summarized in Par. 5.4. The reactivity excursion due to void production is not considered in this benchmark. In the time of interest (see Par. 6.2.2.2) the contribution from variation of fuel temperature is negligible. Hence the reactivity calculated is due only to the fast Boron injection system (JDJ).

The calculated JDJ inserted reactivity trend together with its prompt and delayed neutron components are reported in Figure 139.

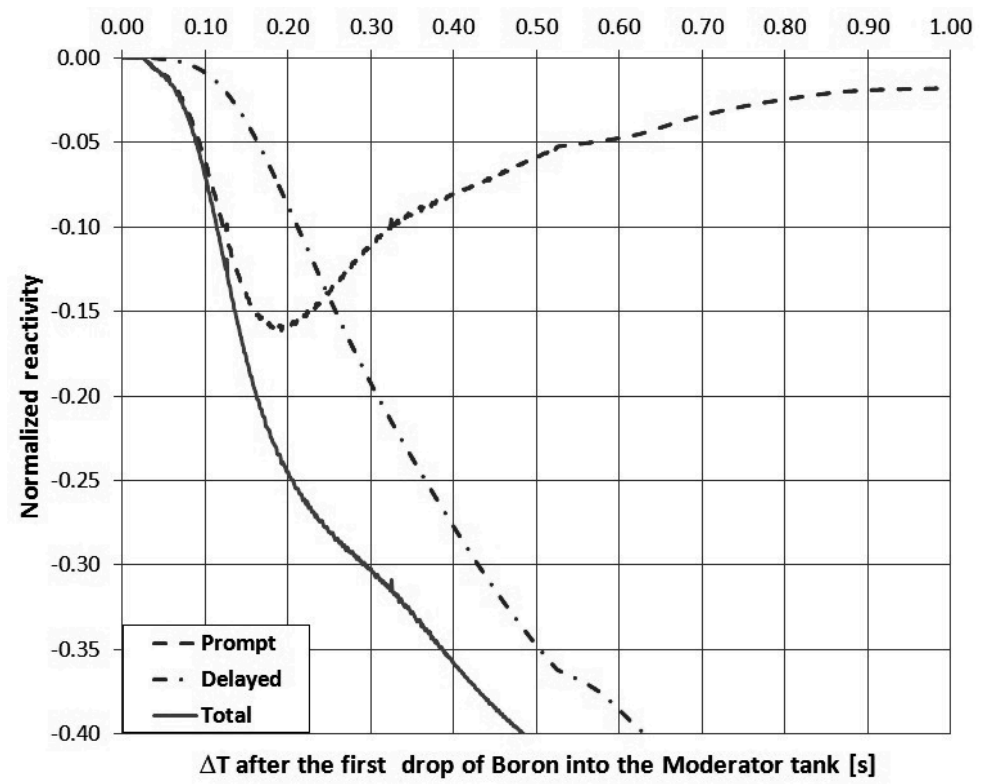

Figure 139 - Prompt, delayed and total inserted reactivity by NESTLE 


\subsubsection{Benchmark of JDJ inserted reactivity using MCNP}

A preliminary work was dedicated to investigate the limit of applicability of MCNP5 to a reactivity calculation in transient scenario. The inserted reactivity by the Boron cloud is made of the contributions from prompt and delayed neutrons. Those contribute are not constant but change in time according to the nuclear reactor dynamics equations [35]. The MCNP5 code allows only static calculation in which the time-dependent effect of delayed and prompt neutrons can't be analyzed. However, the analysis of inserted reactivity calculated by NESTLE of prompt and delayed neutrons has shown that in the LB-LOCA transient the contribution to total reactivity is given mostly by prompt neutrons within time $\Delta t=+0.125 \mathrm{~s}$ (see figure 139). Then, the delayed neutrons contribution increases and became the most relevant after time $\Delta t=+0.250 \mathrm{~s}$. In order of benchmarking the reactivity results calculated by NESTLE, only the MCNP5 values up to $\Delta \mathrm{t}=+0.125 \mathrm{~s}$ should be considered (i.e. when the effect of delayed neutron is negligible).

Nevertheless, this short time window has great importance since in this range the negative reactivity inserted by JDJ has to reverse the power excursion caused by void production and it is of fundamental importance for safety assessment.

The criticality value, i.e. the core $k_{\text {eff }}$, was calculated at several selected times of JDJ injection using the "RELAP-like" core configuration (see Par. 5.5.3.3.3). A further qualification of the RELAP5-3D@/NESTLE results is given by the completely independent methodology used to generate the MCNP5 input deck for realistic ATUCHA-2 operational condition (burnup considerations, Xsec, etc.).

The reactivity was calculated using the formulas reported in APPENDIX G. The reactivity inserted by JDJ is always negative and in all simulated cases the NESTLE code predicts a higher inserted reactivity. The absolute reactivity difference for the time step calculated is reported in Table 30, then, its trend is reported in Figure 140.

The trend of inserted reactivity difference shows that in the limit of applicability of MCNP5 there is in good agreement to the RELAP5-3D@/NESTLE results with absolute differences ranging from $0.03 \$$ to $0.17 \$$. In this time range a further deviation between $0.04 \$$ to $0.10 \$$ has to be considered, due to the Boron shielding effect (see Par 6.2.1.2). Considering the negative inserted reactivity by JDJ calculated by RELAP5-3D@/NESTLE, those corrections are low and within the safety margins.

Finally, the results from the MCNP5 based methodology developed in this research provide an independent qualification of the RELAP5-3DC/NESTLE model used for the safety analysis in the LB-LOCA transient scenario. 
Table 30 - Reactivity results calculated at times of interest for LB-LOCA scenario

\begin{tabular}{|c||c|c|}
\hline$\Delta \mathbf{T}[\mathbf{s}]$ & $\begin{array}{c}\text { Absolute reactivity difference } \\
\text { [NESTLE }- \text { MCNP5| [\$] }\end{array}$ & Err \\
\hline \hline+0.025 & 0.03 & 0.01 \\
\hline+0.075 & 0.15 & 0.01 \\
\hline+0.125 & 0.17 & 0.01 \\
\hline
\end{tabular}

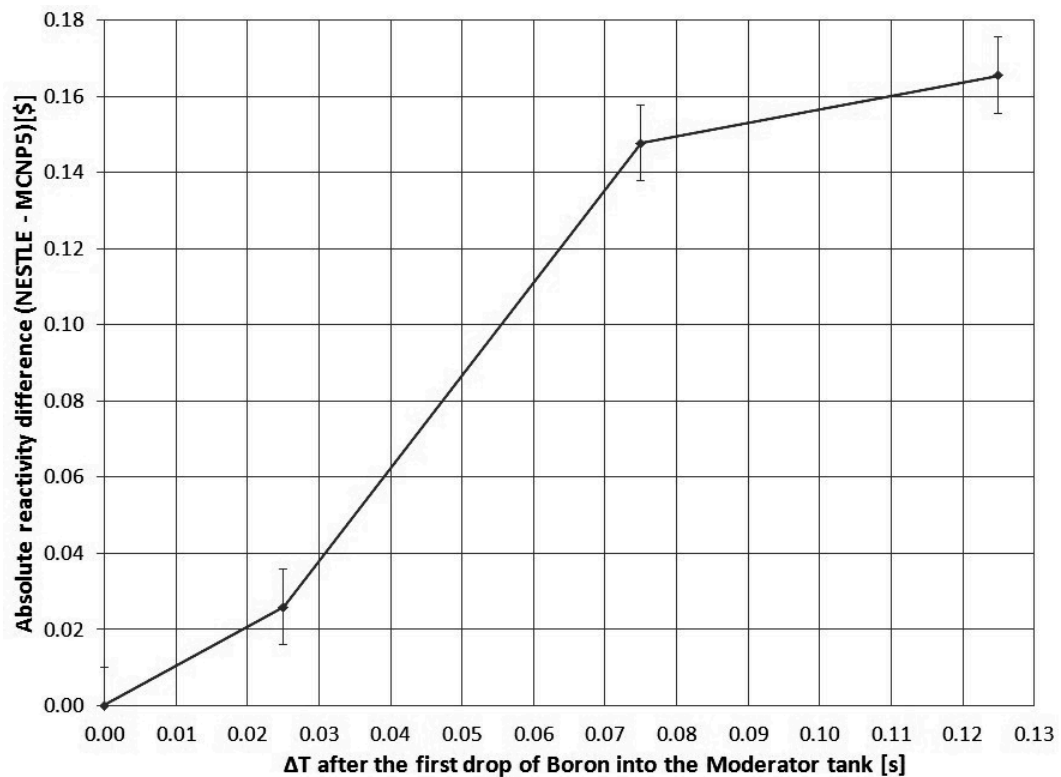

Figure 140 - Absolute reactivity difference between NESTLE and MCNP5 


\section{CONCLUSION}

This thesis consists in the developing of a methodology based on MCNP code to investigate the effects of different level of representation of physical variables and to predict reactivity excursion if several conditions are verified. The methodology was applied to LB-LOCA scenario in ATUCHA-2 PHWR in the framework of the safety analysis of ATUCHA-2 nuclear power plant (NPP) (Chapter 15 FSAR).

In the ATUCHA-2 PHWR the insertion of positive reactivity caused by the void production in coolant channels is compensated mainly by the negative reactivity inserted by shutdown system based on the fast injection of boric acid solution into the moderator tank (JDJ). Analysis of JDJ by a computational fluid dynamics code showed a complex spatial Boron distribution inside the moderator tank.

The so called "Boron self-shielding effect" is indicating the over-estimation of the inserted negative reactivity due by the dilution of the highly concentrated Boron solution inserted by the JDJ when modeling its spatial distribution using thermalhydraulics nodes of large dimensions (order of liters for the ATUCHA-2 case).

The presented methodology permits the investigation of such effect using the capability to generate MCNP based representations of complex and heterogeneous spatial distribution of physical variables with different level of representation.

The effect of Boron self-shielding was analyzed at core level for selected time of interest for 2A LB-LOCA scenario. The feasibility to apply such methodology to a complex scenario as 2A LB-LOCA in ATUCHA-2 nuclear power plant (NPP) has been demonstrated and results were used in the framework of the licensing of Atucha-II NPP (Chapter 15 FSAR).

The steps below were performed to fulfill the objectives:

- Acquisition of expertise in the neutronic field, taking advantage from the participation in international activities;

- Investigation of issue related to the use of Monte Carlo based neutronic codes and related methodologies;

- Development of a methodology and related tools for investigating the power peak excursion in safety analysis;

- Qualification activities to support the reliability of the analyses;

- Application of the methodology for predicting reactivity excursion in case of LOCA transient scenario in ATUCHA-2 PHWR in the framework of the safety analysis (Chapter 15 FSAR). 


\subsection{Innovations}

The application of the proposed methodology helps to evaluate the reactivity excursion due to different spatial characterization of relevant physical quantities in case of the selected accident.

Within the overall objective of the research, the following relevant results may be highlighted:

1. A pioneering tool was developed for advanced three-dimensional coupling between MCNP and computational fluid dynamics codes at the state-ofthe-art of current research in nuclear safety;

2. Demonstration that the application of proposed methodology can be used to evaluate the reactivity excursion for the selected accident condition (LOCA);

3. Overestimation of fast Boron injection effect not visible with system code used for safety analysis;

4. Found local peak factor difference greater than $60 \%$;

5. Application of the methodology developed to the FSAR Chapter 15 of ATUCHA-2 NPP.

\subsection{Future development}

For the safety analysis of the CNA-2 NPP the activity can be considered concluded and no further development are envisaged.

For the methodology development, the following considerations can be useful to point out possible future development of the activity:

1. Improvement of the tool for advanced three-dimensional coupling between MCNP and computational fluid dynamics codes in order to assess if an increased level characterization of physical variables could affects the results;

2. Implementation in the methodology of the capability to collect groupaveraged fission and capture cross sections for a further evaluation of power and Boron self-shielding effects;

3. Perform researches for allowing real dynamic Monte Carlo simulation (delayed neutrons effect calculations);

4. Improve system scalability of Monte Carlo system with research of Parallel system;

5. Improvements on Monte Carlo based burnup methodology;

6. Improvement of thermal-hydraulics boundary condition in the MCNP5 model used within the methodology. 


\section{REFERENCES}

[1] Mayers, "Atucha 2 System Description: Reactor, Reactor Coolant and Moderator System", KWU Technical Report, R10-85-e1002, Erlangen, Germany, 1985.

[2] C. Parisi, "Identification and characterization of a relevant core status", Contract NA-SA UNIPI 01 - Atucha II, SIR-2.1 - rev0, Pisa, January 2008.

[3] F. D'Auria, O. Mazzantini, et al., "DEGB LB-LOCA (2 X 100\% Break in CL) in ATUCHA-2 NPP", DIMNP_NT_628(08), March 2008.

[4] UNIPI-GRNSPG, "A proposal for performing the ATUCHA II accident analyses for licensing purposes", Contract NA-SA UNIPI 01 - Atucha II, University of Pisa Report, DIMNP NT (08) rev3, Pisa, August 2008.

[5] Task Group on Safety Margins Action Plan (SMAP), Final Report NEA/CSNI/R(2007)9, Paris (F), 2007-9.

[6] IAEA, "Safety margins of Operating Reactors, Analysis of Uncertainties and Implications for Decisions Making", IAEA Tecdoc 1332, Vienna, 2003.

[7] IAEA, "Accident Analysis for Nuclear Power Plants", IAEA Safety Reports Series No 23 - pp 1-121, Vienna, 2002.

[8] Petruzzi A., D'Auria F., Micaelli J-C., De Crecy A., Royen J., "The BEMUSE programme (Best-Estimate Methods - Uncertainty and Sensitivity Evaluation)", Int. Meet. on Best-Estimate Methods in Nuclear Installation Safety Analysis (BE-2004) IX, Washington D.C. (USA), November 14-18, 2004.

[9] US NRC, "Regulatory Guide 1.203: Transient and Accident Analysis Methods", US NRC RG, December 2005.

[10] IAEA, "Best Estimate Safety Analysis for Nuclear Power Plants: Uncertainty Evaluation", IAEA Safety Reports Series No 52 - pp 1-162, Vienna, 2008.

[11] OECD, "Task Group on Safety Margins Action Plan (SMAP), Final Report", NEA/CSNI/R(2007)9, Paris, 2007-9.

[12] "Argentinean National Report for the Convention on Nuclear Safety", Buenos Aires, 2007.

[13] IAEA, "Safety of Nuclear Power Plants: Operation", IAEA Safety Standard Series No. NS-R-2 - pp 1- 40, Vienna, 2000.

[14] IAEA, "Safety of Nuclear Power Plants: Design", IAEA Safety Standard Series No. NS-R-1 - pp 1-73, Vienna, 2000.

[15] ARN, "Norma básica de seguridad radiológica", AR 10.1.1. Revisión 3, Aprobada por Resolución del Directorio de la Autoridad Regulatoria Nuclear No 22/01 (Boletín Oficial No 20/11/01), 2001.

[16] NASA-ARN, "Protocol of Common Understanding on the Basic Licensing Concept and some safety subjects", November 1977. 
[17] X-5 Monte Carlo Team, "MCNP - A General Monte Carlo N-Particle Transport Code, Version 5, Volume I: Overview and Theory", Los Alamos National Laboratory, USA, LA-UR-03-1987, April 2003 (Revised 10/3/05).

[18] R. E. MacFarlane, D. W. Muir, "The NJOY Nuclear Data Processing System Version 91", Los Alamos National Laboratory, USA, LA-12740-M UC-413, October 1994.

[19] A. G. Croft, "A User's Manual for the ORIGEN2 Computer Code", Oak Ridge National Laboratory, USA, ORNL/TM-7175 Dist. Category UC-70, July 1980 (Revised 1983).

[20] D. I. Poston, H. R. Trellue, "User's Manual, Version 2.0 for MONTEBURNS, version 1.0", Los Alamos National Laboratory, USA, LA-UR-99-4999, September 1999.

[21] ANSYS CFX-10.0, “User Manual”, 2005.

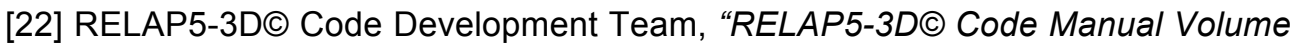
I: Code Structure, System Models, and Solution Methods", Idaho National Laboratory, INEEL-EXT-98-00834, Volume I Revision 2.4, June 2005.

[23] Turinsky P. J., et al., "Nestle: Few-Group Neutron Diffusion Equation Solver Utilizing the Nodal Expansion Method for Eigenvalue, Adjoint, Fixed-Source Steady State and Transient Problems", Electric Power Research Center, North Carolina State University, Raleigh, NC 27695- 7909, June 1994.

[24] F. Moretti, F. Terzuoli, D. Melideo, "CFD Transient Analyses for CNA-2", GRNSPG Report TFR-6. Rev. 0., 2007.

[25] S. C. Frankle, J. M. Campbell, R. C. Little, "Comparison of Criticality Results for the ENDF60 and ENDF66 Libraries", LA-UR-03-0953, Los Alamos National Laboratory, USA, 2003.

[26] M. D. DeHart, "NEWT: a new transport algorithm for two-dimensional discrete ordinates analysis in non-orthogonal geometries", ORNL/TM-2005/39, Version 6, Vol. II, Sect. F21, January 2009.

[27] C. Parisi, K. N. Ivanov, et al., "RELAP5-3D@ three dimensional neutron kinetics coupled thermal- hydraulics analyses of the ATUCHA-2 PHWR", International Conference on the Physics of Reactors "Nuclear Power: A Sustainable Resource", Interlaken, Switzerland, September 14-19, 2008.

[28] Studsvik ${ }^{\mathrm{TM}}$ ScandPower, "HELIOS Methods", 2006.

[29] M. Pecchia, C. Parisi, et al., "Development and Application of MCNP5 and KENO-VI Monte Carlo Models for the ATUCHA-2 PHWR Analysis", Hindawi Publishing Corporation Science and Technology of Nuclear Installations Volume 2011, Article ID 683147.

[30] L. L. Carter, R. A. Schwarz, "MCNP Visual Editor Computer Code Manual", November 2005.

[31] W. M. Stacey, "Nuclear Reactor Physics", Wiley-VCH Verlag GmbH \& Co, KGaA, Weinheim, 2004. ISBN-13: 978-0-471-39127-2. 
[32] M. Pecchia et al., "Benchmark of ATUCHA-2 PHWR RELAP-3D control rod model by Monte Carlo MCNP5 core calculation", PHYSOR 2012 - Advances in Reactor Physics, Knoxville, Tennessee, USA, April 15-20, 2012

[33] M. Pecchia, "NESTLE validation of CR worth prediction", Technical Report NEU-A3/A.3.8.7, December 2011, Pisa, Italy.

[34] M. Silva, J. Fink, et al., "Comparison of Static Reactivity Changes and Channel Power Distributions of Postulated Boron Clouds in Atucah-2 Obtained with the Code Chain WIMS-DRAGON-PUMA and with MCNP", Nucleoelectrica Argentina S.A., 2007.

[35] K. O. Ott, R. J. Neuhold, "Introductory Nuclear reactor dynamics", American Nuclear Society, Illinois 60525, 1985, ISBN 0-89448-029-4.

[36] INTEL®, "Quad-Core Inte/® Xeon® Processor 5400 Series", INTEL $\circledast$ Datasheet.

[37] "SCALE: A Modular Code System for Performing Standardized Computer Analyses for Licensing Evaluation", ORNL/TM-2005/39, Version 6, Vols. I-III, January 2009.

[38] National Nuclear Data Center, "ENDF-6 Formats Manual", Brookhaven National Laboratory, USA, Report BNL-NCS-44945-05-Rev., April 2001.

[39] J. Stoer, R. Bulirsch, "Introduction to Numerical Analysis", Springer-Verlag New York, Inc., 1992, ISBN 0-387-97878-X.

[40] R. D. Mosteller, "The Doppler-Defect Benchmark: Overview and Summary of Results", Joint International Topical Meeting on Mathematics \& Computations and Supercomputing in Nuclear Applications (M\&C + SNA 2007), Monterey, California, April 15-19, 2007.

[41] S. C. Frankle, "A Suite of Criticality Benchmarks for Validating Nuclear Data", Los Alamos National Laboratory, LA-13594, April 1999.

[42] "International Handbook of Evaluated Criticality Safety Benchmark Experiments", NEA Nuclear Science Committee, NEA/NSC/DOC(95)03, 1998.

[43] D. F. Hollenbach, L. M. Petrie, S. Goluoglu, N. F. Landers, M. E. Dunn, "KENO-VI: A General Quadratic Version of the KENO Program", ORNL/TM2005/39, Version 6, Vol. II, Sect. F17, January 2009.

[44] M. Pecchia, et al., "MOx benchmark calculations by deterministic and Monte Carlo codes", Nuclear Engineering and Design, Volume 246, Pages 63-68, Special issue, 2012.

[45] B. Roque, P. Marimbeau, J. P. Grouiller, L. San-Felice, "Specification for the phase 2 of a depletion calculation benchmark devoted to MOx fuel cycles", NEA/NSC/DOC, 9, 2007.

[46] J. Dufek, "Analysis of Efficient Monte Carlo Reactor Cycle Calculations (Theoretical and Feasibility Study)", NURESIM NUCTECH-2004-3.4.3.1-1, November 2007.

[47] Http://mcd.ans.org/jb/bench/Doppler/Solutions/ 
[48] J. Fink, "NOTA TECNICA", NT-FA-07/001, 2004-018/2.

[49] I. C. Gauld, O. W. Hermann, R. M. Westfall, "ORIGEN-S: Scale system module to calculate fuel depletion, actinide transmutation, fission product buildup and decay, and associated radiation source term", Oak Ridge National Laboratory, USA, ORNL/TM-2005/39, November 2006.

[50] T. Downar et al., "Modeling of the Fast Boron Injection System for CNA-II", International Conference on the Physics of Reactors "Nuclear Power: A Sustainable Resource", Interlaken, Switzerland, September 14-19, 2008.

[51] C. Grant, "PUMA version 4. Manual del Usuario", Buenos Aires, 2007. 